\title{
DESARROLLO DE UN SISTEMA MULTIESPECTRAL PARA MICROSCOPÍA DE MENAS
}

\section{TESIS DOCTORAL}

JUAN CARLOS CATALINA HERNÁNDEZ

Ingeniero de Minas

\author{
AÑO: 2018
}





\title{
DESARROLLO DE UN SISTEMA MULTIESPECTRAL PARA MICROSCOPÍA DE MENAS
}

\author{
MEMORIA \\ JUAN CARLOS CATALINA HERNÁNDEZ \\ Ingeniero de Minas \\ DIRECTOR: \\ RICARDO CASTROVIEJO BOLIBAR \\ Dr. Ingeniero de Minas
}

AÑO: 2018 

TESIS DOCTORAL

\section{DESARROLLO DE UN SISTEMA MULTIESPECTRAL PARA MICROSCOPÍA DE MENAS}

por: JUAN CARLOS CATALINA HERNÁNDEZ

Director de la Tesis: RICARDO CASTROVIEJO BOLIBAR

El Tribunal Calificador:

Presidente:

Vocal 1:

Vocal 2:

Vocal 3:

Vocal Secretario:

Acuerda otorgar la calificación de: 




\section{AGRADECIMIENTOS}

Esta tesis doctoral no hubiera sido posible sin la colaboración y apoyo de numerosas personas e instituciones, a quienes agradezco profundamente su aportación a la misma.

En primer lugar, quiero destacar el papel fundamental que ha representado el profesor Ricardo Castroviejo, no sólo como director de la tesis doctoral y del Laboratorio de Microscopía Aplicada y Análisis de Imagen de la Universidad Politécnica de Madrid, sino como promotor de la idea original del proyecto CAMEVA e impulsor de la colaboración entre la UPM y el Centro Tecnológico AITEMIN allá por el año 2005, así como coordinador del actual proyecto AMCO.

Quiero también manifestar mi agradecimiento a los demás participantes en el proyecto CAMEVA, tanto a mi compañero de AITEMIN Fernando Segundo, que realizó la mayor parte de los programas del sistema, como a las compañeras del LMAAI Carolina Brea y Laura Pérez Barnuevo, que aplicaron el sistema CAMEVA seleccionando cuidadosamente muestras, campos y zonas representativas de los distintos minerales, proporcionando los datos de partida para la elaboración de las dos bases de datos de reflectancia VNIR de minerales metálicos, así como al profesor José Antonio Espí, por su contribución a la orientación del sistema a la problemática de la industria. Agradezco igualmente el asesoramiento de los profesores Eric Pirard (Université de Liège, Bélgica) y Heinz-Juergen Bernhardt (Ruhr-Universität Bochum, Alemania).

Se agradece asimismo la contribución de usuarios pioneros de la industria (compañías mineras como Neves Corvo, Cobre Las Cruces, Riotinto, Aguablanca, Kanshanshi, etc.) y de la investigación académica (profesor Joaquín Proenza, Universidad de Barcelona), cuyas demandas de aplicación del sistema han sido importantes jalones en la validación de CAMEVA. Los profesores Alfredo López (UPM) y Fernando Gervilla (Universidad de Granada) han contribuido a la validación del sistema al investigar la relación entre la composición y la reflectancia multiespectral de la cromita y establecer la relación de ésta última, determinada por el sistema CAMEVA, con la tipología del depósito.

El desarrollo del sistema descrito en esta tesis ha sido financiado por el Ministerio de Educación y Ciencia en el marco del Plan Nacional de I+D+I a través del proyecto coordinado CAMEVA (Caracterización Automatizada de Menas Metálicas mediante Visión Artificial), integrado a su vez por los proyectos SEICAMIN (Sistema Experto para la identificación y cuantificación automatizada de minerales de interés industrial (menas), ejecutado por la Universidad 
Politécnica de Madrid, referencia CGL2006_13688_C02_01) y AMAMET (Sistema de visión artificial para el análisis microscópico automatizado de menas metálicas, ejecutado por el centro tecnológico AITEMIN, referencia CGL2006_13688_C02_02).

En la actualidad, el sistema CAMEVA está siendo mejorado sustancialmente en diversos aspectos con el fin de facilitar al máximo su uso por parte de los usuarios finales, y hacer posible su comercialización. Esta actividad está siendo llevada a cabo mediante el proyecto AMCO (Automated microscopic characterization of ores), un proyecto europeo del programa H2020 de tipo "Upscaling” financiado por el EIT RawMaterials (EIT Project $n^{\circ}$ 15039), en el cual se cuenta con la colaboración de David Alarcón, Úrsula Grunwald y Paulo Romero, a los que también agradezco su apoyo durante la redacción de esta tesis. 



\section{RESUMEN}

La presente tesis está centrada en el desarrollo del sistema CAMEVA, un sistema de microscopía multiespectral de reflectancia especular especialmente concebido para facilitar la identificación y caracterización de las fases minerales presentes en secciones pulidas de menas metálicas, así como para automatizar la realización de distintos tipos de análisis cuantitativos sobre ellas. El sistema CAMEVA permite obtener resultados similares a los de un sistema MEB (microscopía electrónica de barrido), superando algunas de sus limitaciones, como sus rígidas y costosas exigencias de infraestructura y especialización o la dificultad de distinguir especies polimorfas, pero a un coste notablemente inferior. Los ensayos realizados muestran que el sistema permite la identificación automatizada y fiable de las menas de interés industrial, a partir de la información multiespectral en el rango VNIR (visible e infrarrojo cercano, entre 400 y $1000 \mathrm{~nm}$ ) recogida en una base de datos específica; esta base de datos, que incluye los 70 minerales de mayor interés, es fácilmente ampliable.

PALABRAS CLAVE: Análisis de imagen; Geometalurgia; Menas metálicas; Microscopía óptica; Reflectancia multiespectral 


\begin{abstract}
DEVELOPMENT OF AN AUTOMATED MULTISPECTRAL SYSTEM FOR ORE MICROSCOPY

The present thesis is focused on the development of the CAMEVA system, a multispectral specular reflectance microscopy system specially conceived to facilitate the identification and characterization of the mineral phases present in polished blocks of metallic ores, as well as to automate the realization of different types of quantitative analyses on them. The CAMEVA system provides results similar to those of a SEM (scanning electron microscopy) system, surpassing some of its limitations, such as its rigid and costly infrastructure requirements and specialization or the difficulty of distinguishing polymorph species, but at a significantly lower cost. The tests carried out show that the system allows for automated and reliable identification of the ores of industrial interest from the multispectral information in the VNIR range (visible and near infrared, between 400 and $1000 \mathrm{~nm}$ ) gathered in a specific database. This database, which includes 70 minerals of interest, is easily expandable.
\end{abstract}

KEYWORDS: Geometallurgy; Image analysis; Metallic ores; Multispectral reflectance; Optical microscopy 
NOMENCLATURA 


\section{NOMENCLATURA}

Seguidamente se explican los principales términos técnicos utilizados en este trabajo, así como, en su caso, sus unidades.

Banda: Cada una de las imágenes que componen una imagen multiespectral o hiperespectral, y que representa la intensidad luminosa asociada a un determinado rango espectral. El caso más conocido es el de las bandas roja, verde y azul que constituyen una imagen en color (RGB).

Bit: Unidad más pequeña de información digital, que puede tener los valores 0 ó 1 El término proviene del inglés, y es un acrónimo de la expresión "binary digit" (dígito binario).

Coeficiente de confiabilidad: El coeficiente de confiabilidad de una clasificación se define como el cociente de la segunda menor distancia de Mahalanobis a un mineral dividida por la menor distancia de Mahalanobis.

Distancia de Mahalanobis: Distancia de una muestra a una clase calculada aplicando la métrica de Mahalanobis (§5.2.1). Es un número adimensional.

Flujo radiante: Potencia de la radiación electromagnética emitida por una fuente o recibida por una superficie. Se mide en W.

Imagen digital: Representación bidimensional de una imagen real, organizada como una matriz numérica en la que cada elemento (píxel) tiene un valor (nivel de gris) proporcional al nivel de brillo del punto correspondiente de la imagen real.

Imagen hiperespectral: Es una imagen que recoge información en un gran número de rangos de longitudes de onda del espectro electromagnético, estrechos y contiguos, que cubren un determinado rango espectral.

Imagen multiespectral: Es una imagen que recoge información en un cierto número de rangos de longitudes de onda del espectro electromagnético (bandas). Estos rangos no necesitan ser ni muy numerosos ni contiguos.

Nivel de gris: Valor numérico entero asignado a un píxel, dentro de un cierto rango de valores admisibles que normalmente está comprendido en el intervalo [0, $\left.2^{\mathrm{n}}-1\right]$, siendo $\mathrm{n}$ la profundidad de la imagen.

Normal: $\quad$ Vector perpendicular a una superficie en un determinado punto de ésta. Se considera que su dirección es alejándose de la superficie.

Patrón de reflectancia: Objeto que presenta una reflectancia uniforme y conocida (calibrada respecto a un patrón de orden superior), y que se suele utilizar para comparar medidas de reflectancia. 
Píxel: $\quad$ Elemento más pequeño de una imagen digital. El término inglés original (pixel) es un acrónimo de la expresión "picture element" (elemento de imagen).

Profundidad de imagen: Es el número de bits empleados para codificar los niveles de gris de una imagen digital. Los valores más frecuentes para la profundidad de una imagen monocroma (o de una banda de una imagen en color) son 8, 12 y 16.

Reflectancia: Fracción del flujo radiante incidente sobre una superficie que es reflejado por la misma. Es adimensional, y se expresa en \%.

Reflectancia difusa: Fracción del flujo radiante total incidente sobre una superficie que es reflejado por la misma, integrando el flujo radiante reflejado en todas las direcciones. Es adimensional, y se expresa en \%.

Reflectancia especular: Fracción del flujo radiante incidente sobre una superficie con un determinado ángulo respecto a la normal que es reflejado por la misma con el mismo ángulo respecto a la normal. En microscopía de reflexión se asume que tanto el flujo radiante incidente como el reflejado son normales a la superficie. Es adimensional, y se expresa en $\%$.

\section{ABREVIATURAS}

A continuación, se refieren por orden alfabético las principales abreviaturas utilizadas en este trabajo, así como, en su caso, sus unidades.

Para los subíndices, se han seguido las convenciones de la norma UNE-EN ISO 80000-1.

En el caso de magnitudes físicas del S.I., se han seguido las denominaciones recogidas en las Normas de las series UNE-EN ISO 80000 (UNE-EN ISO 80000-1, UNE-EN ISO 80000-2, UNE-EN ISO 80000-3, UNE-EN ISO 80000-4 y UNE-EN ISO 80000-6)

En general se han seleccionado para cada magnitud unidades tales que su valor numérico al expresarla en esas unidades no sea ni excesivamente grande, ni demasiado pequeño (en el rango de 0,1 a 1000).

\section{a. Índices y subíndices}

$H \quad$ Subíndice para referirse al patrón de alta reflectividad (High)

i Subíndice para referirse a una banda concreta de una imagen multiespectral

$j, k \quad$ Índices para referirse a un píxel concreto de una imagen. El índice $\mathrm{j}$ indica la fila y el índice $\mathrm{k}$ la columna.

L Subíndice para referirse al patrón de baja reflectividad (Low) 


\section{b. Magnitudes}

$f_{R} \quad$ Factor de escala para convertir el nivel de gris a reflectancia (\%)

$F_{i}(j, k)$ Nivel de gris del píxel $(\mathrm{j}, \mathrm{k})$ de la banda i de una imagen "en bruto" de un campo (número entero)

$G_{i}(j, k)$ Nivel de gris del píxel $(\mathrm{j}, \mathrm{k})$ de la banda i de una imagen corregida de un campo (número entero)

I Intensidad de corriente (A)

$V \quad$ Tensión eléctrica (V)

$P_{H i}(j, k)$ Nivel de gris del píxel $(\mathrm{j}, \mathrm{k})$ de la banda i del patrón de alta reflectancia (número entero)

$P_{L i}(j, k)$ Nivel de gris del píxel $(\mathrm{j}, \mathrm{k})$ de la banda i del patrón de baja reflectancia (número entero)

$R \quad$ Reflectancia especular a incidencia normal (\%)

$R_{H i} \quad$ Reflectancia especular del patrón de alta reflectancia en la banda i (\%)

$R_{L i} \quad$ Reflectancia especular del patrón de baja reflectancia en la banda i (\%) 
ÍNDICE 


\section{$\underline{\text { ÍNDICE }}$}

AGRADECIMIENTOS

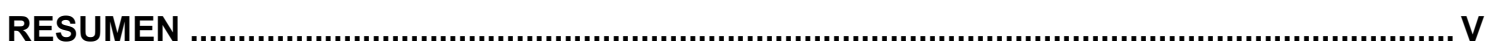

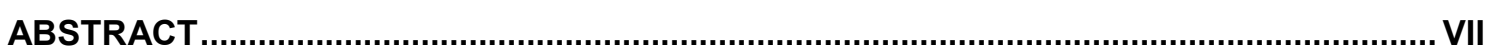

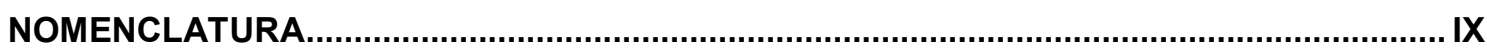

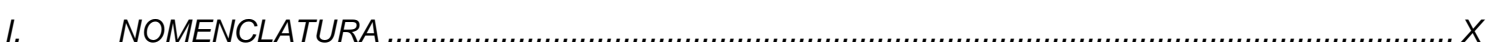

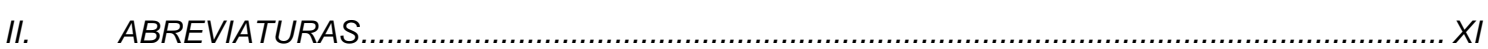

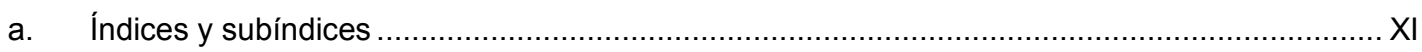

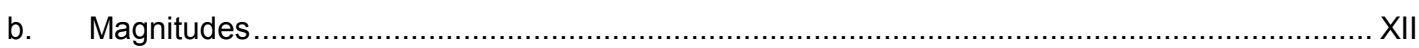

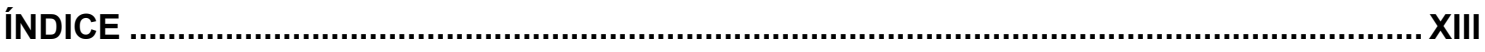

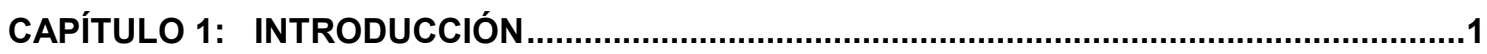

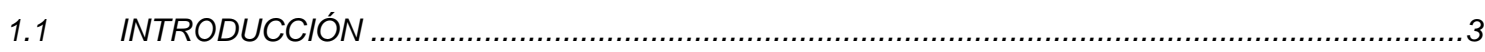

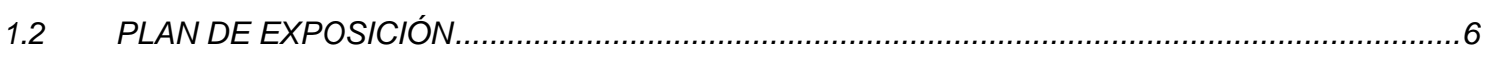

CAPÍTULO 2: PLANTEAMIENTO Y OBJETIVOS …........................................................

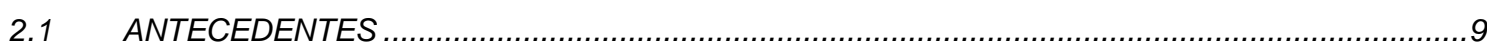

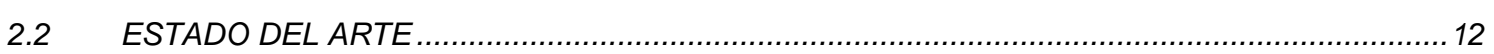

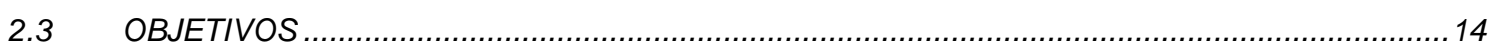

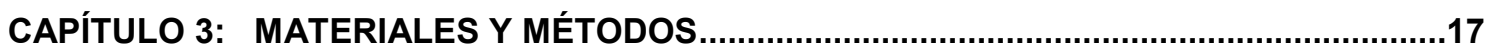

3.1 EQUIPAMIENTO DEL LABORATORIO

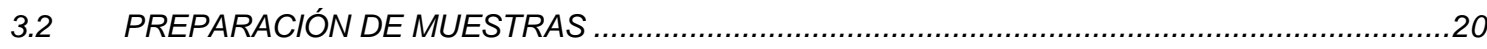

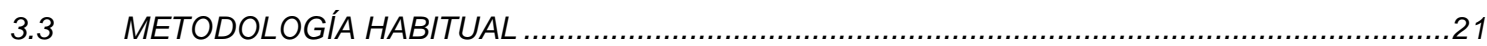

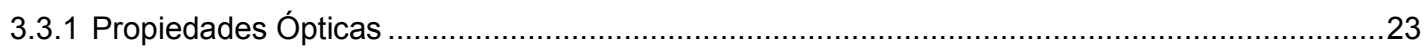

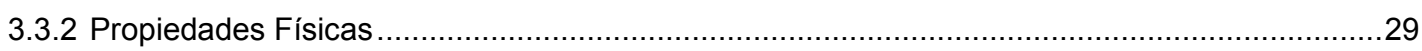

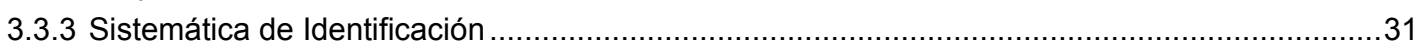

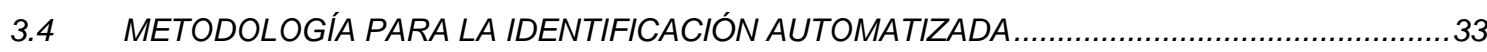

3.4.1 Utilidad y límites de QDF3 para identificación automatizada de menas .....................................34

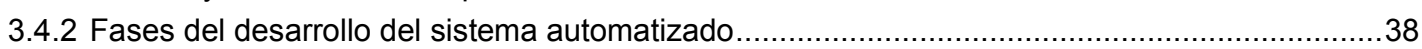

CAPÍTULO 4: DISEÑO Y DESARROLLO DEL SISTEMA AUTOMATIZADO .........................39

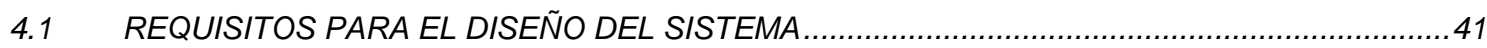

4.2 DISEÑO DEL SISTEMA DE ADQUISICIÓN DE IMÁGENES MICROSCÓPICAS

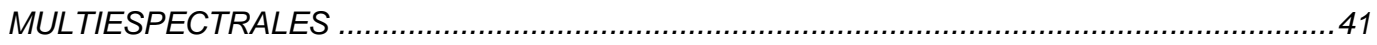

4.2.1 Selección del rango espectral más adecuado para las imágenes ........................................42

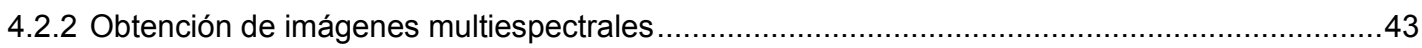

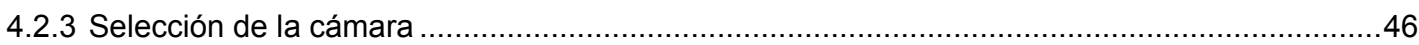

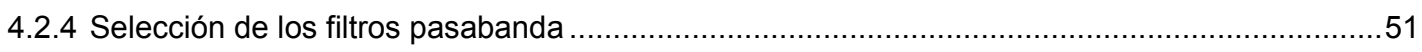

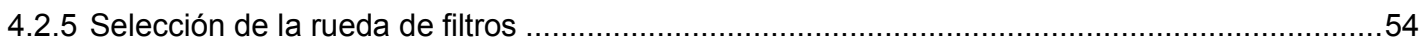

4.2.6 Selección y adaptación de la fuente luminosa del microscopio ................................................55

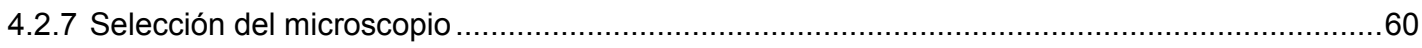

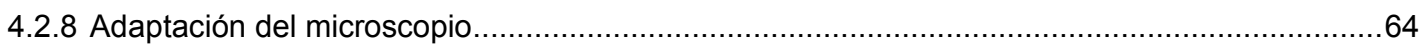

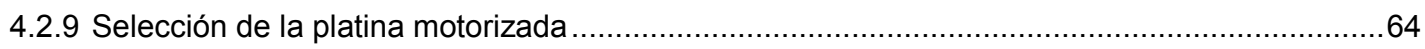

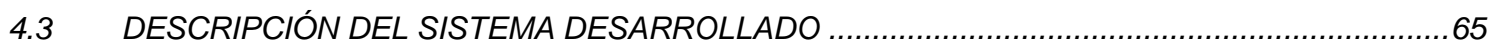

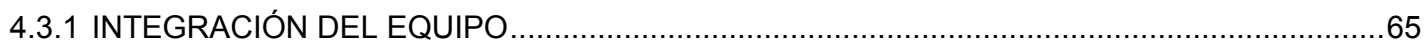

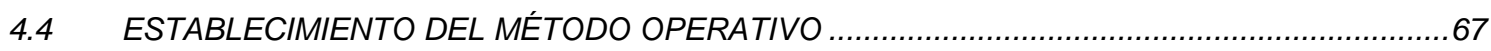

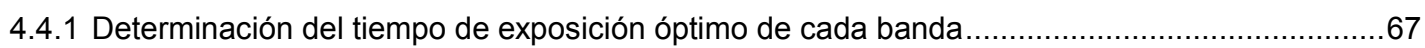

4.4.2 Determinación del plano de enfoque óptimo de cada banda......................................................68

4.4.3 Calibración de la respuesta del instrumento

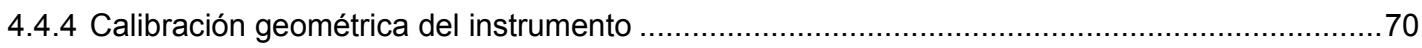




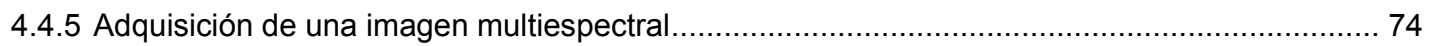

4.4.6 Barrido automático de una preparación...................................................................... 78

4.4.7 Comprobación de la calibración .................................................................................... 79

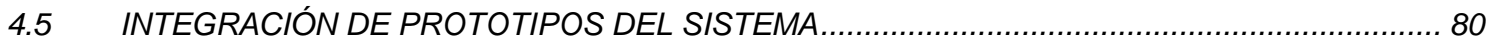

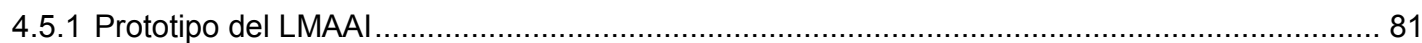

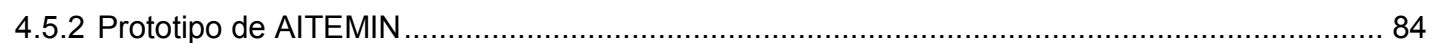

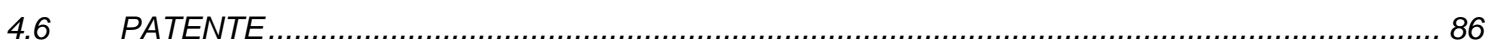

CAPÍTULO 5: PROCESO EXPERIMENTAL ............................................................... 89

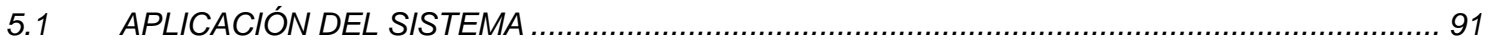

5.2 ESTUDIO DE MÉTODOS DE CLASIFICACIÓN ........................................................... 98

5.2.1 Clasificación por mínima distancia de Mahalanobis .......................................................... 99

5.3 VALIDACIÓN DEL MÉTODO DE CLASIFICACIÓN ............................................................. 100

5.4 ENSAYOS DE VALIDACIÓN SOBRE PROBLEMAS INDUSTRIALES ............................... 103

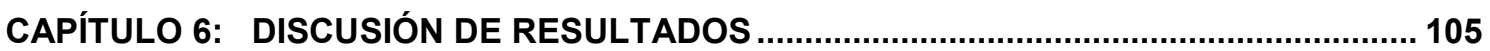

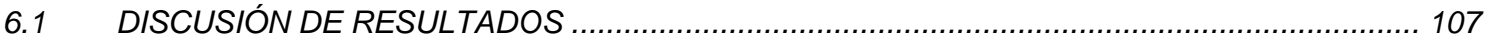

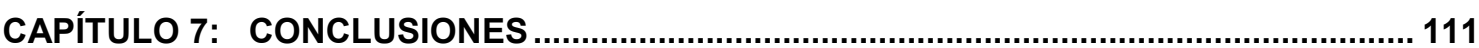

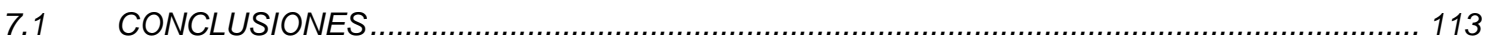

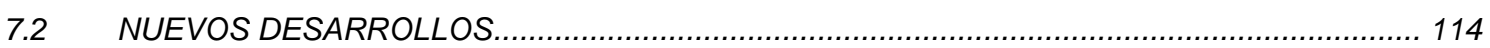

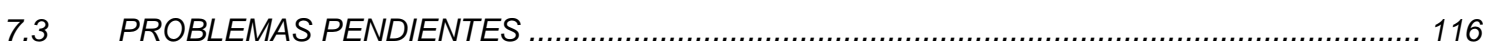

CAPÍTULO 8: REFERENCIAS BIBLIOGRÁFICAS ....................................................... 117

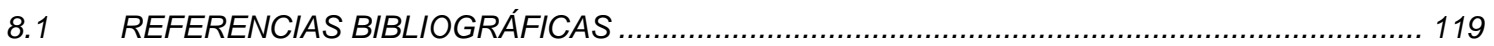




\section{CAPÍTULO 1: INTRODUCCIÓN}




\subsection{INTRODUCCIÓN}

Los mineralogistas en la actualidad se olvidan con demasiada frecuencia de inspeccionar sus especímenes después del desbaste y del pulido para buscar diferencias en las características texturales causadas por inclusiones extrañas. Tales características se revelan particularmente en los compuestos naturales de metal y azufre (Berzelius, 1814).

Berzelius señalaba ya en 1814 el interés de la observación por reflexión para la correcta caracterización y el aprovechamiento eficiente de las menas metálicas. No obstante y a pesar de las observaciones pioneras de Sorby (1861, en: Beck, 1865), las dificultades teóricas (complejidad de la óptica de medios absorbentes) y prácticas (instrumentales), derivadas del carácter habitualmente absorbente (opaco) y anisótropo de dichas menas, retrasaron prácticamente un siglo el desarrollo de la hoy conocida como microscopía de medios absorbentes u opacos, microscopía polarizante de reflexión, mineragrafia o, más habitualmente, microscopía de menas.

La microscopía de menas no alcanza su mayoría de edad, como técnica de estudio mineralógico y de aplicación industrial, hasta la segunda mitad del siglo XX: la obra de Ramdohr (1980) es una referencia básica y, junto con la de Picot y Johann (1982), representan el máximo exponente de la metodología clásica para el estudio microscópico de menas con luz reflejada. Esta metodología combina observaciones cualitativas (forma, color, brillo, zonado, maclas, paragénesis, etc.) y cuantitativas (particularmente dureza VHN y reflectancia especular R, expresión objetiva y cuantitativamente reproducible del brillo), aprovechando el carácter anisótropo ligado a la estructura cristalina de cada especie mineral para definir criterios de observación diagnósticos. Ello introdujo requisitos instrumentales específicos que exigieron modificaciones esenciales en los microscopios de reflexión hasta entonces usados para metalografía: polarizadores y platina rotatoria.

Para la aplicación industrial de la microscopía de menas al control y mejora de los procesos mineralúrgicos, se recurre a la platina integradora o contador de puntos, que permite contabilizar las observaciones realizadas en puntos discretos de la muestra, definidos sobre un retículo o malla regular, para obtener medidas cuantitativas de abundancia (análisis modal), tamaño de grano, grado de liberación, etc.

Esta metodología, hoy tradicional, ha significado un gran avance, pero adolece de algunas limitaciones importantes, entre las cuales hay que destacar, por su relación con el objeto de esta investigación, las siguientes: 
- En cuando a la identificación mineralógica, la dependencia de la visión y, por tanto, de la subjetividad del observador y de sus posibles condicionantes por el entorno o defectos visuales, entre otros.

- En cuanto a la aplicación industrial, mineralúrgica, no sólo la representatividad limitada por el carácter puntual, discreto, de las medidas y por la considerable inversión de tiempo de especialista altamente cualificado, sino también los riesgos de error por percepciones subjetivas o por fatiga.

Estas limitaciones incentivaron el recurso reciente, tan pronto la tecnología estuvo disponible, a métodos basados en el análisis composicional por microscopía electrónica combinado con el análisis de imagen, que representan un avance indudable pero adolecen también de limitaciones importantes, entre las que hay que destacar:

- $\mathrm{Su}$ precio y requisitos de infraestructura y especialización elevados implican una inversión prohibitiva para la mayor parte de las minas.

- Su metodología de identificación basada en la composición química impide la distinción de minerales polimorfos y hace arriesgada o imposible la de minerales que, sin ser polimorfos, tienen un quimismo parecido, como ocurre con las menas de hierro, que con casi el $40 \%$ del mercado representa el metal más importante de la minería mundial (datos de 2011).

El objeto de esta investigación es el desarrollo y puesta a punto de un sistema alternativo que, en la medida de lo posible, combine las fortalezas y supere las limitaciones de ambas metodologías, es decir:

- Que aúne la accesibilidad y precio asequible de la metodología tradicional, con la cuantificación objetiva y automatizada del análisis digital de imagen, recurriendo a la discriminación de imágenes multiespectrales adquiridas con microscopio óptico, en el rango visible y en el infrarrojo cercano (VNIR).

- Que aúne la automatización y el alto rendimiento de las últimas metodologías basadas en microscopía electrónica, con la determinación fiable de fases minerales independientemente de su composición química y con el análisis textural automatizado, haciendo posible la caracterización mineralógica completa con criterios geometalúrgicos actuales. 
Se trata, por tanto, de un sistema

- basado en microscopía óptica de reflexión, cuyo criterio diagnóstico es la reflectancia especular multiespectral VNIR, medida sobre secciones pulidas de menas;

- automatizado, tanto en la medida de la reflectancia como en el barrido de la sección estudiada en platina motorizada $\mathrm{X}-\mathrm{Y}$, lo que supone renunciar a la polarización tradicional y a los criterios de anisotropismo;

- que trabaja ya no sobre puntos de una malla, sino sobre todos los píxeles de una serie de imágenes obtenidas con la relación de cobertura que se decida para cada muestra, pero en todo caso realizando millones de medidas en cada sección, es decir, procesando una cantidad de información incomparablemente superior a la del contador de puntos tradicional;

- y que, tras realizar un solo barrido de la sección para la adquisición de imágenes, permite efectuar múltiples tratamientos matemáticos de la información, para responder a la variedad de las demandas posibles: análisis modal, granulometría, análisis del grado de liberación, caracterización textural, etc.

Desde el punto de vista de la aportación original al acervo de conocimientos existentes que se espera de una tesis doctoral, cabe decir que en los dos siglos transcurridos desde los esfuerzos pioneros de Berzelius se han realizado importantes avances en el campo de la microscopía óptica, tal como se expone en el $\S 2.2$ (Estado del Arte), pero no se ha resuelto todavía el problema capital expuesto por Gribble y Hall (1992, p. 257): "Now that reflectance data is available, it would be of enormous benefit to users of reflected light microscopy if a simple method of light intensity measurement could be incorporated into basic reflected light microscopes, in the way in which sensors have been incorporated into cameras. The estimation of the reflectance value is a key step in the identification of minerals in reflected light, but the human eye is very poor at estimating absolute levels of light intensity".

Este problema, básico para la caracterización automatizada de menas metálicas por métodos ópticos, espera todavía en el siglo XXI el desarrollo de una metodología adecuada: la recensión actualizada por Cook et al. (2017) de los sistemas automatizados hoy disponibles comprende numerosos ejemplos basados en técnicas variadas, pero ninguno en microscopía óptica. La aportación de esta tesis se propone contribuir a superar esta laguna, mediante el diseño $\mathbf{y}$ validación de un sistema fiable, asequible y, tal como requiere su aplicación industrial, de alto rendimiento, basado en microscopía óptica de reflexión. 


\subsection{PLAN DE EXPOSICIÓN}

El plan de exposición seguido en el presente trabajo se estructura de la siguiente forma:

El capítulo 2 comienza con una breve introducción a la historia de la microscopía de reflexión cuantitativa, seguida de la descripción detallada del estado del arte, enmarcada en la actual situación de predominio de los sistemas de microscopía electrónica. Con esto se trata de definir el marco de conocimientos en el que se sitúa la aportación. Finalmente, se exponen tanto el planteamiento inicial de la investigación como los objetivos perseguidos en las distintas fases que ha atravesado.

El capítulo 3 presenta los equipos e instrumentos disponibles en el LMAAI y en AITEMIN como base de partida para el desarrollo del proyecto, así como diversos materiales esenciales, tales como las colecciones de menas empleadas para la construcción de la base de datos de reflectancia multiespectral y para la validación del método.

El capítulo 4 expone las principales actividades realizadas durante la investigación, enfocadas al diseño y la construcción del sistema CAMEVA y el establecimiento del método de trabajo. En particular, se detallan los procesos de definición, selección e integración de sus componentes, el establecimiento de la metodología de calibración y operación del sistema, el desarrollo del software para su manejo y la puesta a punto final.

El capítulo 5 recoge las pruebas realizadas para validar el sistema, así como una breve compilación de diversos ensayos de aplicación real.

El capítulo 6 analiza los resultados obtenidos en dichas pruebas, y valora el impacto técnico y económico que podría tener el sistema en su aplicación rutinaria en la industria.

El capítulo 7 resume las conclusiones obtenidas tras la realización del trabajo, describe las últimas modificaciones realizadas al diseño del sistema en el marco del proyecto AMCO, destaca los problemas pendientes de solución y propone líneas de trabajo para resolverlos o minimizar su efecto. 


\section{CAPÍTULO 2: PLANTEAMIENTO Y OBJETIVOS}




\subsection{ANTECEDENTES}

Existen referencias de aplicaciones de la microscopía de reflexión a varios materiales desde finales del siglo XVIII y son reconocidas aportaciones pioneras como las de Berzelius al estudio de menas de pirrotina desde 1813, pero sólo a principios del siglo XX se sientan las bases teóricas, prácticas e instrumentales para el desarrollo sistemático de la microscopía polarizante de reflexión aplicada a la microscopía de menas.

Tradicionalmente, la identificación de minerales opacos al microscopio de reflexión se ha basado en la observación de características visuales tales como el color, el pleocroísmo, la anisotropía, la reflectancia especular, la birreflectancia, las reflexiones internas, la forma de los granos, su estructura y textura, etc., así como en su dureza. La mayoría de estas propiedades son cualitativas y su determinación requiere la intervención de un observador con cierta experiencia, por lo que los procedimientos de identificación tradicionales tienen una fuerte componente subjetiva y resultan difícilmente automatizables.

En 1931, tras precedentes como Orcel (1927) o Frick (1930), el diseño del fotómetro por Berek $(1931,1937)$ aporta un impulso significativo al desarrollo de métodos basados en datos objetivos y cuantificables, abriendo así las puertas a un proceso de automatización que sólo podría culminar tras la segunda guerra mundial, gracias a los avances que se van produciendo en electrónica y en informática. Para entonces, ya existía una experiencia positiva del potencial de la técnica por lo que respecta a su aplicación a problemas metalúrgicos, gracias a los trabajos de pioneros como Schwartz (1923), Amstutz (1962) o Agarwal et al. (1976), entre otros.

Bowie y Taylor (1958) propusieron el primer método de identificación totalmente cuantitativo, basado únicamente en dos propiedades: la reflectancia especular (R) y la microdureza (VHN, Vickers Hardness Number). Prepararon un diagrama en el que cada mineral se representaba mediante un punto, cuya posición venía dada por la reflectancia media en luz blanca y la microdureza media. Sin embargo, la utilidad de dicho diagrama para la identificación objetiva de menas era muy limitada, puesto que los valores de reflectancia y microdureza que muestran muchos minerales dependen de la orientación de la sección y de la composición. Por ello Gray y Millman (1962) propusieron un diagrama mejorado, en el que cada mineral se representaba mediante una línea que recorría el rango de valores de reflectancia que podía mostrar, y más adelante McLeod y Chamberlain (1968) propusieron otro más completo en el que cada mineral se representaba por dos líneas ortogonales: la vertical indicaba el rango de valores de reflectancia y la horizontal el rango de valores de microdureza. 
Pero ni siquiera estos diagramas mejorados resultaron suficientemente resolutivos, porque muchos minerales presentan considerables solapamientos en los rangos de reflectancia medida con luz blanca, y la medida de la microdureza era difícilmente automatizable. Por este motivo se decidió utilizar otra propiedad cuantitativa de los minerales que puede llegar a ser muy distintiva: la variación de la reflectancia especular con la longitud de onda de la luz, que puede ser caracterizada efectuando medidas multiespectrales (es decir, en varias longitudes de onda) o incluso espectrales (obteniendo un espectro continuo de reflectancia).

La IMA/COM (Commission on Ore Microscopy of the International Mineralogical Association), constituida en 1962 por un grupo internacional de científicos y diseñadores de instrumentos, consideró que las tres propiedades anteriores eran las más prometedoras para conseguir la identificación objetiva de menas, y en su reunión de 1964 adoptó como objetivos la preparación de una serie de patrones de reflectancia calibrados en el National Physical Laboratory del Reino Unido para su uso por todos los miembros y la compilación de un tabla de datos cuantitativos de minerales que incluyera al menos la Microdureza Vickers y la reflectancia especular ( $R, R^{\prime}, R_{o}, R_{e}, R_{e}^{\prime}, R_{p}, R_{m}, R_{g}, R_{a}, R_{b}, R_{c} \ldots$ según el tipo de simetría del mineral) medida en cuatro longitudes de onda: $470 \mathrm{~nm}$ (azul), $546 \mathrm{~nm}$ (verde), $589 \mathrm{~nm}$ (amarillo) y 650 nm (rojo).

A raíz de la decisión de la COM, a mediados de los años 60 los principales fabricantes de microscopios comenzaron a ofrecer sofisticados microfotómetros (Leitz MPV, Zeiss MPM) dotados de tubos fotomultiplicadores muy sensibles capaces de realizar medidas precisas en una pequeña región de unos pocos $\mu \mathrm{m}$ de diámetro a través de filtros de interferencia de banda muy estrecha, lo que facilitó tanto la adquisición de datos de reflectancia para las tablas como la aplicación de métodos cuantitativos para la identificación de menas a partir de medidas de reflectancia o color. Piller (1966) propuso un procedimiento de colorimetría cuantitativa de minerales basado en el cálculo de los valores triestímulo de la CIE a partir de curvas de reflectancia espectral en el rango visible, pero el tiempo necesario para completar una medición podía llegar a 10 minutos, lo que no resultaba práctico para su aplicación sistemática. Desde un punto de vista más teórico, Peckett (1992) actualiza y sistematiza las aportaciones esenciales de Phillips y Henry sobre el color de menas metálicas.

En 1970 la COM publicó una tabla provisional de datos cuantitativos editada por el Departamento de Cristalografía y Mineralogía de la Universidad de Barcelona (Font-Altaba 1970) que recogía los rangos de microdureza Vickers y de reflectancia especular en aire en las cuatro longitudes de onda COM para poco más de cien minerales. Poco después, Uytenbogaardt y Burke (1971) publicaron tablas para la identificación microscópica de menas que compilaban 
tanto descripciones cualitativas (color, birreflectancia, anisotropía, reflexiones internas) como datos cuantitativos (VHN y reflectancia especular en las longitudes de onda COM), siguiendo los pasos de Schneiderhöhn y Ramdohr (1931) y Ramdohr (1955, actualizado en 1980), quienes ya con antelación completaban sus descripciones de menas con medidas cuantitativas, insistiendo en la evidente necesidad de datos objetivos de reflectancia para superar las limitaciones del ojo humano.

La primera edición del Quantitative Data File (QDF) de la COM (Henry 1977) representó un avance considerable sobre la versión provisional de 1970 al aportar datos de composición y de rayos $\mathrm{X}$, así como valores de color cuantitativo y de reflectancia multiespectral (16 medidas entre $400 \mathrm{~nm}$ y $700 \mathrm{~nm}$, a intervalos de $20 \mathrm{~nm}$, en aire y en aceite), aunque únicamente para una parte de los minerales. Una compilación de medidas de reflectancia multiespectral más completa fue recogida por Picot y Johan $(1977,1982)$ en su Atlas of Ore Minerals, que aporta medidas originales de reflectancia entre $420 \mathrm{~nm}$ y $700 \mathrm{~nm}$ (también a intervalos de $20 \mathrm{~nm}$ ) para todos los minerales, además de novedades importantes como información sobre asociaciones minerales frecuentes y sus localizaciones, y láminas en color. Kühnel et al. (1980) proponen un sistema de identificación basado en tarjetas perforadas que codifican diversas propiedades de las menas, entre ellas las recogidas en el QDF.

La segunda edición del Quantitative Data File (QDF2) de la COM (Criddle y Stanley 1986) contenía ya 420 fichas (327 correspondientes a especies minerales individuales y 93 a diversas variantes composicionales y estructurales), aunque no todas estaban completas debido a que el pequeño tamaño de los granos de algunos minerales impedía realizar algunas medidas.

Finalmente, la tercera y última edición del Quantitative Data File (QDF3) de la COM (Criddle y Stanley 1993) contiene 635 fichas, prácticamente todas completas, de las que 510 corresponden a especies minerales y 125 a variantes composicionales y estructurales. Como novedad, cada ficha incluye una representación gráfica de los valores de reflectancia multiespectral, que permite hacerse una idea de la forma de los espectros de reflectancia del mineral para las distintas orientaciones cristalográficas.

Ya en 1979 surgieron métodos de identificación automática asistida por computador basados en el uso de valores de color (Aitkin y Harvey 1979) o de espectros de reflexión en luz visible (Bernhardt 1979). Posteriormente aparecieron métodos de identificación automática basados en la aplicación de los nuevos ordenadores personales que comparaban los valores de reflectancia medidos en un punto del campo microscópico con los datos de las distintas ediciones del Quantitative Data File. Gerlitz et al. (1989) publican un programa informático para PC basado en una versión digital de la base de datos QDF2 de IMA/COM. Bernhardt (1987) desarrolla un 
sistema para identificación automatizada basado precisamente en medidas espectrales puntuales en las 16 bandas (entre 400 y $700 \mathrm{~nm}$, con $20 \mathrm{~nm}$ de separación) del QDF2.

Otros sistemas empleaban modelos avanzados de microfotómetros que incorporaban un monocromador motorizado, lo que permitía obtener espectros continuos de reflectancia de granos minerales individuales, llegando los modelos más avanzados a abarcar amplios rangos espectrales del UV al IR (p. ej., el MPM 800 de Zeiss medía entre 240 y 2100 nm). Desafortunadamente, a pesar de sus indudables ventajas, su elevado coste y la falta de bases de datos de reflectancia de minerales en el UV y el IR no facilitaron la aplicación generalizada de estos métodos de identificación de menas en la industria.

\subsection{ESTADO DEL ARTE}

En síntesis, a pesar de los numerosos intentos realizados para automatizar la identificación de fases minerales mediante el uso de propiedades ópticas cuantitativas, el proceso aún no se ha culminado con éxito. La razón estriba en que en numerosas ocasiones resulta difícil identificar una fase mediante la simple medida de su reflectancia o de su color, siendo necesaria la intervención del especialista para tener en cuenta criterios adicionales (microdureza Vickers, observación bajo luz polarizada, conocimiento de las asociaciones minerales habituales, etc.) que permitan asegurar la exactitud de la identificación. La dificultad para utilizar dichos criterios adicionales de forma automatizada ha impedido la aplicación sistemática de la microscopía óptica de reflexión al análisis cuantitativo de fases en la industria, restringiendo su utilización a los pocos laboratorios dotados de personal especializado existentes en la actualidad. Dado el coste laboral de dichos especialistas y el tiempo necesario para su realización, los análisis manuales mediante contaje de puntos sólo resultan abordables en estudios aislados, y no es factible su aplicación generalizada en la industria.

En esta situación, resultaba lógico abordar el análisis cuantitativo de fases mediante técnicas de microscopía electrónica y, efectivamente, sobre esta base se pusieron a punto diversos sistemas. En el mercado se encuentran con distintos nombres comerciales (QEMSEM, QEMSCAN, MLA, etc., como acrónimos de Quantitative Evaluation of Mineralogy by Scanning Electron Microscope, Mineral Liberation Analyzer, etc.), pero para los fines de este trabajo se designan colectivamente, en lo que sigue, como sistemas MEB (Microscopía Electrónica de Barrido), basados en información de tipo químico, independientemente de la estrategia analítica específica de cada uno de ellos, para identificar y medir automáticamente las distintas fases presentes en una muestra. No obstante, estas técnicas no han resuelto definitivamente el problema, dado que presentan una serie de limitaciones que impiden su uso generalizado: 
- La técnica MEB permite determinar la composición elemental de la muestra en un cierto número de puntos de su superficie, pero esto no es suficiente para discriminar entre fases que, teniendo composiciones similares, presentan estructuras diferentes, cosa relativamente frecuente en ciertas aplicaciones (mineralogía, por ejemplo).

- El coste de los equipos MEB es muy elevado (en principio, del orden del millón de dólares USA, aunque tiende a bajar), y no está al alcance de todas las empresas (ni de todos los países), por lo que el número de unidades en uso en el mundo -no llega a 200es muy inferior a la potencial demanda y a la magnitud de los problemas a resolver.

- El manejo de estos equipos exige personal altamente capacitado, y un entorno especialmente acondicionado con elevados requisitos de estabilidad ambiental.

- La preparación de las muestras para MEB precisa de un equipamiento y un personal especializado que suponen un considerable coste por análisis.

Por todo ello, las técnicas MEB distan de ser la mejor solución al problema del análisis modal en materiales multifásicos, salvo para grandes empresas con acceso a uso intensivo de capital, que puedan permitirse invertir grandes cantidades de dinero en laboratorios de última generación, y que puedan recurrir al análisis microscópico manual en caso de duda.

Teniendo en cuenta lo anterior, resulta razonable el intento de desarrollar nuevas metodologías de análisis que permitan aplicar la microscopía óptica de reflexión al reconocimiento automatizado de minerales, a pesar de la tendencia general del actual mercado a ignorarla. La que parece contar con más posibilidades de éxito es el análisis de imagen, ya que proporciona una gran cantidad de información por cada campo que se adquiere, lo que permitiría caracterizar una preparación procesando un número de campos mucho menor que el número de puntos necesarios con un contador de puntos.

A principios de los 80 se intentó aplicar los primeros sistemas de análisis de imagen, como el QTM720 de Cambridge Instruments, a la identificación de minerales en imágenes obtenidas con una cámara acoplada a un microscopio, pero los resultados no fueron buenos por múltiples motivos (baja sensibilidad y resolución de las cámaras de tubo, alimentación poco estabilizada, ausencia de calibración, opacidad de las aplicaciones, poca información al usuario sobre las limitaciones del sistema, etc.). Hacia 1985 se había abandonado, por su difícil reproducibilidad, el análisis automático de menas metálicas basado en imágenes ópticas (Sutherland and Gottlieb 1991), aunque la técnica siguió siendo útil en otros campos en los que la segmentación era más fácil (metalografía, medicina, biología, etc.).

Durante los años 90 el análisis de imágenes fue aplicado con éxito en otros tipos de análisis microscópico automatizado, como el análisis maceral de carbones de capa (Catalina et al. 1995) 
o el análisis petrográfico de mezclas de carbones (Catalina et al. 2003), que se realizan con luz reflejada monocromática de $546 \mathrm{~nm}$. Estos desarrollos fueron llevados a cabo por el centro tecnológico AITEMIN con el apoyo del INCAR (CSIC) y son precedentes casi inmediatos del sistema CAMEVA porque usaban dos patrones de reflectancia (alta y baja) para su calibración, y empleaban una cámara CCD monocroma y una rueda de filtros para adquirir varias bandas en cada campo (una por cada ángulo de polarización de la iluminación).

Las características básicas de un sistema de adquisición de imágenes microscópicas multiespectrales mediante cámara CCD en color RGB fueron analizadas en Pirard et al. (1999). Posteriormente, Pirard (2004, - et al. 2008) profundiza en las ventajas que presenta el uso de una cámara CCD monocroma y una rueda de filtros de interferencia para la obtención de imágenes multiespectrales de menas en el espectro visible.

El sistema basado en cámara RGB fue el elegido en Berrezueta y Castroviejo (2007) para abordar en el LMAAI (Laboratorio de Microscopía Aplicada y Análisis de Imagen de la UPM) el reconocimiento automatizado de menas metálicas mediante análisis digital de imagen con el fin de determinar parámetros cuantitativos de interés mineralúrgico.

En el LMAAI se ha instalado recientemente (2008) un Microfotómetro de Reflexión Espectral (Spectral Reflectance Microphotometer), que es una versión más avanzada del equipo descrito en Bernhardt (1987), mejorado con un espectrómetro Hamamatsu de fibra óptica, que adquiere espectros continuos en el visible y el infrarrojo cercano, para facilitar el control externo e independiente de los espectros de referencia medidos con el Sistema CAMEVA, los cuales constituyen la base de datos utilizada para la identificación automatizada sobre imágenes, objeto del presente trabajo.

\subsection{OBJETIVOS}

Teniendo en cuenta estos antecedentes y el estado del arte, se abordó en el marco del proyecto CAMEVA (Caracterización Automatizada de Menas Metálicas por Visión Artificial, financiado por el Ministerio de Educación y Ciencia a través del Plan Nacional de I+D+I) el desarrollo de un innovador sistema, actualmente patentado y en uso en el LMAAI, para el reconocimiento automatizado de menas metálicas que permitiera superar las limitaciones que presentaba la microscopía óptica para el análisis cuantitativo de fases, mediante la puesta a punto de unos procedimientos avanzados para la calibración y la operación de un microscopio óptico de reflexión especialmente modificado para adquirir imágenes multiespectrales en una porción del espectro más extensa que la banda visible. La información adicional aportada por la reflectancia de la muestra en el infrarrojo cercano (Near Infrared o NIR, en inglés) y/o en el ultravioleta 
cercano (Near Ultraviolet o NUV, en inglés) permite identificar las distintas fases con mayor certeza que únicamente a partir de la reflectancia en la banda visible (Vis).

El trabajo se realizó en su mayor parte en el Centro Tecnológico AITEMIN y en el LMAAI (Laboratorio de Microscopía Aplicada y Análisis de Imagen de la Universidad Politécnica de Madrid, radicado en la Escuela Técnica Superior de Ingenieros de Minas y Energía) en el marco del proyecto de investigación CAMEVA (Caracterización Automatizada de Menas Metálicas mediante Visión Artificial), proyecto coordinado del Plan Nacional de I+D+I realizado en cooperación por la UPM y AITEMIN, integrado a su vez por los proyectos SEICAMIN (Sistema Experto para la identificación y cuantificación automatizada de minerales de interés industrial (menas), ejecutado por la UPM, referencia CGL2006_13688_C02_01) y AMAMET (Sistema de visión artificial para el análisis microscópico automatizado de menas metálicas, ejecutado por AITEMIN, referencia CGL2006_13688_C02_02).

Este proyecto, financiado por el Ministerio de Educación y Ciencia, se llevó a cabo entre 2007 y 2009, contando también con apoyo del Plan Regional de Investigación Científica e Innovación Tecnológica (IV PRICIT) y del Grupo de Investigación Recursos Minerales (GIRMI-UPM).

El objetivo principal del proyecto CAMEVA era desarrollar y poner a punto un prototipo de sistema de adquisición y proceso digital de imágenes que debía reunir las siguientes capacidades:

- Trabajar con imágenes digitales, para posibilitar la aplicación de técnicas de análisis de imagen y las aplicaciones geometalúrgicas.

- Reconocimiento automático de menas comunes de interés industrial

- Proporcionar medidas cuantitativas aplicables al control de procesos industriales

- Permitir la incorporación de nuevos minerales en la base de datos

- Prestar apoyo al mineralurgista proporcionándole información objetiva sobre la muestra

Los resultados obtenidos permitieron obtener financiación adicional de la UE en el marco del programa H2020 para perfeccionar el sistema e impulsar su comercialización mediante el proyecto AMCO (Automated microscopic characterization of ores, EIT 15039), aprobado en la primera convocatoria (2015) del EIT Raw Materials.

Este proyecto plantea objetivos adicionales para el sistema AMCO, respondiendo a prioridades recientemente establecidas por el EIT Raw Materials, tales como:

- Integrar un prototipo más avanzado del sistema, de fácil manejo, concebido para su aplicación industrial y comercialmente viable 
- Facilitar el aprendizaje y la formación continua en microscopía proporcionando al estudioso una herramienta innovadora que aporta información objetiva y de alto valor diagnóstico para la identificación de menas

- Contribuir a la reducción del impacto ambiental de la minería mediante el control mineralógico de los residuos del proceso y la identificación de componentes tóxicos 


\section{CAPÍTULO 3: MATERIALES Y MÉTODOS}




\subsection{EQUIPAMIENTO DEL LABORATORIO}

El sistema de microscopía multiespectral que se pretende desarrollar está basado en el equipamiento habitual de los laboratorios de microscopía de menas, constituido principalmente por el microscopio óptico de reflexión, en ocasiones asociado a una platina integradora o contador de puntos.

Un microscopio óptico de reflexión es un instrumento específicamente diseñado para la observación microscópica de materiales ópticamente absorbentes u opacos. Para solventar la opacidad del material observado, que impide su observación con luz transmitida, se emplea luz incidente, denominada también epi-iluminación.

El diseño básico del microscopio de reflexión no ha experimentado cambios significativos desde hace más de 30 años. En un microscopio de reflexión convencional (Figura 3-1), la luz procedente del iluminador, tras pasar por los diafragmas de apertura y de campo, se refleja en un espejo semitransparente inclinado a $45^{\circ}$ que la redirige a través del objetivo para incidir perpendicularmente sobre la superficie pulida de la preparación. La luz reflejada especularmente por ésta es recogida por el objetivo, atraviesa el espejo semitransparente, y continúa por el tubo óptico del microscopio hasta el ocular y/o hasta una cámara. La observación puede efectuarse con luz sin polarizar o polarizada. En este último caso (microscopio polarizante), suele emplearse una platina rotativa y puede intercalarse en el tubo óptico un segundo polarizador cuya orientación es regulable (llamado analizador) para comprobar si la muestra presenta anisotropía en alguna de sus propiedades ópticas.

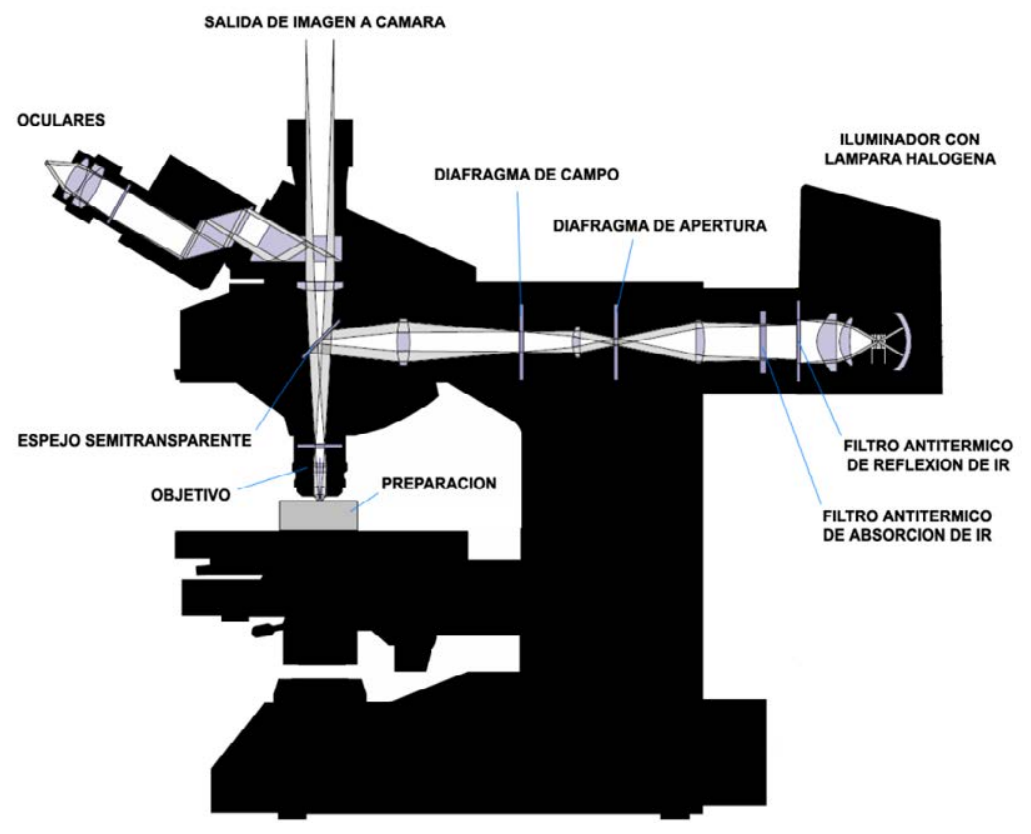

Figura 3-1. Esquema de un microscopio óptico de reflexión típico (modificado de Zeiss, 2010) 


\subsection{PREPARACIÓN DE MUESTRAS}

Las muestras de menas metálicas que se desea caracterizar suelen presentarse en dos formas, dependiendo de su procedencia:

- muestras de mano (fragmentos de roca de dimensiones centimétricas), normalmente obtenidos sobre el terreno o extraídas de testigos de sondeo.

- muestras de molienda (partículas de menos de un milímetro), generalmente tomadas de los flujos de una planta de concentración.

Con el fin de facilitar su manipulación y observación, las muestras (tanto de mano como pulverulentas) se embuten en resina, empleando moldes para obtener probetas de las dimensiones deseadas. Tras su fraguado, las probetas se desbastan para asegurar su planitud y se pulen cuidadosamente para evitar que las diferencias de acabado superficial influyan en la observación, obteniendo lo que se conoce como probetas pulidas (en inglés Polished Blocks, PB). El proceso típico se resume en la Figura 3-2.

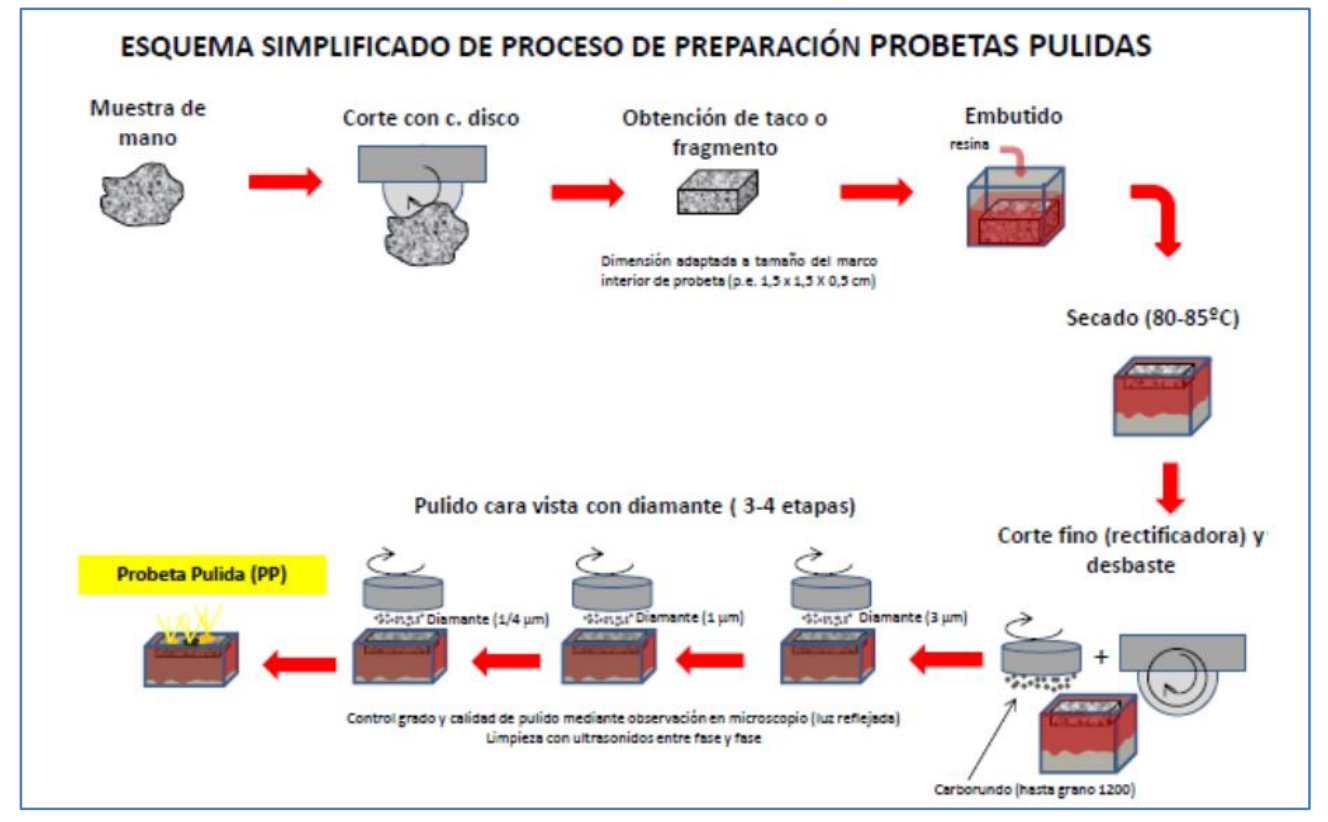

Figura 3-2. Preparación de probetas pulidas a partir de muestras de mano (por Lázaro Sánchez)

La Figura 3-3 muestra diversos tipos de probetas pulidas. Las de la izquierda han sido elaboradas con muestras de mano, y las de la derecha con muestras de molienda.
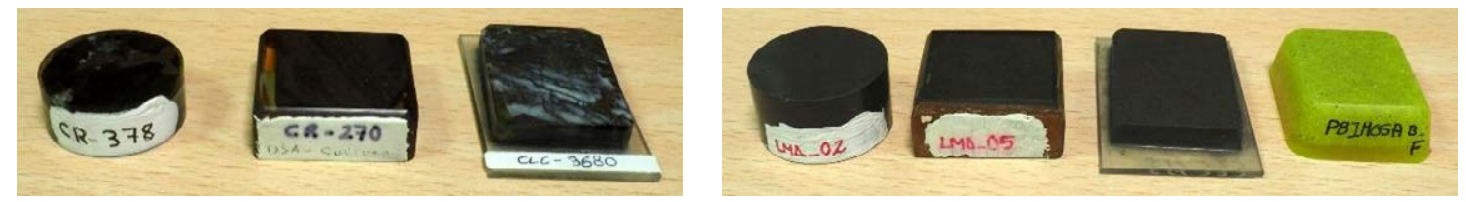

Figura 3-3. Probetas pulidas, preparadas con muestras de mano (izda.) y de partículas (dcha.) 
Otro modo de preparación muy interesante son las láminas transparentes pulidas (Polished Thin Sections, PTS), que gracias a su reducido espesor (típicamente, $30 \mu \mathrm{m}$ ) permiten la observación tanto con luz reflejada como con luz transmitida (Figura 3-4). Este modo de preparación, que tradicionalmente se reservaba para estudios simultáneos de los minerales de ganga y la mena, ha resultado especialmente indicado para concentrados en los que haya que cuantificar la ganga, según se explicará más adelante.

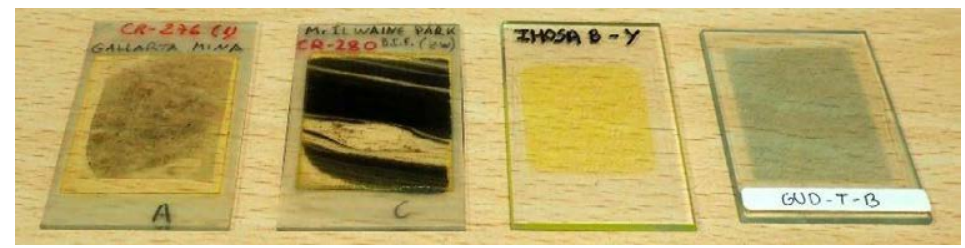

Figura 3-4. Láminas transparentes pulidas preparadas con muestras de mano y de partículas

\subsection{METODOLOGÍA HABITUAL}

La metodología seguida para el estudio de menas metálicas con microscopio polarizante de reflexión ha ido evolucionando en el tiempo, según se expone en $§ 2.1$ y §2.2, pero conservando siempre algunos rasgos esenciales que, si bien se han ido perfeccionando con las innovaciones técnicas disponibles en cada momento para una mejor observación, se apoyan en conceptos y propiedades que se conocen y aplican desde mediados del pasado siglo. Esto se puede apreciar claramente comparando textos clásicos de los años 1950/1960 (vbgr. Schneiderhöhn 1952, Ramdohr 1955/1960, Uytenbogaardt and Burke 1971, Schouten 1962) con otros más recientes (vbgr. Ramdohr 1980, Picot 1977/1982) o incluso actuales, como las sucesivas monografías auspiciadas por el IMA/COM (International Mineralogical Association / Commission on Ore Mineralogy: Jambor y Vaughan, eds. 1990; Cabri y Vaughan, eds. 1998), la excelente síntesis de Criddle (1998) o el resumen comparativo de Pirard (2016).

A grandes rasgos, esta metodología se basa en la combinación de observaciones cualitativas y medidas cuantitativas. Las primeras requieren una educación práctica, una sensibilidad visual y una experiencia de observación que confieren a esta técnica, de alguna forma, el carácter de una disciplina artística, sin menoscabo de su rigor conceptual, pero con un peso inevitable de la percepción subjetiva. Las segundas entran de lleno en la metodología científica clásica, basada en medidas, comparaciones y análisis matemáticos, con la peculiaridad de que, por ser los minerales habitualmente medios anisótropos, sus propiedades varían con la orientación; esto puede mejorar la capacidad de diagnóstico, pero desde el punto de vista instrumental significa ante todo una importante complicación que ha impuesto modificaciones específicas de los microscopios de menas frente a los clásicos de metalografía, más sencillos, con los que comparten el diseño del iluminador de opacos (óptica de reflexión) para trabajar con luz 
incidente, la posibilidad de trabajar con objetivos de inmersión en aceite para mejorar el contraste y, en ocasiones, el recurso al ataque químico (cada vez menos usado para menas metálicas, dado el progresivo desarrollo de observaciones diagnósticas alternativas).

Dichas modificaciones se basan fundamentalmente en el recurso a la luz polarizada para detectar y caracterizar la anisotropía y se concretan principalmente en:

- La introducción, en la trayectoria del haz luminoso incidente sobre la muestra, de un polarizador que sólo deja pasar luz polarizada (luz que vibra en un determinado plano).

- La inserción opcional de un analizador (un segundo polarizador con dirección de vibración a $90^{\circ}$ del anterior) en la trayectoria del haz luminoso reflejado por la muestra.

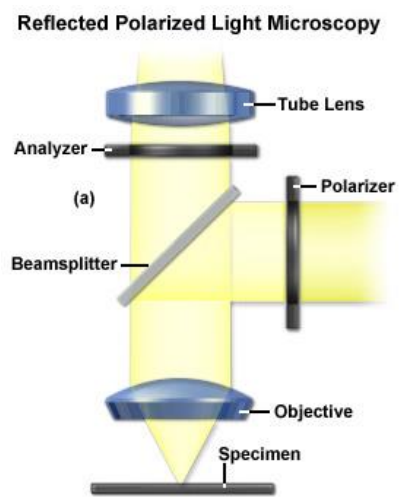

Figura 3-5. Polarizador y analizador en un microscopio de reflexión (Zeiss, 2018)

De esta forma pueden hacerse observaciones en dos configuraciones de polarizadores:

$\rightarrow$ Sólo polarizador: denominada P (PPL en la literatura internacional, de Plane Polarized Light). También conocida, aunque impropiamente, como "con luz natural" o "con nícoles paralelos" (N//).

$\rightarrow$ Polarizador y analizador cruzados a 90 ${ }^{\circ}$ : denominada XP (XP o CP en la literatura internacional, de Crossed Polars). También conocida, aunque impropiamente, como "con luz polarizada" o "con nícoles cruzados" (NX).

Para ambas configuraciones puede optarse por usar objetivos secos (los habituales, que trabajan en aire) o de inmersión (generalmente en aceite con índice de refracción $\boldsymbol{n}$ similar al del vidrio, que mejora la apertura numérica y con ello la resolución y el contraste de la imagen).

- Otra modificación habitual de los microscopios de menas es la transformación de la platina fija (o con desplazamiento X-Y) en platina rotatoria (Figura 3-6), que permite variar a voluntad la orientación del mineral observado con respecto al plano de vibración de la luz incidente, determinado por el polarizador introducido. 


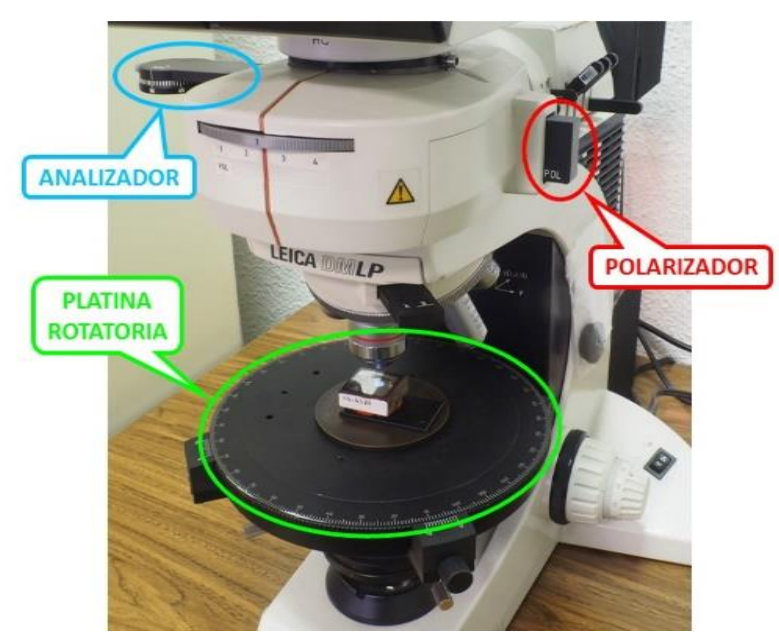

Figura 3-6. Microscopio de menas dotado de polarizador, analizador y platina rotatoria

Este diseño del microscopio ha permitido desarrollar una metodología sistemática de observación, descripción y diagnóstico ampliamente aceptada, que se sintetiza en la Tabla 3-1. Aunque todas las propiedades referidas se observan al microscopio, se indican específicamente las propiedades ópticas (s. str.), que dependen en gran medida de la estructura cristalina, así como de la configuración atómica, del tipo de enlace, etc. Las restantes propiedades, igualmente importantes para el diagnóstico de la especie mineral, suelen designarse como propiedades físicas (s. 1.).

Tabla 3-1. Sistemática de trabajo para la descripción de menas al microscopio óptico de reflexión

\begin{tabular}{|c|c|c|}
\hline \multicolumn{3}{|c|}{ DESCRIPCIÓN DE MENAS CON LUZ REFLEJADA } \\
\hline \multirow{2}{*}{$\begin{array}{c}\text { SÓLO } \\
\text { POLARIZADOR } \\
\text { (P / PPL) }\end{array}$} & $\begin{array}{l}\text { PROPIEDADES } \\
\text { OPTICAS }\end{array}$ & \begin{tabular}{|l} 
- COLOR \\
- BRILLO (+ \% R) \\
- PLEOCROISMO , \\
BIRREFLECTANCIA
\end{tabular} \\
\hline & $\begin{array}{l}\text { PROPIEDADES } \\
\text { FISICAS }\end{array}$ & $\begin{array}{l}\text { - DUREZA (+ VHN) } \\
\text { - MORFOLOGIA } \\
\text { - CRUCERO / EXFOLIACIÓN } \\
\text { - ZONADO } \\
\text { - INCLUSIONES } \\
\text { - INTERCRECIMIENTOS }\end{array}$ \\
\hline \multirow{2}{*}{$\begin{array}{l}\text { POLARIZADOR } \\
\text { Y ANALIZADOR } \\
(\mathbf{X P} / \mathbf{C P})\end{array}$} & $\begin{array}{l}\text { PROPIEDADES } \\
\text { OPTICAS }\end{array}$ & $\begin{array}{l}\text { - ISOTROPISMO I } \\
\text { ANISOTROPISMO \& } \\
\text { COLORES } \\
\text { - REFLEXIONES INTERNAS }\end{array}$ \\
\hline & $\begin{array}{l}\text { PROPIEDADES } \\
\text { FISICAS }\end{array}$ & $\begin{array}{l}\text { - MACLADO } \\
\text { - ALTERACIÓN }\end{array}$ \\
\hline
\end{tabular}

\subsubsection{Propiedades Ópticas}

El color es una sensación óptica fundamental y muy directamente relacionada con el objeto de esta investigación, que trata de superar las limitaciones de la percepción subjetiva mediante la cuantificación rigurosa. En efecto, el color percibido por el ojo humano es importante pero raramente diagnóstico, no sólo por riesgos como el sesgo subjetivo, las limitaciones fisiológicas, daltonismo, fatiga, etc., sino también porque depende de las condiciones de observación, minerales próximos, etc. 
En resumen, el color observado depende de las condiciones del observador y del entorno, de la fuente luminosa (intensidad, temperatura de color, tipo de iluminante; para la descripción cualitativa suele utilizarse lámpara halógena corregida con filtro de luz de día para asimilarla a la luz solar) y, por supuesto, de la composición espectral de la luz reflejada por el mineral.

Ésta puede cuantificarse mediante la medida de la reflectancia especular para tramos prefijados de longitud de onda (como se hace en QDF3), pero es perceptible sólo aproximadamente por el ojo humano, porque los colores de las menas habituales se sitúan todos prácticamente en la misma región del diagrama de cromaticidad del CIE, en un espacio muy restringido. Además, depende también de la calidad del pulido, de la oxidación superficial (formación de pátina o tarnishing), de las variaciones composicionales posibles de la especie mineral (elementos traza, sustituciones, series isomorfas). Todo ello hace que la observación cualitativa, para ser fiable, requiera de una costosa experiencia y que, aun así, las determinaciones cuantitativas multiespectrales sean siempre de una gran ayuda por su objetividad.

La percepción visual permite estimar el valor de la reflectancia a partir del brillo (Tabla 3-2), refiriéndola a valores de minerales conocidos, con tanta mayor confianza cuanto mayor es la experiencia del observador.

Tabla 3-2. Escala de reflectancias de minerales característicos

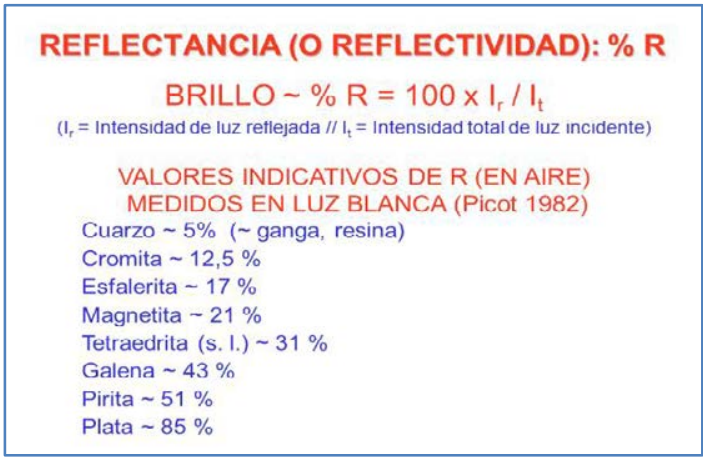

No obstante, no puede cuantificar la composición espectral con una precisión comparable a la del micro-espectrofotómetro. Éste permite, como puede verse en las Figura 3-7 y Figura 3-8 (datos de Criddle y Stanley, QDF3), no sólo definir con precisión los valores de reflectancia espectral, sino también interpretarlos en relación con la percepción subjetiva del color (por ejemplo, la netamente mayor reflectancia en las longitudes de onda más largas explica el color amarillo de la calcopirita, mientras que el espectro más plano pero con predominio de longitudes de onda más cortas explica el tono gris azulado de hematites, así como su birreflectancia: variaciones de $\mathrm{R}$ según la orientación, pero sin cambio del color debido al paralelismo de las curvas R1 y R2). 
84 Chalcopyrite

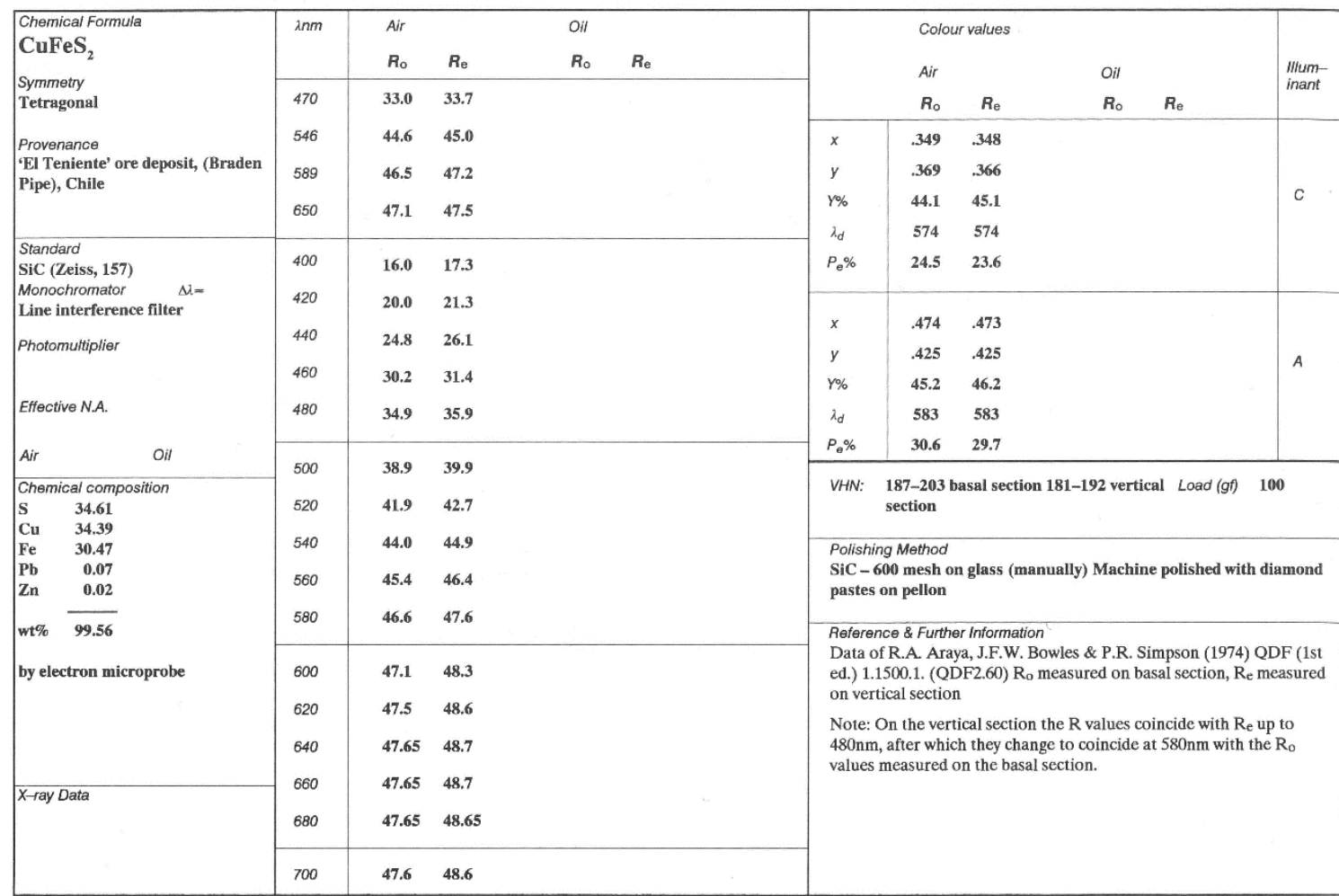

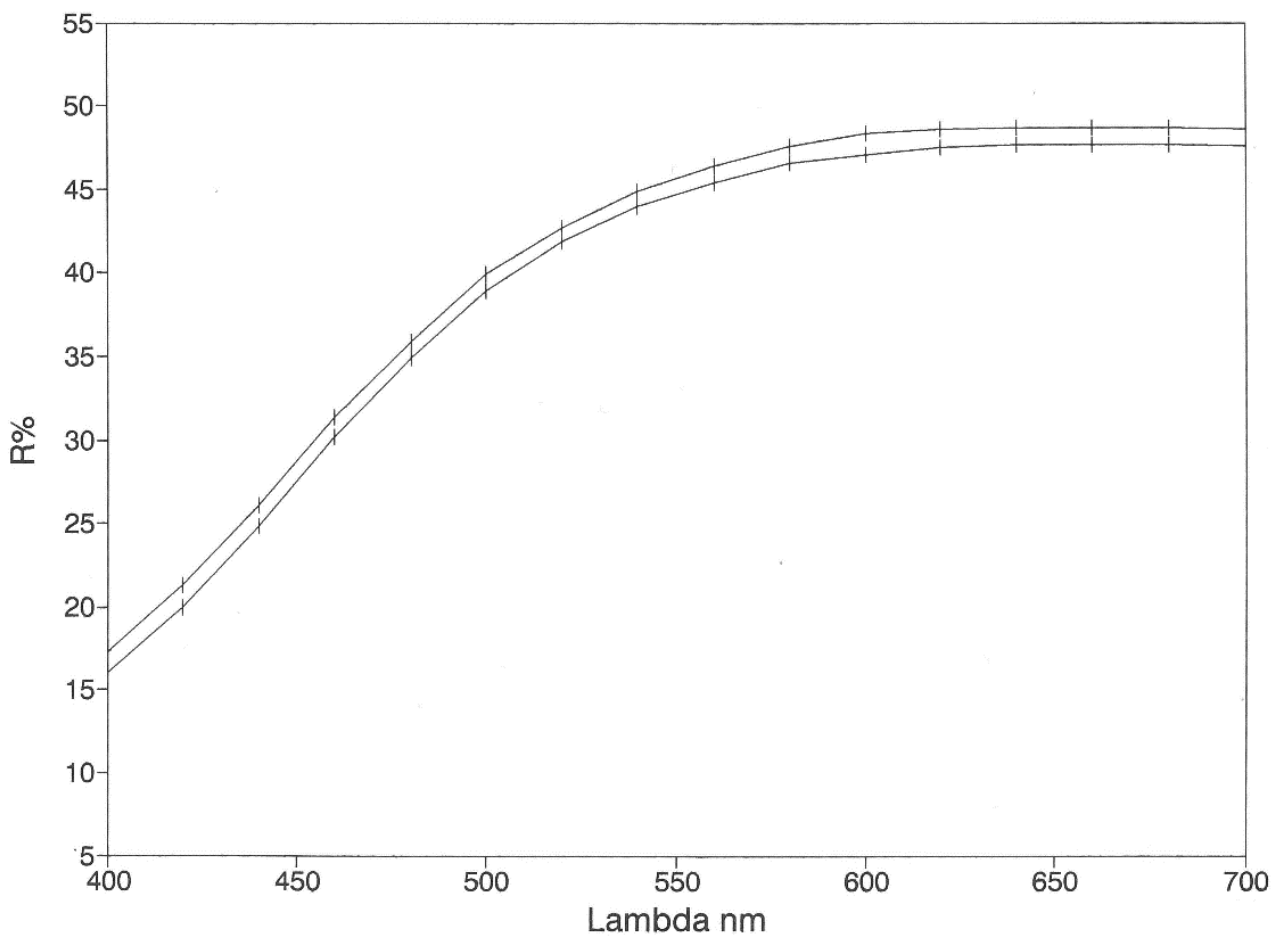

Figura 3-7. Datos de calcopirita (procedente del QDF3 de Criddle y Stanley 1993) 
228 Hematite

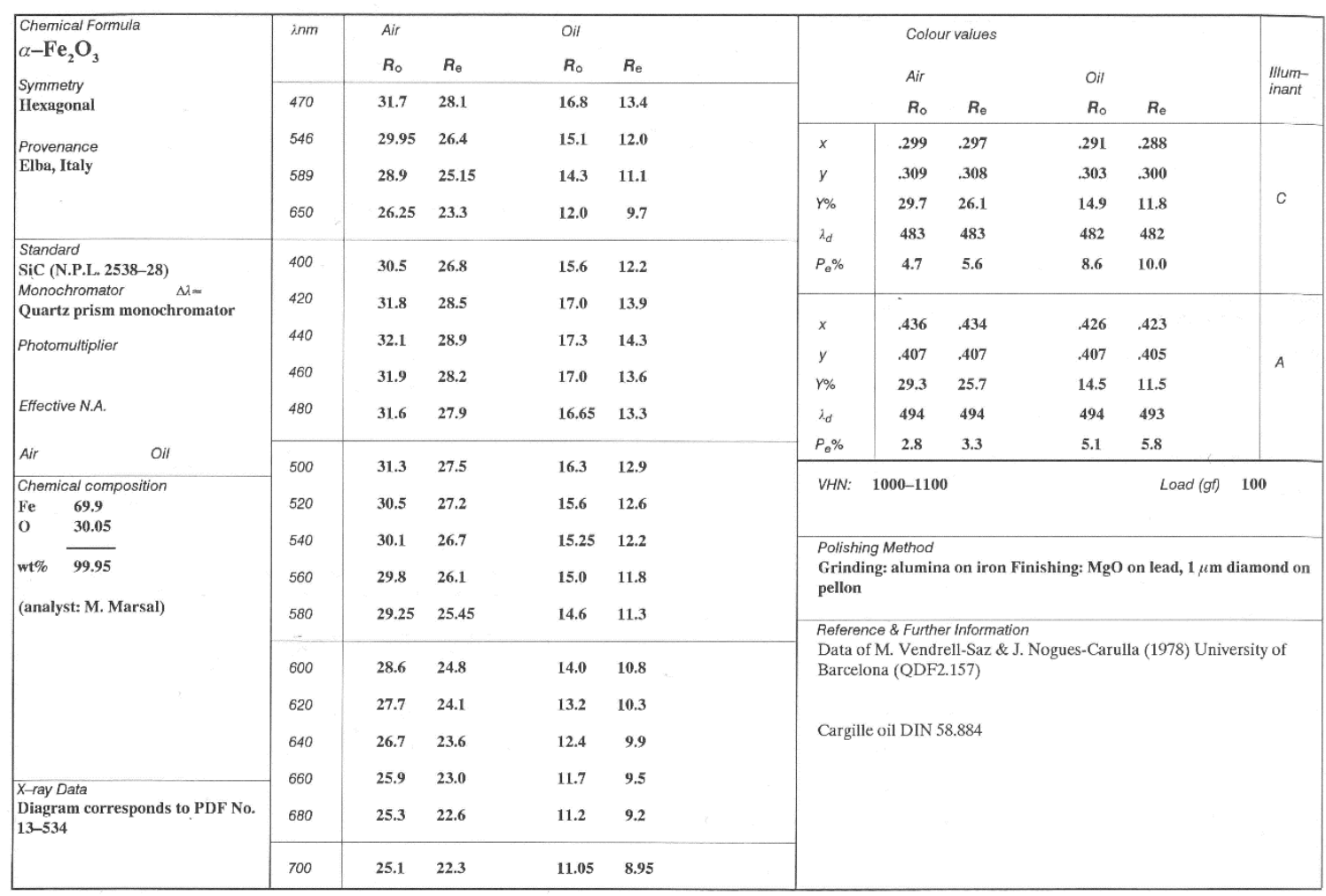

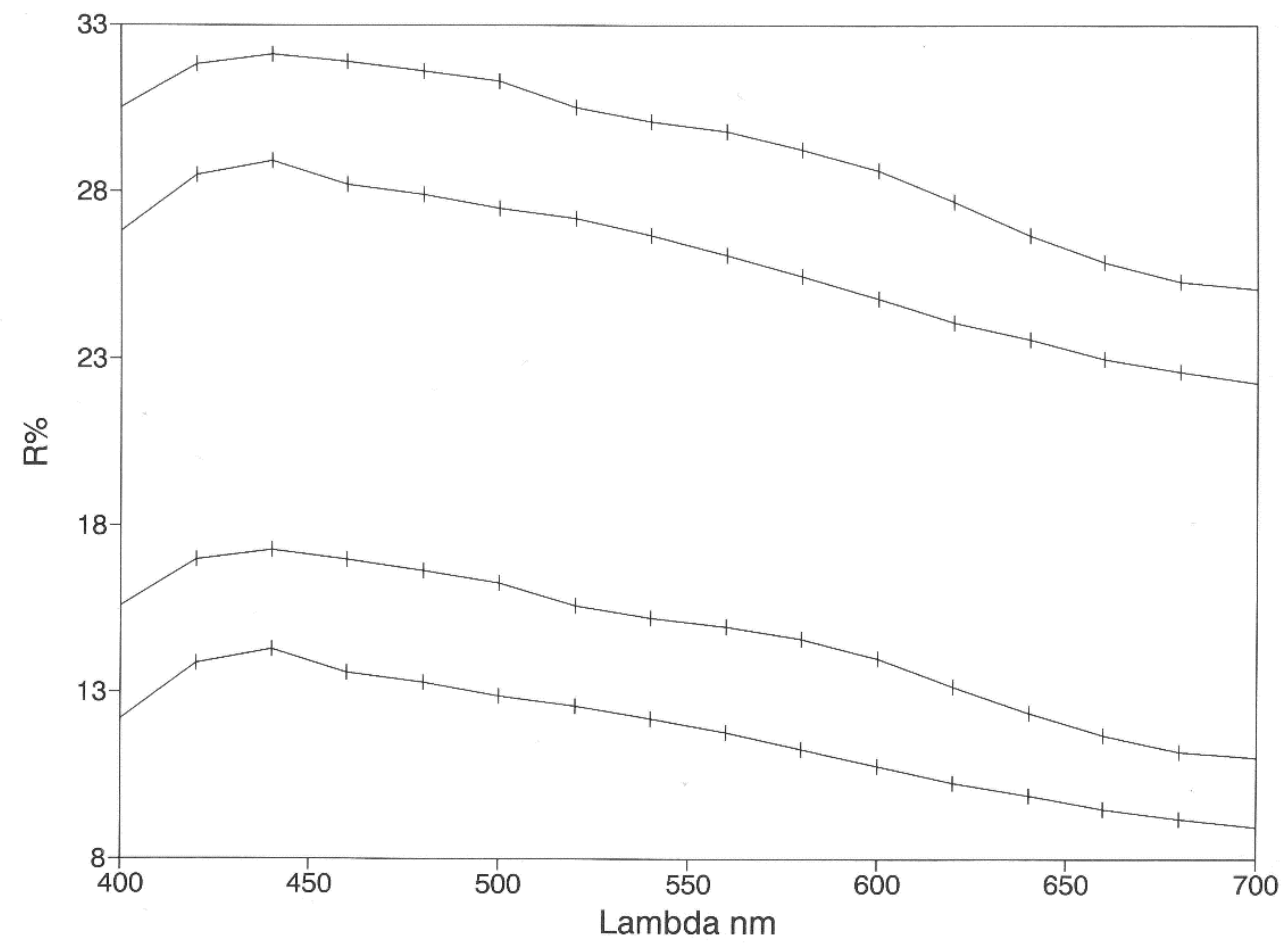

Figura 3-8. Datos de hematites (procedente del QDF3 de Criddle y Stanley 1993) 
En cualquier caso, la metodología tradicional, basada en la estimación del brillo como indicador de la reflectancia, así como en la definición cuidadosa del color y de sus variaciones con la orientación (pleocroísmo), logra en general diagnósticos aceptables si se cuenta con la formación adecuada (Tabla 3-3 y Tabla 3-4), aunque en cuanto al rendimiento no debe olvidarse la recomendación de Ramdohr a los microscopistas de menas: "no permitan nunca que nadie les meta prisa". En efecto, frente a propiedades evidentes como el pleocroísmo de la covellita, se encuentran otras a veces muy sutiles como el pleocroísmo de marcasita o arsenopirita, o la similitud de color y reflectancia de minerales como esfalerita y magnetita.

Tabla 3-3. Caracterización de menas por cambios de color y reflectancia con la orientación

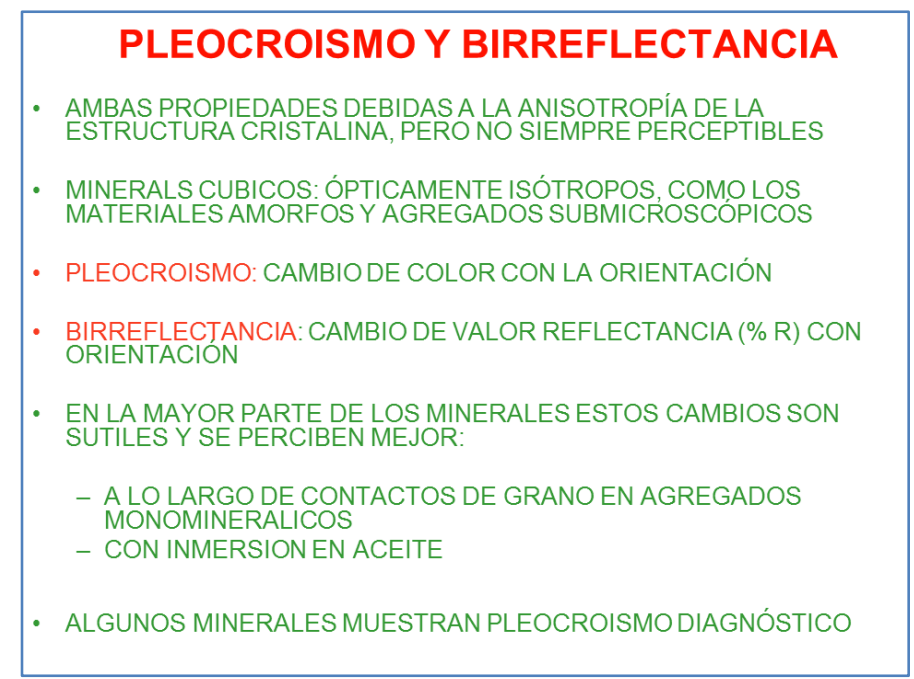

Tabla 3-4. Valores típicos de reflectancia en menas anisótropas

\section{PLEOCROISMO Y BIRREFLECTANCIA}

EJEMPLOS DE MINERALES ANISOTROPOS

\begin{tabular}{|l|l|l|l|l|}
\hline Mineral & $\begin{array}{l}\text { R max. } \\
\%(540 \mathrm{~nm})\end{array}$ & $\begin{array}{l}\text { R min. } \\
\%(540 \mathrm{~nm})\end{array}$ & $\begin{array}{l}\text { Diferencia } \\
\text { (Rmax-Rmin) }\end{array}$ & $\begin{array}{l}\text { Descripción de la } \\
\text { birreflectancia }\end{array}$ \\
\hline Molibdenita & $\mathbf{4 5 , 5}$ & $\mathbf{2 1 , 3}$ & 24,2 & Muy fuerte \\
\hline Covellita & $\mathbf{2 1 , 9}$ & $\mathbf{6 , 8}$ & 15,1 & Fuerte (y pleocroica) \\
\hline Marcasita & $\mathbf{5 5 , 5}$ & $\mathbf{4 8 , 6}$ & 6,9 & Nítida \\
\hline Niquelita & $\mathbf{5 2}$ & 47 & 5 & Nítida (y pleocroica) \\
\hline Cubanita & $\mathbf{4 1}$ & 36,3 & 4,7 & Nítida \\
\hline Hematites & $\mathbf{3 0 , 6}$ & $\mathbf{2 7}$ & 3,6 & Nítida \\
\hline Pirrotita & 37 & 34,6 & 2,4 & Baja pero pleocroica \\
\hline Ilmenita & 19,7 & 18 & 1,7 & Baja pero pleocroica \\
\hline Arsenopirita & $\mathbf{5 2}$ & 49,7 & 2,3 & Baja \\
\hline Enargita & 26 & 25 & 1 & Muy baja \\
\hline
\end{tabular}


Estos casos requieren la observación con objetivos de inmersión, que aumentan el contraste y la saturación del color, pero incrementan el tiempo de observación, en comparación con los procedimientos habituales en petrografía.

La metodología de observación clásica, por tanto, combina observaciones $\mathrm{P}$ y XP, en aire y en aceite (inmersión), ofreciendo cada una de estas cuatro configuraciones del microscopio su parcela de información característica, alguna de ellas a veces incluso diagnóstica, como el cambio de color de covellina al pasar a inmersión (Figura 3-9).

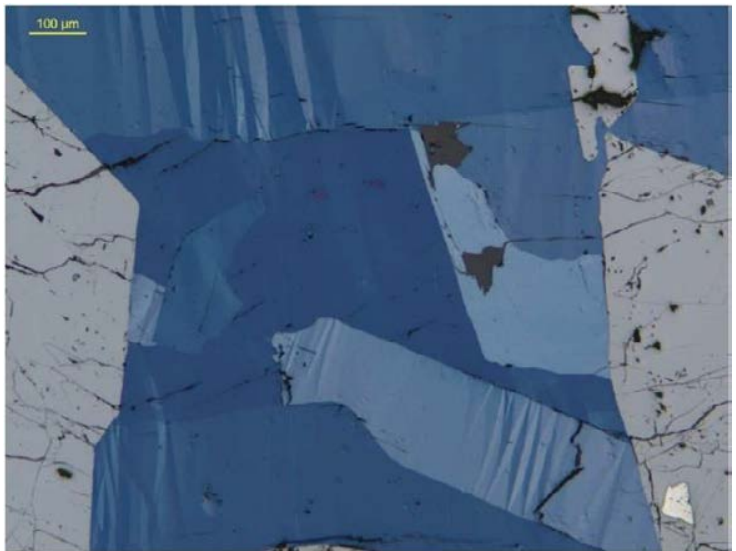

P en aire - Covellina azul pleocroica y maclada. Enargita gris.

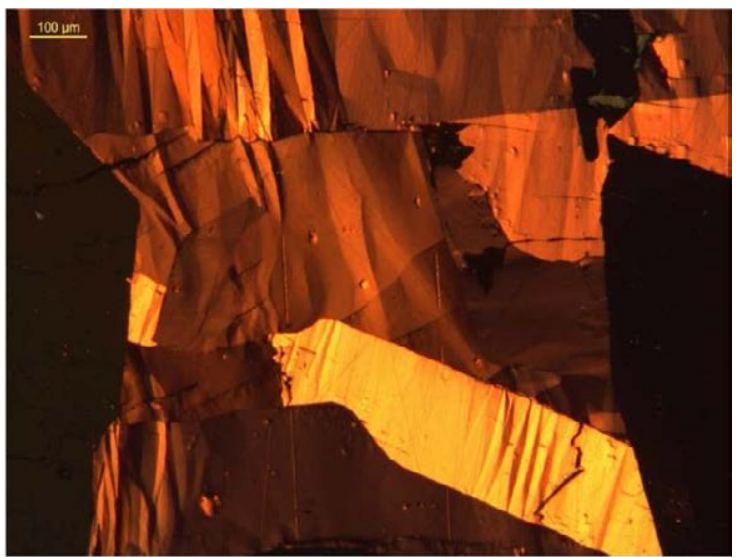

$X P$ en aire - Anisotropismo intenso de covellina, con tonos anaranjados y amarillos. Enargita en extinción.

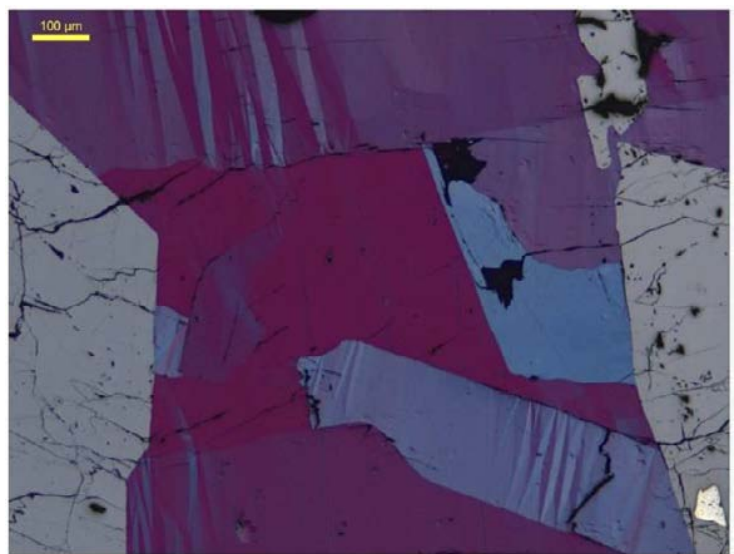

$P$ en aceite - Obsérvese el cambio de color de covellina y el aumento de la saturación en ambos minerales.

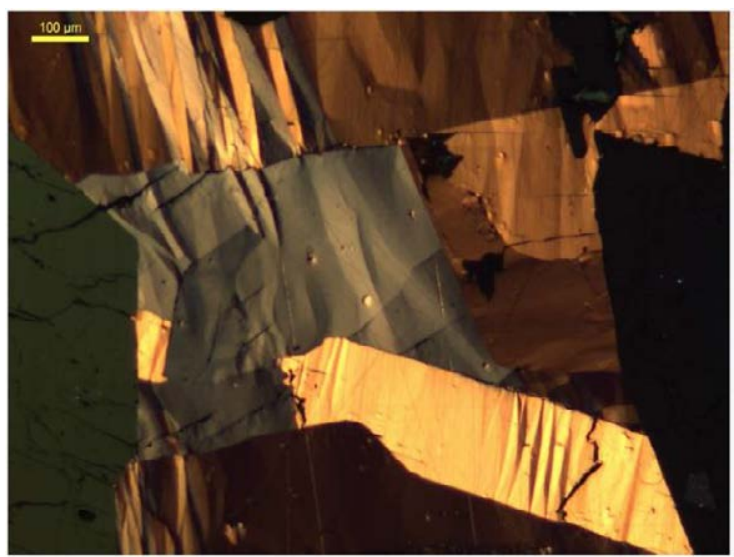

XP en aceite - Obsérvese el cambio de tonalidad en covellina y el aumento de contraste. En el grano de enargita de la izquierda se aprecia ahora que la extinción no era total, gracias al aumento de saturación y contraste en inmersión.

Figura 3-9. Observación sistemática de las propiedades ópticas de una mena compuesta de covellina (columna central) y enargita (laterales) en P y XP, con objetivo seco (en aire) y de inmersión en aceite. 


\subsubsection{Propiedades Físicas}

Las propiedades físicas pueden ser también un apoyo decisivo para el diagnóstico. Una de las más importantes es la dureza, de la cual habitualmente se consideran varios tipos:

- Dureza de pulido (cualitativa): debida al relieve, se estima mediante la Línea de Kalb.

- Dureza de rayado (cualitativa): se estima por las rayas de pulido.

- Microdureza Vickers (VHN -Vickers Hardness Number- cuantitativa).

- Dureza Talmage (semi-cuantitativa): por comparación con minerales patrón (Tabla 3-5).

Puesto que se trabaja siempre con secciones pulidas, la más universal e inmediatamente evidente es la dureza de pulido, que es siempre un dato significativo. Se estima por el relieve del grano mineral (los más duros sobresalen, los más blandos aparecen más hundidos) o por la Línea de Kalb (contorno luminoso móvil en el contacto que no es otra cosa que la concentración de la luz por reflexión desde el borde del mineral duro hacia el blando al alejar la preparación). La Figura 3-10 muestra cómo la Línea de Kalb permite determinar la dureza relativa de los minerales presentes en la preparación (siempre que estén en contacto).
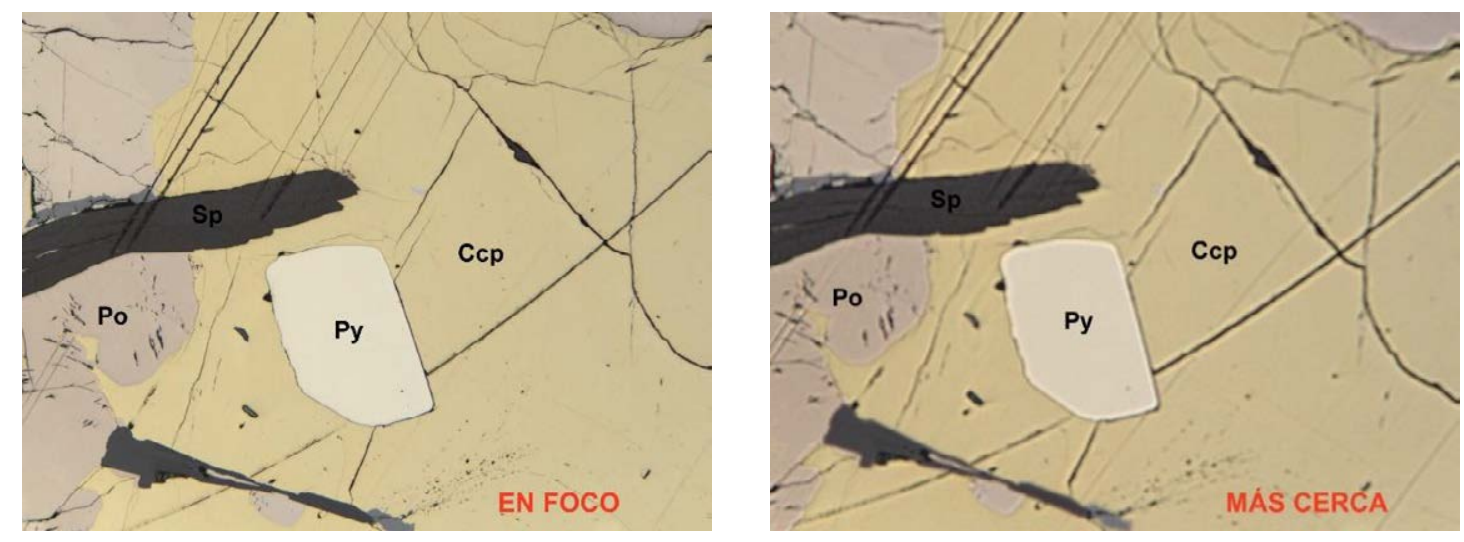

Figura 3-10. Diagnóstico de la dureza de pulido en una mena de pirita (grano central), calcopirita (grano amarillo) y pirrotita (pardo rosado). A la izquierda, imagen enfocada. A la derecha, aparición de la línea de Kalb sobre el mineral más duro al desenfocar acercando la preparación al objetivo. La imagen muestra que la dureza de pirita es superior a la de calcopirita; se observa también una línea más tenue a lo largo del contacto entre pirrotita y calcopirita, lo que significa que aquélla es más dura que ésta, pero no tanto como pirita.

La dureza de rayado se estima comparando la anchura que presentan las rayas de pulido sobre los distintos minerales. Una misma raya puede tener diferentes anchuras en su recorrido, según la dureza del mineral por el que pasa. Por ejemplo, en la Figura 3-10 se puede apreciar que la doble raya de la esquina superior izquierda de la imagen es más profunda (y por tanto más ancha) sobre la calcopirita que sobre la pirrotina, y que la raya curva que cruza la calcopirita apenas deja huella sobre la pirita, por lo que el orden de dureza relativa sería $\mathrm{H}_{\mathrm{py}}>\mathrm{H}_{\mathrm{po}}>\mathrm{H}_{\mathrm{cp}}$. 
Tabla 3-5. Escala de dureza Talmage

\begin{tabular}{l} 
DUREZA TALMAGE \\
(ESCALA CON MENAS COMUNES) \\
A. ARGENTITA \\
B. GALENA \\
C. CALCOPIRITA \\
D. TETRAEDRITA \\
E. NIQUELINA \\
F. MAGNETITA \\
G. ILMENITA \\
La mena estudiada se compara y califica \\
como similar, más dura o más blanda \\
que las menas A-G de la lista \\
\hline
\end{tabular}

Tabla 3-6. Cuantificación de la dureza Vickers

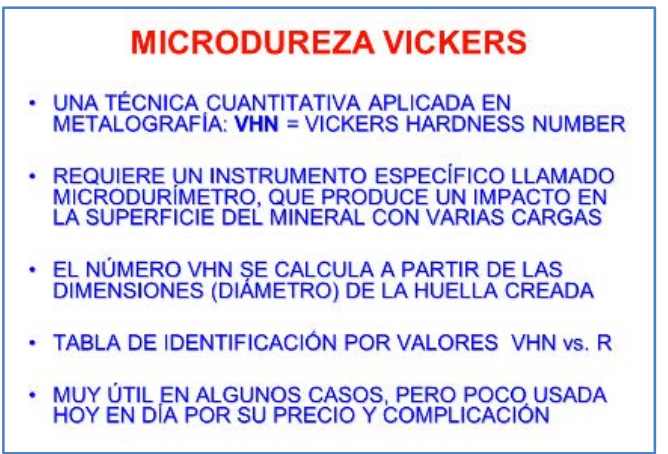

Mención aparte merece la Microdureza Vickers (VHN, Tabla 3-6. Cuantificación de la dureza Vickers): aunque es una técnica importada de la metalografía tuvo una aceptación importante en microscopía de menas, por ofrecer una cuantificación numérica objetiva que en su momento representó un gran avance para el diagnóstico.

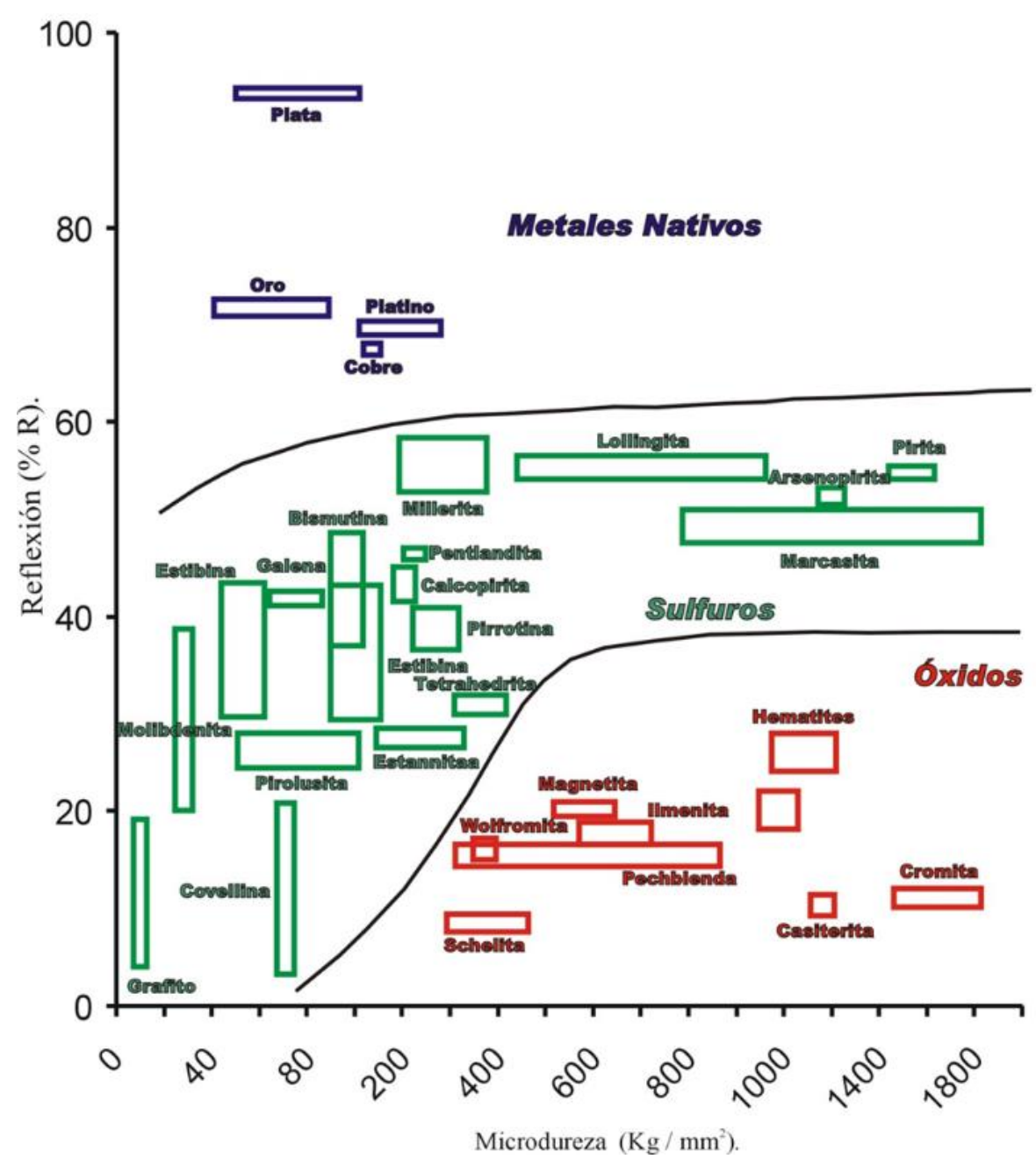

Figura 3-11. Distribución de menas metálicas en el espacio VHN-R (luz blanca) 
Como muestra esquemáticamente la Figura 3-11, la representación de los valores VHN y R (Reflectancia en luz blanca) de las distintas menas permite distinguir inmediatamente no sólo grandes grupos como metales nativos, sulfuros u óxidos, sino también en no pocos casos alcanzar un diagnóstico individual. Este método, que parecía muy prometedor en la segunda mitad del siglo pasado, ha ido perdiendo terreno paulatinamente, a lo que pueden haber concurrido varias razones: el elevado precio y complicado mantenimiento del aparato, el hecho de que muchas veces las menas se presentan en granos tan finos que la huella desborda el grano y no resulta posible un impacto fiable, el progreso de la reflectometría multiespectral, la cual representa una alternativa más informativa que la luz blanca usada en la tabla VHN-R, la posibilidad eventual de acceso al microscopio electrónico, etc.

\subsubsection{Sistemática de Identificación}

Así pues, la identificación microscópica cualitativa de menas metálicas por luz reflejada se basa, hoy como hace cincuenta años, en una descripción sistemática y rigurosa de sus propiedades. Éstas se observan, tal como muestra en esquema la ficha de trabajo (Tabla 3-7) y tal como documentan las fotomicrografías de la Figura 3-9, con luz polarizada (plana, sin analizador: P; con analizador interpuesto: XP) y combinando observación en aire (la habitual) y en aceite (lamentablemente menos habitual hoy en día, pero muy informativa).

Tabla 3-7. Ejemplo de ficha para descripción sistemática de menas

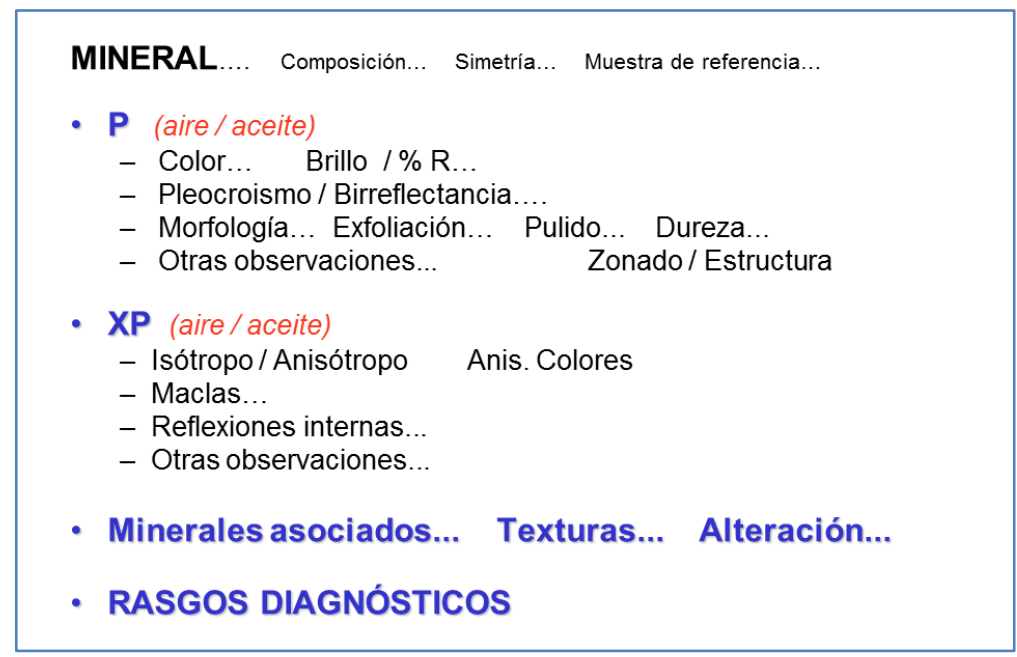

Aunque el reconocimiento inmediato basado en la experiencia puede ser una ayuda importante, el método descrito proporciona las herramientas necesarias para una identificación fiable en general, incluso para el neófito, si recurre a un análisis sistemático y lógico de la información recolectada, como muestra la Figura 3-12. 


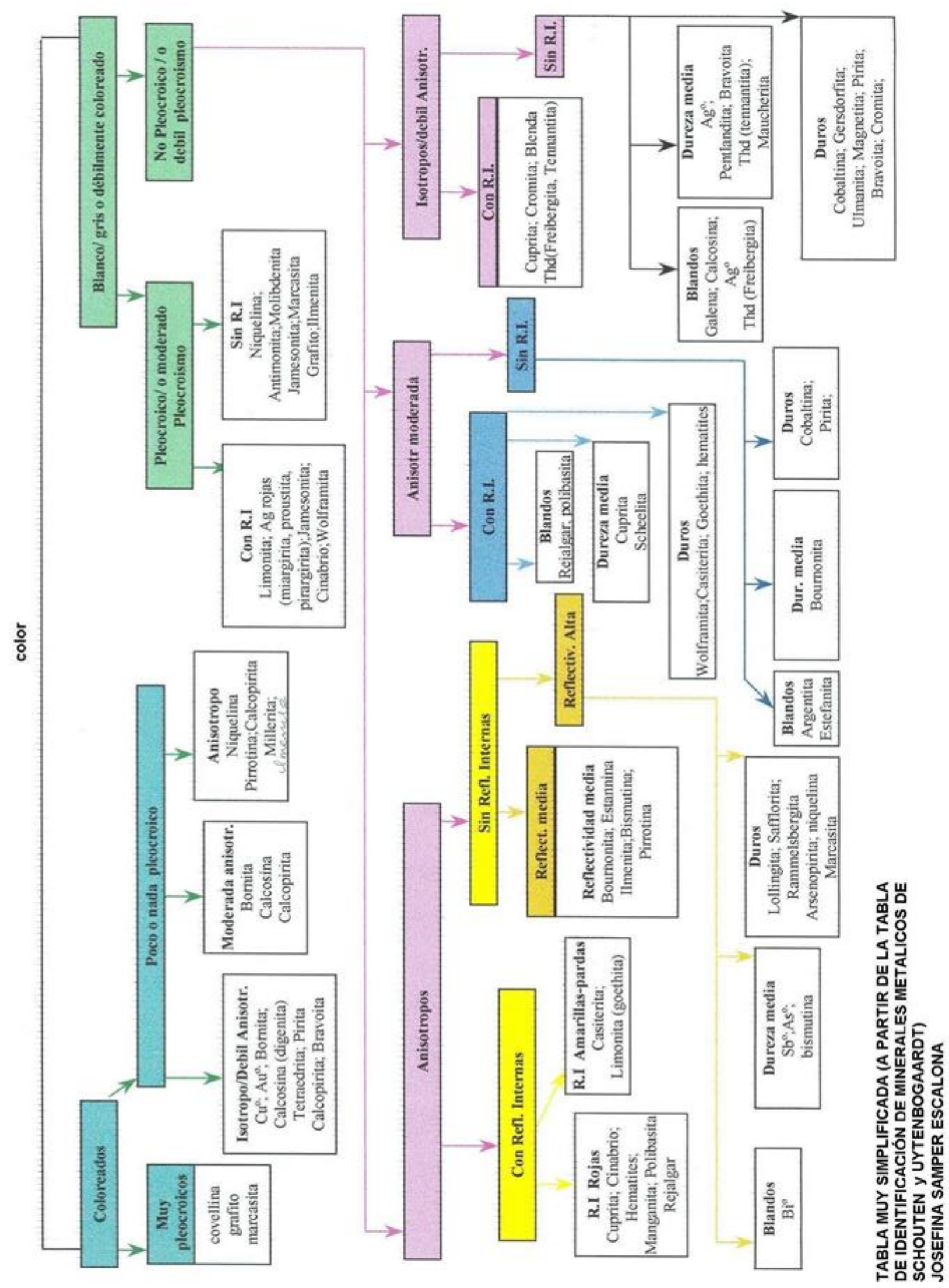

Figura 3-12. Tabla sistemática para la identificación de menas comunes por microscopía de reflexión (simplificada de Schouten 1962, según J. Samper, ETSI Minas y Energía) 


\subsection{METODOLOGÍA PARA LA IDENTIFICACIÓN AUTOMATIZADA}

Por lo que se refiere a los objetivos del presente trabajo, basta con detenerse un momento en las imágenes citadas (fotomicrografías de la Figura 3-9), para apreciar la dificultad de automatizar este procedimiento, ya que implica configuraciones diferentes del microscopio, incluyendo un cambio de objetivo para pasar a inmersión, rotación de la platina, cambios de polarizadores, etc.

Por ello se ha diseñado para la presente investigación un procedimiento que prescinde tanto de la polarización (y, por tanto, de la platina rotatoria, lo que hace posible usar una platina motorizada $\mathrm{X}-\mathrm{Y}$ ) como de la inmersión en aceite (lo que simplifica mucho la adquisición de datos), así como también de la Microdureza VHN, cuya medida sería imposible en el proceso de adquisición automatizado.

Al prescindir de la polarización, ha de asumirse la limitación de trabajar con un único espectro para cada especie, lo que estrictamente es válido únicamente para especies isótropas, ya que sólo la luz polarizada permite la correlación con las direcciones cristalinas. Por ello en QDF3 se opta por la luz polarizada y por la medida de espectros orientados en relación con la estructura cristalina, lo que implica renunciar a la automatización.

Sin embargo, los datos obtenidos con luz natural (no polarizada) han sido también recopilados y publicados por su valor diagnóstico (Folinsbee, 1949, PhD Univ. Harvard). En realidad, se obtienen unas medidas de reflectancia de magnitud intermedia entre los valores R1 y R2 de QDF3. Y en todo caso, tal como se ha comprobado empíricamente con el Sistema CAMEVA y como ilustra el ejemplo de un mineral fuertemente birreflectante como la molibdenita (Figura 3-13), al suprimir el polarizador se obtienen valores mucho más uniformes de $\mathrm{R}$ para cualquier orientación, lo que no sería posible con luz polarizada. Los histogramas de ambas imágenes (Figura 3-14) permiten comprobar cómo la imagen obtenida con luz polarizada es multimodal, mientras que la obtenida con luz natural es monomodal.
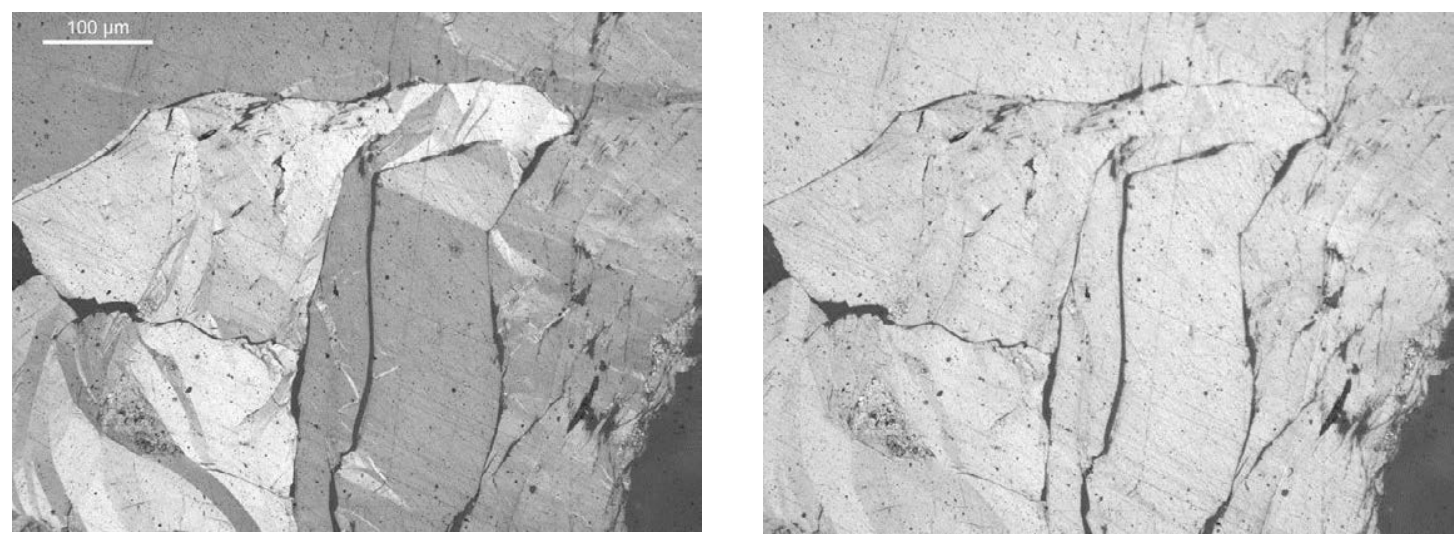

Figura 3-13. Grano de molibdenita observado con luz polarizada (izq.) y con luz natural (dcha.) 

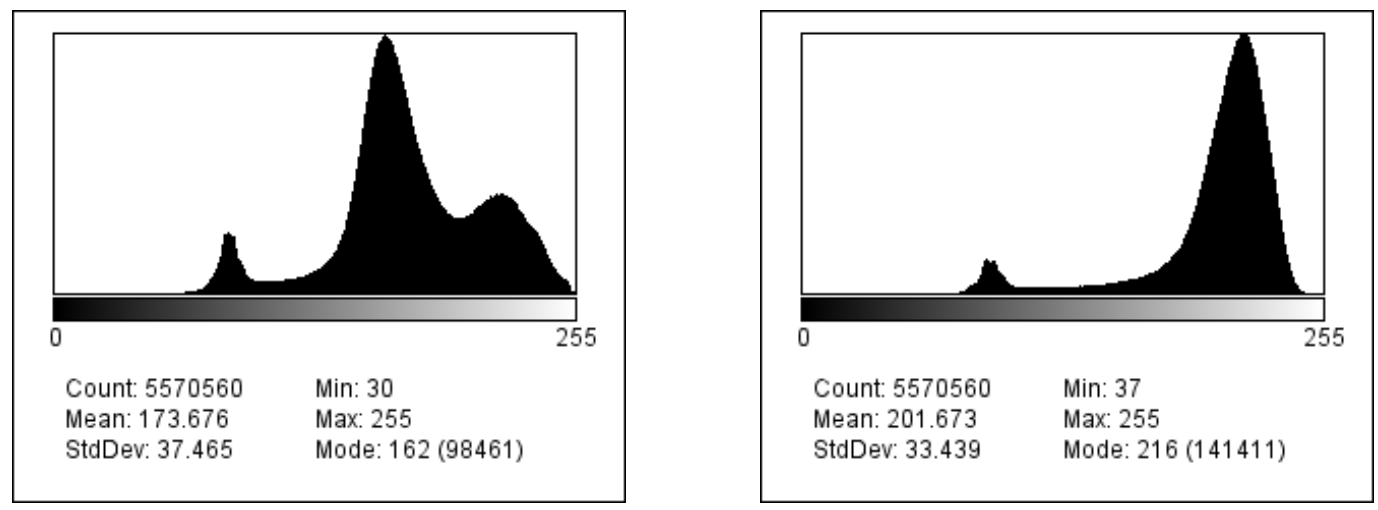

Figura 3-14. Histogramas de las imágenes anteriores. Se observa que el histograma de la imagen obtenida con luz polarizada (izqda.) presenta varios picos solapados para la molibdenita, mientras que el de la imagen obtenida con luz natural (dcha.) presenta un único pico.

El pequeño pico de la izquierda en ambos histogramas corresponde a la ganga (ángulo inf. dcho).

\subsubsection{Utilidad y límites de QDF3 para identificación automatizada de menas}

En la aplicación práctica de los datos de reflectancia del QDF3 para la identificación de minerales no sólo puede resultar cuestionable la distinción de curvas espectrales próximas en el rango visible sino que, aun en minerales en los que en principio cabría esperar una caracterización fácil, ésta puede verse complicada de hecho por factores como la orientación de los granos (de la que depende la magnitud de la medida en medios anisótropos) o la composición (que puede influir significativamente en la magnitud, pero también en la composición espectral de la luz reflejada), aparte de la influencia adicional de factores de difícil cuantificación como la calidad del pulido o la alteración por oxidación superficial (pátina o tarnishing).

Por ello, en su método (MOMI) para la aplicación de la base de datos QDF3 a la identificación de menas, Bernhardt (1987) propone para cada espectro medido con su microfotómetro espectral computarizado, una selección de especies minerales, ordenadas cuando es posible de más a menos probable, en lugar de una identidad única e indiscutible; $\mathrm{y}$, tras una revisión ulterior de la metodología (1990), concluye afirmando categóricamente sus limitaciones, a pesar del gran avance que supone QDF3: "It has to be made clear that the computer only assists in making identifications and computerization cannot replace intensive and extensive training in the use of diagnostic criteria" (cursivas por el autor, p. 204).

En cuanto a la composición química, prácticamente todos los expertos insisten en la influencia de la composición en los parámetros ópticos, particularmente en los valores de reflectancia, lo que se ha demostrado en el caso de la cromita en el marco de esta tesis (López et al. 2017), confirmando una vez más la conclusión de Vaughan (1990, p.100): "Chemical variations in a mineral change its reflectance properties". Y el mismo Criddle, primer autor del QDF3, tras 
analizar las dificultades prácticamente insolubles en el espectro visible que plantean los minerales químicamente variables y con disoluciones sólidas, concluye (1998, p. 7): "It is probable, even in cases as difficult as this, that characteristic and explicable spectra could be obtained if measurement were to be made at appropriate wavelengths in the $U V$ and IR, but these spectroscopic applications have yet to be undertaken". El caso citado de la cromita, investigada en el rango VNIR (Visible e Infrarrojo Próximo) comparando espectros CAMEVA y composiciones determinadas con precisión puntual por microsonda electrónica (López et al. 2017) aporta una confirmación a esta intuición sobre la utilidad de la ampliación del espectro.

Por otra parte, desde un punto de vista práctico y sin apartarse de datos de observación visual directa, tiene interés la consideración de la pirita y dos de sus variedades (s. 1.): melnicovita y bravoíta. La primera, calificada por Ramdohr (1980) como "colloform pyrite" o crystallized $\mathrm{FeS}_{2}$ gel, es una variedad criptocristalina, de aspecto coloforme o incluso amorfo, de composición a veces anómala (ya por elementos menores, ya por la inclusión submicroscópica de otros sulfuros, en un proceso de cristalización forzado por sobresaturación o a temperaturas bajas), relativamente inestable ante la oxidación y de colores variables, habitualmente más oscuros que la pirita cristalina (acentuados por la fácil alteración). La segunda, habitualmente caracterizada al microscopio por su tendencia al idiomorfismo con espectacular zonado de crecimiento, es hasta tal punto atípica que se consideraba una especie diferente hasta que, recientemente, IMA/COM la desacreditó y le atribuyó el nombre nickeloan pyrite o "Pyrite (nickeloan) also known as bravoite", como se denomina en QDF3. Pues bien, los valores de reflectancia en el rango visible (QDF3) de estas dos "piritas" difieren no sólo en valor absoluto (en torno al $50 \%$ para pirita, frente a $\approx 35 \%$ para "Pyrite (nickeloan) also known as bravoite"), sino también en composición espectral. Por lo que respecta a la primera variedad, melnicovita, y en coherencia con las recomendaciones IMA/COM sobre nomenclatura mineral, no se encuentra entre los minerales medidos en QDF3, pero puede presuponerse que sus valores de reflectancia serán frecuentemente más bajos e irregulares que los de la pirita cristalina, como evidencia su aspecto al microscopio.

Este caso ilustra, adicionalmente, otra de las limitaciones de QDF3 (y de IMA/COM) que conviene superar, desde el punto de vista de las aplicaciones prácticas (y, en particular, mineras) a las que se aspira a responder al diseñar el sistema objeto de esta tesis. Entre los términos rechazados por IMA/COM y, por tanto, excluidos de los tratados y tablas de datos oficiales, figuran algunos de indudable interés minero por ser componentes importantes o frecuentes de menas, tales como limonita o psilomelana; como la melnicovita, ambos son agregados de baja cristalinidad o incluso amorfos, frecuentemente heterogéneos, de óxidos de $\mathrm{Fe}$ o $\mathrm{Mn}$ (respectivamente) y habitualmente con impregnaciones o mezclas de otros componentes 
submicrocópicos (como sílice o jarosita) o con diferentes grados de hidratación. Aun admitiendo que no se trata en estos casos de especies minerales y que, por tanto, les conviene más, en rigor, el término de mineraloides que el de minerales, no es menos cierto que el excluir su uso privaría a la industria minera del recurso a unos conceptos indispensables en la práctica, por corresponder a la realidad de menas importantes que van a ser objeto de exploración, extracción o beneficio. Lo que habitualmente se encuentra en la Naturaleza es limonita y psilomelana, más que sus versiones académicas: los minerales puros goethita o romanechita (especies reconocidas por IMA/COM), respectivamente. Y no sólo las especies académicamente aceptadas, sino también dichos materiales pueden ser caracterizados por sus reflectancias multiespectrales, si bien teniendo en cuenta que por sus características específicas (particularmente sus variaciones composicionales y su posible heterogeneidad) más bien habría de hablarse de un rango que de un valor único de reflectancia. Y aquí puede resultar de gran utilidad la ampliación del espectro más allá del rango visible, tal como recomendaba Criddle.

La estrategia elegida para el Sistema CAMEVA es, pues, la caracterización de los materiales de interés industrial como recursos minerales tal como se presentan naturalmente. Es decir, ateniéndose a la realidad que el minero encuentra y a las propiedades diagnósticas impuestas por ésta, aunque en algunos casos desborden las definiciones académicas. Para ello, el programa ha de incluir la posibilidad de ampliar las bases de datos espectrales existentes con medidas ad hoc para materiales específicos, previa definición del problema y selección de las nuevas fases minerales a medir por un profesional.

La opción de CAMEVA por la luz natural, renunciando a la polarización utilizada por QDF3, supone en principio una limitación a la hora de caracterizar la anisotropía óptica de las menas. Esta limitación viene impuesta por las exigencias de automatización que, entre otras cosas, impiden trabajar con la platina rotatoria (requerida para determinar la indicatriz compleja o las direcciones principales de cada grano medido), pero tiene también algunas ventajas. En primer lugar, el realismo, ya que la orientación habitualmente incontrolable de los granos minerales a medir -piénsese, por ejemplo, en concentrados de molienda- excluye a priori que se pueda garantizar siempre (en todos y cada uno de los granos) la determinación de las direcciones ópticas principales y, por tanto, la caracterización individualizada de las reflectancias correspondientes, requisito indispensable para caracterizar el mineral por su anisotropía óptica. $\mathrm{Y}$ esto incluso en el supuesto de que se dispusiese de platina rotatoria, ya que con luz reflejada no es posible el recurso a la platina universal usada para minerales transparentes en luz transmitida. Es razonable, por tanto, poner a punto un método capaz de resolver el problema en todos los casos, independientemente de la orientación, aunque implique renunciar a la luz polarizada. 
Otro factor a tener en cuenta es la ortogonalidad del rayo, tanto del incidente como del reflejado, de la que depende la precisión y confiabilidad del valor medido $\mathrm{R}$ de los rayos p y s, es decir, polarizados con vibración en los planos $\mathrm{p}$ (paralelo al plano de incidencia, el determinado por el rayo incidente y la normal a la superficie del grano) y s (del alemán senkrecht, perpendicular al mismo). Para objetivos con la magnificación requerida para el micro-análisis espectral de menas (p.ej. 20x), los valores relativamente altos de la apertura numérica (p.ej. 0.4 - 0.5) aumentan la inclinación posible de los rayos admitidos, restando precisión a la medida de los rayos polarizados. Lo que es un problema previsiblemente menor o inexistente en la opción de CAMEVA al usar luz natural (no polarizada) y prescindir de la orientación. Conviene recordar al respecto el valor de los parámetros escalares en estos casos, ya que como afirman Cervelle \& Moëllo (1990, p.100) tras analizar los principios de la óptica mineral de reflexión en medios anisótropos: incluso en casos difíciles "reproducible measurements of a scalar nature will still be helpful in identification".

En conclusión, se ha tenido en cuenta que "whereas for microscopic observations in transmitted light an entire range of diagnostic optical properties are readily determined (relative value of $n$, nature of the indicatrix, optic sign, $2 \mathrm{~V}$, birrefringence, etc.), such data cannot be readily (if at all) determined for opaque phases. The two properties that have been adopted as quantitative parameters for identification are reflectance and hardness" (Craig y Vaughan, 1994, p.77). Como la determinación (cuantitativa) automatizada de la dureza es impracticable, queda la reflectancia como único parámetro viable, compatible con una completa automatización. Afortunadamente este único parámetro es también el más útil: "Reflectance is the single most important quantitative parameter that can be used to identify or characterize an opaque mineral" (Ibíd., p. 103). El método desarrollado está basado en la medida de la reflectancia especular multiespectral, renunciando a la polarización en aras del alto rendimiento posible mediante la cuantificación automatizada, pero aumentando la capacidad de diagnóstico con respecto a los espectrómetros convencionales al ampliar el rango espectral hacia UV e IR.

Se aspira así a proporcionar un instrumento que pueda ser útil tanto para la industria, como para la docencia y la investigación, respondiendo a una necesidad largamente sentida por los investigadores y claramente expresada por Gribble y Hall (2003, p.257): "It would be of enormous benefit to users of reflected-light microscopy if a single method of light intensity measurement could be incorporated into basic reflected-light microscopes, in the way in which sensors have been incorporated into cameras. The estimation of the reflectance value is a key step in the identification of minerals in reflected light, but the human eye is very poor at estimating absolute levels of light intensity" 


\subsubsection{Fases del desarrollo del sistema automatizado}

El planteamiento seguido para el desarrollo del sistema comprende las siguientes fases:

- Análisis de la mejor tecnología disponible para la adquisición de imágenes microscópicas multiespectrales, y determinación del rango espectral más adecuado.

- Selección instrumental para lograr equipos que proporcionasen medidas precisas y reproducibles.

- Establecimiento de un procedimiento de medida adecuado para satisfacer los requisitos impuestos al sistema propuesto.

- Selección de los minerales de mayor interés industrial para su incorporación a la base de datos de reflectancias multiespectrales.

- Adquisición de numerosas medidas de la reflectancia especular multiespectral de dichos minerales sobre muestras cuidadosamente seleccionadas por su representatividad y calidad de pulido.

- Análisis de las mismas para llegar a la identificación automatizada de las especies minerales presentes en imágenes de campos microscópicos capturadas sobre una sección pulida.

- Programación de diversas aplicaciones para proceder al análisis digital de imagen y al desarrollo de aplicaciones geometalúrgicas.

- Validación del sistema mediante la realización de ensayos independientes.

La actividad realizada en cada una se expone detalladamente en los capítulos siguientes. 


\section{CAPÍTULO 4: DISEÑO Y DESARROLLO DEL SISTEMA} AUTOMATIZADO 


\subsection{REQUISITOS PARA EL DISEÑO DEL SISTEMA}

El diseño de un sistema automatizado de microscopía óptica de reflexión que reúna las características descritas en el $\S 1.1$ (Introducción) obliga a buscar soluciones innovadoras a diversos retos impuestos por las condiciones en que debe trabajar y la limitada experiencia previsible del operador que lo maneje. Por ello se pasará revista a continuación a estas circunstancias, y se estudiará la solución más adecuada para las distintas situaciones.

En el apartado $\$ 3.4$ (Metodología para la identificación automatizada) ya se avanzaron las principales líneas del procedimiento, que se pueden concretar en:

- necesidad de trabajar con luz no polarizada para evitar variaciones incontrolables de la reflectancia debidas a la orientación en menas anisótropas;

- uso de objetivos secos para evitar problemas derivados del uso de aceite de inmersión;

- basar el reconocimiento de los minerales en su reflectancia multiespectral, de mucha mayor capacidad diagnóstica que la reflectancia en luz blanca o el color, tanto subjetivo como basado en coordenadas CIE o valores RGB;

- renuncia en un primer estadio al diagnóstico basado en propiedades físicas (distintas formas de dureza, hábito cristalino, exfoliación, zonado, etc.) y en datos químicos; no obstante, las imágenes adquiridas podrían correlacionarse en un segundo estadio con alguna de estas propiedades;

- uso de una platina motorizada X-Y para automatizar el barrido de una preparación, en lugar de la platina rotatoria tradicional;

- exigencia de una calidad de pulido suficiente para garantizar la obtención de medidas reproducibles;

- independizar la fase de adquisición de imágenes del tratamiento matemático de éstas, tanto para la identificación de las fases minerales como para los cálculos de caracterización geometalúrgica.

\subsection{DISEÑO DEL SISTEMA DE ADQUISICIÓN DE IMÁGENES MICROSCÓPICAS MULTIESPECTRALES}

La adquisición de imágenes microscópicas multiespectrales de reflectancia no es una tarea que pueda realizarse de forma sencilla en un microscopio convencional. Es preciso tener en cuenta numerosos detalles para realizar las modificaciones oportunas al microscopio de forma que la operación pueda culminarse con éxito. 
En los apartados siguientes se estudiará el rango espectral más adecuado para abordar el problema, y en función de aquél se pasará revista a los distintos elementos del microscopio y a los componentes auxiliares que junto con él integrarán el sistema de adquisición de imágenes microscópicas multiespectrales de reflectancia especular.

\subsubsection{Selección del rango espectral más adecuado para las imágenes}

Los microscopios ópticos de reflexión están concebidos para facilitar la observación visual de preparaciones pulidas por parte de operadores humanos, así como la adquisición de fotografías para ilustrar y documentar estudios e informes. Ambas tareas exigen la visualización de imágenes en color, por lo que precisan que el sistema óptico del microscopio opere adecuadamente en la parte visible del espectro, es decir, entre 400 y $700 \mathrm{~nm}$.

Por este motivo resulta factible aplicar un procedimiento como el descrito en Pirard et al. (2004) para capturar imágenes multiespectrales constituidas por unas pocas bandas del espectro visible. No obstante, la capacidad diagnóstica de dichas imágenes, aunque superior a la de las imágenes en color RGB de Berrezueta y Castroviejo (2007), es aún limitada, por lo que resultaría muy conveniente aumentar el número de bandas, aproximándose al esquema de 16 medidas entre 400 y $700 \mathrm{~nm}$ empleado por el QDF3 de Criddle y Stanley (1993), lo que permitiría aprovechar directamente su base de datos de reflectancia multiespectral.

Sin embargo, ¿por qué limitar las imágenes al espectro visible? Como se advirtió en el §3.4.1, a pesar de su alto nivel de detalle, los datos de reflectancia multiespectral de QDF3 no permiten garantizar una discriminación segura entre ciertos minerales, y es de esperar que empleando luz no polarizada todavía resulte más difícil. Por ello podría resultar ventajoso ampliar al infrarrojo y/o al ultravioleta el rango espectral cubierto por las imágenes, con el fin de disponer de información adicional para mejorar dicha discriminación.

Con este propósito se investigó la respuesta espectral de los tipos de sensores de imagen más habituales, y se pudo comprobar que las versiones monocromas de los sensores de silicio (CCD y CMOS) suelen ser sensibles a longitudes de onda entre 350 y $1050 \mathrm{~nm}$, es decir, desde el ultravioleta cercano (near ultraviolet, NUV) hasta el infrarrojo cercano (near infrared, NIR). También existían sensores de InGaAs (arseniuro de indio y galio) sensibles al infrarrojo medio (short-wavelength infrared, SWIR) entre $900 \mathrm{~nm}$ y $1700 \mathrm{~nm}$, e incluso versiones especiales con sensibilidad extendida hasta $2200 \mathrm{~nm}$ o hasta $2500 \mathrm{~nm}$, pero su alto precio y las restricciones existentes para su exportación por ser Tecnología de Doble Uso (civil/militar) desaconsejaron su utilización en el sistema. La Figura 4-1 muestra las curvas de respuesta espectral típicas de un sensor CCD de silicio y un sensor InGaAs normal. 


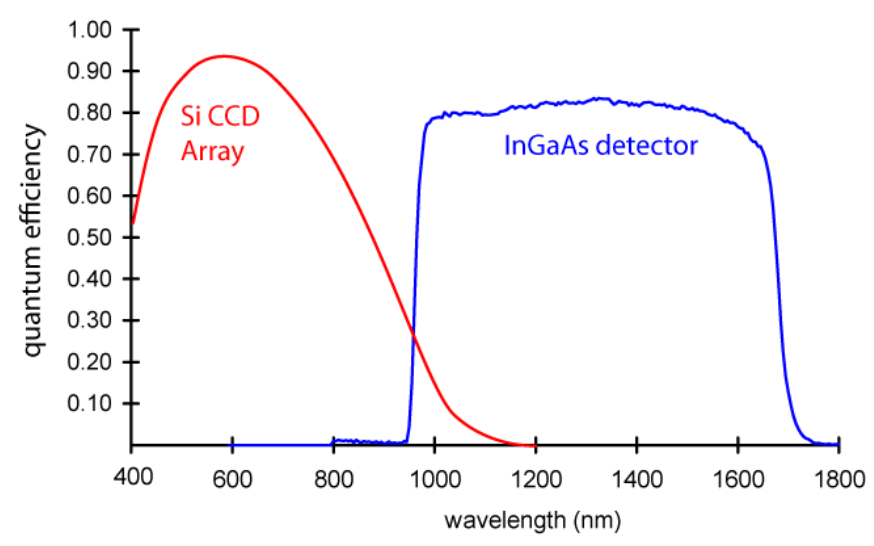

Figura 4-1. Curvas de respuesta espectral de un sensor CCD de silicio y un sensor InGaAs (PVEducation.org, 2018)

Teniendo en cuenta lo anteriormente expuesto, se decidió que lo más conveniente sería tratar de aprovechar al máximo el rango de sensibilidad de los sensores de silicio, extendiendo el rango espectral de operación del sistema para cubrir desde el ultravioleta cercano hasta el infrarrojo cercano. No obstante, la operación en el ultravioleta cercano quedó pendiente de la realización de pruebas prácticas, porque se anticipaban posibles dificultades con la menor transmisividad de las lentes y la baja intensidad de iluminación disponible en esta banda.

\subsubsection{Obtención de imágenes multiespectrales}

Existen en el mercado diversas soluciones para la obtención de imágenes multiespectrales, que se pueden clasificar en tres grupos, atendiendo a la escala espacio-temporal con que se capturan las imágenes:

- Captura simultánea de imágenes bidimensionales en unas pocas bandas, mediante:

$>$ una cámara dotada de un sensor multiespectral (p. ej.: cámara CCD en color o cámara PixelCam RGB+NIR)

$>$ una cámara dotada de un sistema de reparto espectral de la luz mediante prismas/espejos dicroicos y varios sensores monocromos o multiespectrales ( $\mathrm{p}$. ej.: cámara en color 3-CCD o cámara multiespectral FluxData FD-1665 3-CCD Multispectral Camera)

varias cámaras acopladas, cada una dotada de un sensor monocromo y un filtro pasabanda (p. ej.: sistema de cámaras Tetracam Micro-MCA)

Este grupo de soluciones está especialmente indicado para adquirir imágenes de (o desde) objetos en movimiento, de seres vivos, células, etc., que varían en el tiempo con rapidez. 
- Captura secuencial de una imagen bidimensional en una serie de bandas, mediante:

$>$ una cámara monocroma y una rueda de filtros pasabanda

$>$ una cámara monocroma y un filtro pasabanda sintonizable

Este grupo de soluciones es el más conveniente para obtener imágenes multiespectrales (más complejas que en color RGB) de objetos estáticos, porque proporciona la mejor calidad de imagen al menor coste.

- Captura sucesiva de imágenes unidimensionales en numerosas bandas, mediante:

$>$ una cámara monocroma y un espectrógrafo de imagen (p. ej.: cámara espectral SPECIM FX10). Para obtener imágenes bidimensionales con esta cámara es necesario que haya desplazamiento relativo de la escena respecto a la cámara.

Este tipo de soluciones es el mejor compromiso calidad/precio para la observación de productos sobre una cinta transportadora, o para la toma de imágenes de grandes extensiones de terreno o de cultivos desde una plataforma aérea. En microscopía sólo sería aplicable empleando una platina motorizada para desplazar la muestra a velocidad contante bajo el objetivo.

Cada solución tiene sus ventajas e inconvenientes, por lo que no hay una opción perfecta para todas las aplicaciones. Sin embargo, en el caso del sistema CAMEVA, sólo sería adecuado el segundo grupo de soluciones, porque los objetivos de microscopio normales no pueden enfocar simultáneamente todo el rango espectral deseado, como se detalla en $\S 4.2 .3$, y se hace necesario adoptar una adquisición (enfoque y captura) secuencial de cada banda.

Para capturar secuencialmente imágenes bidimensionales en una serie de bandas, el uso de un filtro pasabanda sintonizable es una solución muy atractiva, por la rapidez para cambiar de banda y la total ausencia de vibraciones. Existen dos tipos principales de filtros sintonizables:

- Filtro sintonizable de cristal líquido (LCTF - Liquid Crystal Tunable Filter). Es un tipo de filtro óptico sintonizable electrónicamente que proporciona una alta calidad de imagen. La marca más conocida se denomina VariSpec, y está disponible en diversos rangos espectrales ():

400-720 nm (VIS), con anchos de banda de 7, 10 ó $20 \mathrm{~nm}$

> 650-1100 nm (SNIR), con anchos de banda de 7 ó $10 \mathrm{~nm}$

$>$ 850-1800 nm (LNIR), con anchos de banda de 6 ó $20 \mathrm{~nm}$

> 1200-2450 nm (XNIR), con ancho de banda de $9 \mathrm{~nm}$ 
Typical VIS-10 Varispec Filter
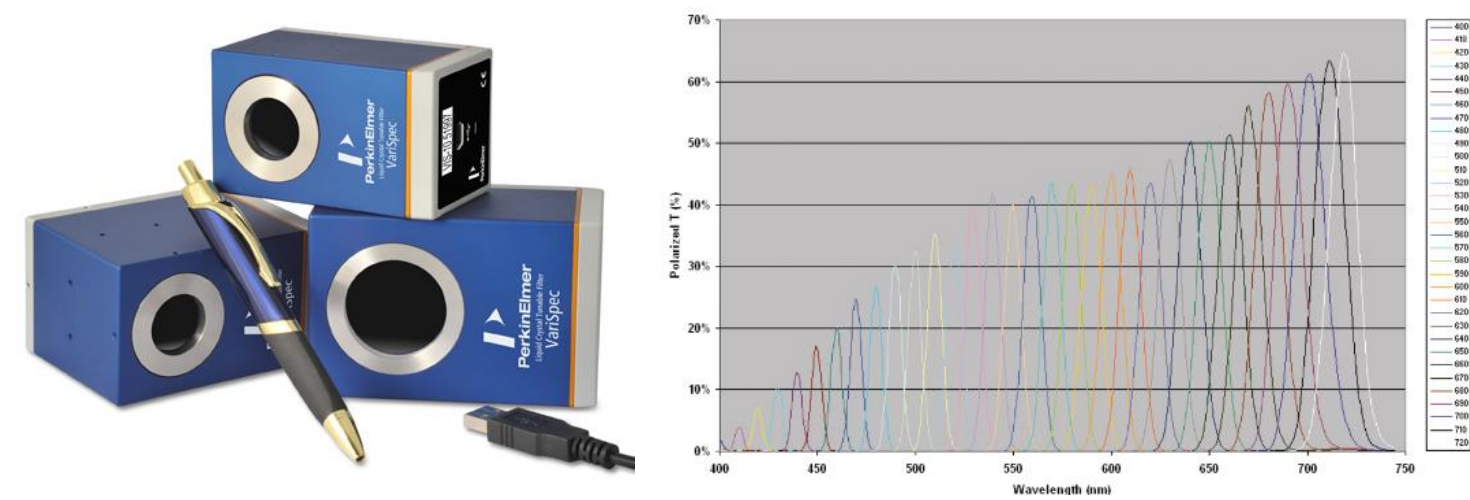

Figura 4-2. Filtros sintonizables de cristal líquido - Curvas de transmisión del filtro VIS-10 (VariSpec)

No obstante, ninguno de los filtros cubre todo el rango de sensibilidad de los sensores de silicio, desde $350 \mathrm{~nm}$ hasta $1050 \mathrm{~nm}$, por lo que sería necesario emplear dos unidades con rangos solapados: una VIS y una SNIR, que tendrían que ir acopladas a un espejo dicroico inclinado a $45^{\circ}$ para repartir (o recombinar) el haz luminoso. El tiempo necesario para sintonizar estos filtros es relativamente largo, del orden de decenas de milisegundos, comparable a una rueda de filtros. El elemento de entrada del filtro es un polarizador lineal, por lo que la transmisión de luz no polarizada es la mitad de la que tendría luz polarizada linealmente en la orientación correcta. Dado que el filtro absorbe toda la luz no transmitida, el umbral de daño para longitudes de onda VIS y NIR es relativamente bajo: $500 \mathrm{~mW} / \mathrm{cm}^{2}$. Las longitudes de onda del LWIR y el UV lo dañan fácilmente.

- Filtro acústico-óptico (AOTF - Acousto-Optic Tunable Filter). Es un tipo de filtro óptico sintonizable mediante radiofrecuencia que proporciona una elevada velocidad de conmutación, del orden de decenas de microsegundos. Por sus características está orientado a la selección de longitudes de onda en haces ópticos coherentes o colimados de pequeña anchura. Tanto la entrada como la salida están polarizadas. Está disponible en varios rangos, desde el UV hasta el MWIR, y en diversos anchos de banda, generalmente bastante estrechos.

Desafortunadamente, ninguno de los tipos de filtro óptico sintonizable descritos resulta idóneo para su aplicación en el sistema CAMEVA, fundamentalmente porque en todos ellos la luz transmitida está polarizada, y el sistema debe trabajar con luz no polarizada.

Por ello, la solución finalmente elegida para la obtención de imágenes multiespectrales con el sistema CAMEVA es la combinación de una cámara monocroma (una cámara monocanal sensible a un amplio rango de longitudes de onda), y una rueda de filtros (cargada con filtros ópticos pasabanda) para seleccionar la banda espectral activa en un instante dado. 


\subsubsection{Selección de la cámara}

En el apartado anterior, el término "cámara monocroma" se refiere a una cámara de vídeo dotada de un sensor monocanal con una curva de sensibilidad espectral continua y razonablemente uniforme que abarca un amplio rango de longitudes de onda, y que proporciona imágenes de niveles de gris que representan la intensidad luminosa reflejada por los objetos observados.

Estrictamente hablando, el adjetivo "monocromo" significa "un solo color", por lo que no se está usando correctamente al referirse a una cámara sensible a todos los colores del espectro visible, pero es el término habitualmente empleado en el sector, y como tal se usa aquí. En lenguaje coloquial, se emplearía la denominación "blanco y negro", que tampoco sería correcta porque la cámara proporciona imágenes en tonos de gris intermedios entre el blanco y el negro.

Las dos tecnologías principales con las que hoy en día se pueden fabricar en silicio sensores de imagen para cámaras se denominan CCD y CMOS. Aunque hoy en día los sensores CMOS han mejorado considerablemente y son netamente superiores a los CCD en la mayoría de características, cuando se diseñó el sistema CAMEVA la situación era muy diferente y los sensores CCD eran la única opción viable para una aplicación de microscopía cuantitativa.

Un sensor CCD (Charge-Coupled Device - dispositivo acoplado por carga) es un circuito integrado que tiene en su superficie una matriz bidimensional de elementos de imagen (píxeles) sensibles a la luz, cada uno constituido por un fotodiodo y un pozo de potencial asociado. Cuando incide luz sobre el fotodiodo, parte de los fotones incidentes son absorbidos, generando pares electrón-hueco que dan lugar a la acumulación gradual de carga eléctrica en el pozo de potencial. Al término del tiempo de integración, las cargas acumuladas en los píxeles de un CCD con interline transfer se traspasan a los registros de transferencia verticales, que a su vez las transportan línea a línea hasta el registro de desplazamiento horizontal, y éste columna a columna hasta un amplificador que convierte cada carga a un voltaje analógico, que constituye la señal de salida del sensor CCD. Las cámaras de vídeo CCD con interfaz digital tienen circuitería adicional que convierte estos voltajes a valores digitales de 8, 10 ó 12 bits por píxel.

La idoneidad de una cámara CCD para una aplicación depende de sus características concretas. El número de píxeles y su tamaño determinan la resolución efectiva. La cantidad de electrones que saturan el pozo de potencial se conoce como capacidad total del pozo (Full Well Capacity FWC), y es proporcional al tamaño del píxel $\left(\sim 1000\right.$ electrones $\left./ \mu \mathrm{m}^{2}\right)$. El rango dinámico indica la máxima variación de intensidad de señal que puede cuantificarse mediante el sensor, y se suele calcular como el cociente del FWC dividido por el ruido de lectura, que es el ruido generado en el amplificador por el proceso de conversión de carga a voltaje. 
Otra fuente importante de ruido es la corriente de oscuridad (Dark Current), cuya magnitud depende de la temperatura. Por ello, las cámaras de video de alta sensibilidad para uso científico suelen incorporar un sistema de refrigeración termoeléctrica (Peltier) que reduce la temperatura del sensor respecto al ambiente para minimizar este ruido: por cada $20{ }^{\circ} \mathrm{C}$ de reducción, la corriente de oscuridad disminuye en un orden de magnitud, y a $-30{ }^{\circ} \mathrm{C}$ ya es despreciable.

Una de las características más importantes de un sensor de imagen es la relación entre el número de electrones generados y el número de fotones incidentes, que se denomina eficiencia cuántica (Quantum Efficiency - QE) y depende de la longitud de onda de la luz y de las particularidades constructivas del CCD. La eficiencia cuántica a cada longitud de onda define la forma de la curva de sensibilidad espectral del sensor.

Existen tipos especiales de sensores CCD que incorporan modificaciones que mejoran significativamente su rango espectral o su comportamiento en situaciones de baja luminosidad:

- CCD con sensibilidad a longitudes de onda fuera del rango espectral normal. Se puede lograr que un CCD sea sensible a una región espectral especial mediante la aplicación de fósforos de conversión de longitud de onda sobre la superficie del detector. Los fósforos para este propósito se eligen de forma que absorban la energía del fotón en la región espectral de interés y emitan luz en la región de sensibilidad espectral normal del CCD.

- $\mathrm{CCD}$ con electrodos fabricados en materiales transparentes. Debido a que los electrodos superficiales de polisilicio o aluminio absorben o reflejan gran parte de las longitudes de onda más cortas, muchos diseños recientes emplean otros materiales transparentes a la luz, como el óxido de indio y estaño, para mejorar la transmisión y, por tanto, la eficiencia cuántica en un rango espectral más amplio.

- Backthinned CCD: es un sensor CCD que ha sido adelgazado mediante el ataque químico del sustrato de silicio, de forma que pueda ser iluminado desde el lado posterior, con lo que la luz ya no tiene que atravesar la estructura de electrodos de su superficie. El dispositivo resultante es delicado y relativamente costoso, pero permite conseguir eficiencias cuánticas del orden del $90 \%$. Su respuesta puede ser incrementada aún más aplicando recubrimientos antirreflejo a la superficie posterior del sensor.

- EMCCD (Electron Multiplying CCD): tipo de sensor CCD que incorpora un registro de multiplicación de electrones entre la salida del registro de transferencia horizontal y el amplificador de carga. En este registro, una pequeña fracción $(\approx 1 \%)$ de los electrones que pasan se ven multiplicados mediante el proceso de ionización por impacto, que genera una gran cantidad (centenares o miles) de electrones secundarios. Los EMCCD proporcionan simultáneamente una alta sensibilidad y una alta velocidad de lectura. 
Los sensores CCD comerciales pueden clasificarse en dos grupos, según el tipo de aplicación para el que han sido diseñados:

- CCD para consumo. Sensores de pequeño formato $(\leq 1 / 2$ ") y bajo coste, para permitir su uso en dispositivos de consumo, como webcams, teléfonos móviles, cámaras de videovigilancia, cámaras fotográficas y de vídeo no profesionales, etc. Suelen incorporar un mosaico de filtros RGB tipo Bayer para obtener imágenes en color.

- CCD para uso científico. Sensores de gran formato ( $\geq^{2 / 3}$ ”) con alta eficiencia cuántica y bajo nivel de ruido, que proporcionan imágenes de alta calidad. Los píxeles suelen ser de mayor tamaño para obtener mayor sensibilidad. Pueden ser en color o monocromos.

La Figura 4-3 muestra algunos ejemplos de curvas de sensibilidad espectral de sensores CCD para uso científico (Murphy 2001). El sensor Kodak 1401e es una variante del 1401 que incorpora un recubrimiento mejorado que incrementa la sensibilidad en el azul y el UV. El sensor Sony ICX075 es un CCD interline con recubrimiento mejorado. El Sony ICX061 es un CCD interline con alta sensibilidad al azul y microlentes. El Sony ICX285 es un CCD interline con electrodos transparentes y microlentes. Por último, el sensor SITe ST001 es un CCD backthinned de alto coste con eficiencia cuántica mejorada en todo el rango espectral.

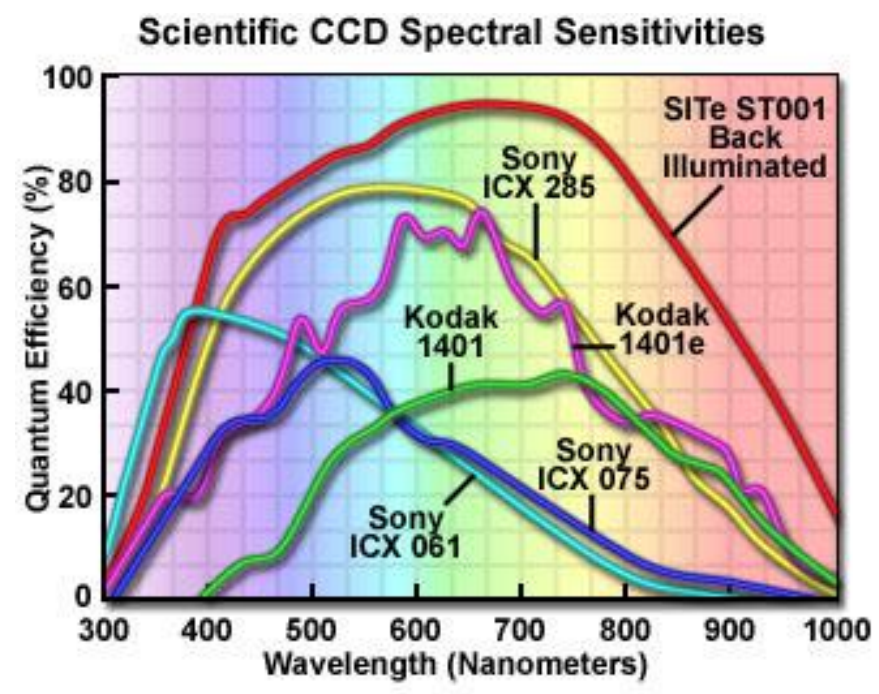

Figura 4-3. Curvas de sensibilidad espectral de antiguos sensores CCD de uso cientifico (Zeiss, 2018)

Tras analizar las opciones disponibles en 2007 para el sistema se decidió que lo más conveniente sería emplear una cámara de vídeo basada en el sensor Sony ICX285AL, un CCD monocromo de formato $2 / 3$ " muy popular en aplicaciones científicas e industriales por su alta calidad de imagen, alta sensibilidad, bajo smear (desbordamiento vertical), baja corriente de oscuridad y excelentes características anti-blooming (evita que un píxel saturado afecte a los vecinos). 
El sensor ICX285AL incorpora la tecnología EXView HAD CCD, una tecnología de SONY en la que la unión P-N de los fotodiodos está especialmente fabricada para tener una eficiencia de conversión de fotones a electrones mucho mejor, en especial en el infrarrojo. Además, cada fotodiodo tiene una lente microscópica Super HAD fabricada sobre él para captar y enfocar mejor la luz en la unión semiconductora activa (Figura 4-4). Esto da como resultado una mejora en la sensibilidad a la luz de 2 veces para la luz visible y 4 veces para el infrarrojo cercano ( 800 $\sim 900 \mathrm{~nm}$ ) en comparación con las versiones de CCD convencionales que ofrece SONY.
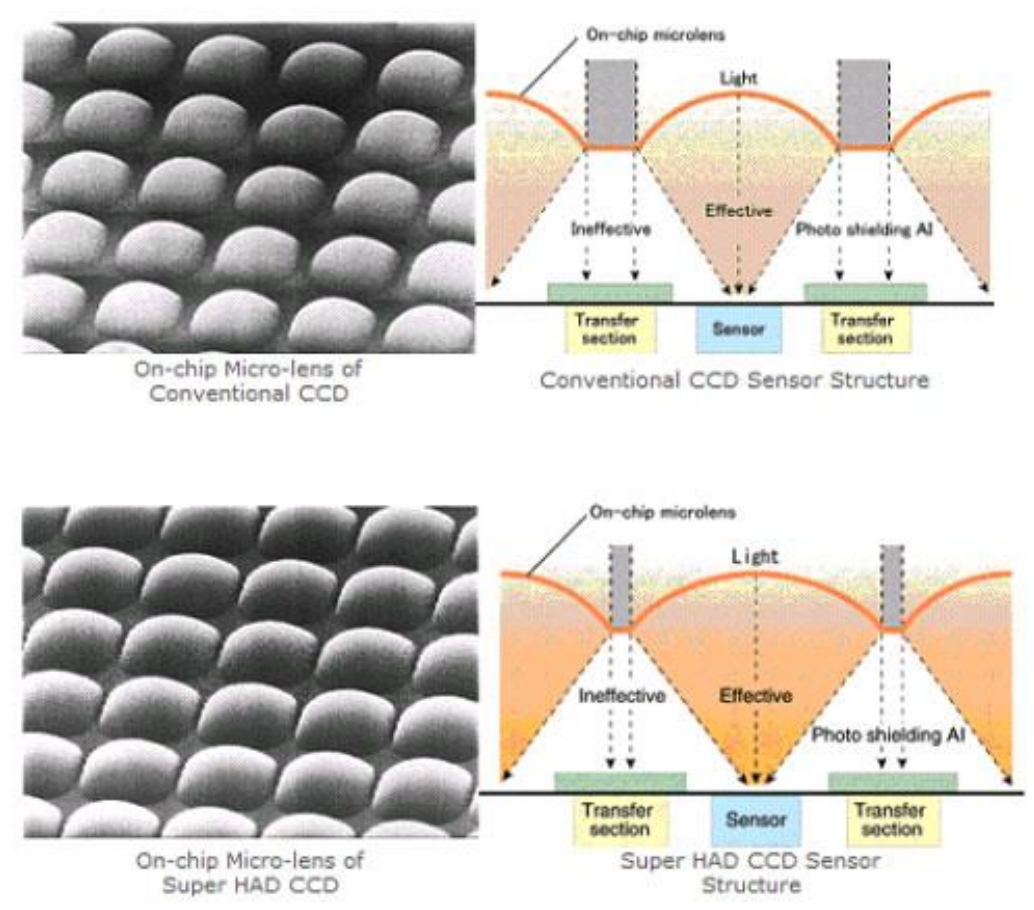

Figura 4-4. Comparación de un sensor Super HAD CCD con un CCD convencional (Sony, 2007)

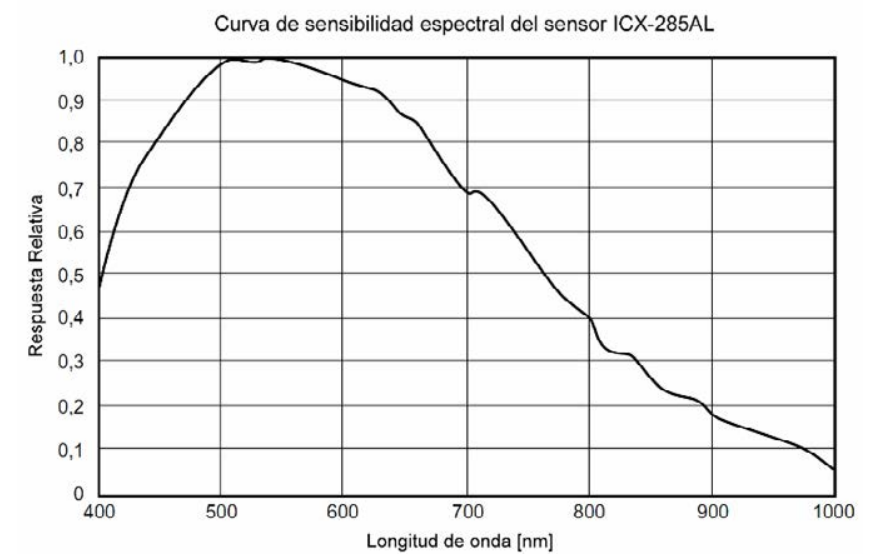

Figura 4-5. Curva de sensibilidad espectral del sensor CCD monocromo ICX285AL (Sony, 2007)

La respuesta espectral del sensor ICX285AL se muestra en la Figura 4-5. En ella puede verse que presenta sensibilidad en el rango del infrarrojo cercano (NIR) hasta $1000 \mathrm{~nm}$, y se vislumbra 
que también mostrará algo de sensibilidad al ultravioleta cercano (NUV) hasta al menos 360-370 $\mathrm{nm}$, por lo que debería cumplir las expectativas de rango espectral fijadas en §4.2.1.

Tabla 4-1. Características de las cámaras Basler Scout scA1400-17fm y Qimaging Retiga EXi

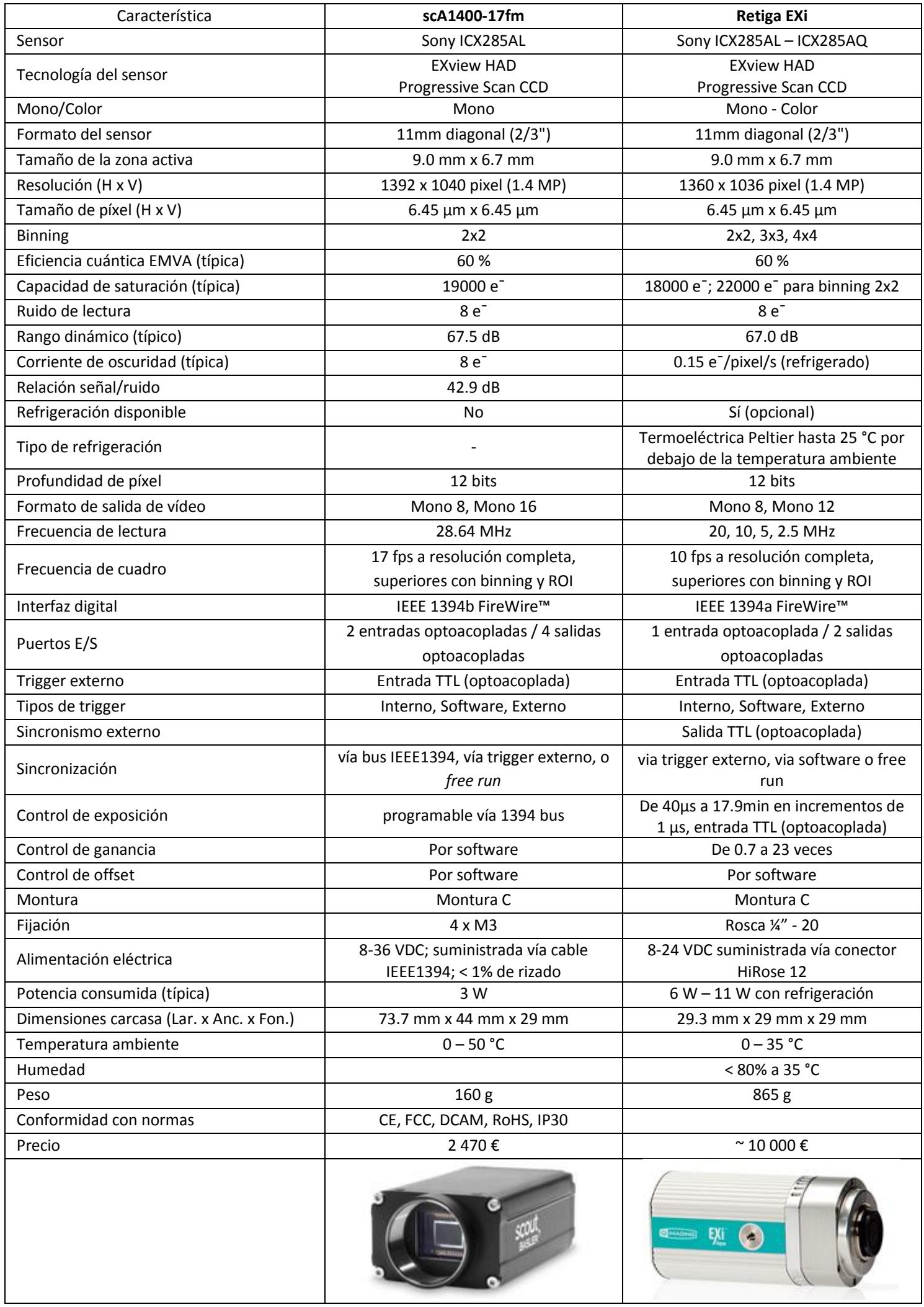


A la hora de elegir la cámara de vídeo para CAMEVA se consideró la posibilidad de adquirir un modelo con refrigeración termoeléctrica, por su inferior nivel de ruido térmico. Sin embargo, dado su alto coste se solicitó al proveedor el préstamo de una cámara para poder realizar pruebas de su comportamiento en condiciones reales. El modelo que se probó fue una Retiga EXi de la marca canadiense QImaging, que venía con su propio software de adquisición de imágenes, con el cual funcionaba bien. No obstante, dado que la cámara tenía que ser operada por el software del sistema CAMEVA, se hicieron pruebas para intentar controlarla mediante la librería de proceso de imágenes Matrox MIL 8 que se iba a usar para desarrollar el software de adquisición de imágenes, pero todos los intentos resultaron fallidos, por lo que se tuvo que descartar su uso.

Al final se seleccionó la cámara Basler Scout scA1400-17fm, por la experiencia positiva que se había tenido con otras cámaras del mismo fabricante y por tener una interfaz digital Firewire 1394b estándar que podía ser controlada fácilmente desde la librería MIL 8.0. Las características de los dos modelos de cámara que fueron considerados se recogen en la Tabla 4-1.

\subsubsection{Selección de los filtros pasabanda}

Para la selección de los filtros pasabanda que iban a ser utilizados en el sistema CAMEVA se decidió imitar el esquema empleado en QDF3, distribuyendo los filtros uniformemente en el intervalo espectral que se deseaba cubrir, aunque lógicamente con una mayor separación. QDF3 emplea 16 filtros de interferencia con un ancho de banda de $10 \mathrm{~nm}$ y una separación entre centros de banda de $20 \mathrm{~nm}$ para cubrir el intervalo entre 400 y $700 \mathrm{~nm}$. En CAMEVA se emplean 13 filtros de interferencia con una separación entre centros de banda de $50 \mathrm{~nm}$ para cubrir el intervalo entre 400 y $1000 \mathrm{~nm}$.

El otro parámetro que quedaba por decidir era el ancho de banda de los filtros, para lo cual se realizó una búsqueda de filtros de interferencia comerciales con las características deseadas. Tras estudiar la oferta de las marcas Andover, Newport, CVI y Melles Griot, la elección se decantó por esta última, porque ofrecía juegos de filtros que cubrían el visible a un precio interesante.

Los juegos de filtros estaban disponibles en tres anchos de banda (Full Width at Half-Maximum FWHM): 10, 40 y $80 \mathrm{~nm}$. Se juzgó que el FWHM ideal sería $40 \mathrm{~nm}$, para que la transmisión de luz fuera máxima con el mínimo solapamiento. No obstante, finalmente hubo que pedir los filtros por separado, porque los juegos únicamente estaban disponibles con $\emptyset 50 \mathrm{~mm}$, mientras que la rueda elegida sólo admitía filtros de Ø $25 \mathrm{~mm}$.

Los filtros adquiridos tenían las siguientes longitudes de onda centrales (Center Wavelength CWL): 400, 450, 500, 500, 600, 650, 700, 750, 800, 850, 900, 950 y $1000 \mathrm{~nm}$. 
Las especificaciones generales de estos filtros pasabanda eran:

- Tolerancia de la CWL: + 10,0 / - 0,0 nm

- FWHM: $40 \pm 8 \mathrm{~nm}$

- Bloqueo: 0,01\% de transmisión máxima fuera de la banda de paso (de rayos $\mathrm{X}$ a 3,5 $\mu \mathrm{m}$ )

- Diámetro: $25 \mathrm{~mm} \pm 0,5 \mathrm{~mm}$

- Grosor: $\leq 6.9 \mathrm{~mm}$.

- Calidad superficial: 80-50 "scratch and dig"

- Temperatura nominal de operación: $20^{\circ} \mathrm{C}$

- Límites de temperatura: de $-50{ }^{\circ} \mathrm{C}$ a $70{ }^{\circ} \mathrm{C}$

- Coeficiente de temperatura: de 0,016nm/ ${ }^{\circ} \mathrm{C}(@ 400 \mathrm{~nm})$ a 0,027 nm/ ${ }^{\circ} \mathrm{C}(@ 820 \mathrm{~nm})$

- Construcción: Laminada y sellada con epoxi resistente a la humedad en un anillo protector de aluminio

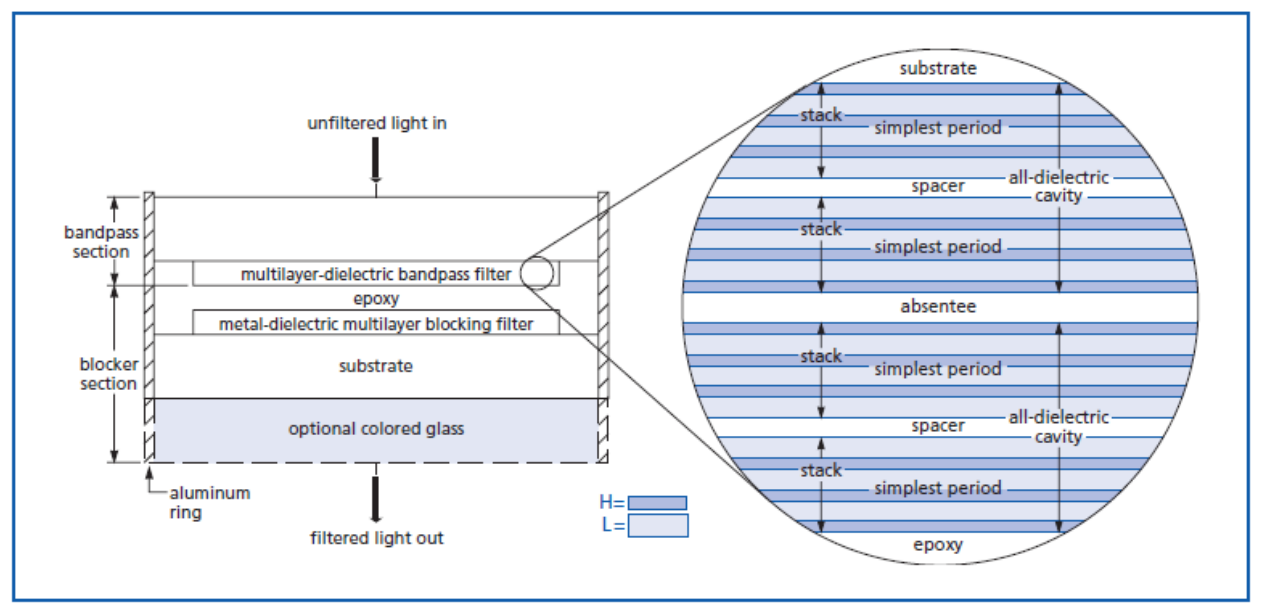

Figura 4-6. Construcción de un filtro de interferencia de dos cavidades típico (Melles Griot, 2007)

En la Figura 4-6 se muestra la estructura constructiva de un filtro de interferencia de dos cavidades típico, junto con una vista ampliada que muestra la estructura detallada de capas que componen el filtro pasabanda multicapa completamente dieléctrico. H simboliza una capa de un espesor óptico de exactamente un cuarto de la longitud de onda (la longitud de onda nominal del filtro) de un material de alto índice (típicamente sulfuro de zinc, $\mathrm{ZnS}$ ), mientras que L simboliza una capa de un espesor óptico de exactamente un cuarto de la longitud de onda de un material de bajo índice (típicamente criolita, $\mathrm{Na}_{3} \mathrm{AlF}_{6}$ ). El espaciador (spacer) es una capa de material de alto índice de un espesor de media longitud de onda, y la capa ausente o de acoplamiento (absentee) es una capa de material de bajo índice de un espesor de media longitud de onda. Todas estas capas se forman por deposición al vacío. 
Los filtros Melles Griot emplean estructuras de bloqueo multicapa (generalmente filtros híbridos metal- dieléctrico) para limitar la transmitancia al 0,01 por ciento por encima de la banda de paso. Es posible hacer un bloqueo más estricto, pero esto aumenta el costo del filtro y compromete la transmisión máxima. El vidrio coloreado se usa a menudo para suprimir la transmisión por debajo de la banda de paso. El anillo de aluminio protege los bordes del filtro, y el cemento epoxi protege las capas de la humedad y une las secciones pasabanda y de bloqueo.

Además de los filtros de interferencia, se decidió montar en la primera posición de la rueda una combinación de filtros KG3-ND0.9 (ND0.9: densidad neutra del 12,5\% de transmisión) para que el operador del microscopio pudiera mirar por los oculares sin ser deslumbrado. Esto dejaba dos posiciones de la rueda de filtros libres, lo que más tarde fue aprovechado para hacer pruebas de adquisición de imágenes con dos filtros ultravioleta: un filtro 03 FIU 135 con CWL $370 \mathrm{~nm}$ y FWHM 10 nm, y un filtro 03 FIU 133 con CWL 355 nm y FWHM 15 nm.

Las curvas de transmisividad reales de los filtros del sistema CAMEVA se muestran en la Figura 4-7, que representa los datos obtenidos con un espectrómetro Ocean Optics USB650 Red Tide. Este instrumento determina espectros entre $350 \mathrm{~nm}$ y $1000 \mathrm{~nm}$ con un paso de $1 \mathrm{~nm}$, por lo que la curva del filtro de $1000 \mathrm{~nm}$ queda necesariamente incompleta. Puede observarse que la transmisividad máxima de estos filtros de interferencia es relativamente baja (en torno al $60 \%$ ) y su FWHM de $40 \mathrm{~nm}$ hace que se solapen muy poco.

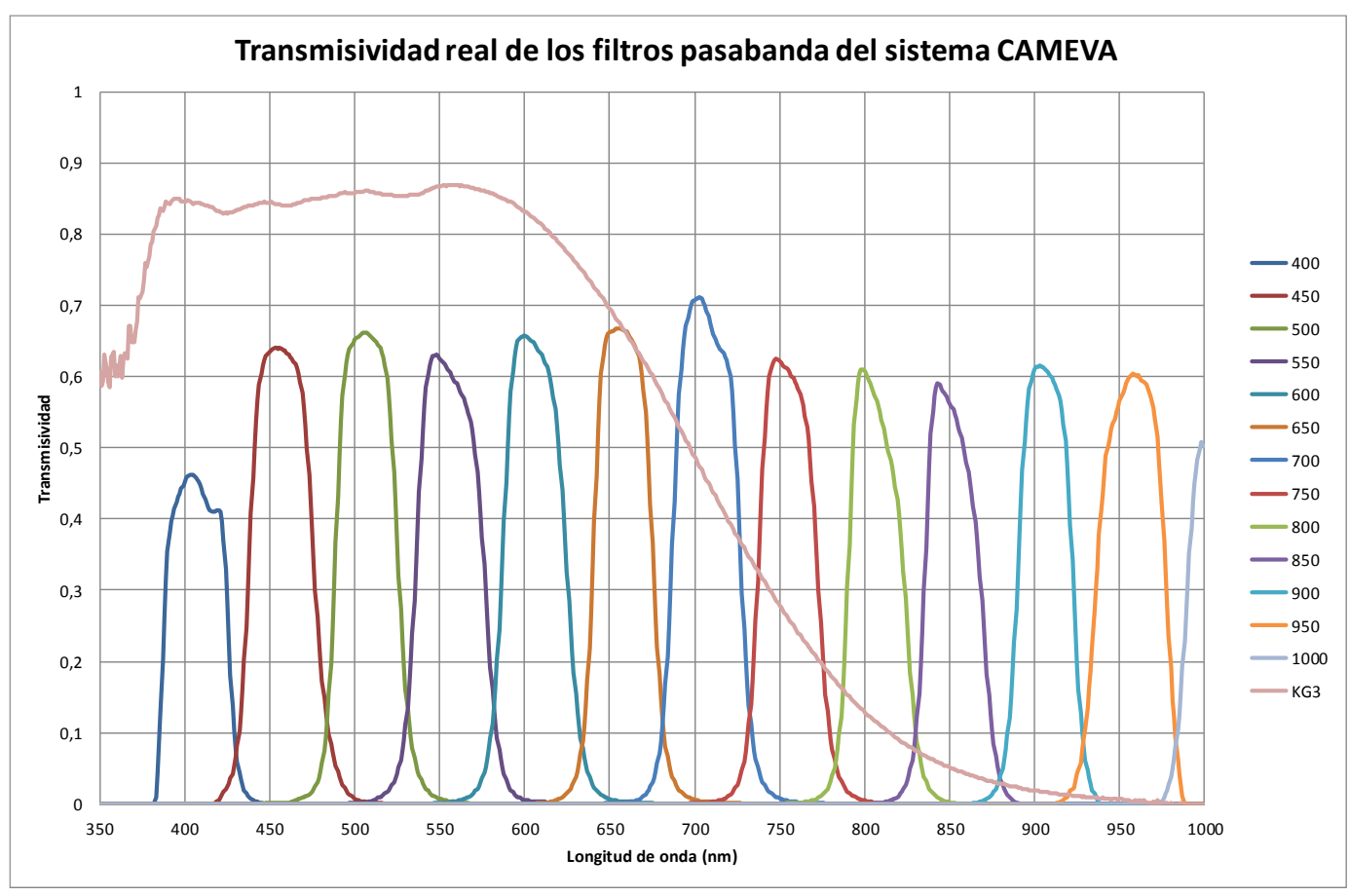

Figura 4-7. Curvas de transmisividad real de los 13 filtros pasabanda del sistema CAMEVA y del filtro KG3 solo (sin filtro ND0.9) (realización propia) 


\subsubsection{Selección de la rueda de filtros}

Igualmente se llevó a cabo una búsqueda de las ruedas de filtros motorizadas para microscopio disponibles en el mercado. Se localizaron pocos modelos que resultaran adecuados para el sistema CAMEVA, ya que la mayoría tenían como máximo 12 posiciones para filtros de Ø 25 $\mathrm{mm}$, lo que era claramente insuficiente. Entre los modelos encontrados destacó por su capacidad (16 posiciones) y precio contenido (la mayor parte de las ruedas eran mucho más caras) la rueda de filtros RPF Max-16 de la firma DTA, una empresa italiana originalmente centrada en el desarrollo de equipos para astronomía.
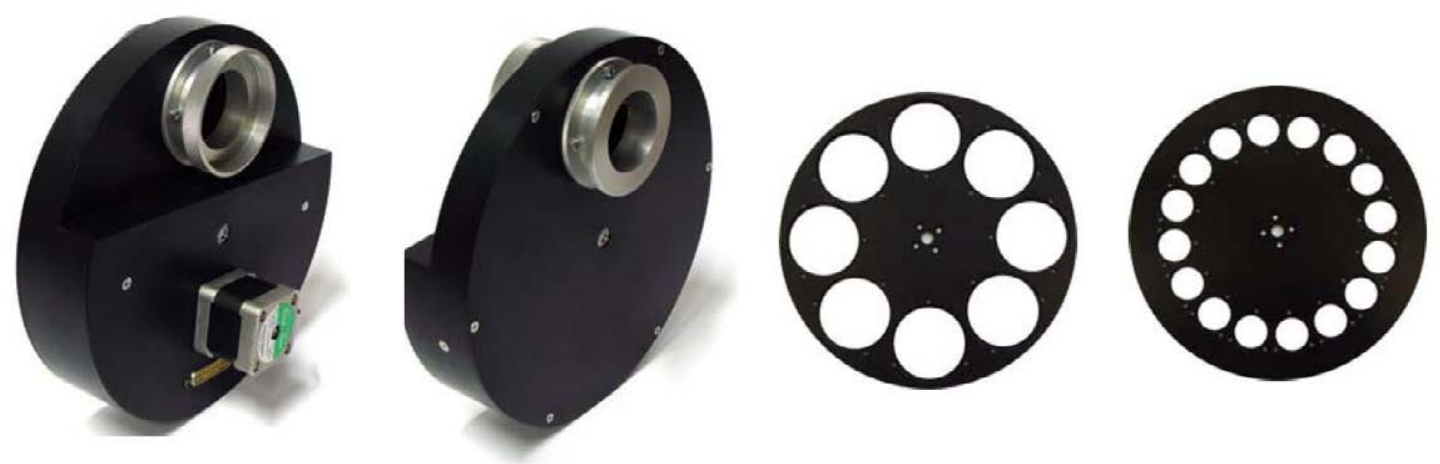

Figura 4-8. Rueda de filtros DTA RPF Max: vistas posterior y frontal, discos para 8 y 16 filtros (DTA)

Esta rueda (ver Figura 4-8) admitía dos tipos de discos portafiltros internos: uno para 8 filtros de Ø $50 \mathrm{~mm}$ y otro para 16 filtros de Ø $25 \mathrm{~mm}$, y se ofrecían discos portafiltros adicionales para facilitar el cambio de juegos completos de filtros. Aunque la rueda había sido concebida para su montaje en telescopios, el proveedor podía suministrar también adaptadores para intercalarla entre la fuente luminosa y el estativo de las principales marcas de microscopios, por lo que AITEMIN adquirió una rueda RPF Max-16 con adaptadores para microscopios Zeiss, y la UPM adquirió otra con adaptadores para microscopios Leica DM.

La Figura 4-9 muestra cómo quedó montada la rueda en los dos microscopios. En la foto del microscopio Leica puede verse el tubo de extensión que hubo que fabricar para poder acoplar la fuente luminosa a la rueda, debido a la orientación invertida que debía adoptar ésta.

El control de la rueda se puede efectuar mediante un software suministrado por el fabricante, así como mediante una API accesible desde diversos lenguajes de programación, como, por ejemplo, C++. También puede realizarse directamente desde cualquier sistema operativo, enviando comandos de texto al controlador de la rueda a través de la vía serie, lo cual es una opción muy interesante a futuro, si el sistema operativo del ordenador de control pasara a ser de 64 bits. 

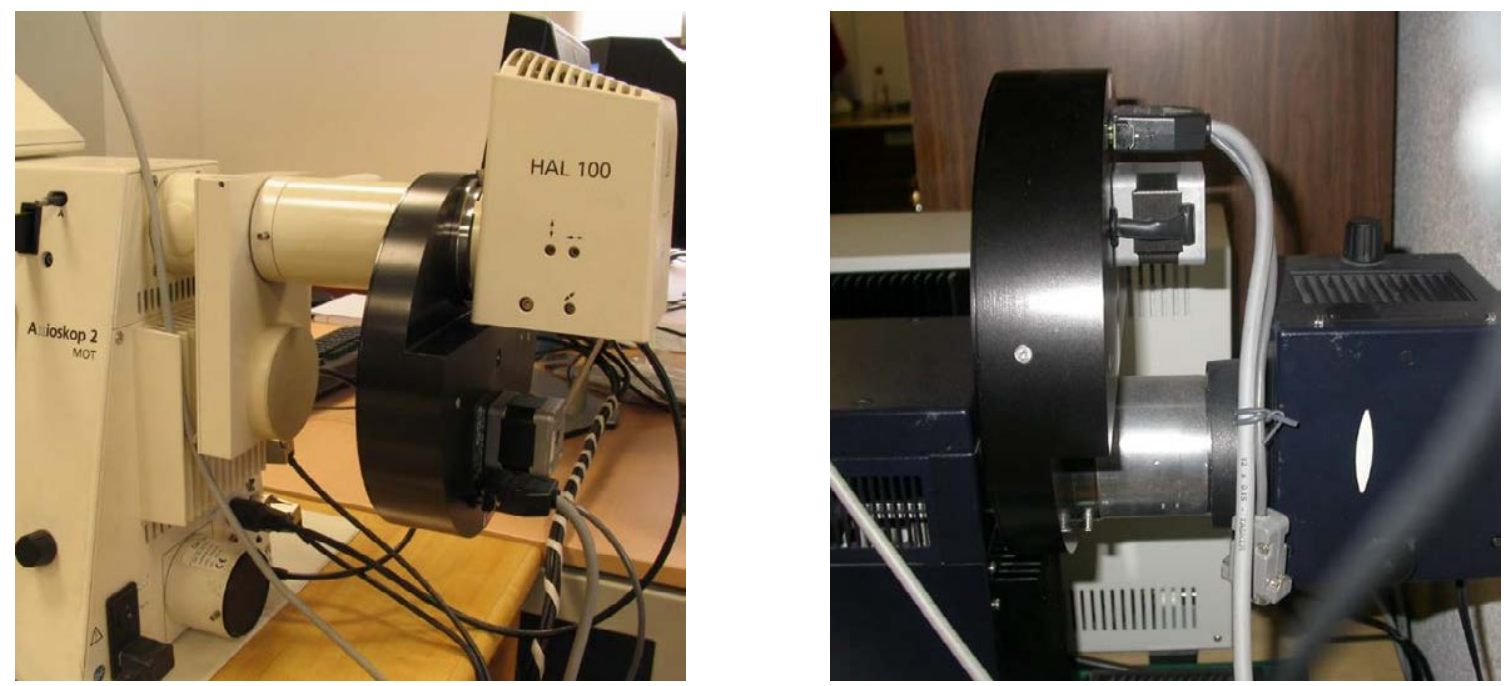

Figura 4-9. Ruedas de filtros DTA RPF Max-16 montadas en microscopios Zeiss y Leica (propias)

Los parámetros por defecto del controlador tuvieron que ser modificados para que la rueda funcionara de forma correcta, dado que la elevada masa de los filtros de interferencia elegidos hacía que la inercia del disco portafiltros fuera mucho mayor de lo previsto. Por ello la rueda de AITEMIN fue enviada temporalmente al fabricante para que éste procediera al ajuste óptimo de los parámetros de control.

\subsubsection{Selección y adaptación de la fuente luminosa del microscopio}

La mayor parte de los microscopios que se comercializan en la actualidad incorporan fuentes luminosas basadas en el uso de un diodo LED blanco de alta potencia. Este tipo de fuente luminosa presenta notables ventajas, entre ellas la capacidad de encenderse y alcanzar el régimen de funcionamiento nominal de modo prácticamente instantáneo, una gran estabilidad a corto y medio plazo y una baja producción de calor, lo que reduce el efecto del calentamiento de la fuente sobre la intensidad y la composición espectral de la iluminación.

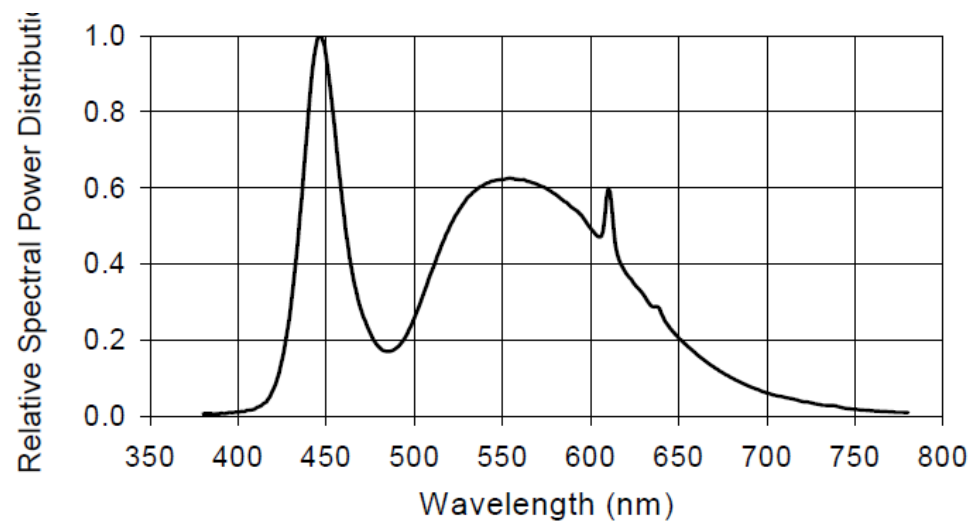

Figura 4-10. Espectro de la luz de un LED blanco de potencia (Luxeon Star - 5500 K) (Luxeon) 
Sin embargo, los diodos LED blancos emiten luz con una composición espectral restringida al espectro visible y muy poco uniforme (Figura 4-10), puesto que en realidad consisten en un diodo LED azul recubierto de un fósforo amarillo. Esto los hace inadecuados para su aplicación en un sistema multiespectral que deba abarcar el visible y el infrarrojo cercano.

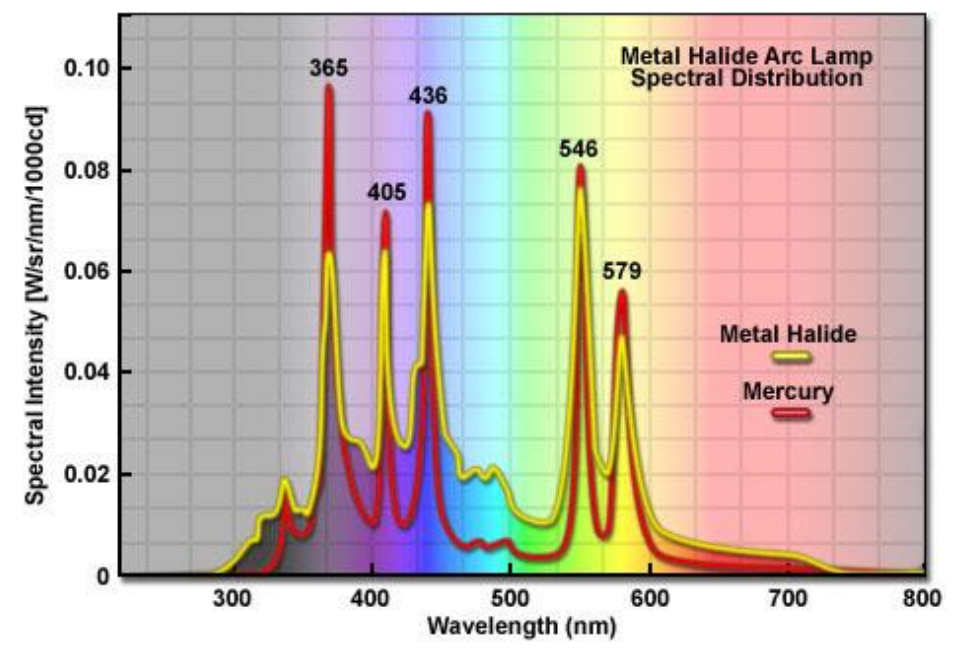

Figura 4-11. Intensidad espectral de una lámpara de haluro metálico comparada con la de una lámpara de mercurio (Zeiss, 2018)

Otra opción muy interesante como fuente luminosa en microscopía, sobre todo de fluorescencia, es la lámpara de haluro metálico, una lámpara de arco con una distribución espectral similar a la tradicional lámpara de mercurio, pero que presenta claras ventajas sobre ésta: mayor emisión en las regiones entre picos (Figura 4-11), mayor uniformidad espacial y temporal, lo que la hace más fiable para medidas cuantitativas, acoplamiento mediante guía de luz líquida, vida mucho más larga, menos problemas de alineación, mejor rendimiento, etc. No obstante, su distribución espectral carece casi por completo de infrarrojo, por lo que también tuvo que ser descartada.

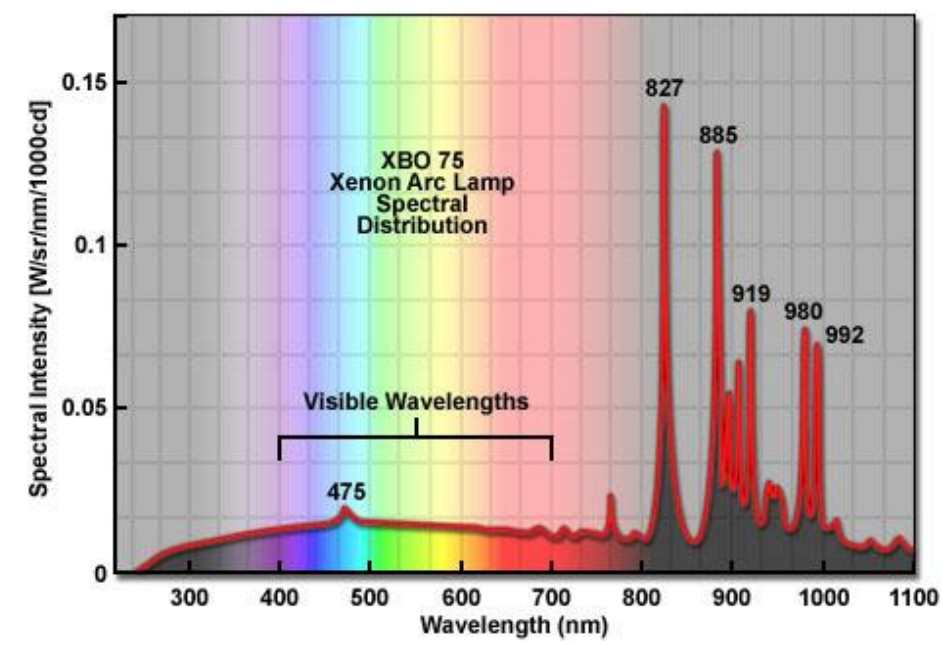

Figura 4-12. Intensidad espectral de una lámpara de xenon XBO 75 (Zeiss, 2018) 
La única lámpara de descarga que presenta una emisión significativa en el infrarrojo cercano es la lámpara de arco de xenón. De hecho, sólo un $25 \%$ de la potencia emitida recae en el visible, mientras que el $70 \%$ corresponde a longitudes de onda superiores a $700 \mathrm{~nm}$. Sin embargo, su espectro (Figura 4-12) presenta un complejo patrón de líneas entre 750 y 1000 nm, y su brillo sufre fluctuaciones debidas a distintos fenómeno que afectan al arco, por lo que no resulta una fuente luminosa ideal para esta aplicación.

Por todo ello, el sistema CAMEVA deberá hacer uso de la fuente luminosa más clásica, basada en una lámpara incandescente halógena con filamento de wolframio, a pesar de los problemas de producción de calor y estabilidad de la temperatura de color que implica, en particular cuando la temperatura ambiente no está suficientemente controlada.

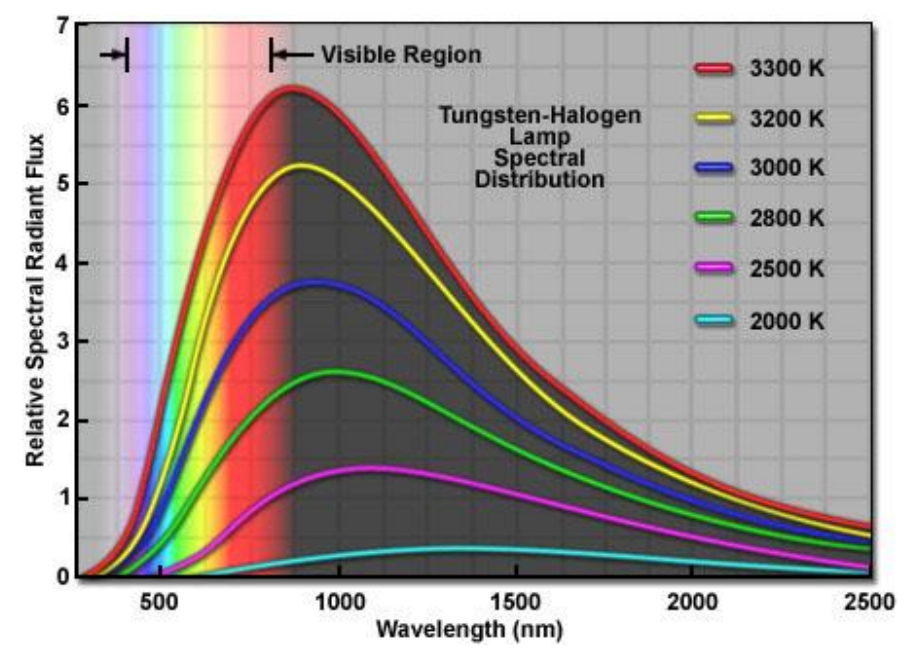

Figura 4-13. Distribución espectral de una lámpara halógena a distintas temperaturas (Zeiss, 2018)

Como muestra la Figura 4-13, la lámpara halógena presenta un espectro continuo y relativamente uniforme muy similar al espectro de emisión teórico del cuerpo negro. A las temperaturas de color típicas de las lámparas empleadas en microscopía (de $3200 \mathrm{~K}$ a $3450 \mathrm{~K}$ ) la mayor parte de la energía emitida (en torno al 85\%) se encuentra en la región infrarroja del espectro, mientras que sólo un 13-15\% cae en el visible y menos del 1\% en el ultravioleta.

La Figura 4-14 recoge tres curvas que modelizan el comportamiento de una fuente luminosa (“lamp housing" en la nomenclatura de Leica) de alta calidad: el modelo LH 106Z. En ella puede verse que, de todo el flujo radiante emitido por la lámpara halógena (curva azul), menos de un $30 \%$ es recogido por el espejo y el colector y proyectado hacia la salida de la fuente. El resto es absorbido por la carcasa y transferido al ambiente como calor, principalmente por convección. De la radiación proyectada (curva rosa), la mayor parte es infrarroja (NIR y SWIR), que podría dañar los elementos internos del microscopio, por lo que debe ser filtrada. 


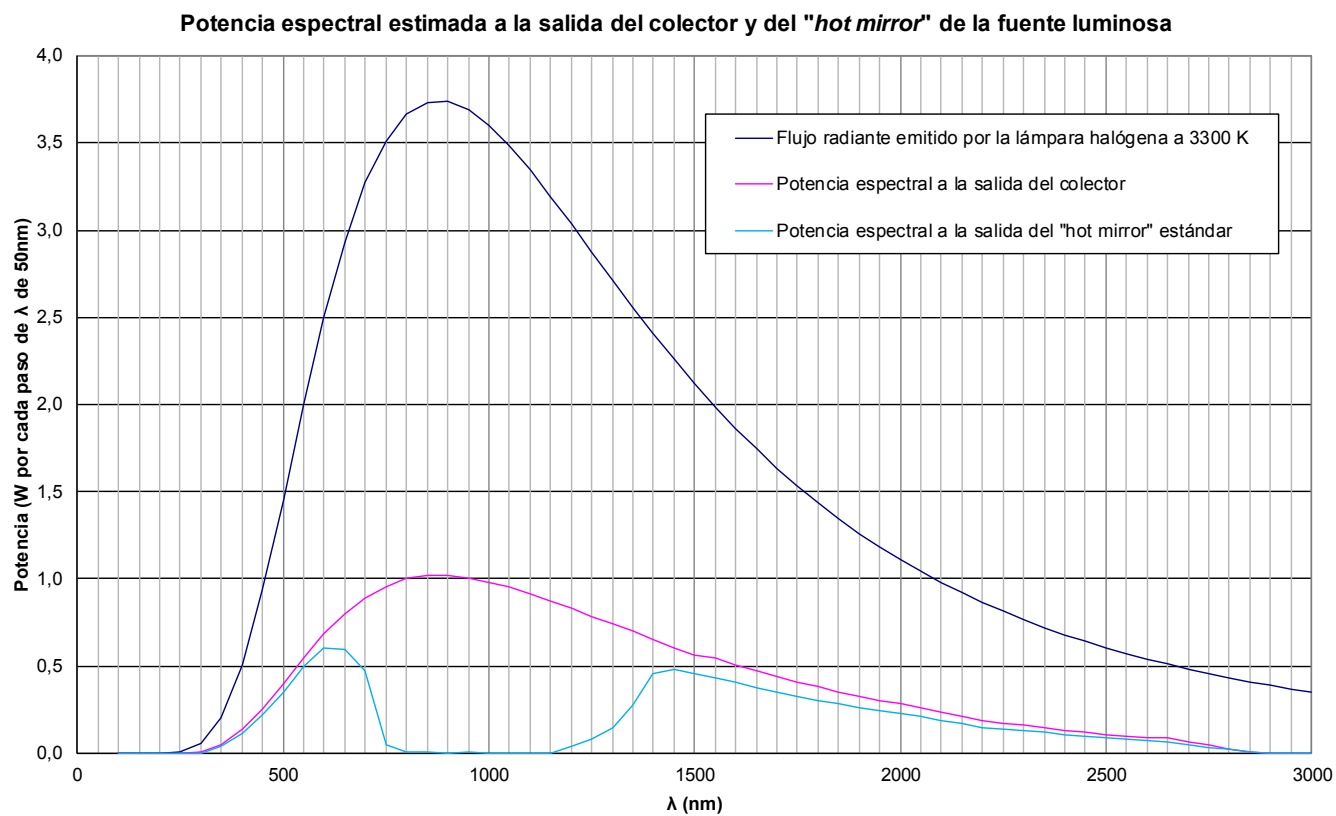

Figura 4-14. Estimación de la potencia espectral suministrada por la fuente luminosa Leica LH $106 Z$ con la lámpara halógena OSRAM $64623 \mathrm{HLX}(12 \mathrm{~V} 100 \mathrm{~W} 3300 \mathrm{~K} 2800$ lm) y “hot mirror” estándar (realización propia)

Por este motivo, las fuentes luminosas incorporan en la salida un filtro de tipo "hot mirror", que deja pasar la luz visible, pero bloquea las longitudes de onda del infrarrojo cercano (curva cian). En el sistema CAMEVA, este filtro debe ser sustituido por otro que admita el paso de una cierta cantidad de radiación infrarroja, que sea suficiente para permitir la adquisición de imágenes VNIR con la cámara, pero que no pueda producir daños a los elementos internos.

En un principio, se seleccionó para este cometido un filtro híbrido (con recubrimiento metálico y dicroico) de la firma Reynard Corporation que tenía la curva de transmisión que se muestra en la Figura 4-15. Esta curva presenta una transmisión máxima del 85\% a $600 \mathrm{~nm}$, transmisión superior al 50\% en todo el infrarrojo cercano y reflexión superior al 95\% en el infrarrojo medio, por lo que parecía adecuada para esta aplicación. Además, su precio era razonable.
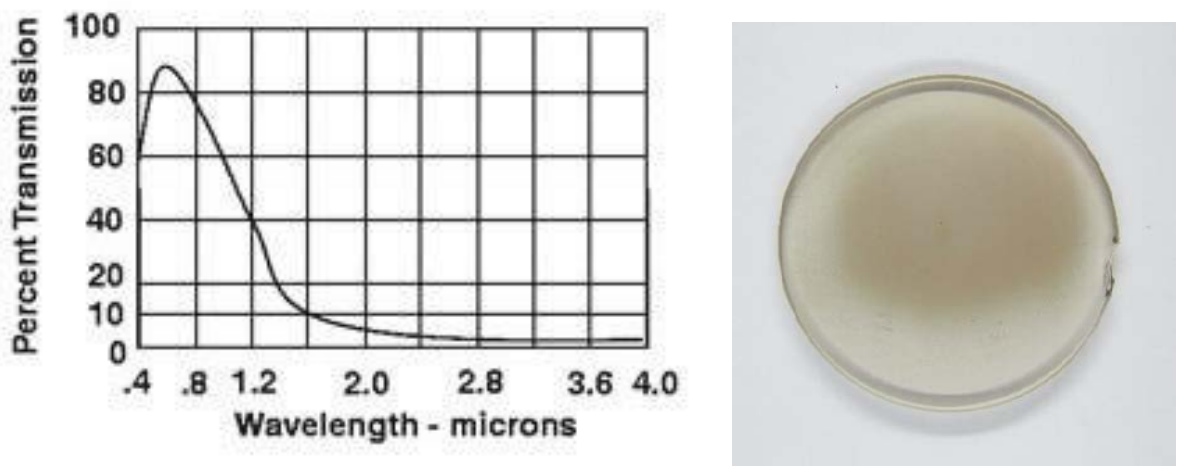

Figura 4-15. Curva de transmisión del filtro híbrido (Reynard Corporation) y filtro dañado (propia) 
Sin embargo, a los pocos meses de uso, se detectó que este filtro había sido dañado por el calor de la fuente luminosa (Figura 4-15, derecha), y hubo que buscar otro con mejores prestaciones. Tras consultar con distintos proveedores, la única opción viable fue encargar la fabricación de un filtro "custom" (es decir, personalizado), con una curva de transmisión específicamente diseñada para esta aplicación. La curva del filtro finalmente elegido se muestra en la Figura 4-16.

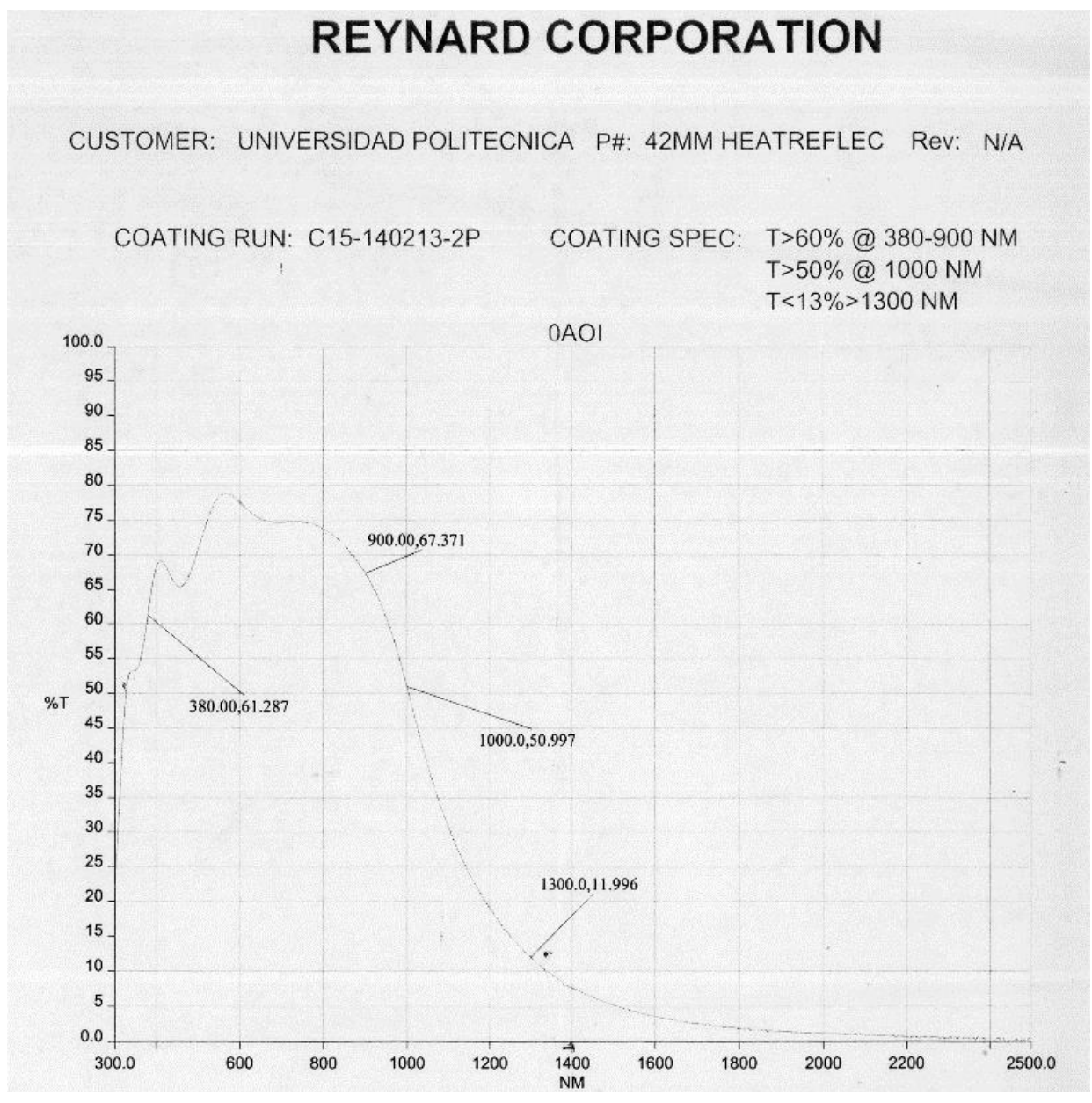

Figura 4-16. Curva de transmisión del filtro "custom” fabricado específicamente para esta aplicación

En ella se puede observar que el nuevo filtro refleja una proporción de radiación infrarroja superior al anterior, sobre todo a longitudes de onda por encima de $1000 \mathrm{~nm}$. El precio de este filtro es muy superior al del filtro híbrido anterior porque hay que fabricarlo "a medida", depositando sobre un sustrato adecuado (de sílice fundida) un recubrimiento especialmente diseñado para obtener la curva de transmisión deseada. Este recubrimiento se consigue mediante un proceso de deposición por lotes que tiene un alto coste, por lo que se decidió encargar un lote de 8 filtros para repartirlo entre el mayor número de filtros posible. Seis de estos filtros eran de Ø $39 \mathrm{~mm}$ (para microscopios Leica) y dos de Ø $42 \mathrm{~mm}$ (para microscopios Zeiss). Estos son los filtros actualmente usados en las fuentes luminosas de los dos prototipos del sistema CAMEVA. 


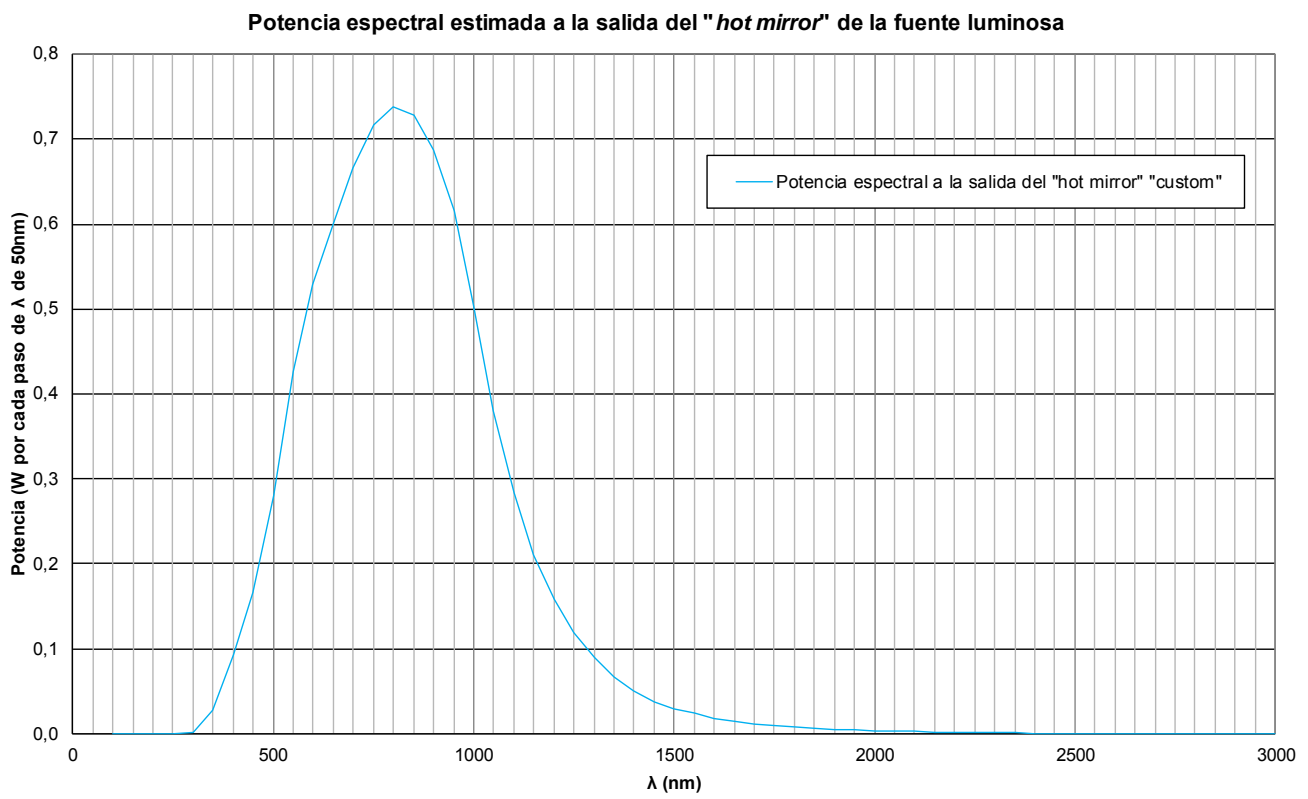

Figura 4-17. Estimación de la potencia espectral suministrada por la fuente Leica LH $106 Z$ con la lámpara halógena OSRAM $64623 \mathrm{HLX}(12 \mathrm{~V} 100 \mathrm{~W} 3300 \mathrm{~K} 2800 \mathrm{~lm})$ y el filtro “custom” (realización propia)

La distribución de potencia espectral suministrada por la fuente luminosa Leica LH $106 Z$ con este filtro "custom" instalado se representa en la Figura 4-17. A partir de ella puede estimarse el reparto aproximado de potencias por bandas espectrales, que se recoge en la Tabla 4-2:

Tabla 4-2. Estimación de la potencia suministrada en cada banda por la fuente Leica LH $106 Z$ con la lámpara halógena OSRAM $64623 \mathrm{HLX}(12 \mathrm{~V} 100 \mathrm{~W} 3300 \mathrm{~K} 2800 \mathrm{~lm})$ y el filtro “custom”

\begin{tabular}{|c|c|c|}
\hline Banda & Rango de longitud de onda & Potencia suministrada \\
\hline NUV & $<0,4 \mu \mathrm{m}$ & $27,8 \mathrm{~mW}$ \\
\hline VIS & $0,4 \mu \mathrm{m}-0,7 \mu \mathrm{m}$ & $2761 \mathrm{~mW}$ \\
\hline NIR & $0,7 \mu \mathrm{m}-1 \mu \mathrm{m}$ & $3988 \mathrm{~mW}$ \\
\hline SWIR & $1 \mu \mathrm{m}-3 \mu \mathrm{m}$ & $1538 \mathrm{~mW}$ \\
\hline MWIR & $3 \mu \mathrm{m}-8 \mu \mathrm{m}$ & $0 \mathrm{~mW}$ \\
\hline LWIR & $8 \mu \mathrm{m}-15 \mu \mathrm{m}$ & $0 \mathrm{~mW}$ \\
\hline
\end{tabular}

\subsubsection{Selección del microscopio}

Al seleccionar el microscopio más adecuado para integrar el sistema CAMEVA es preciso tener en cuenta los requisitos enumerados en el apartado $§ 4.1$ y la necesidad de que pueda operar en el rango espectral que va del ultravioleta cercano al infrarrojo cercano. Un posible condicionante para la adquisición de imágenes en este rango lo constituyen los elementos ópticos del microscopio, entre los que se cuentan las lentes del iluminador, el espejo semitransparente del cubo reflector, la lente del tubo óptico y, sobre todo, el objetivo, que es el elemento más crítico. 
Estos elementos han sido diseñados para operar en el espectro visible, por lo que a priori desconocemos si se van a comportar adecuadamente en el infrarrojo cercano y en el ultravioleta cercano. Afortunadamente, los principales fabricantes de microscopios ofrecen en su web información muy detallada sobre su amplia gama de objetivos, con el fin de facilitar su selección por parte de los usuarios. Entre esta información se encuentra la curva de transmisión del objetivo, que permite confirmar si un objetivo es capaz de operar más allá del rango visible. En la Figura 4-18 se muestra la curva de transmisión de un objetivo particularmente adecuado para su utilización en el sistema, como es el EC Epiplan Neofluar 20x/0.5 Pol, de la firma Zeiss.

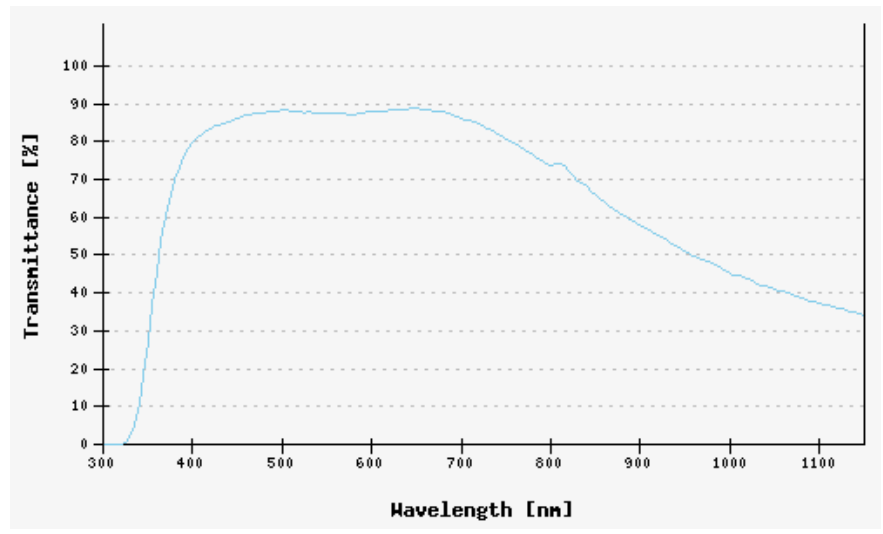

Figura 4-18. Curva de transmisividad espectral del objetivo EC Epiplan Neofluar 20x/0.5 Pol

(Zeiss, 2010)

La curva permite comprobar que dicho objetivo puede ser utilizado sin problemas para adquirir imágenes en el rango infrarrojo cercano, y su forma da pie a estimar que podría funcionar también en el SWIR, al menos hasta $1400 \mathrm{~nm}$, y probablemente más allá. En el ultravioleta cercano, sin embargo, la brusca caída de la transmisividad entre 370 y $340 \mathrm{~nm}$ permite suponer que será prácticamente imposible obtener imágenes a longitudes de onda inferiores a $350 \mathrm{~nm}$.

Los objetivos microscópicos de mayor calidad están diseñados para que los colores rojo, verde y azul queden enfocados en el mismo plano, de forma que sea posible ver perfectamente enfocadas las imágenes en color. Esto se consigue gracias al uso de lentes de distintos materiales, con propiedades ópticas complementarias, que permiten minimizar las aberraciones cromáticas en el rango de longitudes de onda que va de 450 a $650 \mathrm{~nm}$, aproximadamente. Fuera de este rango, los objetivos pueden funcionar correctamente o no, según su diseño, pero el plano de enfoque se apartará tanto más cuanto mayor sea el alejamiento de ese rango óptimo. La gráfica de la Figura 4-19 muestra un ejemplo característico de cómo evoluciona la cota del plano de enfoque en un objetivo semiapocromático de magnificación $20 \mathrm{X}$ al variar la longitud de onda de la luz entre 400 y $1000 \mathrm{~nm}$. 


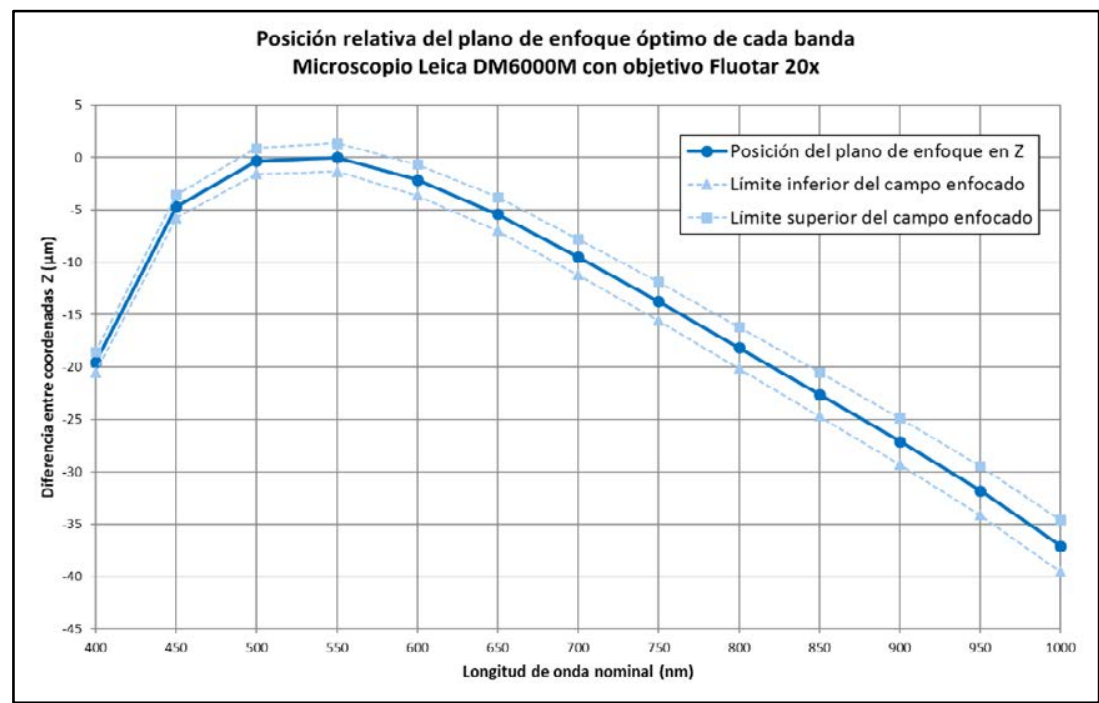

Figura 4-19. Curva que recoge la variación de la posición del plano de enfoque óptimo para las distintas bandas, así como los límites inferior y superior del campo enfocado (realización propia)

La profundidad de campo de un objetivo de microscopio viene dada por la fórmula

donde:

$$
Z=\frac{n \lambda}{N A^{2}}
$$

$n$ es el índice de refracción del medio (1 para el aire)

$\lambda$ es la longitud de onda de la luz

$N A$ es la apertura numérica (Numeric Aperture), un parámetro constructivo del objetivo que a su vez viene dada por

donde:

$$
N A=n \cdot \operatorname{sen}(\theta)
$$

$n$ es el índice de refracción del medio (1 para el aire)

$\theta$ es la mitad de la apertura angular del cono de luz capturado por el objetivo

Como $n$ y $N A$ son adimensionales, la profundidad de campo $Z$ vendrá expresada en las mismas unidades que tenga la longitud de onda. Para el objetivo Leica Fluotar 20X/0.45 P cuyo comportamiento se representa en la gráfica de la Figura 4-19, la profundidad de campo variará entre $2 \mu \mathrm{m}$ a $400 \mathrm{~nm}$ y $5 \mu \mathrm{m}$ a $1000 \mathrm{~nm}$ (se indican mediante líneas de trazos los límites superior e inferior del campo enfocado a cada longitud de onda).

Dicha gráfica pone de relieve un importante requisito para el diseño del sistema CAMEVA: dada la notable separación de los planos de enfoque comparada con la profundidad de campo de los objetivos, será imprescindible realizar un enfoque independiente de cada una de las bandas espectrales consideradas, por lo que es imperativo que el microscopio disponga de enfoque motorizado controlable por ordenador, lo cual normalmente obliga a seleccionar un microscopio de gama media o alta. 
Otro elemento esencial del que debe disponer el microscopio elegido para la integración del sistema es la platina XY motorizada, cuyo cometido es permitir al software del sistema la realización de barridos automatizados de secciones pulidas con un grado de cobertura seleccionable por el operador. La platina debe tener una precisión (y repetibilidad) suficiente para asegurar la concordancia de las imágenes de un barrido con cobertura del 100\% de la superficie de la preparación, y puede venir integrada en el microscopio o ser suministrada por separado.

Además del enfoque y la platina XY, en los microscopios de alta gama existen otras motorizaciones que pueden ser interesantes para esta aplicación:

- Revólver de objetivos, que permitiría al software del sistema capturar imágenes de la muestra con distintos objetivos. Esto puede ser útil para obtener vistas de conjunto de la muestra, o para facilitar la discriminación de partículas en muestras de concentrado o de flujos de planta de concentración.

- Torreta para cubos reflectores, que permitiría al software del sistema cambiar de técnica de observación a discreción. Esto puede ser útil para pasar de campo claro a fluorescencia en ciertos casos en los que este modo pueda resultar beneficioso (p. ej., para discriminar ganga y resina, o para reconocer minerales fluorescentes).

- Rueda de diafragmas de campo. En ciertos microscopios, se ha sustituido el diafragma de campo del iluminador por una rueda motorizada con orificios de distinto tamaño, con el fin de controlar el tamaño efectivo del campo visual de una forma objetiva y totalmente repetible. El fabricante ofrece la posibilidad de sustituir esa rueda con orificios de diversos tamaños por una rueda con orificios de tamaño fijo y polarizadores orientados en distintos ángulos, lo que permitiría iluminar la muestra con luz polarizada en distintos planos, y aproximar el efecto que tendría el giro de la muestra a distintos ángulos en una platina rotatoria.

Teniendo en cuenta todo lo anterior, y dado que el Laboratorio de Microscopía Aplicada de la Escuela Técnica Superior de Ingenieros de Minas y Energía disponía de un gran número de microscopios de marca Leica con los que se podría intercambiar componentes, si fuera necesario, se consultó con expertos de la casa Leica para conocer los modelos de microscopio más recomendables y establecer las configuraciones y componentes más adecuados para esta aplicación. Tras un proceso de optimización de la configuración, la UPM adquirió finalmente un microscopio Leica DM6000 M, un modelo con un avanzado grado de motorización, diseñado para llevar a cabo tareas de investigación en el campo de los materiales con luz incidente. 


\subsubsection{Adaptación del microscopio}

Dado que en su uso normal -observación visual a cargo de un operador humano- no es necesario trabajar fuera del rango visible, los microscopios suelen contar en su entrada de luz con un filtro de absorción de calor que impide el paso de cualquier longitud de onda infrarroja procedente de la fuente luminosa, con el fin de resguardar los componentes internos del calor emitido por ésta. Habitualmente se trata de un filtro del tipo KG3 o KG1, que absorbe las longitudes de onda superiores a $700 \mathrm{~nm}$. En algunas marcas de microscopios se llega al extremo de colocar dos filtros de este tipo juntos, evitando cualquier posibilidad de que pase luz infrarroja. Este filtro protector debe ser retirado del microscopio para poder adquirir imágenes en el rango NIR

Otra precaución que debe tomarse con el microscopio es la retirada del polarizador que normalmente se inserta en el camino óptico al final del iluminador, justo antes del revólver de cubos reflectores. Asimismo, debe comprobarse que no haya un polarizador montado a la entrada del propio cubo reflector, algo habitual en algunos cubos reflectores para aplicaciones de polarización. Por último, será necesario retirar el analizador, si estuviera presente.

\subsubsection{Selección de la platina motorizada}

Al cabo de un cierto tiempo de uso del microscopio se hizo evidente que la platina motorizada original dejaba bastante que desear, ya que sólo admitía una muestra y ocasionaba errores de posición considerables en el barrido automático. Por ello se buscó una platina de alta calidad que fuera adaptable a las principales marcas de microscopios, para tratar de uniformizar el sistema, en la medida de lo posible.

La platina finalmente seleccionada fue el modelo SCAN ${ }^{\text {plus }} 100 \times 100$ de la firma Märzhäuser. Se trata de una platina de alta precisión, utilizable con luz transmitida o reflejada, adaptable a múltiples marcas de microscopio, con un rango de movimiento de 100 x $100 \mathrm{~mm}$, resolución de $0,05 \mu \mathrm{m}$, precisión de $\pm 1 \mu \mathrm{m}$ y repetibilidad $\leq 0,2 \mu \mathrm{m}$, gracias a encoders lineales que proporcionan realimentación de posición en ambos ejes.

Esta platina no se conecta al microscopio, sino a una tarjeta controladora TANGO PCI-S que debe ser instalada en el ordenador donde se ejecuta el software del sistema. Se necesita también un joystick de 2 ejes para manejar la platina manualmente.

Dado el amplio rango de movimiento de la platina, es posible montar sobre ella varias secciones pulidas y realizar el barrido de cada una sucesivamente. Esto permitiría aprovechar la noche para la adquisición de varias series de imágenes, reduciendo consecuentemente las horas de operario necesarias para la realización de los análisis. 


\subsection{DESCRIPCIÓN DEL SISTEMA DESARROLLADO}

La metodología seguida para desarrollar el sistema aborda las dos vertientes del problema: por un lado, se integra un equipo que permite adquirir imágenes microscópicas de reflectancia especular en distintas bandas del espectro, y por otro se desarrolla un método operativo para calibrar y manejar dicho equipo, asegurando la obtención de medidas cuantitativas precisas y reproducibles de la reflectancia multiespectral sobre la superficie de una sección pulida.

\subsubsection{INTEGRACIÓN DEL EQUIPO}

El equipo está constituido por dos elementos principales: el instrumento y la unidad de control y proceso, así como una serie de patrones de reflectancia calibrados. El instrumento consiste en un microscopio óptico de reflexión dotado al menos de platina y enfoque motorizados, al que se realiza una serie de modificaciones (ver Figura 4-20) con el fin de permitir la adquisición de imágenes multiespectrales más allá de la banda visible. La unidad de control y proceso consiste en un equipo informático que ejecuta diversas aplicaciones que controlan los distintos elementos del instrumento y que asisten al operador en la aplicación del método operativo avanzado para calibración y operación del sistema.

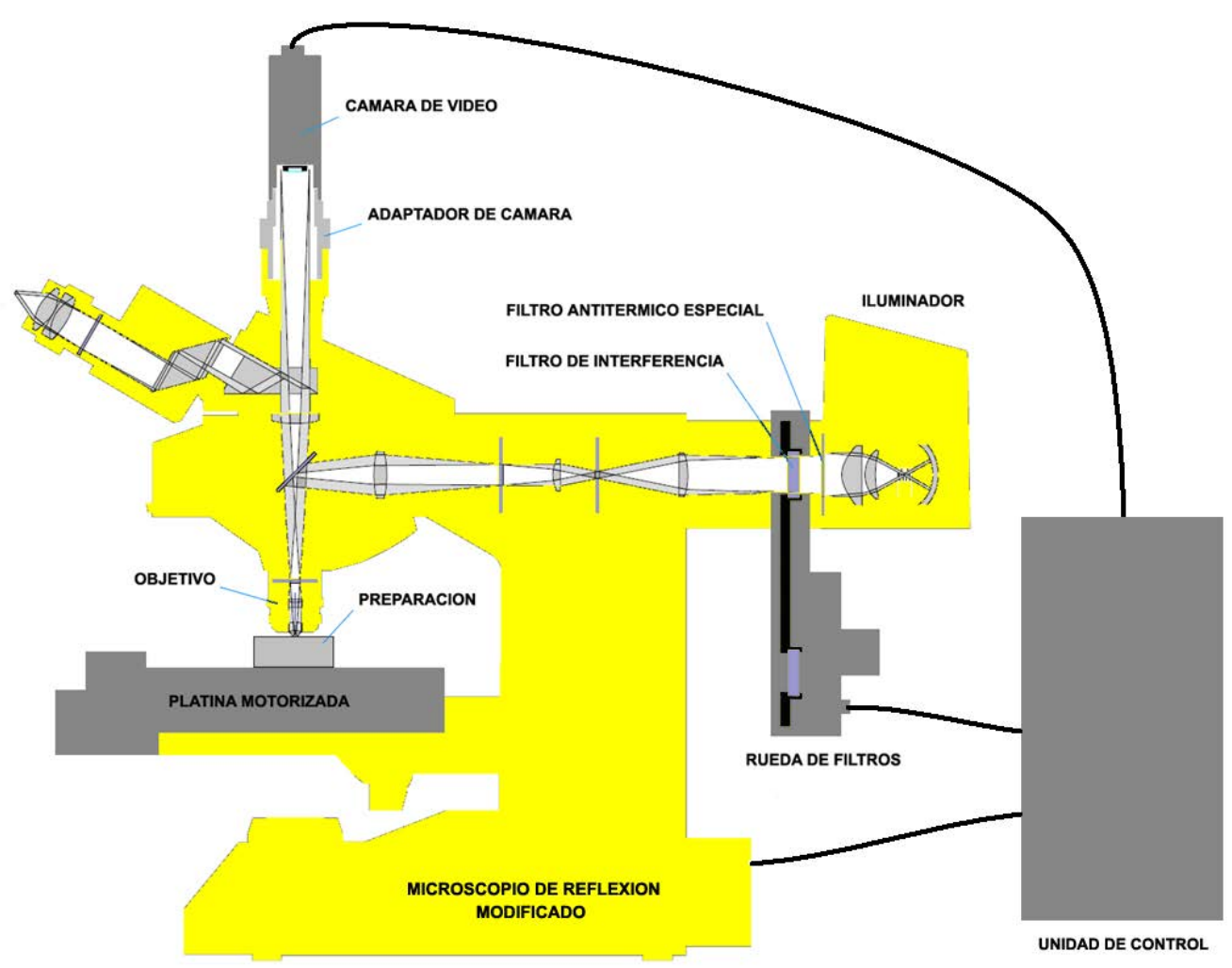

Figura 4-20. Esquema del microscopio modificado para integrar el sistema CAMEVA (modificado sobre Zeiss, 2010, realización propia) 
Las modificaciones principales que es necesario realizar al microscopio son las siguientes:

i. Cambio de la fuente luminosa original por un dispositivo que proporcione iluminación en las bandas de interés (es decir, visible e infrarrojo cercano y, opcionalmente, ultravioleta cercano). Por ejemplo, para trabajar en el visible y en el infrarrojo cercano se puede utilizar un iluminador con lámpara halógena convencional al que se le haya retirado el filtro antitérmico tipo "hot mirror" que normalmente se pone en la salida para reflejar la radiación infrarroja de vuelta hacia la lámpara e impedir su paso al microscopio. Este filtro debe ser sustituido por otro que refleje longitudes de onda más largas y que deje pasar parte del infrarrojo cercano al microscopio.

ii. Retirada de todos los filtros protectores antitérmicos que absorben el infrarrojo, que están situados normalmente a la entrada de la iluminación al microscopio.

iii. Retirada de todos los filtros polarizadores existentes en el camino óptico del microscopio (p.ej. el polarizador normalmente montado antes del módulo reflector, o el analizador), para realizar la observación con luz no polarizada.

iv. Incorporación de una cámara de vídeo monocroma, preferentemente con sensor CCD, que presente suficiente sensibilidad en toda la banda espectral de interés (debe retirarse el filtro de bloqueo del infrarrojo, si lo tuviera). La cámara debe disponer de una interfaz digital que permita controlar a voluntad el tiempo de exposición, y que proporcione imágenes de 12 bits por píxel, para aprovechar el rango dinámico del sensor. El adaptador de cámara será elegido teniendo en cuenta el tamaño y la resolución del sensor y las dimensiones y la resolución deseadas para la imagen. Lo ideal es utilizar un adaptador con factor de aumento $1 \mathrm{x}$, porque que no contiene lentes.

v. Incorporación de una rueda de filtros motorizada para seleccionar las bandas espectrales en las que se adquieren las imágenes. En esta rueda irán montados los filtros pasabanda (normalmente, filtros de interferencia con ancho de banda entre 10 y $50 \mathrm{~nm}$ ) correspondientes a las bandas de interés. La rueda de filtros puede ir intercalada entre la fuente luminosa y el microscopio o entre el microscopio y la cámara; el resultado final en ambos casos es equivalente (salvo que la muestra presente fluorescencia), pero la primera opción resulta más conveniente porque permite aplicar un filtro para evitar el deslumbramiento del operador durante la observación manual.

Otras modificaciones que podrían ser necesarias, dependiendo de la banda de interés, son:

vi. Sustitución de los objetivos estándar por objetivos especiales que tengan un mejor comportamiento en el ultravioleta y/o en el infrarrojo (p.ej. objetivos de reflexión). Esto sólo es aconsejable si hay que trabajar en el UV por debajo de $350 \mathrm{~nm}$, porque la calidad de imagen de esos objetivos en el visible es significativamente menor. 
vii. Sustitución de elementos ópticos internos del microscopio (lentes del sistema de luz incidente, lente del tubo óptico, prismas del repartidor de luz para documentación, etc.) por otros de materiales que presenten mayor transmisión en el ultravioleta, como fluorita o sílice. Esto sólo resulta necesario para trabajar en el UV por debajo de $350 \mathrm{~nm}$.

\subsection{ESTABLECIMIENTO DEL MÉTODO OPERATIVO}

El método operativo comprende diversos procedimientos: unos están concebidos para calibrar el instrumento y optimizar su funcionamiento, mientras que otros hacen uso de dicha calibración para corregir las imágenes recién capturadas, asegurando la calidad, exactitud, repetibilidad y correcto registro de las imágenes de reflectancia multiespectral resultantes.

Los procedimientos de corrección se aplican cada vez que se adquieren imágenes de una muestra, mientras que los procedimientos de calibración son discrecionales: se ejecutan ocasionalmente y, por supuesto, siempre que se altere algún elemento del microscopio.

Los procedimientos desarrollados permiten realizar, entre otras, las siguientes operaciones:

\subsubsection{Determinación del tiempo de exposición óptimo de cada banda}

Aunque los filtros de interferencia elegidos presentan unas curvas de transmisión similares (Figura 4-7), la potencia luminosa que incide en el sensor de la cámara cambia notablemente de una banda a otra porque ni la fuente luminosa proporciona la misma potencia en todas las bandas (Figura 4-17) ni la transmitancia de las lentes es uniforme. Además, la sensibilidad de la cámara (Figura 4-5) varía considerablemente con la longitud de onda. Si bien el proceso de calibración permite compensar estas diferencias, la calidad de la imagen final inevitablemente se resiente cuando la imagen de partida es demasiado oscura, por lo que es recomendable partir de un nivel de señal adecuado en todas las bandas. Una forma de conseguirlo sería empleando una tensión de lámpara diferente para cada banda, pero esta solución presenta serios inconvenientes: el rango práctico de variación de la tensión de la lámpara es limitado, y dejaría poco margen para aumentar la potencia en las bandas oscuras, el proceso de adquisición se demoraría porque habría que esperar unos segundos a que el iluminador se estabilizara suficientemente después de cada cambio, y el continuo cambio comprometería la estabilidad de la iluminación.

Afortunadamente, el hecho de que la cámara disponga de interfaz digital permite recurrir a una solución equivalente, aunque mucho menos problemática: fijar un tiempo de exposición diferente para cada banda. Por esta razón se ha desarrollado un procedimiento para establecer el tiempo de exposición óptimo en cada banda mediante un algoritmo de aproximaciones sucesivas 
que toma imágenes de un patrón de reflectancia conocida. En cada paso, el algoritmo evalúa el histograma de la imagen y ajusta el tiempo de exposición intentando que el valor de la moda se aproxime al nivel de gris correspondiente a la reflectancia nominal del patrón para esa banda. Para calcular dicha correspondencia se aplica el factor de conversión deseado para las imágenes finales, que normalmente viene expresado en porcentaje de reflectancia por cada nivel de gris. El objetivo final de esta operación es que las imágenes adquiridas por el instrumento aprovechen al máximo el rango dinámico de la cámara sin llegar a sufrir saturación, por lo que debe realizarse periódicamente con cada uno de los objetivos utilizados, con el fin de ir compensando el envejecimiento de la lámpara de la fuente luminosa.

\subsubsection{Determinación del plano de enfoque óptimo de cada banda}

En un microscopio, el enfoque de la imagen no se efectúa mediante la adaptación de lentes u otros elementos del camino óptico, sino mediante el ajuste de la separación entre el objetivo y la muestra, que se controla a través del desplazamiento vertical de la platina (movimiento en el eje Z). La mayoría de los objetivos de microscopio están diseñados para su uso por un observador humano, por lo que proporcionan la máxima calidad de imagen en la parte central de la banda visible (entre 450 y $650 \mathrm{~nm}$ ). Normalmente, esto se logra mediante un diseño acromático, que combina lentes de distintos tipos de vidrio para conseguir que la luz azul se enfoque en el mismo plano que la luz roja, y que la luz verde se enfoque en un plano próximo, de forma que las imágenes de los tres colores puedan verse suficientemente nítidas al mismo tiempo (y, por lo tanto, desde una misma posición del eje Z).

Lamentablemente, no ocurre lo mismo para longitudes de onda inferiores a $450 \mathrm{~nm}$ o superiores a $650 \mathrm{~nm}$. En estos casos, la luz se enfoca en planos crecientemente alejados del plano de enfoque rojo-azul, por lo que las imágenes correspondientes a esas longitudes de onda no se ven nítidas desde dicha posición, y requieren que se reenfoque el microscopio. En consecuencia, durante el uso práctico del instrumento, y dado que no es posible tomar todas las imágenes desde una misma posición del eje $\mathrm{Z}$, resulta preferible enfocar independientemente cada banda de la imagen multiespectral, para conseguir un enfoque óptimo en todas ellas.

Afortunadamente, como el proceso de enfoque no produce cambios en el camino óptico del microscopio, las distancias entre los planos de enfoque óptimo de las distintas bandas son fijas para cada objetivo, por lo que, una vez enfocada una banda, las demás pueden enfocarse "a ciegas", simplemente sumando los correspondientes ajustes a la posición del plano de enfoque de esa banda. Para determinar dichos ajustes se ha desarrollado un procedimiento que enfoca automáticamente una preparación que presente buen contraste en todas las bandas, determinando 
el valor de la coordenada $\mathrm{Z}$ del microscopio en el punto de enfoque óptimo de cada una de ellas. Seguidamente, se calculan las diferencias entre el valor de $Z$ en una de las bandas, que será considerada como banda de referencia para el enfoque, y los valores de $\mathrm{Z}$ en el resto de las bandas (ver Figura 4-19), y se guardan en un archivo para su uso ulterior. Esta operación debe realizarse una sola vez con cada uno de los objetivos utilizados.

\subsubsection{Calibración de la respuesta del instrumento}

La calibración de la respuesta del instrumento es una operación esencial para asegurar la exactitud de las medidas de reflectancia y garantizar la reproducibilidad de los resultados, tanto a lo largo del tiempo como entre distintos laboratorios. El procedimiento está basado en la adquisición de imágenes de patrones de reflectancia conocida en cada una de las bandas, con el fin de caracterizar las imperfecciones del instrumento para poder compensarlas posteriormente mediante el procedimiento desarrollado para la adquisición de una imagen multiespectral. Las principales imperfecciones son la falta de uniformidad en la distribución de la iluminación en el campo visual del instrumento y las "manchas" (variaciones locales en la respuesta del sistema óptico) originadas por motas de polvo, suciedad o deterioro en filtros, lentes, cámara, etc.

Para evitar que los arañazos y las partículas de suciedad del patrón (inevitables en cualquier patrón en uso) puedan falsear la calibración, el procedimiento desarrollado realiza un pequeño barrido en X e Y sobre el patrón y promedia las imágenes de los campos recorridos aplicando un novedoso algoritmo que filtra tanto las zonas excesivamente oscuras como las excesivamente claras para impedir que intervengan en el cálculo. El proceso está diseñado de forma que las imágenes promedio obtenidas tengan una resolución efectiva de 16 bits por píxel. La Figura 4-21 muestra una imagen típica del patrón de alta reflectancia con sus defectos, así como la imagen resultante del proceso de filtrado y promediado en un barrido de $4 \times 4$ campos sobre dicho patrón.

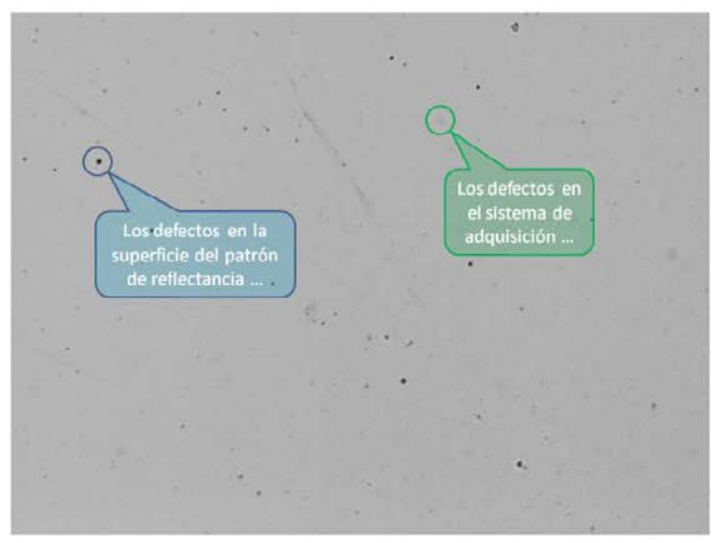

Detalle de la imagen de un campo del patrón de alta reflectancia

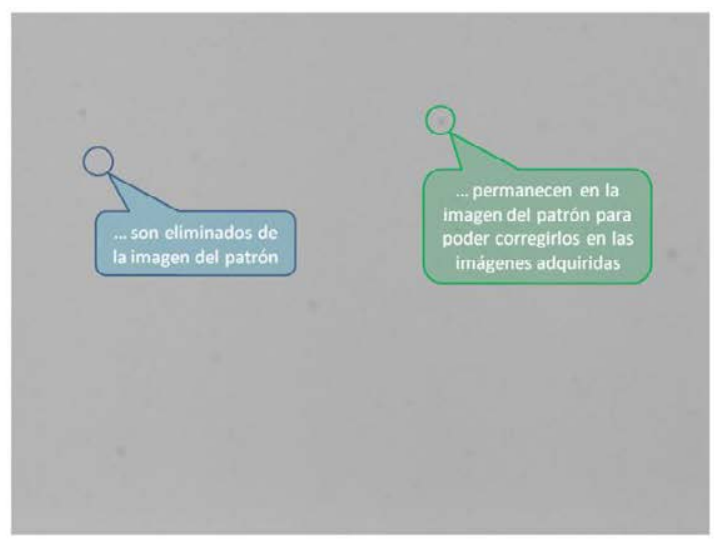

Detalle de la imagen procesada del patrón de alta reflectancia

Figura 4-21. Eliminación de defectos del patrón en el proceso de filtrado y promediado (propia) 
Para calibrar el instrumento adecuadamente es necesario emplear al menos dos patrones, que idealmente deberían tener reflectancias nominales próximas a los límites superior e inferior de la franja de reflectancias en la que se va a trabajar. No obstante, si se dispusiera de patrones adicionales con reflectancias nominales intermedias también sería posible aprovecharlos para afinar aún más la calibración.

Frente a la práctica habitual de calibrar un sistema de adquisición usando un solo patrón claro, o usando un patrón claro y una imagen de negro (adquirida simplemente impidiendo que llegue luz a la cámara) el uso de un patrón claro y un patrón oscuro permite caracterizar con mayor precisión el comportamiento real del sistema óptico de un microscopio de luz incidente, en particular en lo relativo a la luz reflejada y dispersada en las lentes del objetivo, que en buena medida es independiente de la reflectancia de la muestra.

En resumen, este procedimiento de calibración incorpora varias novedades: la imagen de un patrón se obtiene promediando un cierto número de imágenes adquiridas en distintos puntos, se aplica un algoritmo de promediado que filtra los defectos manifiestos del patrón, y se emplea un patrón de baja reflectancia (en lugar de una imagen de negro) además del patrón de alta reflectancia. Esta operación debe realizarse frecuentemente con cada uno de los objetivos utilizados, con el fin de mantener el instrumento perfectamente calibrado a pesar de la evolución temporal de la intensidad y de la distribución de la luz procedente de la fuente luminosa.

\subsubsection{Calibración geométrica del instrumento}

Al hacer las primeras tomas a través de los filtros pasabanda, se hizo evidente que las imágenes de las distintas bandas presentaban un registro incorrecto (Figura 4-22 izda.). Este defecto resulta especialmente problemático en los bordes de los granos, donde se producen efectos de halo que pueden dar lugar a identificaciones erróneas, con la consiguiente aparición de fases inexistentes.
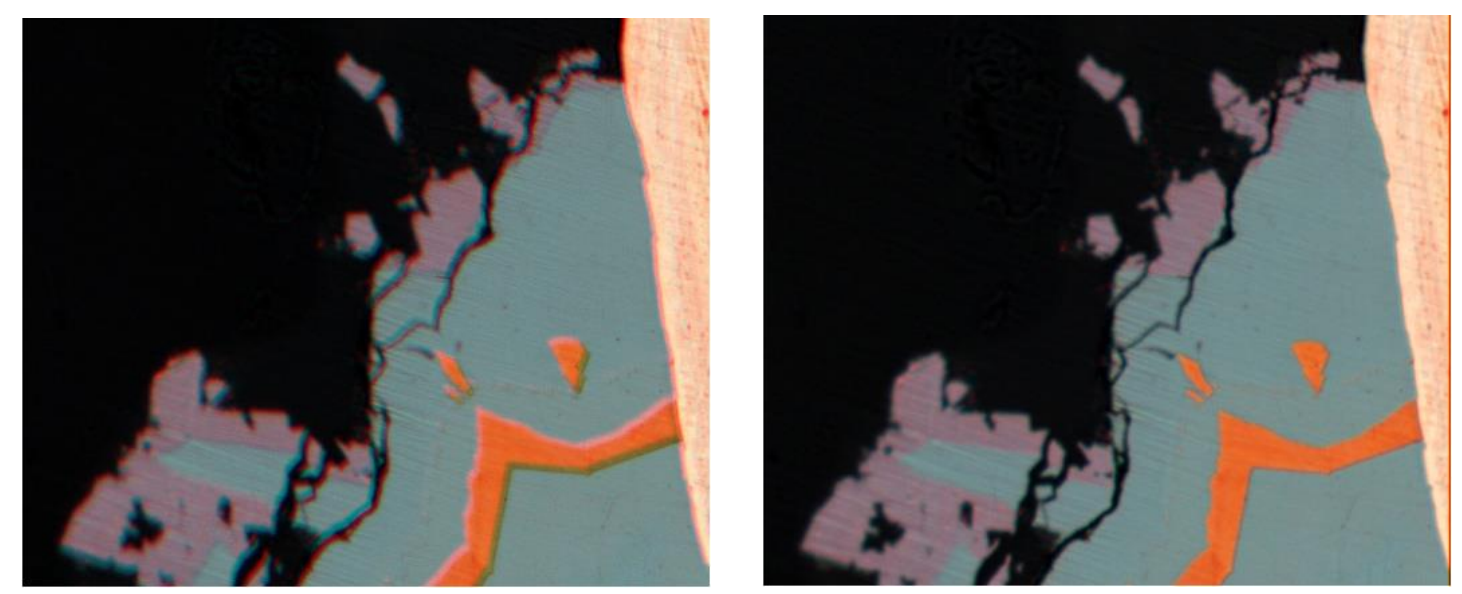

Figura 4-22. Imagen en falso color antes y después de aplicar corrección geométrica (detalle) 
Estudiando el comportamiento de los objetivos de las dos principales marcas de microscopios (Leica y Zeiss), se pudo comprobar que tanto la posición del centro óptico de la imagen (Figura 4-23) como la escala efectiva de ésta (Figura 4-24) varían con la longitud de onda de la luz.

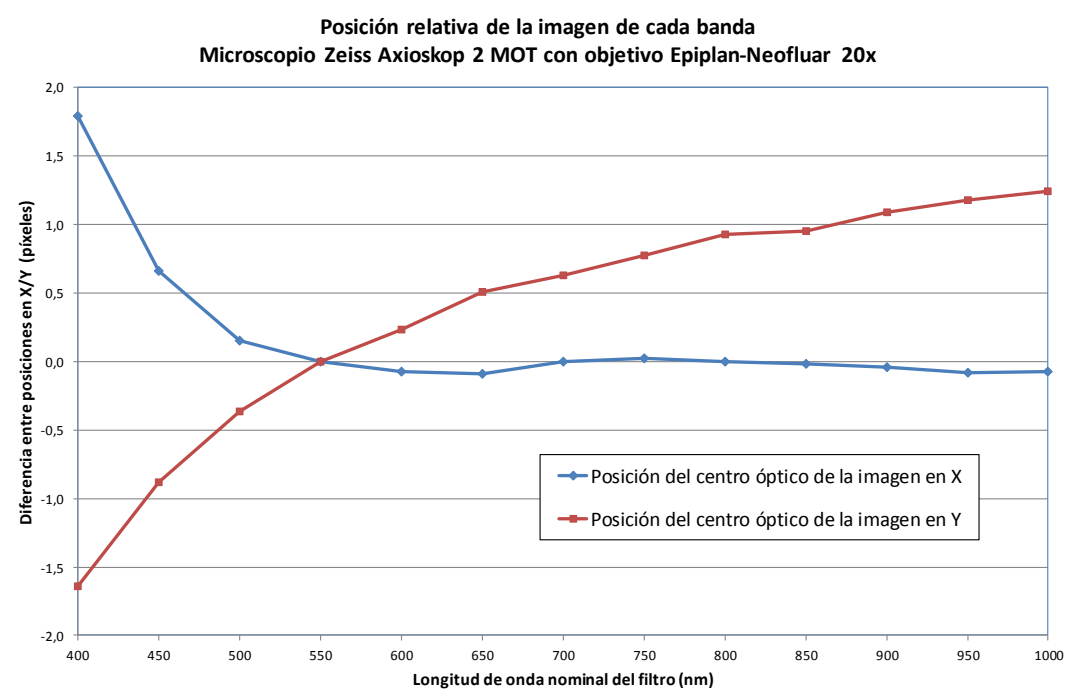

Figura 4-23. Curvas que recogen el desplazamiento del centro óptico entre las distintas bandas

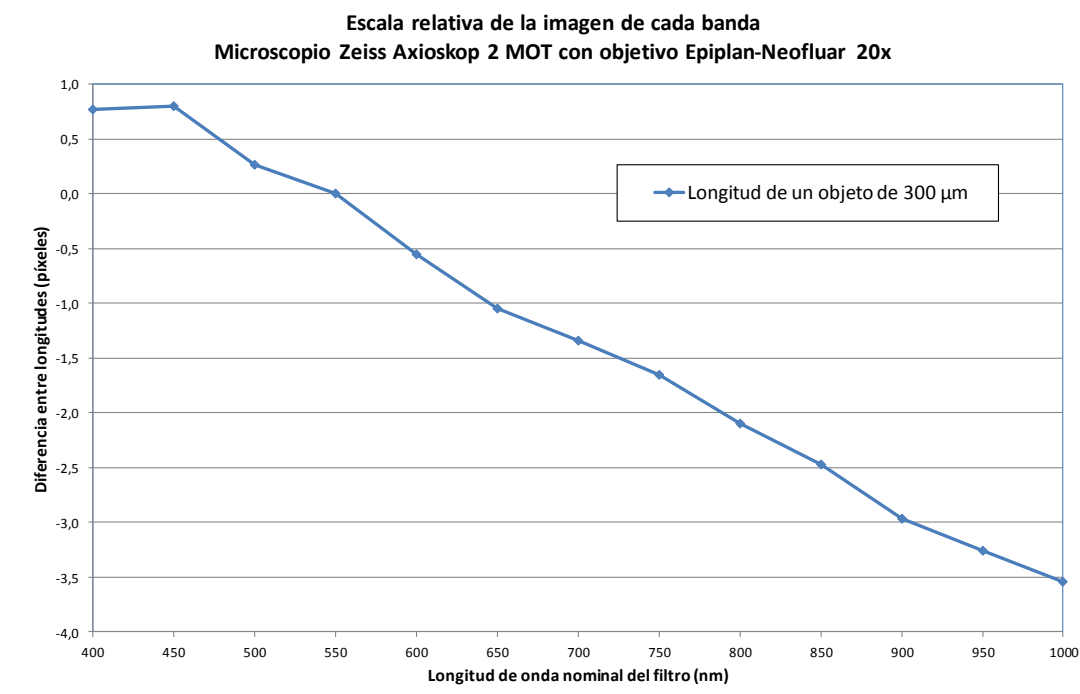

Figura 4-24. Curva que recoge la variación de la escala de la imagen entre las distintas bandas (realización propia)

Por este motivo, se ha desarrollado un novedoso procedimiento de calibración geométrica del instrumento que determina automáticamente las correcciones que hay que aplicar a cada banda para conseguir un registro perfecto (Figura 4-22 dcha.).

El procedimiento está basado en el uso de un "blanco" como el de la Figura 4-25, con una disposición reticular de puntos reflectantes de tamaño y separación conocidos, que debe ser colocado, enfocado y centrado en el campo visual del instrumento por el operador del sistema. 

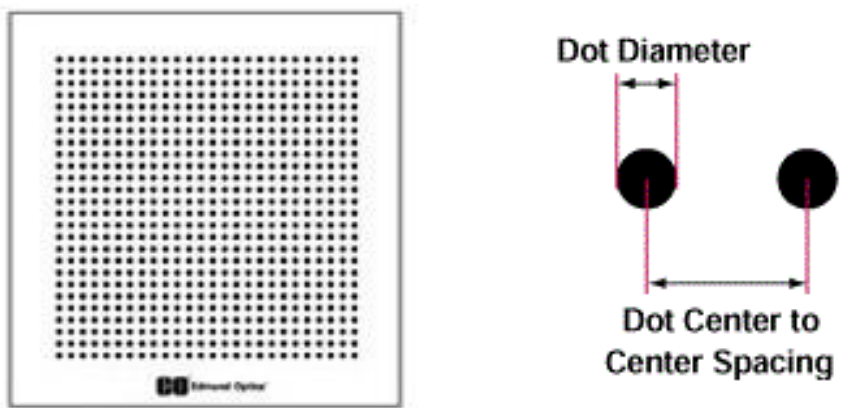

Figura 4-25. Blanco de vidrio para corrección de distorsión de 25 x 25mm (Edmund Optics, 2018)

Una vez hecho esto, el operador arranca el proceso de calibración propiamente dicho, que realiza las siguientes operaciones en cada una de las bandas: captura de la imagen del blanco, binarización de la imagen para aislar las zonas que destaquen del fondo (los puntos de la red y pequeños defectos del blanco), eliminación de las zonas que no cumplan ciertos límites de tamaño y distancia al borde de la imagen (para descartar los puntos situados en el borde y los defectos del blanco), selección de las cuatro zonas más próximas a las esquinas de la imagen, y extracción de las coordenadas de imagen de sus respectivos centros de gravedad ( $\left.\mathrm{X}_{\mathrm{CGi}}, \mathrm{Y}_{\mathrm{CGi}}\right)$.

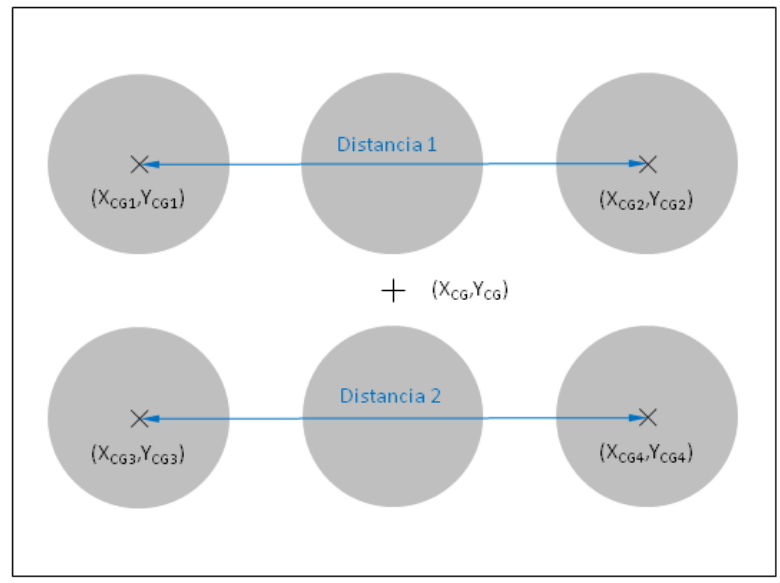

Figura 4-26. Calibración geométrica del sistema de adquisición mediante un blanco de puntos (realización propia)

A partir de ellas se determinan los parámetros finales de la calibración geométrica, que serán utilizados en el procedimiento desarrollado para la adquisición de una imagen multiespectral: el promedio $\left(\mathrm{X}_{\mathrm{GC}}, \mathrm{Y}_{\mathrm{CG}}\right)$ de los cuatro centros de gravedad será considerado como el centro de gravedad global de la imagen, que es asimilable al centro óptico, y el promedio de las distancias euclídeas entre los centros de gravedad 1 y 2 y entre los centros de gravedad 3 y 4 , junto con el conocimiento de la distancia de separación real entre dichos puntos, permitirán calcular la escala efectiva de la imagen. La Figura 4-26 muestra gráficamente el concepto de este proceso de 
calibración geométrica. Esta operación debe realizarse una sola vez con cada uno de los objetivos, por lo que el momento ideal para llevarla a cabo es durante la instalación del sistema, o tras el montaje de un objetivo nuevo.

Otro problema de tipo geométrico, aunque completamente diferente, es la existencia de un pequeño error de orientación entre los ejes del sensor de la cámara y los ejes de la platina motorizada, prácticamente inevitable debido a que el ajuste de la orientación de la cámara debe hacerse a mano. Aunque el ángulo suele ser inferior a dos grados y no tiene trascendencia en la adquisición de imágenes aisladas, sus consecuencias se hacen patentes al componer un mosaico con imágenes adquiridas en el barrido automático de una preparación (Figura 4-28 izda.), por lo que resulta aconsejable medirlo para poder corregirlo posteriormente (Figura 4-28 dcha.).

El procedimiento de calibración geométrica descrito anteriormente ha sido ampliado para incorporar una segunda etapa de proceso específicamente concebida para medir este ángulo de forma automática. En esta segunda etapa se ordena a la platina realizar un desplazamiento en el eje $\mathrm{X}$ de una magnitud similar a la distancia entre los puntos de las esquinas, para llevar un punto de un lado al lado contrario de la imagen, tras lo cual se determina su nuevo centro de gravedad sobre la imagen de una sola banda. El ángulo $\alpha$ entre los ejes de la platina y los de la cámara puede ser calculado como el arco tangente de los desplazamientos $\Delta \mathrm{X}$ y $\Delta \mathrm{Y}$ producidos. La Figura 4-27 muestra gráficamente el efecto producido al desplazar el blanco una cierta distancia hacia la derecha respecto a la situación de la Figura 4-26, así como el ángulo $\alpha$ determinado por los desplazamientos $\Delta \mathrm{X}$ y $\Delta \mathrm{Y}$ del centro de gravedad del punto inferior derecho (correspondiente al anterior centro de gravedad 3). Esta operación debe realizarse cada vez que se monte o se altere la posición de la cámara, pero sólo es necesario hacerla con uno de los objetivos.

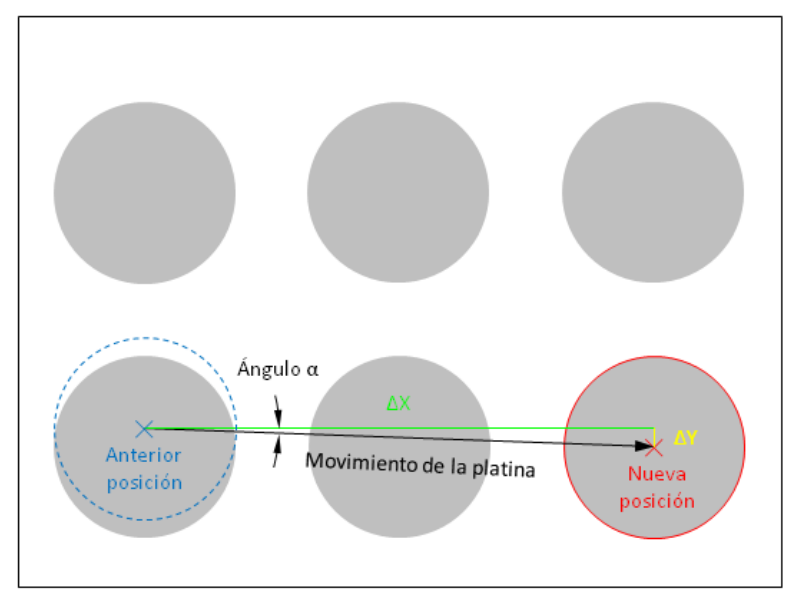

Figura 4-27. Calibración del ángulo de la cámara mediante el desplazamiento de los puntos del blanco (realización propia) 

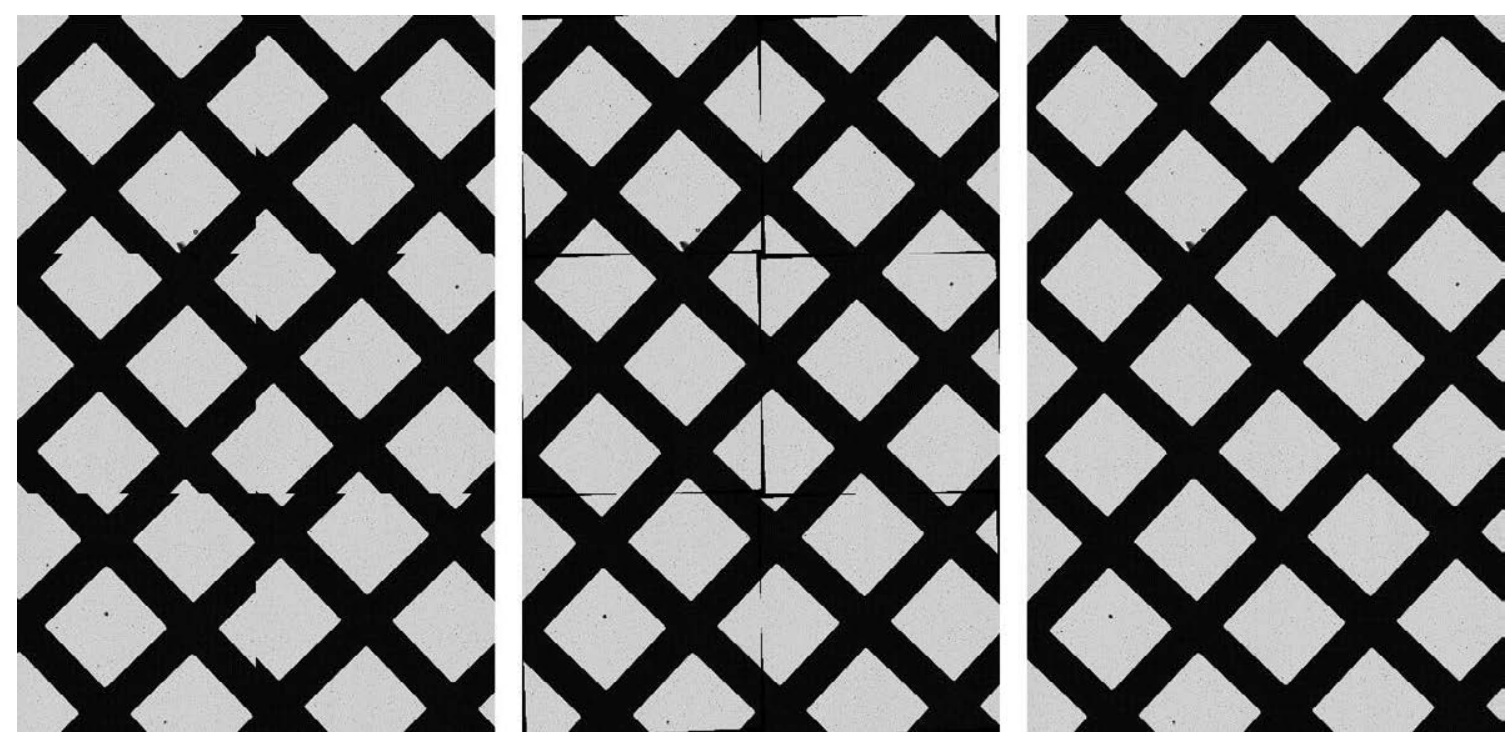

Figura 4-28. Mosaico de imágenes antes (izda.) y después (centro) de la corrección del error de orientación cámara-platina. A la derecha, tras el redimensionamiento de las imágenes rotadas. (realización propia)

\subsubsection{Adquisición de una imagen multiespectral}

Se ha desarrollado un procedimiento para obtener imágenes multiespectrales de una preparación microscópica en las que los valores de gris de cada píxel representan exactamente la reflectancia especular del correspondiente punto de la muestra en las distintas bandas consideradas. El procedimiento consiste en la adquisición de una imagen multiespectral "en bruto" empleando los tiempos de exposición y ajustes de posición de enfoque determinados previamente mediante los procedimientos 4.4.1 y 4.4.2, seguida de la aplicación sucesiva de dos correcciones: una corrección de la respuesta del instrumento, basada en las imágenes de los patrones de reflectancia adquiridas según el procedimiento 4.4.3, y una corrección geométrica, basada en los parámetros determinados en el procedimiento 4.4.4.

La adquisición de la imagen multiespectral "en bruto" se lleva a cabo mediante un proceso en el que se van obteniendo sucesivamente imágenes de 16 bits por píxel de cada una de las bandas consideradas, tras fijar el tiempo de exposición de la cámara, aplicar el ajuste de posición de enfoque y seleccionar el filtro de la rueda que corresponden a cada una de ellas. Dado que la cámara ya proporciona imágenes de 12 bits por píxel, para conseguir imágenes de 16 bits por píxel se puede optar por acumular 16 cuadros consecutivos de la cámara o por desplazar el acumulador 4 bits a la izquierda, en función de las necesidades de velocidad de adquisición y precisión del resultado. También puede optarse por una solución intermedia, como acumular 4 cuadros y desplazar el acumulador 2 bits a la izquierda, por ejemplo. 
A continuación, se efectúa la corrección de la respuesta del instrumento, en la que se determina la reflectancia correspondiente a cada uno de los píxeles mediante la interpolación (o incluso extrapolación) de su nivel de gris entre los niveles de gris que presente dicho píxel en las imágenes de dos patrones, según la fórmula siguiente:

$$
G_{i}(j, k)=\frac{1}{f_{R}}\left(R_{L i}+\frac{F_{i}(j, k)-P_{L i}(j, k)}{P_{H i}(j, k)-P_{L i}(j, k)}\left(R_{H i}-R_{L i}\right)\right)
$$

Donde:

$G_{i}(j, k)$ es la reflectancia del píxel $(\mathrm{j}, \mathrm{k})$ de la banda i de la imagen corregida del campo

$f_{R}$ es el factor de conversión de nivel de gris a reflectancia especular

$F_{i}(j, k)$ es el nivel de gris del píxel $(\mathrm{j}, \mathrm{k})$ de la banda i de la imagen "en bruto" del campo

$P_{H i}(j, k)$ es el nivel de gris del píxel (j, k) de la banda i del patrón de alta reflectancia

$P_{L i}(j, k)$ es el nivel de gris del píxel $(\mathrm{j}, \mathrm{k})$ de la banda i del patrón de baja reflectancia

$R_{H i}$ es la reflectancia especular del patrón de alta reflectancia en la banda i

$R_{L i}$ es la reflectancia especular del patrón de baja reflectancia en la banda i

Para acelerar el cálculo, esta fórmula puede reordenarse de forma que sólo sea necesario realizar dos operaciones aritméticas de imagen (una resta y una división):

$$
G_{i}(j, k)=\frac{F_{i}(j, k)-N_{i}(j, k)}{D_{i}(j, k)}
$$

Donde

$$
N_{i}(j, k)=P_{L i}(j, k)-\frac{R_{L i}}{R_{H i}-R_{L i}}\left(P_{H i}(j, k)-P_{L i}(j, k)\right)
$$

y

$$
D_{i}(j, k)=\frac{f_{R}}{R_{H i}-R_{L i}}\left(P_{H i}(j, k)-P_{L i}(j, k)\right)
$$

son imágenes constantes que pueden ser calculadas con antelación. 
De esta forma, la imagen "en bruto" se transforma eficientemente en una nueva imagen, en la que el nivel de gris de cada pixel representa directamente la reflectancia de la muestra (aplicando el factor de conversión $f_{R}$ deseado), con lo que se corrigen de forma efectiva la falta de uniformidad de la iluminación del campo microscópico y los posibles defectos del sistema óptico en las distintas bandas espectrales. La imagen corregida mantiene la resolución original de 16 bits por píxel, pero suele truncarse a 8 bits para reducir el espacio ocupado en disco, si no se requiere una alta resolución en la medida de reflectancia.

Finalmente se aplica a esta imagen una corrección geométrica derivada de la calibración geométrica del instrumento que se realizó tras la instalación del sistema. Esta corrección consiste básicamente en la aplicación sucesiva de un desplazamiento, un escalado y otro desplazamiento a cada banda de la imagen, de forma que todas ellas pasen a tener el mismo centro que la banda seleccionada como referencia y la escala física prefijada para la imagen final (especificada en $\mu \mathrm{m} /$ píxel). Además, se corrige el error de orientación entre los ejes de la cámara y los ejes de la platina mediante la rotación de la imagen un ángulo igual y de sentido opuesto al medido en la calibración. Todas estas transformaciones pueden ser realizadas en un único paso mediante una operación de proceso digital de imagen denominada "warping", lo que acelera considerablemente el proceso.

La aplicación de este novedoso procedimiento permite obtener imágenes microscópicas multiespectrales de alta calidad expresadas en unidades de reflectancia absoluta, con un perfecto registro de las distintas bandas, que además presentan una escala geométrica prefijada y cuyos ejes son paralelos a los ejes de la platina, por lo que resulta muy fácil referenciar puntos y construir mosaicos a partir de ellas. Estas imágenes podrán ser luego utilizadas para identificar la fase correspondiente a cada píxel, y establecer la composición, distribución, granulometría, etc. de las distintas fases.

Las imágenes multiespectrales obtenidas pueden ser convertidas a imágenes en color RGB o en otras coordenadas de color, con el fin de reproducir el color real de cada fase observada al microscopio para aplicaciones de documentación fotomicrográfica, evitando las desviaciones ligadas a la subjetividad del observador o a variaciones instrumentales introducidas por las cámaras en color convencionales. Por ejemplo, combinando las bandas de 400 y $450 \mathrm{~nm}$ para obtener la banda azul, las bandas de 500 y $550 \mathrm{~nm}$ para obtener la banda verde, y las bandas de 600 y $650 \mathrm{~nm}$ para obtener la banda roja se consiguen imágenes RGB con un color muy natural.

La Figura 4-29 muestra las 13 bandas de la imagen multiespectral de un campo microscópico, así como la banda pancromática y la conversión a imagensintética en color RGB. 

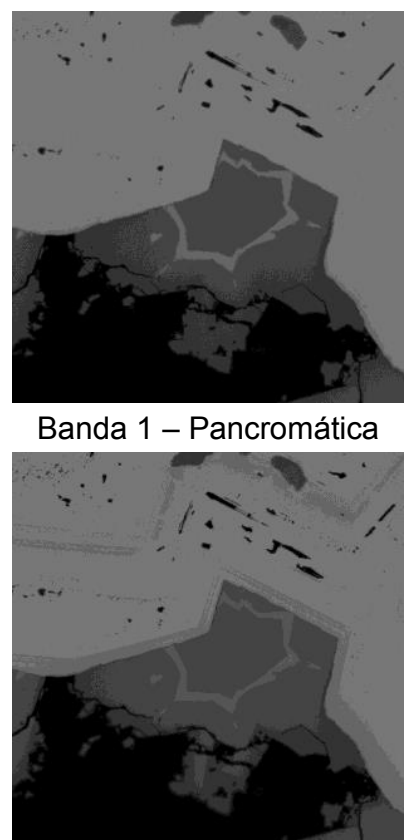

Banda $4-500 \mathrm{~nm}$

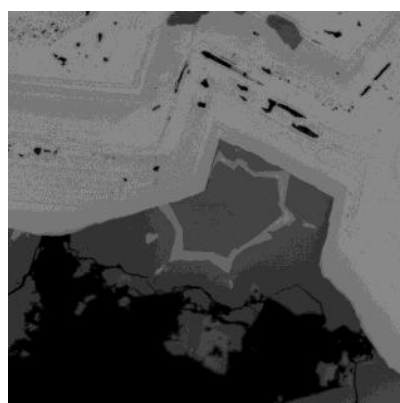

Banda $7-650 \mathrm{~nm}$

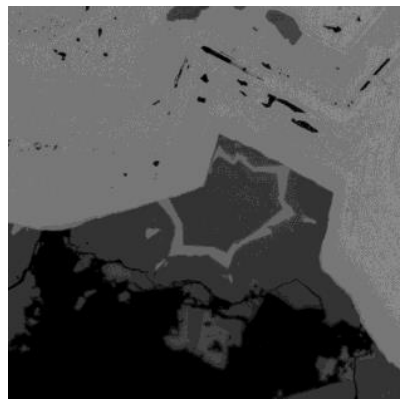

Banda $10-800 \mathrm{~nm}$

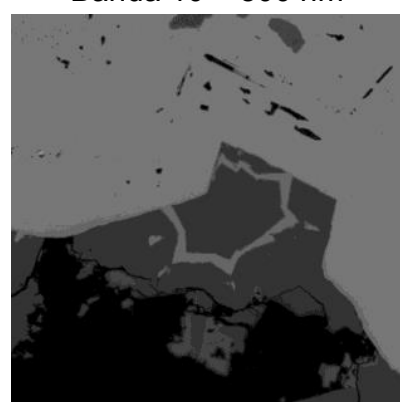

Banda $13-950 \mathrm{~nm}$

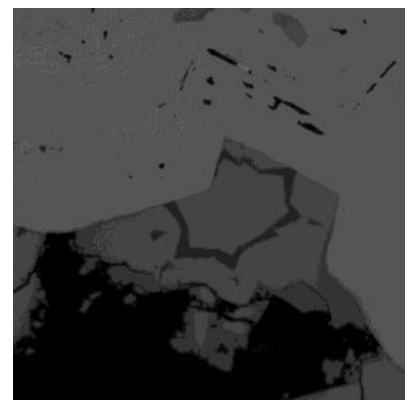

Banda $2-400 \mathrm{~nm}$

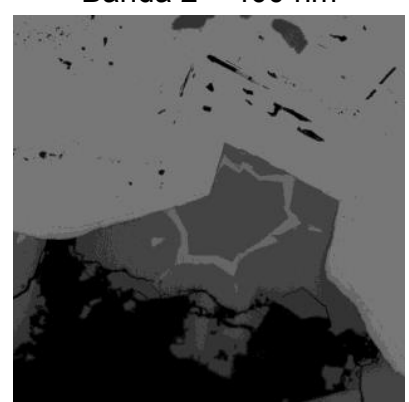

Banda $5-550 \mathrm{~nm}$

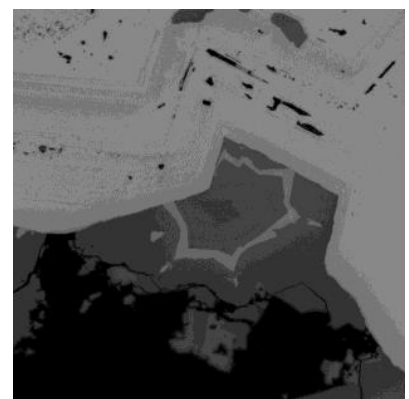

Banda $8-700 \mathrm{~nm}$

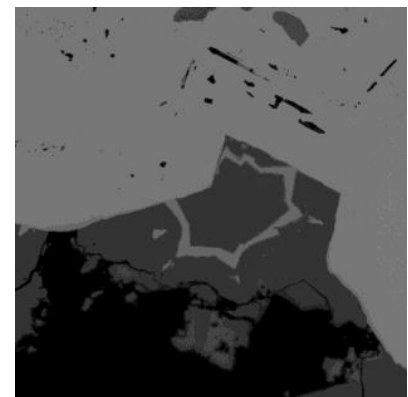

Banda $11-850 \mathrm{~nm}$

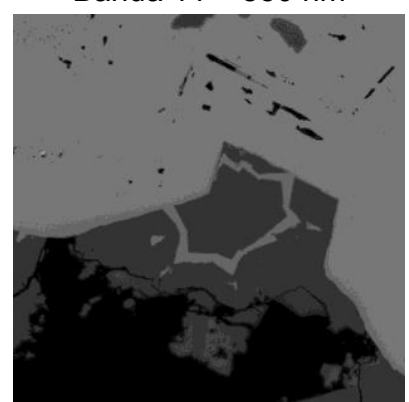

Banda $14-1000 \mathrm{~nm}$

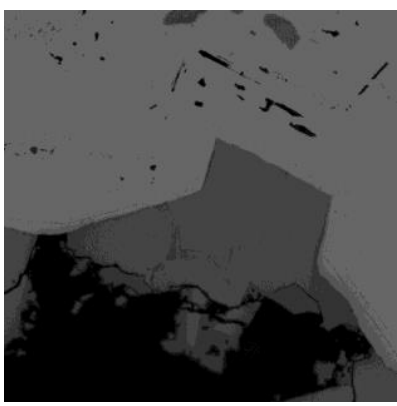

Banda $3-450 \mathrm{~nm}$

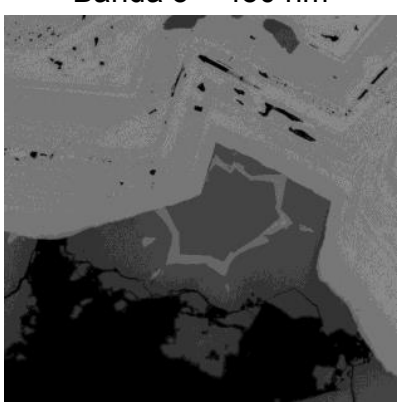

Banda $6-600 \mathrm{~nm}$

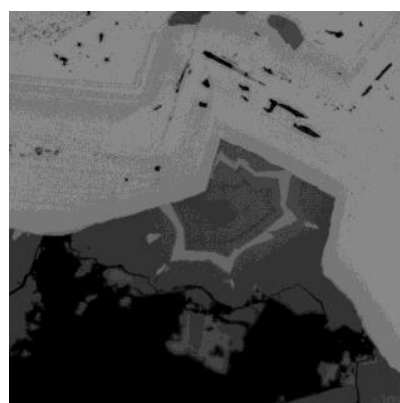

Banda $9-750 \mathrm{~nm}$

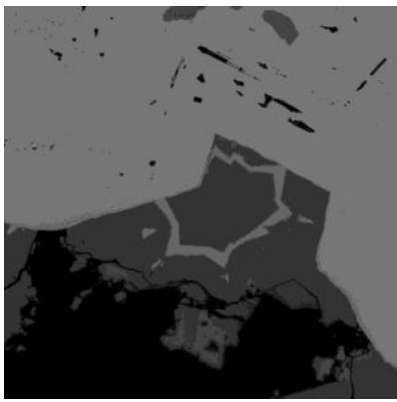

Banda $12-900 \mathrm{~nm}$

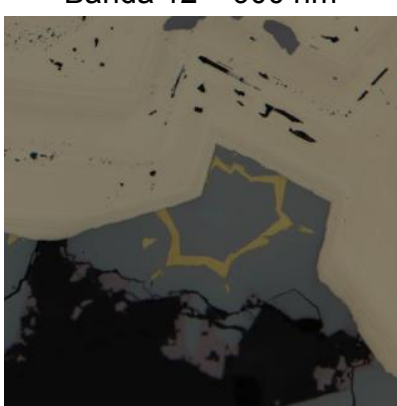

RGB en falso color

Figura 4-29. Ejemplo de imagen multiespectral adquirida por el sistema CAMEVA, formada por 13 bandas adquiridas a intervalos de $50 \mathrm{~nm}$ entre 400 y $1000 \mathrm{~nm}$. Se incluye la banda pancromática y una vista en color RGB obtenida combinando las bandas de 400 a $650 \mathrm{~nm}$. (realización propia) 
Conviene destacar que un procedimiento equivalente puede ser aplicado para la adquisición de imágenes multiespectrales de transmitancia absoluta mediante un microscopio óptico de luz transmitida modificado de una forma parecida: tan sólo es necesario reemplazar las referencias a reflectancia por transmitancia. Por ejemplo, para calibrar la respuesta del instrumento se emplearían patrones de transmitancia, en lugar de patrones de reflectancia, pero por lo demás el procedimiento seguido sería el mismo. Este procedimiento ha sido aplicado por AITEMIN para la adquisición de imágenes en color de preparaciones histológicas en el marco de un convenio de colaboración con la Universidad de Castilla La Mancha.

\subsubsection{Barrido automático de una preparación}

Se ha desarrollado un procedimiento para adquirir automáticamente una serie de imágenes multiespectrales de una sección pulida, mediante el barrido de una zona rectangular de su superficie con un porcentaje de cobertura dado. La zona rectangular que se desea barrer es seleccionada por un operario mediante la indicación de dos vértices opuestos. A continuación, se realiza el enfoque (manualmente, por el operario, o de forma automática, por el sistema) de siete campos distribuidos por la zona (Figura 4-30), a partir de los cuales se determina un plano de regresión del enfoque que será utilizado para interpolar la coordenada $\mathrm{Z}$ de enfoque (o de predicción de enfoque) para la adquisición de cada campo.

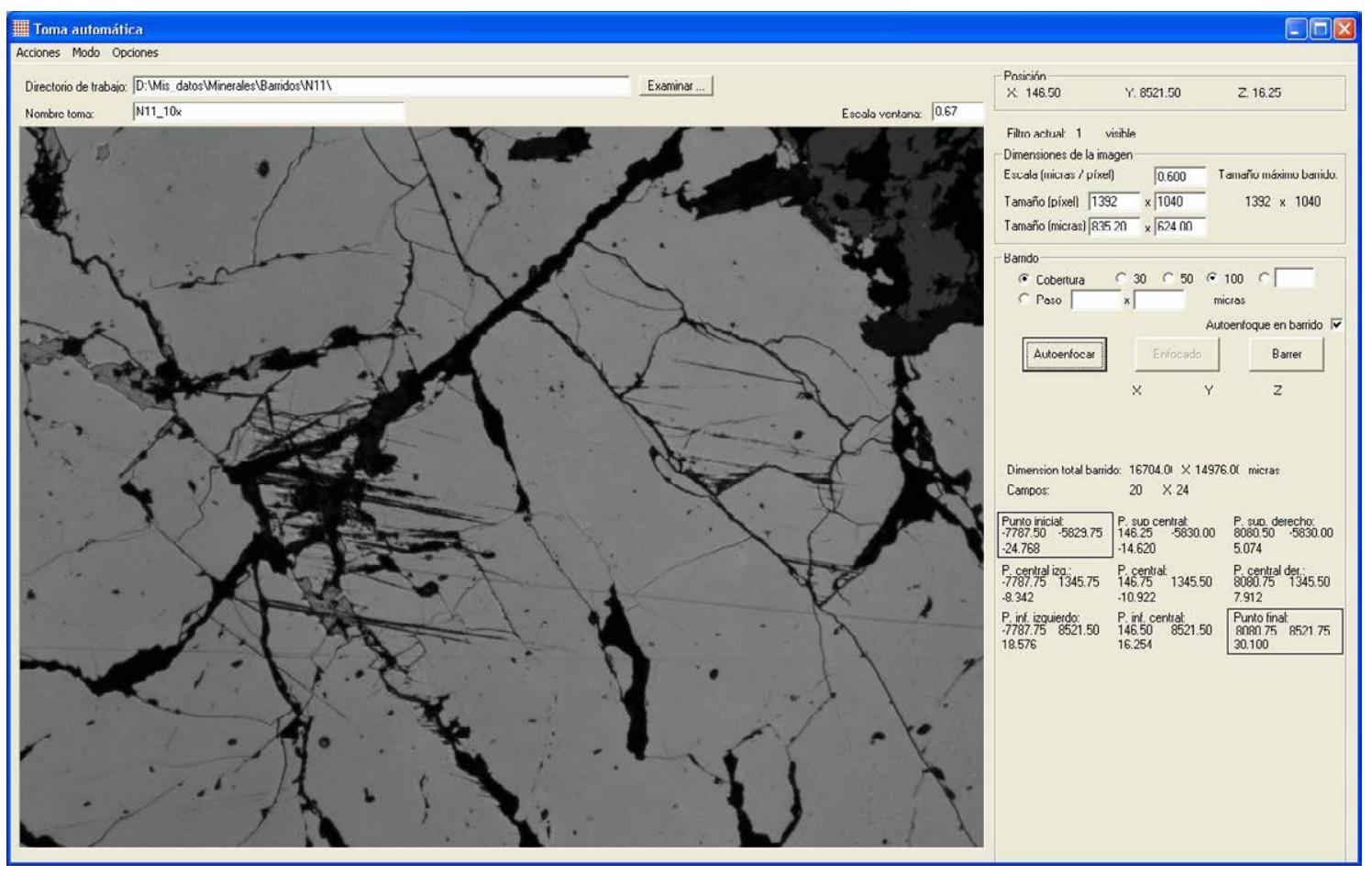

Figura 4-30. Captura de la pantalla de barrido automático tras el enfoque de los campos iniciales 
Una vez hecho esto, la unidad de control y proceso comienza a ejecutar una secuencia automática de adquisición de imágenes que efectúa un barrido de la zona seleccionada de la preparación con el porcentaje de cobertura especificado, enfocando automáticamente cada campo (opcionalmente) y adquiriendo una imagen multiespectral de reflectancia en cada uno, que se almacena en una carpeta de disco en la unidad de control y proceso (Figura 4-31).

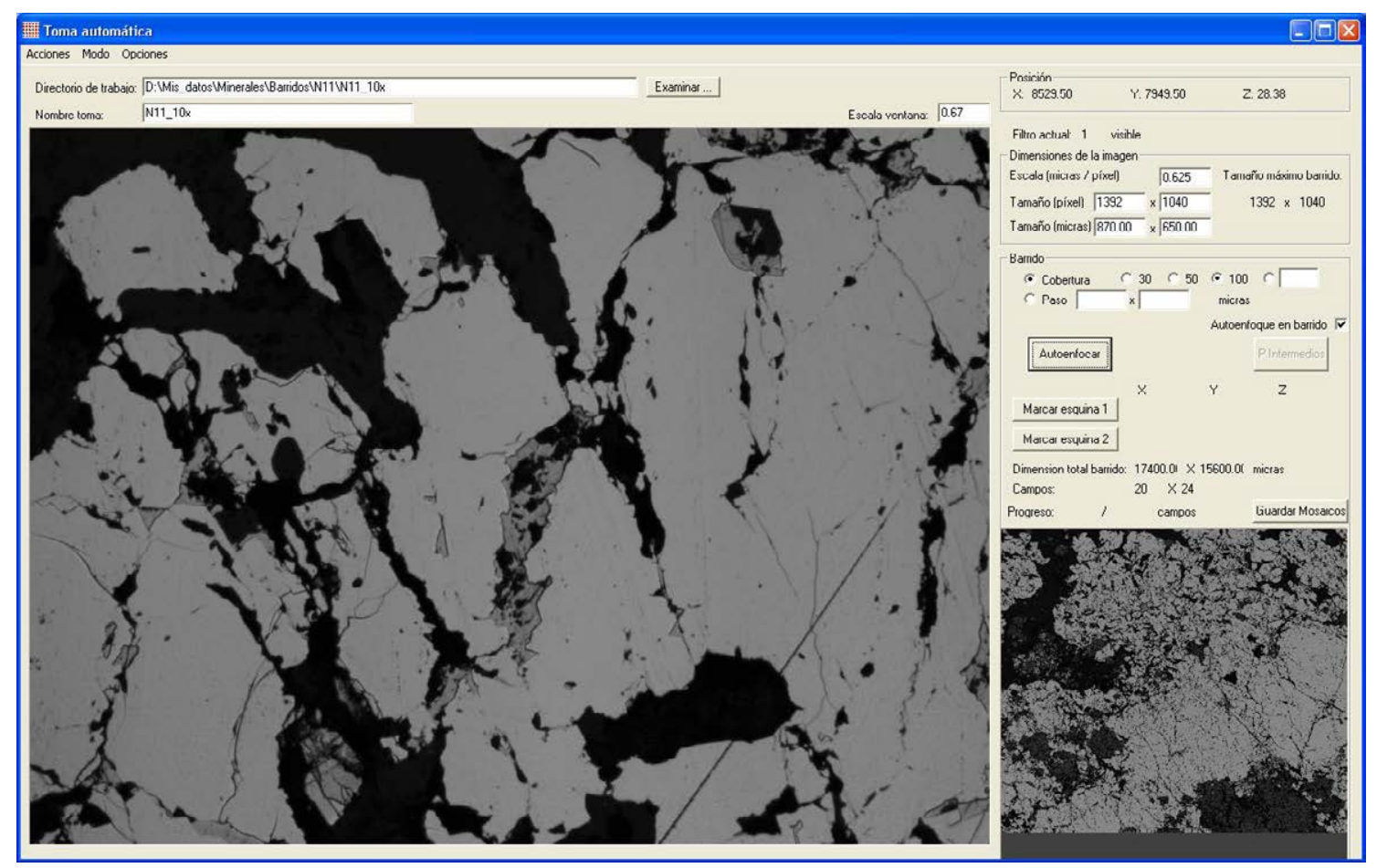

Figura 4-31. Captura de la pantalla de barrido automático tras barrer una preparación

\subsubsection{Comprobación de la calibración}

Se ha desarrollado un procedimiento para comprobar si la calibración actual de la respuesta del instrumento sigue siendo válida o, por el contrario, el instrumento debe ser recalibrado. Para ello es necesario situar en la platina el patrón de alta reflectancia especular, enfocarlo, y pulsar el botón de comprobación. Ello desencadena la secuencia operativa siguiente:

i. Adquisición y corrección de una imagen multiespectral de la superficie del patrón.

ii. Evaluación del histograma de la imagen de 16 bits en cada una de las bandas

iii. Determinación de la media de los valores de reflectancia de cada imagen a partir de su histograma

iv. Reducción del número de valores del histograma a 12 bits, y filtrado gaussiano del histograma de 12 bits resultante 
v. Determinación de la moda de los valores de reflectancia sobre el histograma filtrado

vi. Comparación de los valores de reflectancia medidos con los valores de reflectancia teórica de las distintas bandas para ver si difieren en más del valor prefijado

vii. Representación en pantalla de los errores encontrados y del diagnóstico final

Es recomendable que el operador del sistema CAMEVA realice esta comprobación periódicamente, y siempre antes de una adquisición, para confirmar que el sistema está correctamente calibrado (Figura 4-32).

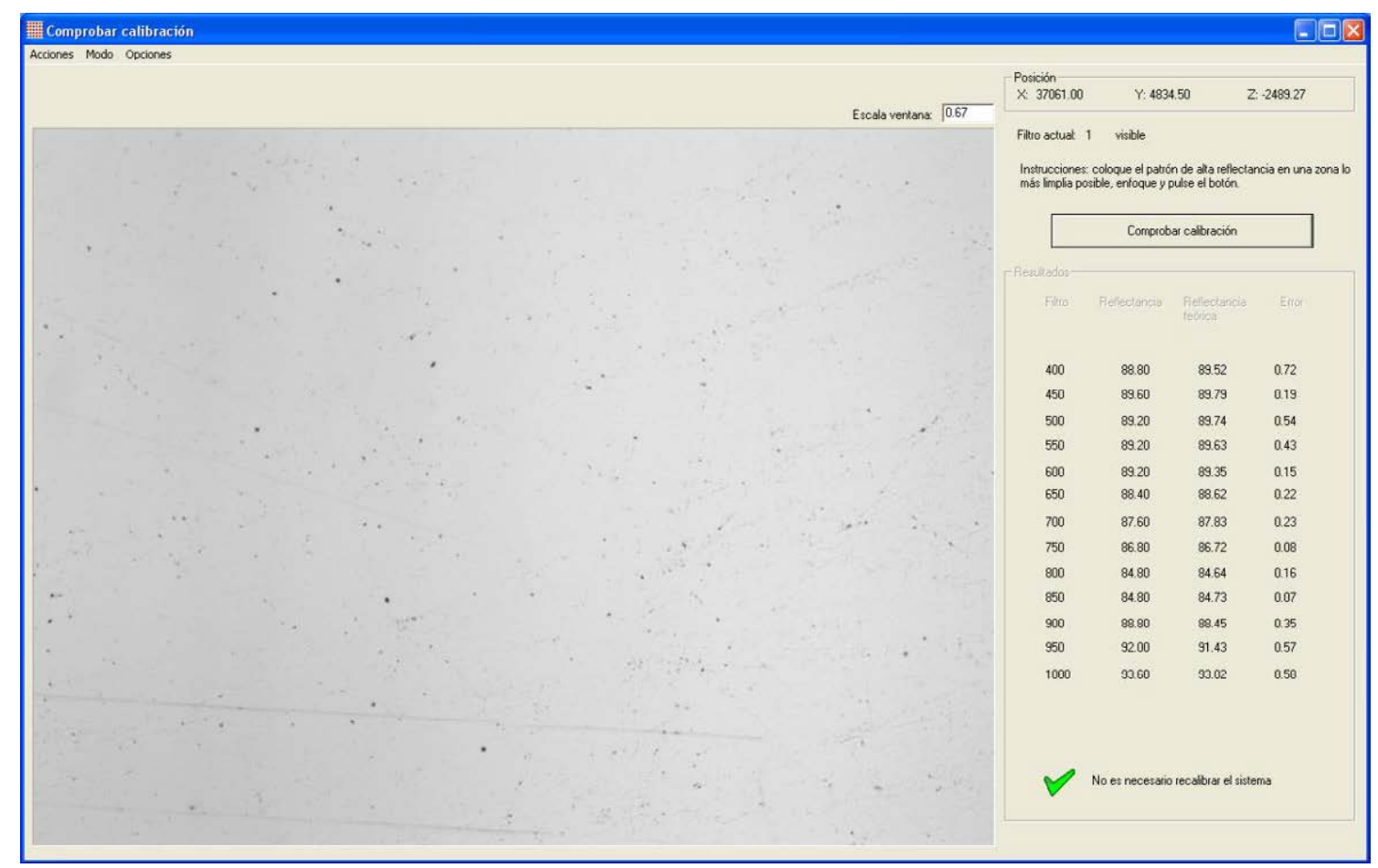

Figura 4-32. Captura de la pantalla de comprobación de la calibración

Igualmente es aconsejable realizarla al terminar una serie de adquisiciones manuales, así como al concluir un barrido, para confirmar que el sistema no ha derivado en exceso durante el tiempo que haya durado la adquisición. Si el sistema hubiera dejado de estar calibrado, se debería valorar la conveniencia de repetir la adquisición tras una recalibración.

\subsection{INTEGRACIÓN DE PROTOTIPOS DEL SISTEMA}

En el proyecto CAMEVA se han integrado dos prototipos del equipo, basados en sendos microscopios de los dos principales fabricantes. El prototipo del LMAAI (Laboratorio de Microscopía Aplicada y Análisis de Imagen, en la Escuela Técnica Superior de Ingenieros de Minas y Energía de Madrid, UPM) está basado en un microscopio Leica de gama alta totalmente 
motorizado, mientras que el del Centro Tecnológico AITEMIN aprovecha un microscopio Zeiss de gama media que sólo tiene motorizados el enfoque y la platina, por lo que precisa la intervención del operador para cambiar de objetivo o de cubo reflector.

\subsubsection{Prototipo del LMAAI}

El equipo del LMAAI está integrado por los siguientes elementos:

- El instrumento es un microscopio de luz reflejada Leica modelo DM6000 M, con los siguientes elementos:

○ Fuente luminosa ajustable LH $106 Z$ para lámpara halógena 12V 100W

- Eje automatizado de luz incidente (con rueda de diafragmas de campo de seis posiciones: cuatro dotadas de polarizadores a $0^{\circ}, 45^{\circ}, 90^{\circ}$ y $135^{\circ}$, y dos posiciones sin polarizador)

- Torreta motorizada para cuatro cubos reflectores, con 3 cubos: BF ("Bright Field" - campo claro), Smith (prisma de Smith), y para ajuste de iluminación.

○ Tubo de visión y documentación BDT 25+ V100/50/0

○ Oculares HC PLAN S 10x/22 Br. M

- Suplemento de tubo con una salida de documentación

- Adaptador para cámara rosca C HC 0.70x

- Revólver para 6 objetivos motorizado, con los siguientes objetivos:

- Objetivo PL Fluotar 20x/0.45 P

- Objetivo PL Fluotar 10x/0.25 P

- Objetivo PL Fluotar 5x/0.12 P

- Objetivo N Plan 2.5x/0.07 Pol

○ Platina motorizada BM, $72 \times 38 \mathrm{~mm}$

- A este microscopio se le han realizado las siguientes modificaciones (Figura 4-33):

i. Sustitución del filtro antitérmico "hot mirror" estándar de la fuente luminosa por uno "custom" fabricado expresamente para el sistema, que permite el paso de luz con longitudes de onda entre 300 y $1300 \mathrm{~nm}$ y refleja el resto, incluyendo el calor, hacia el interior del iluminador (Figura 4-16).

ii. Retirada del filtro polarizador existente a la entrada del cubo reflector BF, para trabajar con luz no polarizada.

iii. Sustitución del adaptador para cámara rosca C HC 0.70x (con lentes) por un adaptador para cámara de rosca C HC 1x (sin lentes). 
iv. Incorporación de una cámara de vídeo monocroma Basler Scout scA1400-17fm, con sensor CCD de 2/3” Sony ICX285AL de 1392 x 1040 píxeles, interfaz digital IEEE 1394b (FireWire b) y montura de rosca C. Su gran tamaño de píxel $(6,45$ x $6,45 \mu \mathrm{m})$ proporciona un rango dinámico real de 11,2 bits $(67,5 \mathrm{~dB})$. La curva de respuesta del sensor (Figura 4-5) revela que es especialmente adecuado para adquirir imágenes en el visible y en el infrarrojo cercano hasta $1000 \mathrm{~nm}$.

v. Incorporación de una rueda de filtros DTA RPF Max-16, montada entre el iluminador y el microscopio, controlada mediante un puerto serie RS232. En ella se han montado 13 filtros de interferencia Melles Griot de Ø $25 \mathrm{~mm}$, con longitudes de onda nominales (CWL) de 400, 450, 500, 550, 600, 650, 700, 750, 800, 850, 900, 950 y $1000 \mathrm{~nm}$, ancho de banda (FWHM) $40 \mathrm{~nm}$ y transmitancia mínima del 50\% (Figura 4-7). Además, en la primera posición se ha colocado una combinación pancromática, compuesta por un filtro KG3 y otro de densidad neutra ND0.9, que permite al operador observar la muestra a través de los oculares sin deslumbrarse.

vi. Incorporación de un tramo de tubo de $60 \mathrm{~mm}$ para separar el iluminador de la rueda de filtros, con la que interfería por limitaciones de espacio.

vii. Sustitución de la platina motorizada original por una platina motorizada de precisión Märzhäuser SCANplus. Se trata de una platina de alta calidad, utilizable con luz transmitida o reflejada, adaptable a múltiples marcas de microscopio, con las siguientes características:

- Rango de movimiento: 100 x $100 \mathrm{~mm}(4 "$ x 4")

- Repetibilidad: $\leq 0,2 \mu \mathrm{m}$ (unidireccional, a lo largo de todo el rango)

- Precisión: $\pm 1 \mu \mathrm{m}$ (medición conforme a VDI / DGQ 3441)

- Resolución: 0,05 $\mu \mathrm{m}$ (tamaño del paso más pequeño)

- Ortogonalidad: $<10$ segundos de arco

- Motor: Motor paso a paso de 2 -fases

- Velocidad máxima: $240 \mathrm{~mm} / \mathrm{s}$, con husillo de bolas de paso $4 \mathrm{~mm}$

- Fines de carrera: ópticos, de haz luminoso

- Material: aluminio

- Acabado: recubrimiento anódico, lacado en negro

- Peso: 4,6 kg

Esta platina se controla desde una tarjeta Tango PCI-S montada en la unidad de control y proceso. 

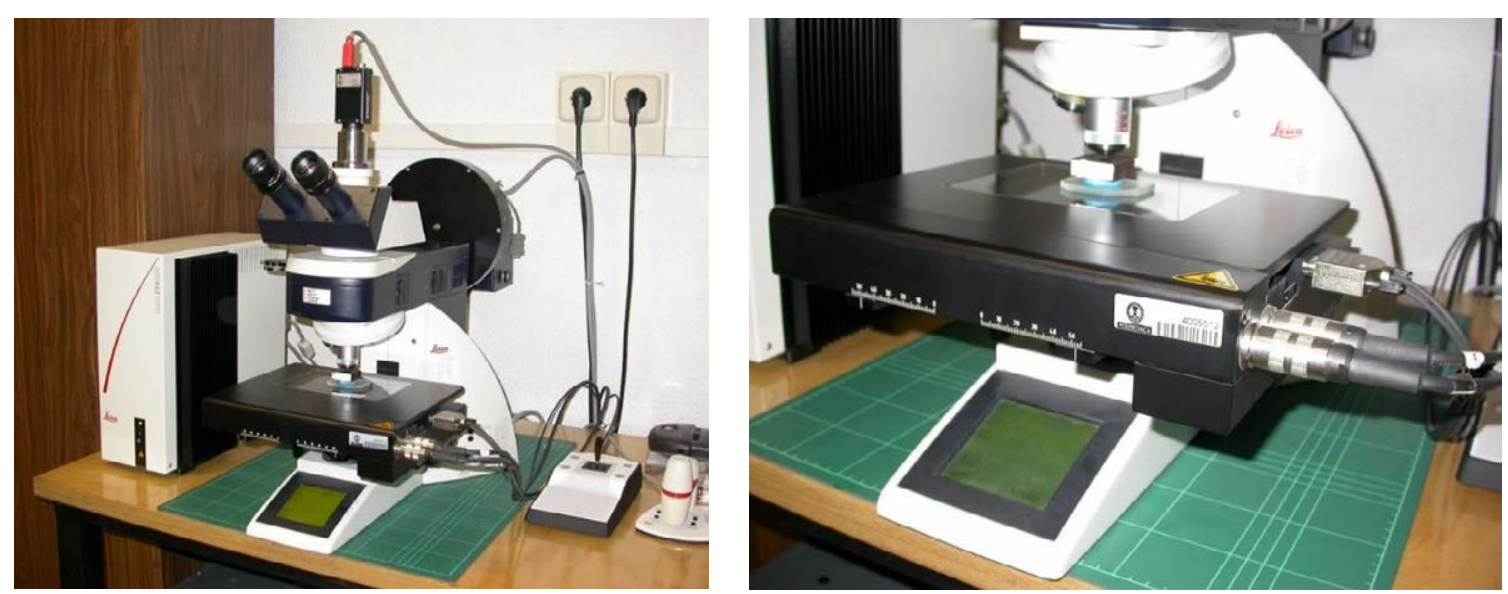

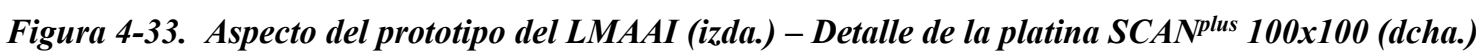

- Otros elementos auxiliares de gran importancia para el correcto funcionamiento del sistema son:

i. Patrones de reflectancia. Para la calibración se emplea dos patrones de reflectancia especular de la firma Ocean Optics (Figura 4-34), uno de alta reflectancia (referencia STAN-SSH, fabricado en sílice fundida con recubrimiento de aluminio, con $\mathrm{R} \approx 89 \%$ ) y otro de baja reflectancia (referencia STAN-SSL, fabricado en vidrio negro, con $\mathrm{R} \approx 4,5 \%$ ). Ambos cuentan con su correspondiente curva de calibración, lo que ha permitido calcular con exactitud su reflectancia promedio en cada una de las bandas.
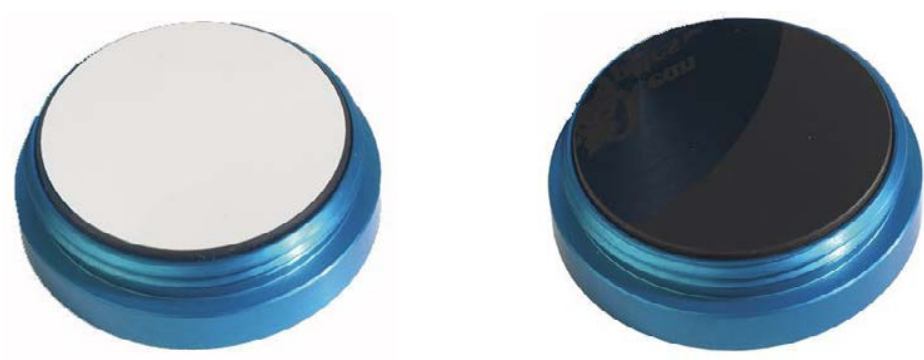

Figura 4-34. Patrones de reflectancia especular STAN-SSH (izda.) y STAN-SSL (dcha.) (Ocean Optics)

ii. Patrón geométrico. Se emplea un divisor de haz 50/50 del tipo "polka-dot" (referencia \#46-461 de Edmund Optics) o un dot grid target para corrección de distorsión (referencia \#58-509 de Edmund Optics), que por sus características constructivas (placa transparente sobre la que se ha depositado una matriz bidimensional de puntos reflectantes) resultan adecuados para realizar la calibración geométrica del sistema con objetivos de 5x a 20x. 
- La unidad de control y proceso es un ordenador Dell Precision 390 con sistema operativo Windows XP 32-bit al que están conectados los elementos del instrumento (microscopio, cámara, rueda de filtros y platina) y que ejecuta una aplicación de software especialmente desarrollada para operar el sistema de acuerdo con el método operativo descrito anteriormente. La cámara tiene una interfaz Firewire 1394b, que requiere la instalación de una tarjeta adaptadora Firewire para la conexión del cable de la cámara al ordenador. La tarjeta seleccionada para esta tarea fue la MATROX Meteor2 1394, una tarjeta PCI dotada internamente de un conector de alimentación tipo disco que permite alimentar la cámara desde la fuente de alimentación del ordenador. El ordenador dispone de una gran pantalla de 24 pulgadas con una resolución de $1920(\mathrm{H})$ x 1200 (V) píxeles que permite visualizar con todo detalle las imágenes adquiridas por el sistema, y de dos discos duros de 300 GB en configuración RAID 1.

\subsubsection{Prototipo de AITEMIN}

El equipo de AITEMIN está integrado por los siguientes elementos:

- El instrumento es un microscopio Zeiss modelo Axioskop 2 MOT, con estativo para luz transmitida e incidente, sistema de enfoque macro/micrométrico HARMONIC DRIVE de mayor precisión y libre de retroceso, motorizado y gobernable también en modo manual, con los siguientes elementos:

○ Iluminador HAL 100 para lámpara halógena $12 \mathrm{~V} 100 \mathrm{~W}$, compuesto por carcasa, colector y reflector.

- Rueda de filtros MOT de 8 posiciones para filtros de $25 \mathrm{~mm}$, en la que se han montado cuatro polarizadores a $0^{\circ}, 45^{\circ}, 90^{\circ}$ y $135^{\circ}$

- Sistema de epiiluminación con diafragma de apertura y diafragma de epicampo

- Revólver portafiltros de 5 posiciones, con modulo reflector estándar, módulo reflector para fluorescencia y modulo reflector Pol P\&C.

- Fototubo binocular ergonómico con altura graduable de 6 a $25^{\circ}$ (triocular) para Foto/Video con reparto de luz (100 vis:100 doc) y campo visual de $23 \mathrm{~mm}$

○ Oculares WPL 10x/23 Br. foc.

- Adaptador vídeo 60-C 1"1.0x (sin lentes)

- Revólver de objetivos 6x H W 0.8 Cod, con varios objetivos Epiplan-Neofluar (ultraplanos de fluoruro de Lantano), para luz incidente en campo claro:

- Objetivo EC Epiplan-Neofluar 20x/0.5 Pol

- Objetivo EC Epiplan-Neofluar 10x/0.25 Pol

- Objetivo EC Epiplan-Neofluar 5x/0.13 Pol 
- Objetivo Epiplan-Neofluar 20x/0.5 Oil Pol

- Objetivo Epiplan-Neofluar 50x/1.0 Oil Pol

○ Platina motorizada Märzhäuser DC 4"x4" (65x50mm), manejada desde un panel de control de 2 ejes MCU/WIS a través de un controlador de motores MCU 28.

- A este microscopio se le han realizado las siguientes modificaciones:

i. Sustitución del filtro antitérmico "hot mirror" estándar del iluminador por uno “custom" fabricado expresamente para el sistema, que permite el paso de luz con longitudes de onda entre 300 y $1300 \mathrm{~nm}$ y refleja el resto, incluyendo el calor, hacia el interior del iluminador (Figura 4-16).

ii. Retirada del filtro polarizador existente a la entrada del cubo reflector estándar, para trabajar con luz no polarizada.

iii. Incorporación de una cámara de vídeo monocroma Basler Scout scA1400-17fm, con sensor CCD de 2/3” Sony ICX285AL de 1392 x 1040 píxeles, interfaz digital IEEE 1394b (FireWire b) y montura de rosca C. Su gran tamaño de píxel (6,45 x $6,45 \mu \mathrm{m})$ proporciona un rango dinámico real de 11,2 bits. La curva de respuesta del sensor (Figura 4-5) revela que es especialmente adecuado para adquirir imágenes en el infrarrojo cercano hasta $1000 \mathrm{~nm}$.

iv. Incorporación de una rueda de filtros DTA RPF Max-16, montada entre el iluminador y el microscopio, controlada mediante un puerto serie RS232. En ella se han montado 13 filtros de interferencia Melles Griot de Ø $25 \mathrm{~mm}$, con longitudes de onda nominales (CWL) de 400, 450, 500, 550, 600, 650, 700, 750, 800, 850, 900, 950 y $1000 \mathrm{~nm}$, ancho de banda (FWHM) $40 \mathrm{~nm}$ y transmitancia mínima del 50\% (Figura 4-7). Además, en la primera posición se ha colocado una combinación pancromática, compuesta por un filtro KG3 y otro de densidad neutra ND0.9, que permite al operador observar la muestra a través de los oculares sin deslumbrarse.

v. Incorporación de una extensión de tubo de $90 \mathrm{~mm}$ para separar la rueda de filtros del estativo, para mejorar la calidad de la imagen y reducir la aportación de calor.

- Otros elementos auxiliares de gran importancia para el correcto funcionamiento del sistema son los patrones de reflectancia especular y los patrones geométricos. El prototipo de AITEMIN emplea patrones idénticos a los usados en el prototipo del LMAAI, como puede observarse en la Figura 4-35. 

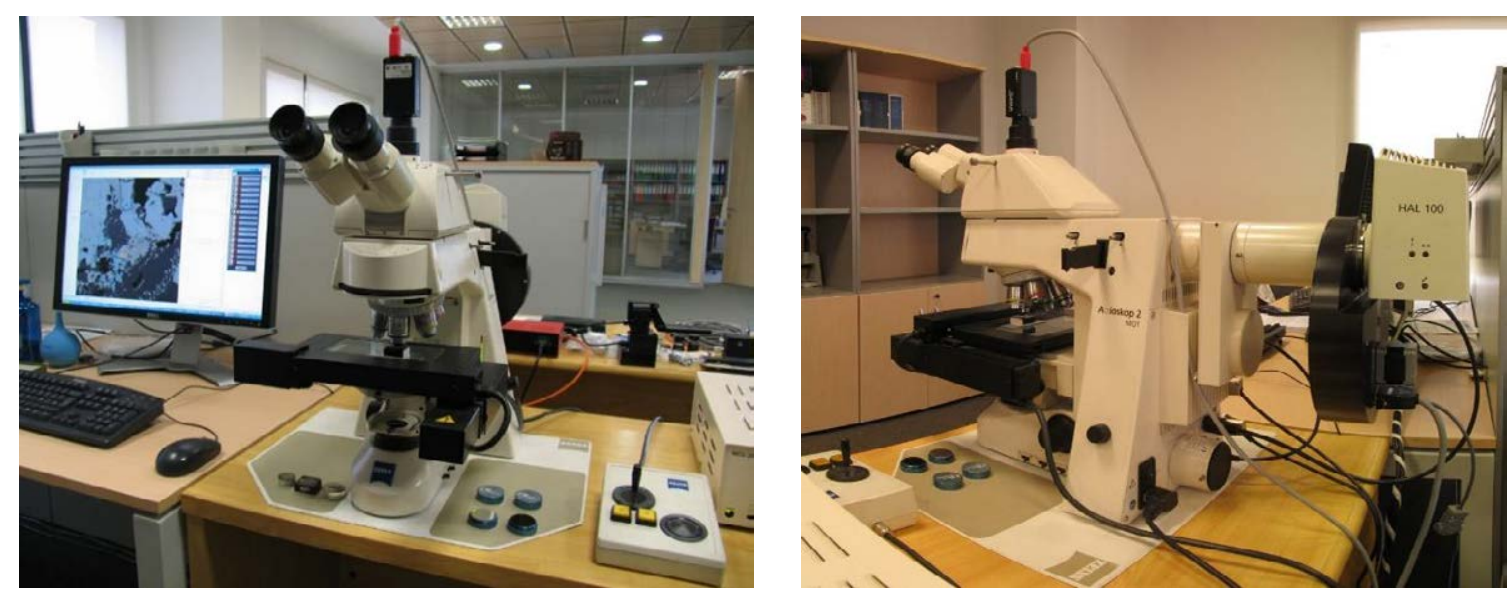

Figura 4-35. Aspecto del prototipo de AITEMIN (realización propia)

- La unidad de control y proceso consiste en un ordenador Dell Dimension 8300 con sistema operativo Windows XP 32-bit al que están conectados los elementos del instrumento (microscopio, cámara y rueda de filtros) y que ejecuta la misma aplicación de software que el prototipo del LMAAI, ya que ha sido desarrollada específicamente para funcionar con las dos principales marcas de microscopios: Leica y Zeiss. Asimismo, incorpora una tarjeta adaptadora MATROX Meteor2 - 1394 para la conexión del cable de la cámara al ordenador. El ordenador dispone de una gran pantalla de 24 pulgadas con una resolución de $1920(\mathrm{H})$ x 1200 (V) píxeles que permite visualizar con todo detalle las imágenes adquiridas por el sistema, y de dos discos duros para conseguir suficiente capacidad de almacenamiento de imágenes.

\subsection{PATENTE}

A la terminación del proyecto CAMEVA se consideró conveniente proteger mediante una patente el sistema desarrollado, por lo que se abordó el estudio del tipo de patente más adecuado. Dado que el software no puede ser objeto de patente, se decidió solicitar una patente de invención con examen previo que cubriera los procedimientos desarrollados para la calibración y operación del sistema de adquisición de imágenes microscópicas multiespectrales de reflectancia especular, es decir, el objeto de esta tesis.

La solicitud de patente fue presentada el 31 de marzo de 2011, aunque sus reivindicaciones tuvieron que ser reformuladas el 21 de marzo de 2012 para solventar las objeciones del examen previo. Finalmente, la patente fue concedida con fecha 25 de mayo de 2013, publicándose la concesión el 7 de junio de 2013. 
Los datos de la patente son:

Modalidad: PATENTE DE INVENCION CON EXAMEN PREVIO Nº 201130499

Solicitud: $\quad 31 / 03 / 2011$

Concesión: $\quad 28 / 05 / 2013$

Titulares:

- UNIVERSIDAD POLITÉCNICA DE MADRID (50\%)

- ASOCIACIÓN PARA LA INVESTIGACIÓN y DESARROLlO INDUSTRIAL DE LOS RECURSOS NATURALES (AITEMIN) (50\%)

Inventores:

- CASTROVIEJO BOLIBAR, Ricardo;

- ESPI RODRÍGUEZ, José Antonio;

- BREA, Carolina Beatriz;

- PÉREZ BARNUEVO, Laura;

- CATALINA HERNÁNDEZ, Juan Carlos y

- SEGUNDO GARCÍA, Fernando

Título: $\quad$ MÉTODO PARA OBTENER IMÁGENES MULTIESPECTRALES DE REFLECTANCIA ABSOLUTA.

Resumen: Se describe un procedimiento para llevar a cabo medidas cuantitativas en diferentes bandas de interés mediante un microscopio óptico de reflexión (o de luz transmitida) modificado. Dichas medidas se realizan de forma automatizada gracias a la intervención de una unidad de control que se acopla con el microscopio modificado para asistir en la calibración del dispositivo. Adicionalmente, también lleva a cabo correcciones de las imágenes tomadas de acuerdo con la banda de interés para que cada nivel de gris se asocie con un nivel de reflectancia real de la muestra (o de transmitancia) para la que se ha tomado la imagen. 

CAPÍTULO 5: PROCESO EXPERIMENTAL 


\subsection{APLICACIÓN DEL SISTEMA}

Los prototipos del sistema descritos en el $\S 4.5$ permiten obtener imágenes microscópicas multiespectrales en las que el nivel de gris de cada píxel representa la reflectancia especular en el correspondiente punto de la preparación para cada banda espectral. Esta información será el criterio fundamental que se usará para la identificación de las especies minerales presentes en una muestra.

Para ello, las bandas de la imagen multiespectral de un campo de una muestra son analizadas píxel a píxel para realizar un proceso de clasificación que permita identificar el mineral correspondiente a cada uno de ellos. De esta forma se genera una imagen clasificada del campo, en la que cada píxel tiene como valor el índice del mineral correspondiente en una lista de los minerales reconocidos por el sistema.

Para cada píxel $(j, k)$ de la imagen de un campo se extrae un vector $\boldsymbol{x}$ de $N$ componentes, que son los valores de reflectancia especular $G_{i}(j, k)$ en cada banda, al que tras la clasificación se le asigna un número entero (en principio de 8 bit), que será el índice $I$ del mineral correspondiente. Representándolo mediante fórmulas:

$$
\vec{x}=\left[R_{1}, R_{2} \cdots R_{N}\right] \rightarrow I=\varphi(\vec{x})
$$

donde

$$
R_{i}=G_{i}(j, k)
$$

Es decir:

$$
\begin{gathered}
I(j, k)=\varphi\left(\left[G_{1}(j, k), G_{2}(j, k) \cdots G_{N}(j, k)\right]\right) \\
I(j, k) \in\left\{I_{1}, I_{2} \cdots I_{M}\right\}
\end{gathered}
$$

donde

$I_{i}(j, k)$ es el índice del mineral para el píxel $(\mathrm{j}, \mathrm{k})$ de la imagen clasificada del campo

$G_{i}(j, k)$ es la reflectancia especular del píxel $(\mathrm{j}, \mathrm{k})$ de la banda i de la imagen corregida del campo $\varphi(x)$ es la función de clasificación de minerales a partir de su espectro de reflectancia especular $I_{m}$ es el índice del mineral $\mathrm{m}$ en la lista $\left\{I_{1}, I_{2} \cdots I_{M}\right\}$ de minerales reconocidos por el sistema

La Figura 5-1 muestra un ejemplo de obtención de una imagen clasificada a partir de una imagen multiespectral. La imagen de la izquierda es una vista en color (valores RGB aproximados a partir de las reflectancias de las bandas 2, 3, 4, 56 y 7) del campo, y la de la derecha es la imagen clasificada (sus valores son índices en la lista de minerales). 

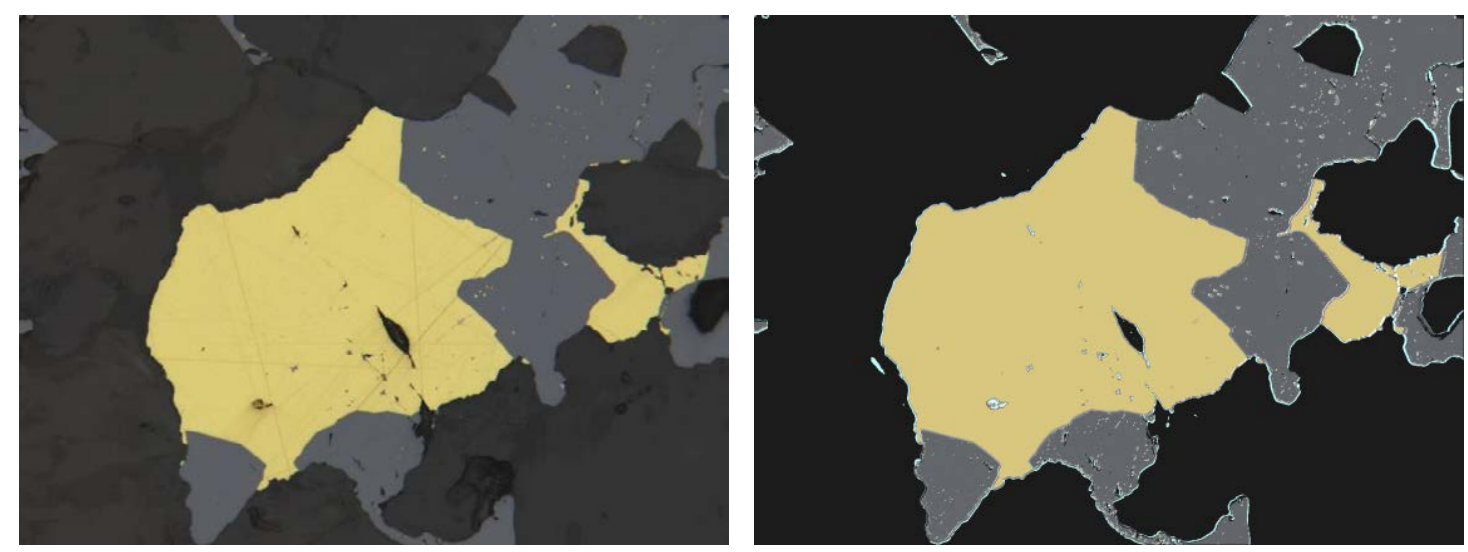

Figura 5-1. Obtención de una imagen clasificada (dcha.) a partir de una imagen multiespectral (izda) (realización propia)

Puede observarse que la imagen clasificada presenta índices incorrectos (se muestran en tono azulado) en las zonas cercanas al contorno de los granos y de poros. Esto se debe a dos motivos:

- El proceso de pulido origina en ocasiones el fenómeno del relieve en el contorno de los granos, por el cual la superficie del mineral aparece inclinada, y refleja de vuelta al objetivo un menor porcentaje de la luz incidente, por lo que el contorno de los granos queda más oscuro que su interior, lo que a veces provoca identificaciones incorrectas.

- En las zonas de contacto entre granos se producen en ocasiones transiciones graduales entre los valores de reflectancia de los minerales, lo que genera espectros intermedios entre los de los dos minerales, que pueden ser incorrectamente identificados. Por ello, sería conveniente aplicar un filtro detector de bordes para localizar los píxeles situados en los bordes de los granos, y poder procesarlos de forma diferente a las zonas del interior de los granos.

Las imágenes clasificadas constituirán la base de la que partirán el resto de los procesos de aplicación del sistema, ya que serán sometidas a diferentes procesos matemáticos con el fin de dar respuesta a las cuestiones planteadas por el estudio: abundancia de cada mineral, tamaño de grano, existencia y caracterización de intercrecimientos, grado de liberación, etc.

Este tipo de resultados aportan a este sistema una clara ventaja sobre los métodos manuales basados en el contador de puntos, que manejan una cantidad muy inferior de datos porque no pueden adquirir ni procesar imágenes.

Para hacer posible una identificación objetiva y reproducible han de compararse las medidas obtenidas en cada caso con unos valores de referencia previamente establecidos para las distintas menas. Aunque existen bases de datos de reflectancia multiespectral como QDF3, éstas están 
circunscritas al espectro visible y han sido obtenidas con luz polarizada, por lo que no son directamente aplicables al sistema desarrollado. Por ello ha sido necesario elaborar bases de datos propias adaptadas a las características del sistema: trabajo con luz natural (no polarizada) y rango espectral extendido al NIR (y potencialmente al NUV), además del visible, prescindiendo además de los objetivos de inmersión en aras de una automatización ágil.

La Figura 5-2 muestra curvas promedio de reflectancia VNIR obtenidas por el sistema sobre varios minerales (pirita, calcopirita, pirrotita, cubanita, covellina, hematites, magnetita, goethita y esfalerita; Brea et al. 2010), y las compara con las curvas publicadas en el rango visible (Criddle y Stanley 1993). Se observa claramente que la información adicional en el IR permite apreciar cambios de tendencia muy acusados -compárese, p. ej., pirrotita con pirita o calcopiritao que facilitan la diferenciación, p. ej. entre pirrotita y cubanita, cuyas curvas se solapan bastante en el visible.

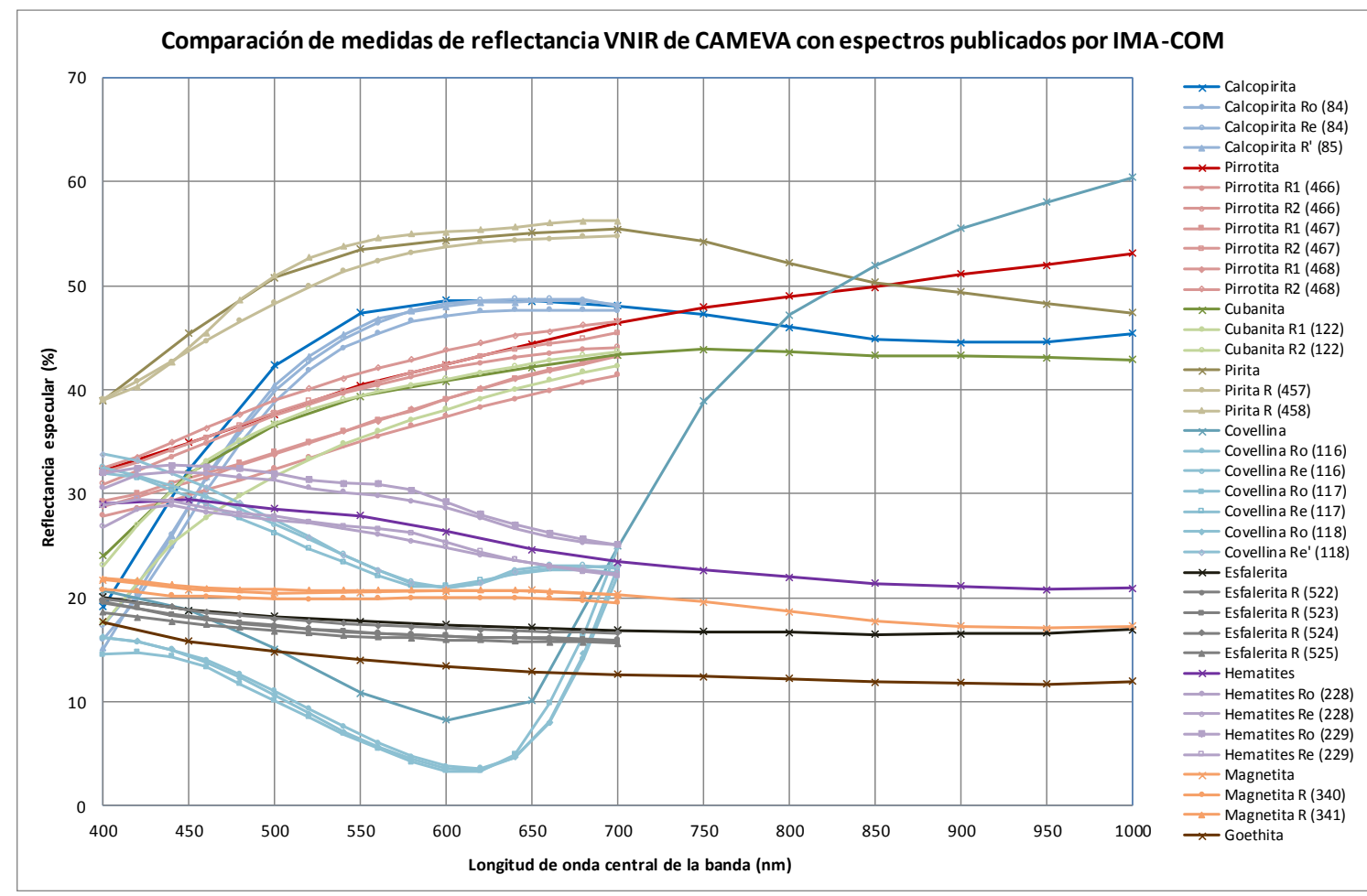

Figura 5-2. Comparación de medidas de reflectancia multiespectral VNIR del sistema CAMEVA con espectros publicados por IMA-COM en su QDF III (los limitados al tramo 400-700 nm) (realización propia)

Los dos prototipos del sistema CAMEVA han sido sometidos a numerosas pruebas, en particular el situado en el LMAAI de la UPM, que fue empleado por la investigadora Carolina Brea en su Tesis de Maestría (Brea 2009) para recopilar una base de datos de reflectancia especular multiespectral en el rango VNIR de una selección de 38 minerales, elegidos por constituir las principales menas metálicas de interés económico e industrial (Tabla 5-1). 
Tabla 5-1. Valores de reflectancia multiespectral de las principales menas metálicas

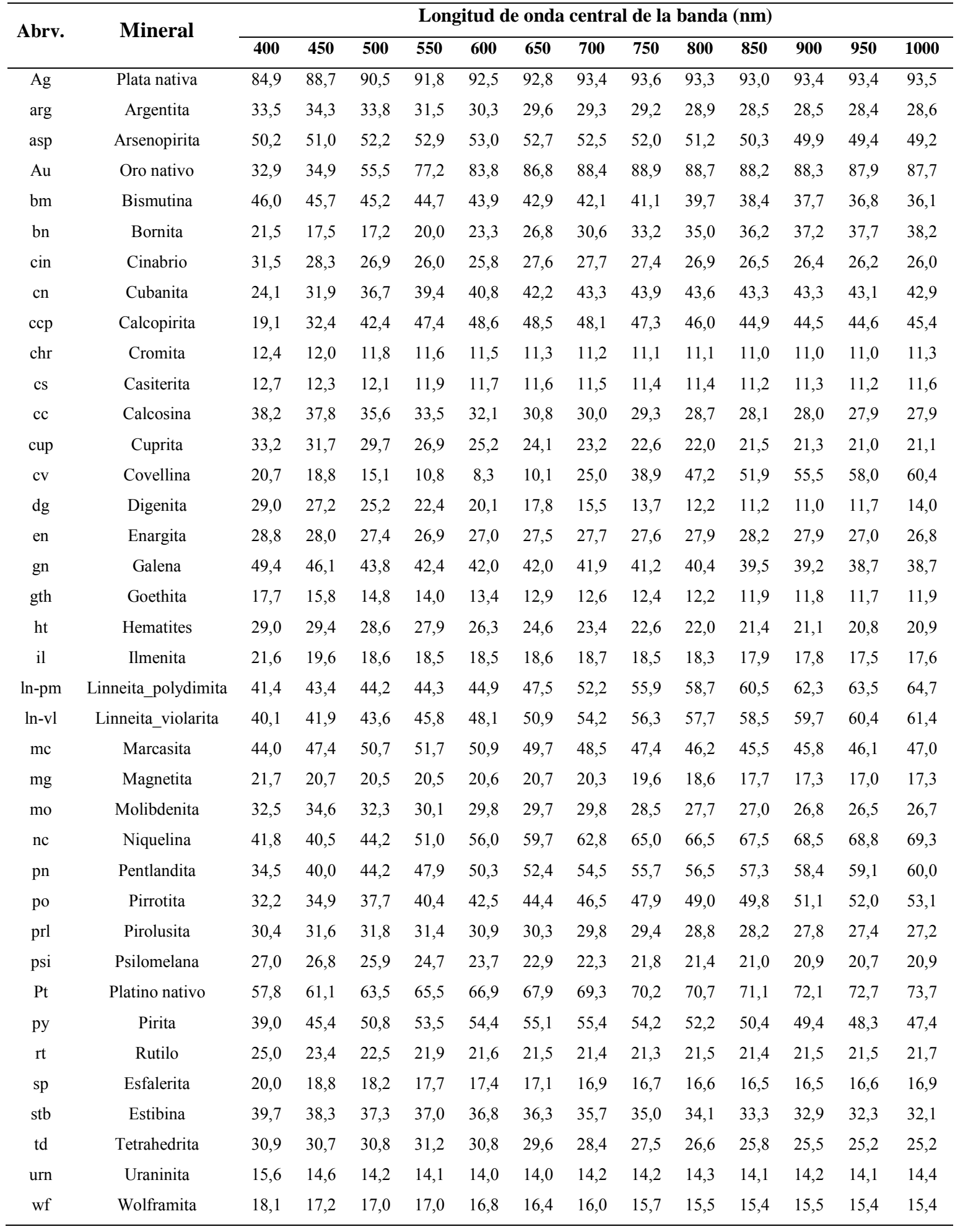

La lista se amplió a 70 minerales tras una segunda fase de adquisición llevada a cabo por la investigadora del proyecto Laura Pérez Barnuevo, y los datos obtenidos han sido incorporados a las bases de datos de IMA/COM, accesibles en Internet (Castroviejo et al., 2010). 


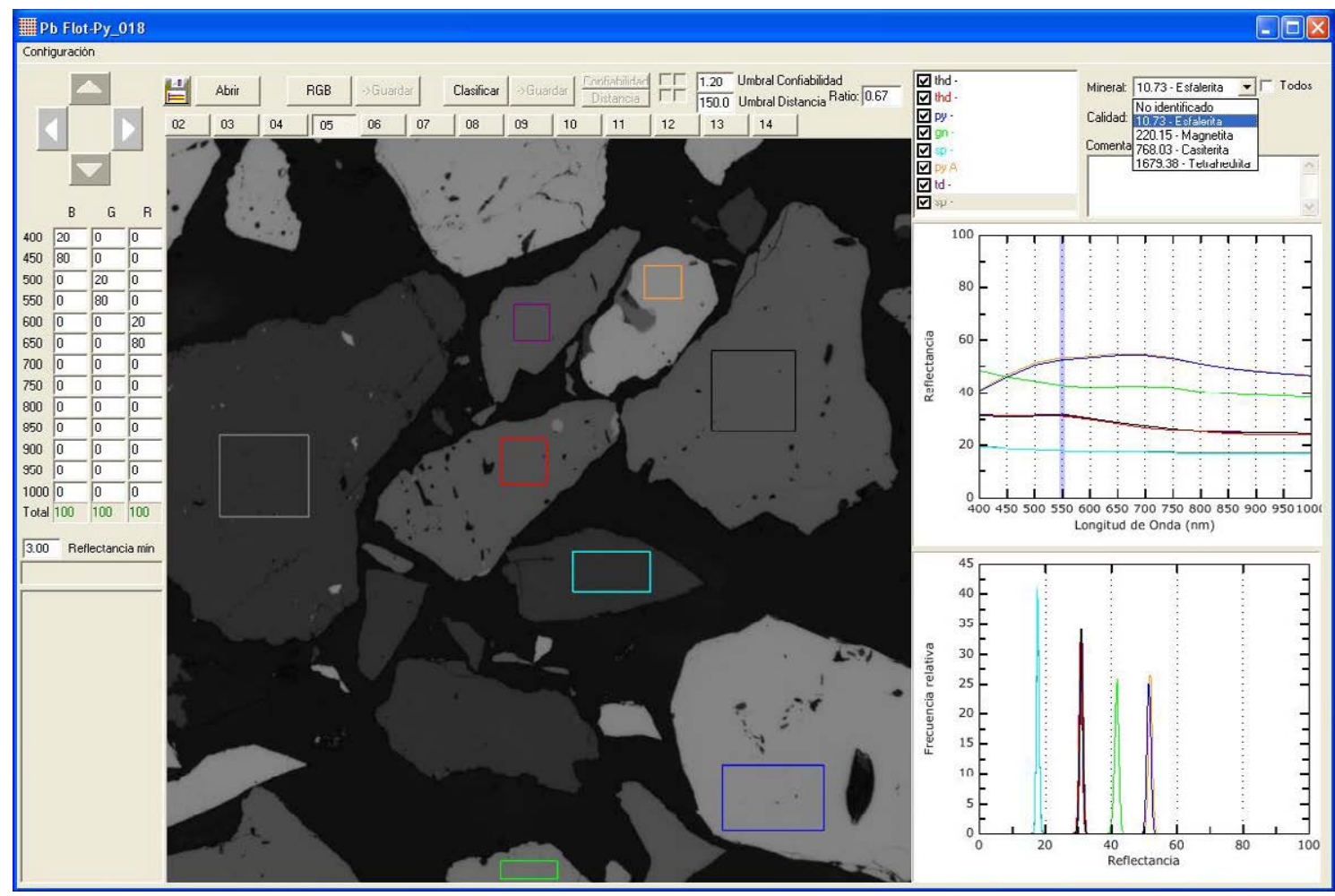

Figura 5-3. Programa de asistencia al análisis manual. Permite recorrer las imágenes almacenadas y marcar en ellas zonas rectangulares, asignándoles la etiqueta del mineral correspondiente. (propia)

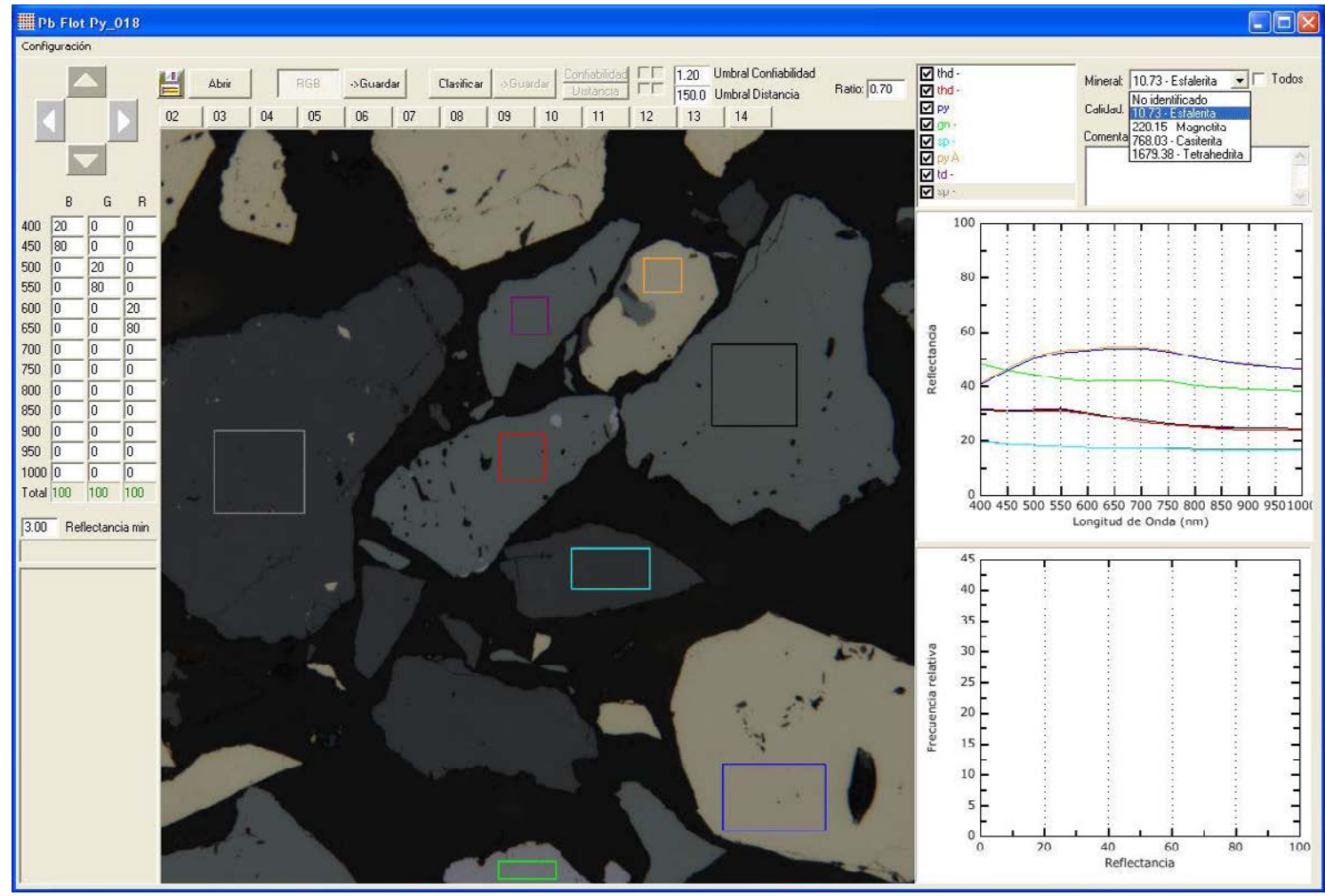

Figura 5-4. Programa de asistencia al análisis manual. Permite visualizar las imágenes multiespectrales como imágenes sintéticas en color RGB, estimadas como una combinación lineal de las distintas bandas, aplicando los coeficientes de la tabla situada en la parte izquierda de la ventana. (realización propia) 
Las bases de datos del sistema CAMEVA se han elaborado a partir de una colección de muestras cuidadosamente seleccionadas por su representatividad y calidad de pulido. Sobre estas muestras se ha realizado la adquisición de una gran cantidad de imágenes multiespectrales características de las distintas menas consideradas, que han sido almacenadas en disco. Un programa especialmente diseñado para asistir al operador permite al especialista en mineralogía examinar las imágenes almacenadas y delimitar en ellas zonas rectangulares de tamaño discrecional sobre regiones libres de defectos de las diversas fases minerales, asignándoles la etiqueta del mineral correspondiente (Figura 5-3 y Figura 5-4). Esto genera automáticamente archivos de datos (en modo texto) con los valores de reflectancia multiespectral de todos los píxeles de las zonas seleccionadas, que quedan así disponibles para ser procesados o incluso para ser incorporados como muestras adicionales a la base de datos de minerales.

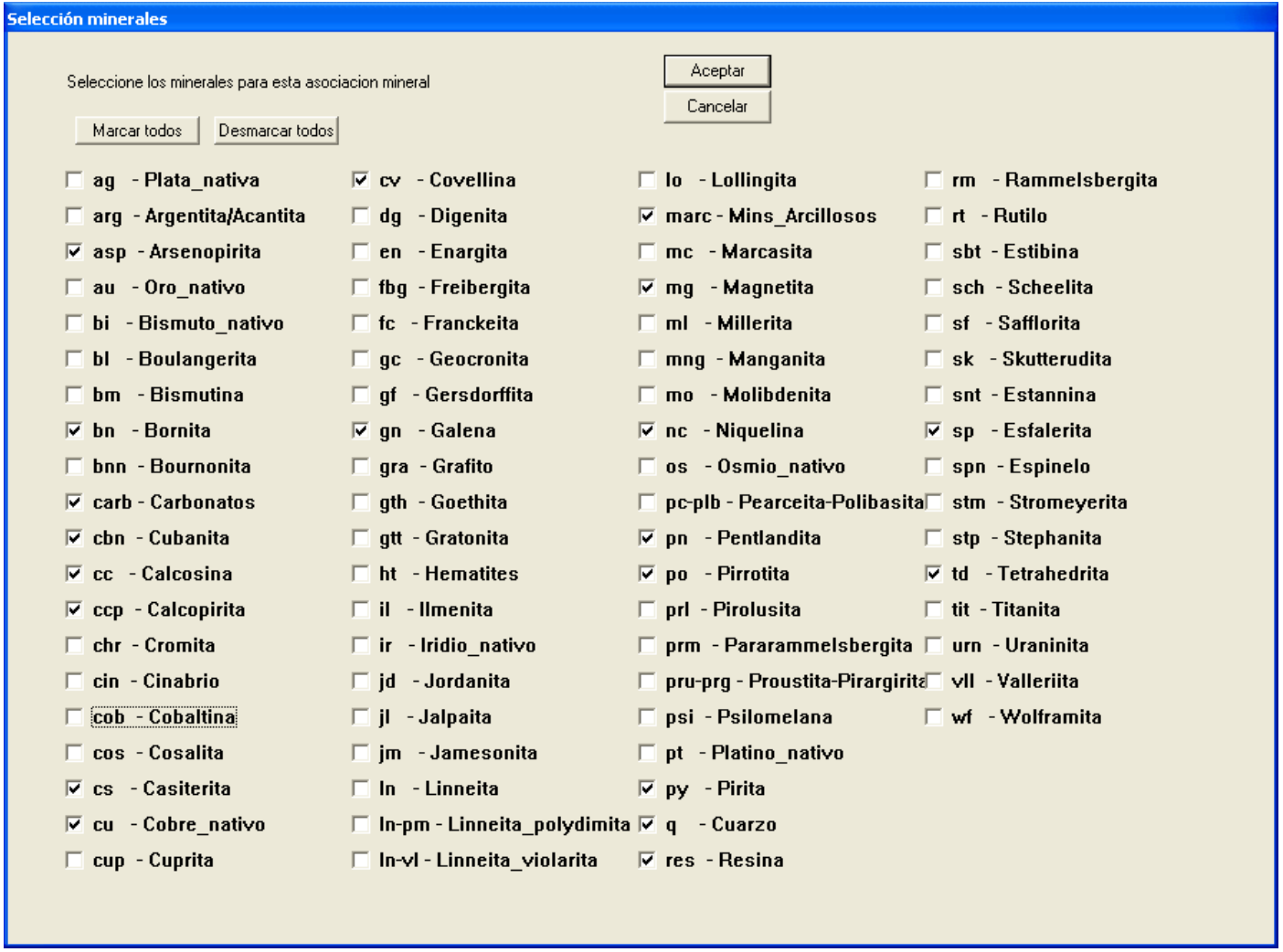

Figura 5-5. Ventana para seleccionar los minerales de la base de datos que se desea considerar en la clasificación (realización propia)

El software desarrollado en el sistema permite al operador seleccionar los minerales que desea considerar a la hora de clasificar la imagen de una forma muy sencilla, como se muestra en la Figura 5-5, que presenta los minerales elegidos para un determinado análisis, dentro de la lista de 70 minerales considerados en la segunda base de datos, engrosada con la resina y algunos minerales de ganga. 
El software del sistema contempla la incorporación de minerales adicionales a la base de datos de una forma sencilla. Para ello sólo es necesario agregar el nuevo mineral a la lista, asignándole una abreviatura y un número de índice únicos, así como el color RGB con el que se representará en las imágenes clasificadas, con lo cual ya se puede emplear para etiquetar zonas. A continuación, se localizan granos de ese mineral en muestras bien pulidas y limpias de pátina, y se marcan y etiquetan diversas zonas del mineral, tratando de recoger su variabilidad natural, para que el sistema pueda aprender sus características de la forma más general posible. Una vez hecho esto, se procede a entrenar el sistema de clasificación con los valores de los píxeles de dichas zonas, con lo que el nuevo mineral ya puede ser reconocido (ver $\S 5.2$ ).

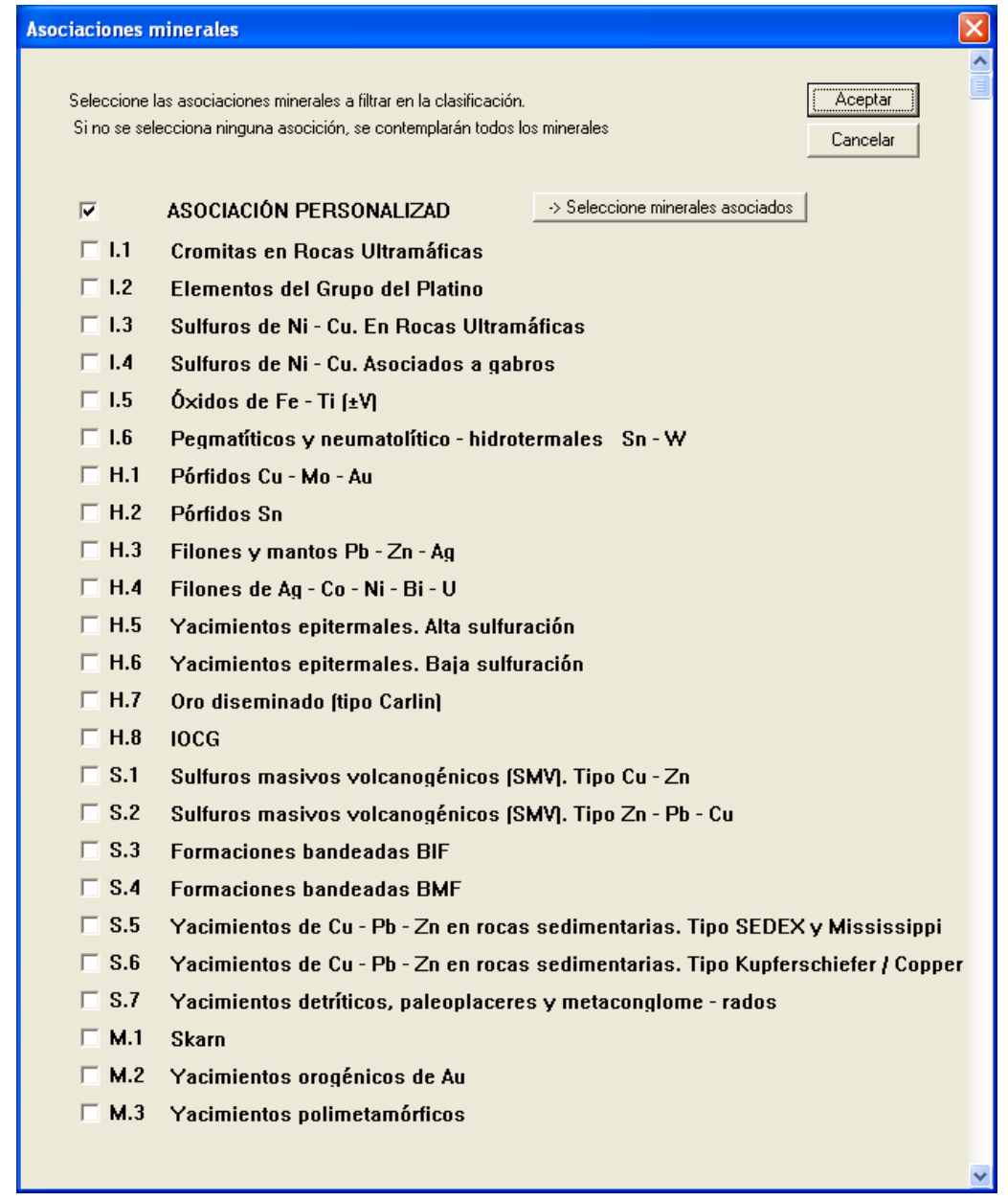

Figura 5-6. Ventana de selección de asociaciones minerales consideradas para la selección de minerales considerados en la clasificación (realización propia)

Por otra parte, se ha introducido en el software la posibilidad de indicarle el tipo de asociación mineral al que pertenece una muestra (Figura 5-6), lo que permite al sistema aplicar unas tablas que restringen automáticamente los minerales considerados, que se han definido a partir de la sistematización metalogenética conocida propuesta en Castroviejo y Berrezueta (2009). 


\subsection{ESTUDIO DE MÉTODOS DE CLASIFICACIÓN}

Los datos recogidos en la base de datos pueden ser aprovechados posteriormente para desarrollar procedimientos de identificación de minerales que puedan ser aplicados en el análisis automático de las imágenes. En el caso concreto del sistema CAMEVA, una muestra está constituida por el vector de los 13 valores de reflectancia especular medida en las 13 bandas de interés:

$$
\vec{x}=\left[R_{400}, R_{450}, R_{500}, R_{550}, R_{600}, R_{650}, R_{700}, R_{750}, R_{800}, R_{850}, R_{900}, R_{950}, R_{1000}\right]
$$

En una primera aproximación al problema, se ensayó el comportamiento de cuatro técnicas de clasificación:

- mínima distancia euclídea

- mínima distancia de Mahalanobis

- Spectral Angle Mapper (SAM)

- MOMI (Bernhardt, 1987)

Para estas primeras pruebas, se empleó una base de datos recopilada de forma manual con el sistema CAMEVA del LMAAI, que contaba con un total de 1082 muestras procedentes de zonas representativas de 33 minerales distintos. La identificación de los minerales fue realizada por los expertos del LMAAI, tanto sobre las propias imágenes adquiridas como al microscopio, en caso de duda.

Con ellas se realizaron diversos ensayos de la capacidad discriminatoria de las cuatro técnicas de clasificación. En cada ensayo, las muestras de la base de datos se reparten aleatoriamente en dos grupos: uno que se emplea para entrenar los algoritmos de clasificación, y otro que se destina a evaluar la corrección de la clasificación. El porcentaje de muestras asignado al entrenamiento ha sido uno de los parámetros variables en las diversas pruebas realizadas.

La Tabla 5-2 muestra los resultados promedio de la ejecución de diez ensayos de clasificación con cada una de las cuatro técnicas consideradas, para distintos porcentajes del total de muestras destinados al entrenamiento $(40 \%, 60 \%$ y $80 \%)$.

Los resultados obtenidos muestran que la mínima distancia de Mahalanobis es la técnica de clasificación que mejores resultados da en la práctica en esta aplicación, ya que es capaz de clasificar correctamente muchas más muestras que las otras tres técnicas. Además, presenta un comportamiento claramente dependiente del tamaño de la muestra de entrenamiento: cuanto mayor sea ésta, menor es el error cometido en la clasificación del resto de las muestras. Esta tendencia no aparece en el resto de las técnicas ensayadas. 
Tabla 5-2. Pruebas de clasificación mediante diferentes técnicas de zonas seleccionadas manualmente pertenecientes a la base de datos. La clasificación se realiza con los 13 valores de reflectancia especular global de la zona, calculados a partir de la moda del histograma de cada banda. Se muestran los resultados promedio para distintos porcentajes de zonas destinadas al entrenamiento del clasificador.

\begin{tabular}{|c|c|c|c|c|c|c|c|c|c|c|c|c|c|c|}
\hline & & & \multirow{2}{*}{\multicolumn{3}{|c|}{$\begin{array}{c}\text { Bien clasificadas por } \\
\text { Mín. Dist. Euclídea }\end{array}$}} & \multirow{2}{*}{\multicolumn{3}{|c|}{$\begin{array}{l}\text { Bien clasificadas por } \\
\text { Mín. Dist. Mahalanobis }\end{array}$}} & \multirow{2}{*}{\multicolumn{3}{|c|}{$\begin{array}{l}\text { Bien clasificadas por } \\
\text { Spectral Angle Mapper }\end{array}$}} & \multirow{2}{*}{\multicolumn{3}{|c|}{$\begin{array}{c}\text { Bien clasificadas por } \\
\text { MOMI }\end{array}$}} \\
\hline & & \multirow{2}{*}{ Total } & & & & & & & & & & & & \\
\hline & & & \multicolumn{3}{|c|}{$\%$ destinado a entren. } & \multicolumn{3}{|c|}{$\%$ destinado a entren. } & \multicolumn{3}{|c|}{$\%$ destinado a entren. } & \multicolumn{3}{|c|}{$\%$ destinado a entren. } \\
\hline Mineral & Código & muestras & $40 \%$ & $60 \%$ & \begin{tabular}{|l}
$80 \%$ \\
\end{tabular} & $40 \%$ & $60 \%$ & \begin{tabular}{|l|}
$80 \%$ \\
\end{tabular} & $40 \%$ & $60 \%$ & $80 \%$ & $40 \%$ & $60 \%$ & $80 \%$ \\
\hline Plata nativa & ag & 25 & $100,0 \%$ & $100,0 \%$ & $100,0 \%$ & $100,0 \%$ & $100,0 \%$ & $100,0 \%$ & $100,0 \%$ & $100,0 \%$ & $100,0 \%$ & $100,0 \%$ & $99,2 \%$ & $100,0 \%$ \\
\hline Arsenopirita & apy & 85 & $0,0 \%$ & $100,0 \%$ & $100,0 \%$ & $99,8 \%$ & $99,8 \%$ & $100,0 \%$ & & & $95,0 \%$ & & & $95,0 \%$ \\
\hline Argentita/Acantita & $\mathrm{arg} / \mathrm{ac}$ & 19 & & & $100,0 \%$ & & $100,0 \%$ & & & & $100,0 \%$ & & & $100,0 \%$ \\
\hline Bismutina & $\mathrm{bm}$ & 15 & & & $100,0 \%$ & & & $100,0 \%$ & & & $83,3 \%$ & & & $83,3 \%$ \\
\hline Bornita & bn & 25 & $\%$ & 100 , & $100,0 \%$ & $94,0 \%$ & & $100,0 \%$ & & & $2,0 \%$ & & & $2,0 \%$ \\
\hline Cinabrio & $\operatorname{cin}$ & 14 & & & $96,7 \%$ & $100,0 \%$ & &, $0 \%$ & & & $96,7 \%$ & & & $0 \%$ \\
\hline Cubanita & $\mathrm{cn}$ & 49 & $100,0 \%$ & $100,0 \%$ & $100,0 \%$ & $100,0 \%$ & & $100,0 \%$ & & 100 & $100,0 \%$ & & $0,0 \%$ & $0,0 \%$ \\
\hline Calcopirita & cpy & 46 & & & $77,0 \%$ & $100,0 \%$ & & $100,0 \%$ &, $0 \%$ & & $100,0 \%$ & & $100,0 \%$ & $00,0 \%$ \\
\hline Cromita & $\mathrm{cr}$ & 15 & $2 \%$ & $50,0 \%$ & $56,7 \%$ & $95,6 \%$ & 100, & $100,0 \%$ & $100,0 \%$ & $100,0 \%$ & $100,0 \%$ & & $100,0 \%$ & $100,0 \%$ \\
\hline Casiterita & cs & 10 & & & $95,0 \%$ & & & & & & $100,0 \%$ & & & $100,0 \%$ \\
\hline Calcosina & ct & 19 & & & $20,0 \%$ & & 100 & & & & $5,0 \%$ & & & $2,5 \%$ \\
\hline Cuprita & cup & 9 & & & & & & & & & & & & $80,0 \%$ \\
\hline Covellir & & & 8 & $\%$ & & & & & & & & & & $2,4 \%$ \\
\hline & & & & & & & & & & & $0,0 \%$ & & & $0,0 \%$ \\
\hline$a$ & & & & &, $7 \%$ & & & & & & $5 \%$ & & & $5 \%$ \\
\hline Goet & goe & & & & $.7 \%$ & & & 10 & & & $6,7 \%$ & & &, $0 \%$ \\
\hline Hematites & $\mathrm{ht}$ & 3 & & $91,7 \%$ & $92,5 \%$ & & & $5 \%$ & & & $97,5 \%$ & & & $7,5 \%$ \\
\hline IImenita & il & 24 & $7 \%$ & $100,0 \%$ & $100,0 \%$ & & & $100,0 \%$ & & 100 & $100,0 \%$ & & & $100,0 \%$ \\
\hline Marcasita & mar & 46 & & $100,0 \%$ & $100,0 \%$ & & & & & & & & & $100,0 \%$ \\
\hline Magnetita & $\mathrm{mg}$ & 22 & & $94,4 \%$ & $96,0 \%$ & & & $96,0 \%$ & & & $100,0 \%$ & & & $100,0 \%$ \\
\hline Molibdenita & & 1 & & $79,2 \%$ & $80,0 \%$ & & & $100,0 \%$ & & & $100,0 \%$ & & & $100,0 \%$ \\
\hline Niquelina & $\mathrm{nc}$ & 2 & $100,0 \%$ & $100,0 \%$ & $100,0 \%$ & $100,0 \%$ & 100 & $100,0 \%$ & & $100,0 \%$ & $100,0 \%$ & & $100,0 \%$ & $100,0 \%$ \\
\hline Pent & & & & & & & & & & & $85.0 \%$ & & & $0,0 \%$ \\
\hline Pirrotita & & & & & & & & & & & $87,8 \%$ & & & $95,6 \%$ \\
\hline Pirolusita & & & & & 100 & & & & & & $100,0 \%$ & & & $100,0 \%$ \\
\hline Psilomelana & psi & 38 & $95,7 \%$ & $96,9 \%$ & $95,0 \%$ & $96,5 \%$ & & $100,0 \%$ & & & $95,0 \%$ & & & $93,8 \%$ \\
\hline Platino nativo & $\mathrm{pt}$ & 18 & $100,0 \%$ & $100,0 \%$ & $100,0 \%$ & $100,0 \%$ & $100,0 \%$ & $100,0 \%$ & $100,0 \%$ & $100,0 \%$ & $100,0 \%$ & $100,0 \%$ & $100,0 \%$ & $100,0 \%$ \\
\hline Pirita & py & 22 & $84,6 \%$ & $87,0 \%$ & $84,0 \%$ & $95,4 \%$ & $90,7 \%$ & $94,0 \%$ & $100,0 \%$ & $100,0 \%$ & $100,0 \%$ & $0,0 \%$ & $100,0 \%$ & $100,0 \%$ \\
\hline Rutilo & ru & 29 & $95,0 \%$ & $98,6 \%$ & $100,0 \%$ & & $90,3 \%$ & $100,0 \%$ & & $41,0 \%$ & $40,0 \%$ & $1,7 \%$ & $41,7 \%$ & $40,0 \%$ \\
\hline Esfalerita & & 29 & $57,8 \%$ & $73,6 \%$ & $71,7 \%$ & $91,7 \%$ & $90,3 \%$ & $98,3 \%$ & & $25,7 \%$ & $23,3 \%$ & $24,4 \%$ & $22,2 \%$ & $20,0 \%$ \\
\hline Estibina & & 14 & & $50,0 \%$ & & & $98,6 \%$ & $100,0 \%$ & & $97,2 \%$ & $100,0 \%$ & & $94,4 \%$ & $100,0 \%$ \\
\hline Tetral & thd & 27 & $100,0 \%$ & $100,0 \%$ & $100,0 \%$ & & $100,0 \%$ & $100,0 \%$ & & & $85,0 \%$ & & & $85,0 \%$ \\
\hline Wolframita & wf & 14 & & & & & & & & & $100,0 \%$ & & $98,6 \%$ & $100,0 \%$ \\
\hline Promedio & & 1082 & $81,07 \%$ & $82,73 \%$ & $82,07 \%$ & $94,18 \%$ & $95,61 \%$ & \begin{tabular}{|l|}
$\mathbf{9 7}, 58 \%$ \\
\end{tabular} & $85,82 \%$ & $85,05 \%$ & $85,21 \%$ & $85,87 \%$ & $85,01 \%$ & $\begin{array}{l}85,21 \% \\
\end{array}$ \\
\hline
\end{tabular}

\subsubsection{Clasificación por mínima distancia de Mahalanobis}

Esta técnica de clasificación asigna una muestra desconocida a la clase más próxima según la métrica de distancia de Mahalanobis, basada en el cálculo del vector promedio y la inversa de la matriz de covarianzas de los vectores de muestra que definen cada clase.

Para clasificar un vector de características $\vec{x}$ se calcula la distancia de Mahalanobis de $\vec{x}$ a cada uno de los vectores medios de las clases consideradas, y se asigna $\vec{x}$ a la clase para la cual la distancia de Mahalanobis es mínima.

El cuadrado de la distancia de Mahalanobis $d^{2}$ del vector $\vec{x}$ a la clase $i$ se calcula como:

$$
d^{2}=\left(\vec{x}-\vec{\mu}_{i}\right)^{T} C_{i}^{-1}\left(\vec{x}-\vec{\mu}_{i}\right)
$$

donde

$\vec{\mu}_{i}$ es el vector promedio de la clase $i$

$C_{i}^{-1}$ es la inversa de la matriz de covarianzas de la clase $i$ 
La principal ventaja de este clasificador es que el proceso de aprendizaje sólo afecta la clase a la que se agregan (o de la que se eliminan) los vectores, por lo que es bastante sencillo (y rápido) volver a entrenar el clasificador después de la adición de nuevas muestras de mineral. Para entrenar la clase i, es suficiente calcular el vector promedio $\vec{\mu}_{i}$ y el inverso de su matriz de covarianza $C_{i}^{-1}$.

\subsection{VALIDACIÓN DEL MÉTODO DE CLASIFICACIÓN}

En una primera etapa, se puso en marcha un procedimiento de clasificación de zonas que permitiera al programa de asistencia al operador identificar el mineral correspondiente a cada zona marcada por el operador. Para validar la calidad de la clasificación por zonas se repartió el conjunto de las zonas rectangulares seleccionadas y clasificadas por los especialistas en dos grupos: uno, al que se asignó aleatoriamente una parte de las zonas, se utilizó para entrenar el clasificador, y el otro, con el resto de las zonas, se utilizó para ponerlo a prueba.

Para la clasificación de las zonas, en lugar de la media para cada banda de los valores de reflectancia de todos los píxeles de una zona, se tomó la moda de dichos valores, con el fin de reducir la influencia de los pequeños defectos superficiales (rayas de pulido, poros, grietas finas, pequeñas saltaduras, etc.) que suelen aparecer en las imágenes de las preparaciones, y que, por ser oscuros, tienden a afectar a la media en mucha mayor medida que a la moda.

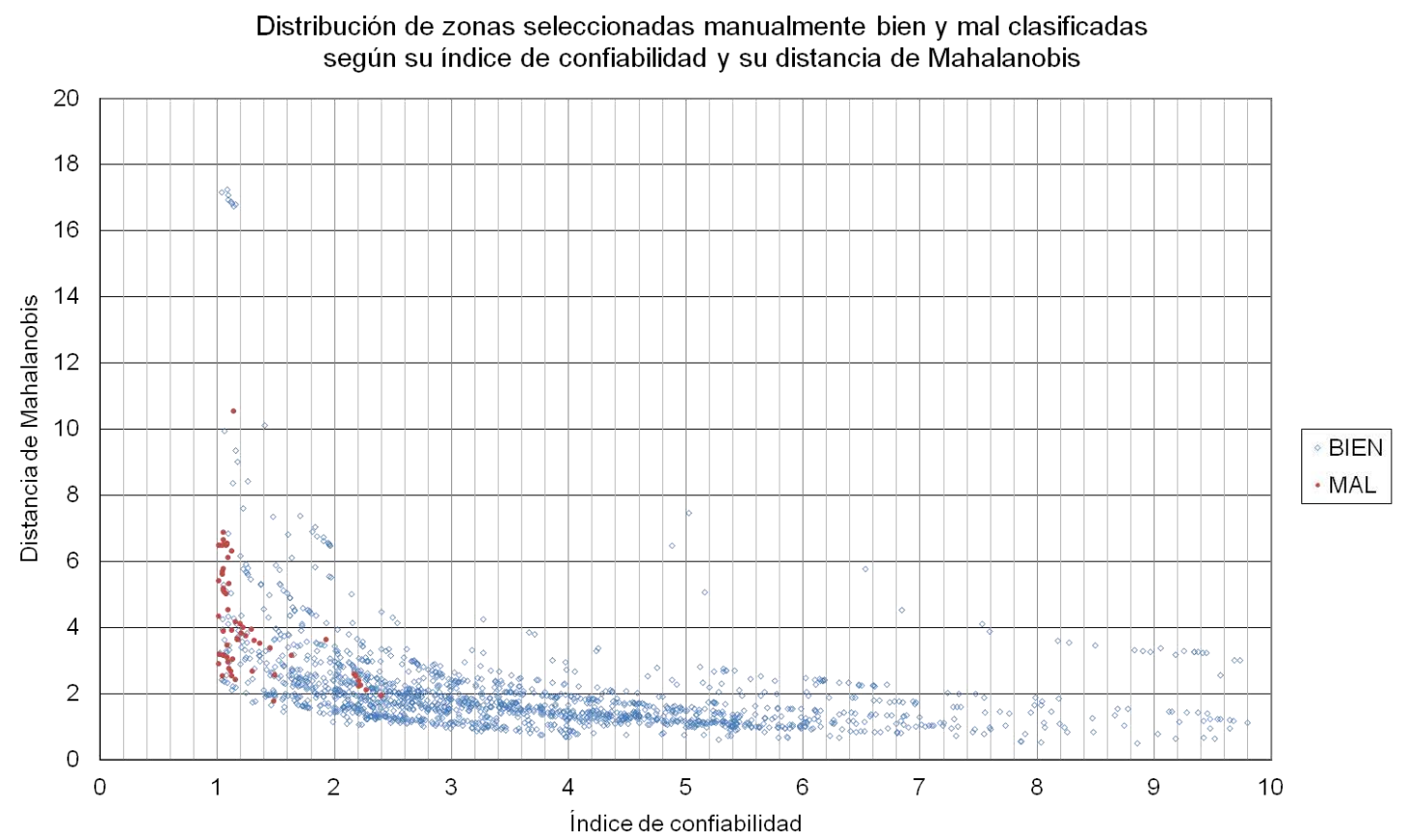

Figura 5-7. Distribución de las zonas seleccionadas por los especialistas en función de los valores de distancia e índice de confiabilidad obtenidos en su clasificación por la técnica de la mínima distancia de Mahalanobis. Las zonas mal clasificadas se representan en rojo. (realización propia) 
La Figura 5-7 muestra cómo se distribuyen los resultados de la clasificación de las zonas seleccionadas por los especialistas sobre el conjunto de las muestras de ensayo en función de los valores obtenidos para la mínima distancia de Mahalanobis y el índice de confiabilidad (definido como el cociente entre la segunda menor distancia y la distancia mínima). Las zonas mal clasificadas se representan en rojo, y las zonas bien clasificadas en azul. Se puede observar que las zonas mal clasificadas casi siempre muestran valores muy bajos del índice de confiabilidad.

Los errores de clasificación no se reparten uniformemente entre los distintos minerales: la Tabla 5-3 muestra los resultados de la clasificación del grupo de zonas de control, en la que se ve que sólo una pequeña parte de los minerales presentan errores de clasificación.

Desafortunadamente, no resulta sencillo extender los buenos resultados de la clasificación de zonas al conjunto de una imagen cualquiera, ya que para ello sería necesario proceder a la previa segmentación de las zonas uniformes de la imagen, que no es una tarea fácilmente automatizable.

Se ha realizado una búsqueda de métodos de segmentación de imágenes que puedan resultar adecuados para esta aplicación. Los más prometedores son los métodos mixtos basados en la detección de bordes combinada con el crecimiento de regiones homogéneas a partir de "semillas" adecuadamente distribuidas, pero estos métodos no son fáciles de implementar en la práctica, por lo que no han podido ser probados aún.

Por ello, la versión actual del programa de identificación de minerales procesa individualmente cada uno de los píxeles de una imagen multiespectral, generando una imagen de paleta de colores que identifica la especie mineral a la que ha sido asignado cada píxel. Si un píxel presenta una reflectancia más baja que un valor mínimo o no cumple unas condiciones dadas de fiabilidad en la clasificación -distancia máxima a la clase y coeficiente de confiabilidad mínimo-, se le asigna la etiqueta "no clasificado". El coeficiente de confiabilidad de una clasificación se define como el cociente de la segunda menor distancia de Mahalanobis a un mineral dividida por la menor distancia de Mahalanobis.

Posteriormente, se contabiliza el número de píxeles asignado a cada número de etiqueta, y con dichos datos se obtienen los resultados del análisis modal.

Como resultado, el sistema descrito alcanza una tasa de identificación automática de fases comparable a la obtenida por un equipo SEM, pero resulta mucho más asequible (su coste es unas 7 veces menor), lo que lo hace utilizable en un gran número de aplicaciones e industrias, y con requisitos mínimos de infraestructura. 
Tabla 5-3. Resultados de la clasificación de píxeles de zonas seleccionadas manualmente (entrenamiento con todos los píxeles del 70\% de las zonas, clasificación de todos los píxeles del 30\% restante de las zonas)

\begin{tabular}{|c|c|c|c|c|c|c|c|c|}
\hline Abrv. & Mineral & $\begin{array}{l}\text { Total } \\
\text { zonas } \\
\text { clasif. }\end{array}$ & $\begin{array}{c}\text { Total } \\
\text { píxeles }\end{array}$ & $\begin{array}{c}\% \\
\text { píxeles } \\
\text { correctos }\end{array}$ & $\begin{array}{c}\text { Distan. } \\
\text { media } \\
\text { correctos }\end{array}$ & $\begin{array}{c}\text { Distan. } \\
\text { media } \\
\text { incorrec. }\end{array}$ & $\begin{array}{c}\text { Confiabil. } \\
\text { media } \\
\text { correctos }\end{array}$ & $\begin{array}{c}\text { Confiabil. } \\
\text { media } \\
\text { incorrec. }\end{array}$ \\
\hline Abrv. & Mineral & Zonas & Píxeles & $\% \mathrm{OK}$ & Dist. OK & Dist. Nok & Conf. OK & Conf. Nok \\
\hline $\mathrm{Ag}$ & Plata nativa & 12 & 5654 & 100,00 & 13,86 & - & 61,11 & - \\
\hline $\arg$ & Argentita & 6 & 8748 & 96,71 & 13,14 & 28,42 & 2,93 & 1,35 \\
\hline asp & Arsenopirita & 10 & 333275 & 99,55 & 13,24 & 357,66 & 28,40 & 1,32 \\
\hline $\mathrm{Au}$ & Oro nativo & 6 & 1444 & 100,00 & 14,25 & - & 76,97 & - \\
\hline $\mathrm{bm}$ & Bismutina & 11 & 6092 & 99,47 & 32,96 & 134,11 & 7,86 & 1,09 \\
\hline bn & Bornita & 9 & 77145 & 100,00 & 13,21 & - & 11,37 & - \\
\hline $\operatorname{cin}$ & Cinabrio & 5 & 13433 & 92,67 & 12,43 & 16,25 & 2,62 & 1,24 \\
\hline $\mathrm{cn}$ & Cubanita & 14 & 346304 & 99,96 & 12,72 & 112,32 & 30,50 & 1,63 \\
\hline ccp & Calcopirita & 4 & 205300 & 97,39 & 14,45 & 132,76 & 2,18 & 4,90 \\
\hline $\mathrm{chr}$ & Cromita & 5 & 549479 & 99,09 & 19,72 & 73,84 & 4,36 & 1,31 \\
\hline $\mathrm{cs}$ & Casiterita & 14 & 127921 & 99,97 & 15,18 & 89,05 & 9,28 & 1,16 \\
\hline $\mathrm{cc}$ & Calcosina & 3 & 780656 & 94,83 & 12,19 & 211,95 & 2,24 & 6,60 \\
\hline cup & Cuprita & 3 & 103188 & 99,71 & 13,57 & 61,25 & 6,48 & 1,27 \\
\hline $\mathrm{cv}$ & Covellina & 4 & 171559 & 99,99 & 17,48 & 3306,14 & 141,91 & 1,05 \\
\hline $\mathrm{dg}$ & Digenita & 3 & 70 & 100,00 & 39,40 & - & 12,30 & - \\
\hline en & Enargita & 5 & 105903 & 97,22 & 13,15 & 31,18 & 2,74 & 1,28 \\
\hline gn & Galena & 10 & 110782 & 99,96 & 13,62 & 46,36 & 13,08 & 1,55 \\
\hline gth & Goethita & 4 & 82968 & 97,09 & 6,17 & 114,53 & 1,12 & 3,05 \\
\hline ht & Hematites & 4 & 18326 & 99,83 & 13,47 & 46,26 & 5,57 & 1,50 \\
\hline il & Ilmenita & 4 & 306553 & 98,97 & 12,89 & 26,43 & 2,80 & 1,23 \\
\hline $\ln$ & Linneita & 10 & 22167 & 99,96 & 15,22 & 69,39 & 12,93 & 1,18 \\
\hline $\mathrm{mc}$ & Marcasita & 15 & 121610 & 99,96 & 17,22 & 98,80 & 12,11 & 1,15 \\
\hline $\mathrm{mg}$ & Magnetita & 5 & 336262 & 99,32 & 12,01 & 26,96 & 3,15 & 1,16 \\
\hline mo & Molibdenita & 6 & 61484 & 99,87 & 13,34 & 25,91 & 5,68 & 1,18 \\
\hline $\mathrm{nc}$ & Niquelina & 7 & 44112 & 100,00 & 12,85 & - & 22,36 & - \\
\hline pn & Pentlandita & 8 & 47917 & 91,87 & 14,97 & 20,70 & 10,70 & 1,27 \\
\hline po & Pirrotita & 12 & 304686 & 99,73 & 17,31 & 41,00 & 3,55 & 1,10 \\
\hline prl & Pirolusita & 3 & 2302 & 99,74 & 12,28 & 22,29 & 4,36 & 1,24 \\
\hline psi & Psilomelana & 12 & 245086 & 99,66 & 12,75 & 22,32 & 3,27 & 1,29 \\
\hline $\mathrm{Pt}$ & Platino nativo & 11 & 17189 & 99,01 & 15,66 & - & 58,53 & - \\
\hline py & Pirita & 7 & 482269 & 100,00 & 14,39 & 80,32 & 13,16 & 1,52 \\
\hline $\mathrm{rt}$ & Rutilo & 11 & 481618 & 88,51 & 13,86 & 19,87 & 1,85 & 1,18 \\
\hline $\mathrm{sp}$ & Esfalerita & 10 & 279350 & 99,63 & 14,21 & 161,84 & 2,78 & 5,48 \\
\hline stb & Estibina & 9 & 117978 & 97,39 & 20,72 & 29,15 & 2,73 & 1,21 \\
\hline $\mathrm{td}$ & Tetrahedrita & 8 & 46626 & 99,95 & 12,07 & 41,99 & 6,18 & 1,30 \\
\hline urn & Uraninita & 5 & 26217 & 99,69 & 14,20 & 55,69 & 2,88 & 2,40 \\
\hline \multirow[t]{2}{*}{$\mathrm{wf}$} & Wolframita & 4 & 128685 & 98,69 & 13,16 & 150,71 & 2,56 & 7,70 \\
\hline & Totales & 279 & 6120358 & 97,84 & & & & \\
\hline
\end{tabular}




\subsection{ENSAYOS DE VALIDACIÓN SOBRE PROBLEMAS INDUSTRIALES}

Una aplicación inmediata del sistema CAMEVA es la asistencia a los estudiantes de ingeniería y geología en la identificación de menas metálicas, que hoy en día desborda las posibilidades de su currículum académico.

Sin embargo, el interés principal del sistema para la industria se centra en la caracterización geometalúrgica de muestras de mano o de testigos de un yacimiento (Figura 5-8), así como en el análisis sistemático de muestras molidas procedentes de concentrados o de los distintos flujos de una planta de concentración de menas.
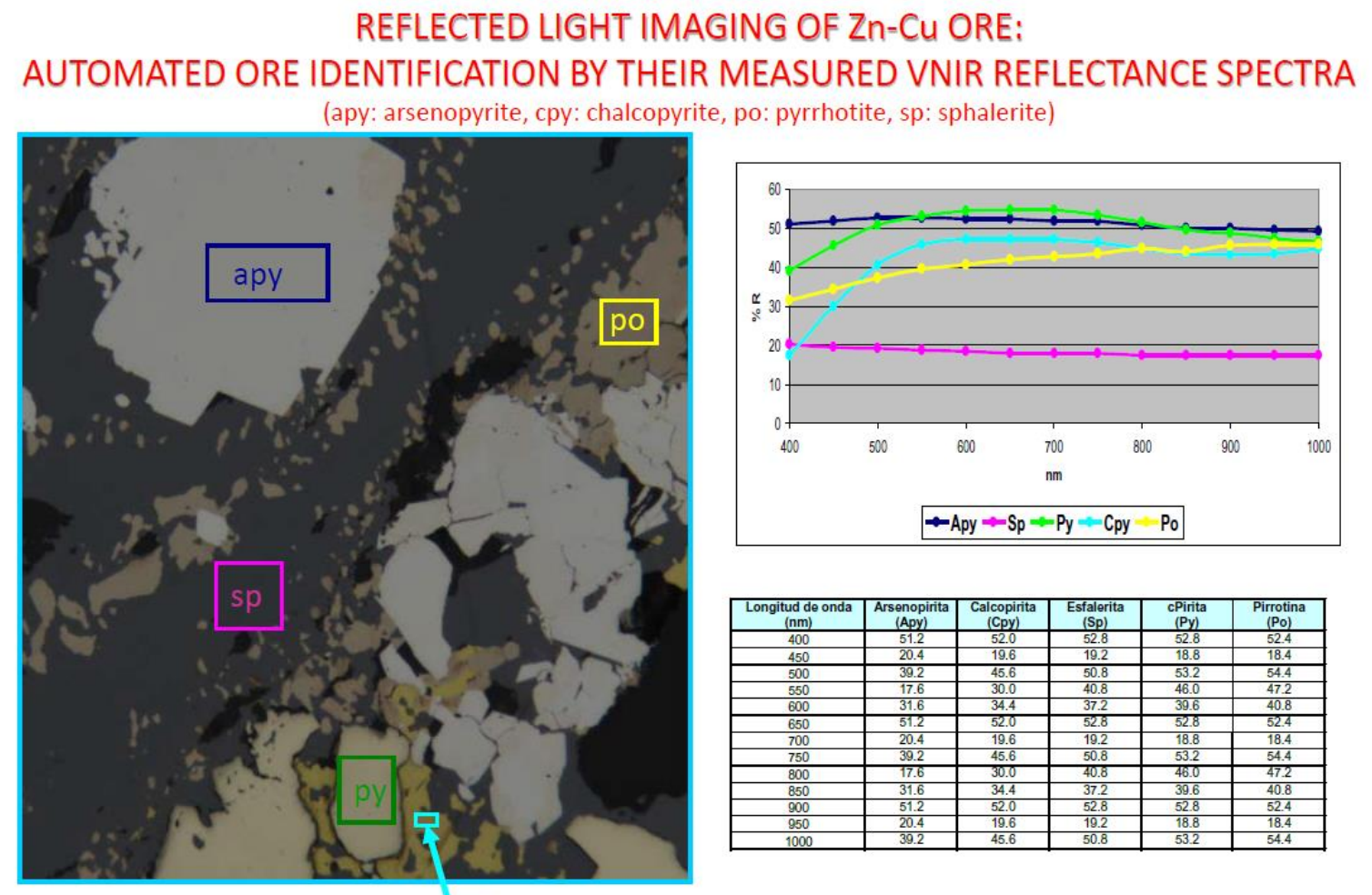

\section{Cpy}

Figura 5-8. Ejemplo de aplicación para asistencia al operador o a estudiantes de ingeniería y geología

El sistema CAMEVA ha sido aplicado en la caracterización de muestras de más de una docena de minas de diversas partes del mundo, como España, Portugal, Zambia, Perú, Rusia, etc. Desafortunadamente, no es posible presentar un listado detallado por razones de confidencialidad.

Un interés de índole más científica viene dado por la capacidad del sistema para establecer correlaciones entre la reflectancia de algún mineral (o serie isomorfa) y su composición, que tiene que ser establecida por análisis químico o mediante microsonda. Al respecto de esta 
capacidad se puede mencionar el artículo López et al. (2017), donde se estudia la relación entre la reflectancia y la composición en el caso de las cromitas.

Por último, una reciente aplicación muy novedosa consistió en el estudio y la obtención de imágenes y medidas de reflectancia multiespectral en el rango VNIR de un mineral desconocido, que han sido adjuntadas en la propuesta presentada al IMA/COM para el reconocimiento de un nuevo mineral Aiglsperger et al. (2018). 


\section{CAPÍTULO 6: DISCUSIÓN DE RESULTADOS}




\subsection{DISCUSIÓN DE RESULTADOS}

El análisis de los resultados precedentes muestra claramente que el sistema desarrollado permite, en general, la identificación automatizada de las menas metálicas con un elevado nivel de confianza. Esta identificación se ha controlado sistemáticamente en las menas comunes, cuantificando el nivel de confianza por medio de la distancia de Mahalanobis, con el resultado de tasas de acierto habitualmente próximas al 100\%. La Tabla 5-3 presenta los resultados de una de estas pruebas, en las que se ha entrenado el sistema con los píxeles del $70 \%$ de las zonas seleccionadas y se clasifican los píxeles del $30 \%$ restante de las zonas.

Las menas de interés industrial son sólo una pequeña fracción de las aproximadamente 1500 especies de menas conocidas: se estima su número en poco más de una treintena de especies (Criddle, 1998). Aunque este número puede variar ligeramente según los autores y las épocas, se puede aceptar la selección de 37 especies minerales elaborada por Bowie y Simpson (1980) como representativa. Todas ellas están comprendidas en la selección de 70 "menas comunes" investigadas y medidas para la puesta a punto del sistema CAMEVA. Para las restantes menas, en general carentes de interés industrial, escasas o muy poco frecuentes, cabe aplicar el mismo método, ampliando previamente la base de datos espectrales mediante la medida de las correspondientes muestras como patrones de referencia. El sistema está programado para ello.

En general, la incorporación sistemática del rango IR cercano -espectros VNIR- refuerza la fiabilidad de la identificación, en comparación con el espectro visible tradicionalmente medido: por ejemplo, la pirrotita muestra una tendencia IR muy peculiar, mejorando claramente el contraste visible con cubanita o calcopirita (cf. Figura 5-2). No obstante, se ha detectado en casos excepcionales, incluso en el rango VNIR, una similitud en los espectros de ciertas menas, como p. ej. casiterita y cromita, que podría inducir a confusión o indeterminación al identificarlas. Este problema se puede superar introduciendo en la base de datos la opción “asociación mineral”, ligada a la tipología del yacimiento investigado, ya que dichos minerales se ubican en tipologías muy diferentes. El "software" del sistema es suficientemente abierto como para poder incorporar (opcionalmente) esta información, digitalizada a partir de la sistematización metalogenética conocida (Castroviejo y Berrezueta, 2009).

Demostrada la viabilidad de la identificación automatizada, cabe interrogarse sobre el interés práctico e industrial de la innovación (Sistema CAMEVA), lo que requiere compararla tanto con las técnicas tradicionales de reconocimiento por microscopía (óptica) de reflexión como con los recientes sistemas automatizados basados en microscopía electrónica. 
Tabla 6-1. Comparación de las tres principales técnicas para caracterización de menas

\begin{tabular}{|c|c|c|c|}
\hline & $\begin{array}{c}\text { CP (Contador de } \\
\text { Puntos) }\end{array}$ & CAMEVA & MEB \\
\hline $\begin{array}{l}\text { PRECIO ADQUISICIÓN } \\
\text { (estimación, k€) }\end{array}$ & 25 & $100-120$ & $600-1000$ \\
\hline $\begin{array}{l}\text { Exigencias de } \\
\text { INFRAESTRUCTURA }\end{array}$ & Bajas & Bajas & Altas \\
\hline MOVILIDAD & Alta & Alta & Imposible \\
\hline $\begin{array}{l}\text { ESPECIALIZACIÓN del } \\
\text { operario }\end{array}$ & Alta & Media & Alta \\
\hline VERSATILIDAD & Muy baja & Alta & Alta \\
\hline RENDIMIENTO & $\begin{array}{c}\text { Bajo } \\
\text { (lento y limitado) }\end{array}$ & $\begin{array}{c}\text { Alto } \\
\text { (rápido y eficiente) }\end{array}$ & $\begin{array}{c}\text { Alto } \\
\text { (rápido y } \\
\text { eficiente) }\end{array}$ \\
\hline $\begin{array}{l}\text { ASEQUIBILIDAD para } \\
\text { PYMES y consultores }\end{array}$ & Asequible & Asequible & Inasequible \\
\hline $\begin{array}{l}\text { FORTALEZAS } \\
\text { METODOLÓGICAS }\end{array}$ & $\begin{array}{c}\text { Observación } \\
\text { directa (permite } \\
\text { interpretación } \\
\text { cualitativa) }\end{array}$ & $\begin{array}{c}\text { Medida de } \\
\text { reflectancia } \\
\text { multiespectral } \\
\text { (IMA/COM) } \\
\text { Polimorfos } \\
\text { Menas de Fe } \\
\text { Grafito } \\
\text { Muy útil para } \\
\text { docencia }\end{array}$ & $\begin{array}{l}\text { Composición } \\
\text { química } \\
\text { Series isomorfas } \\
\text { Minerales transpa- } \\
\text { rentes (ganga) }\end{array}$ \\
\hline $\begin{array}{l}\text { LIMITACIONES } \\
\text { METODOLÓGICAS }\end{array}$ & $\begin{array}{l}\text { Fatiga visual } \\
\text { Subjetividad } \\
\text { Lentitud } \\
\text { No info } \\
\text { voluminosa }\end{array}$ & $\begin{array}{l}\text { Composición } \\
\text { química } \\
\text { Series isomorfas } \\
\text { Minerales transpa- } \\
\text { rentes (ganga) }\end{array}$ & $\begin{array}{c}\text { Polimorfos } \\
\text { Menas de Fe } \\
\text { Fases no } \\
\text { detectables por } \\
\text { SEM (grafito...) }\end{array}$ \\
\hline
\end{tabular}

La Tabla 6-1 resume una comparación de las tres principales técnicas en uso actualmente, recogiendo criterios como precio, rendimiento, movilidad (capacidad de traslado a mina o a localidades con escasa infraestructura, p.ej. para campañas de exploración), etc. Se concluye, en las dos últimas filas, con un análisis de las principales fortalezas y limitaciones metodológicas de cada técnica y, en la columna derecha, con la indicación del equipo que podría considerarse mejor elección según cada uno de los criterios empleados. Se trata, evidentemente, sólo de una orientación muy general, que luego habría de matizarse con los diferentes precios y prestaciones de cada uno de los equipos existentes, en un mercado en continua evolución. 
Frente a las técnicas manuales con contador de puntos $(\mathrm{CP})$ y desde un punto de vista práctico, funcional, el sistema CAMEVA al prescindir de la polarización renuncia a una parte importante de la información visible, pero compensa esta limitación con el acopio de datos espectrales objetivos y precisos que superan ampliamente las capacidades del ojo humano. Su rendimiento es también muy superior, al introducir mejoras como el enfoque automatizado (compensado para cada tramo espectral) y la platina motorizada que permiten la adquisición automatizada de las imágenes. Al no depender del ojo humano, se eliminan los problemas relacionados con la fatiga del observador y se alcanzan cotas de producción impensables para un operador humano (por ejemplo, la cuantificación de millones de partículas minerales).

Otra importante ventaja adicional es la versatilidad, ya que la adquisición de la información mineralógica (imagen) se hace una sola vez, se archiva y luego se puede procesar matemáticamente tantas veces como se desee para responder a diferentes demandas (análisis modal, granulometría, grado de liberación, análisis textural, etc.), mientras que un operador manual tiene que repetir el proceso de adquisición para cada nueva demanda. Frente a los recientes sistemas basados en microscopía electrónica, MEB, el rendimiento es similar pero el precio del sistema CAMEVA es mucho más asequible (en torno al $15 \%$ ) y sus requerimientos de infraestructura y mantenimiento, mucho menos exigentes. Además, el software CAMEVA es flexible y abierto a los diversos tipos de asociaciones minerales, mientras que habitualmente la programación de los sistemas MEB está prevista para una asociación determinada y debe cambiarse al variar ésta, lo que puede ocurrir en distintas zonas de un mismo yacimiento.

Por otra parte, el análisis comparativo de las prestaciones analíticas permite constatar algunas fortalezas y limitaciones específicas de cada una de las técnicas empleadas. En primer lugar, el tipo de información utilizada para el reconocimiento de las partículas minerales (química u óptica en los sistemas MEB o CAMEVA, respectivamente) permite suponer, en principio, cierta superioridad en caso de fases isomorfas o polimorfas a los sistemas MEB o CAMEVA, respectivamente, ya que los minerales de series isomorfas admiten variación composicional sin cambiar necesariamente las propiedades ópticas y los polimorfos tienen la misma composición, aun variando las propiedades ópticas. Esto debe, no obstante, matizarse, porque los sistemas MEB determinan sólo con aproximación las composiciones químicas y no pueden discriminar entre fases minerales de composiciones próximas. No obstante, cabe pensar en mayores prestaciones de los sistemas MEB, en general, en la caracterización de minerales de TR (Tierras Raras), que frecuentemente tienen variaciones composicionales amplias, no siempre reflejadas en diferencias de parámetros ópticos. 
En cambio, el sistema CAMEVA es netamente superior para la investigación de menas de Fe, de gran importancia industrial, ya que las composiciones de los principales óxidos (hematites, magnetita, goethita, limonita) son parecidas y, a pesar de recientes avances (Figueroa et al., 2011), no se discriminan fácilmente con MEB, mientras que sus propiedades ópticas, por el contrario, son diagnósticas (Figura 5-2).

Finalmente, debe indicarse que los sistemas automatizados precisan que las preparaciones tengan una calidad de pulido superior a la que sería aceptable para las técnicas manuales. El motivo es que un defecto de pulido (relieve, rayadura, arranque de grano, etc.) puede originar una estimación incorrecta de la reflectancia e inducir un error de identificación en la zona afectada, que habría sido obviado por un operador manual. En el caso de los sistemas MEB, esta exigencia de calidad del pulido es aún más alta. 
CAPÍTULO 7: CONCLUSIONES 


\subsection{CONCLUSIONES}

Las principales conclusiones del presente trabajo son:

i. El análisis mineralógico automatizado es una poderosa herramienta de apoyo para la optimización del proceso mineralúrgico. La magnitud y rendimiento de los procesos modernos de concentración de menas requieren la automatización de estas aplicaciones y el recurso a técnicas de análisis digital de imagen, las cuales se han ido decantando por métodos basados en microscopía electrónica (MEB) en los últimos años, dadas las limitaciones de la microscopía (óptica) de menas clásica. No obstante, los avances recientes en electrónica y en informática posibilitan el desarrollo de sistemas ópticos competitivos como CAMEVA, el cual supera algunas de las limitaciones de los sistemas MEB, como su elevado precio, sus rígidas y costosas exigencias de infraestructura y especialización o la dificultad de distinguir especies polimorfas, manteniendo prestaciones similares en cuanto a rendimiento y calidad de información.

ii. Los ensayos realizados muestran que el sistema CAMEVA permite la identificación automatizada y fiable de las menas de interés industrial, a partir de la información espectral VNIR disponible en una base de datos específica; y sugieren prestaciones similares para otras menas, a partir de las medidas de reflectancia especular VNIR que se pueden obtener con el mismo equipo. Por otra parte, su programación flexible y abierta permite el archivo y tratamiento matemático de toda la información digital para responder a cualquiera de los requerimientos de planta (análisis modal, grado de liberación, caracterización textural, etc.).

iii. Es posible la medida fiable y repetitiva de espectros de reflectancia

iv. Es viable realizar la caracterización de las menas sin tener en cuenta la anisotropía, es decir, empleando luz no polarizada. De esta forma, es posible la automatización completa del proceso.

v. El proceso de imágenes en lugar de medidas puntuales da una inmensa ventaja al método sobre los métodos manuales basados en contador de puntos porque permite una multiplicidad de determinaciones con una sola adquisición.

vi. Otra ventaja incuestionable es la incomparablemente mayor cantidad de datos procesados frente a la capacidad de un operador humano con platina integradora. 
vii. Frente a los sistemas de microscopía electrónica, el sistema proporciona un rendimiento comparable por un coste muy inferior, y resultados incluso superiores con algunos tipos de menas (por ejemplo, las ferríferas, que representan casi el $40 \%$ de la producción minera metálica).

viii. El mercado para estas aplicaciones de microscopía electrónica ha entrado en crisis debido a la falta de innovación, lo que destaca el interés de una alternativa cualificada como esta.

\subsection{NUEVOS DESARROLLOS}

Como se mencionó en el \$2.3, actualmente está en curso el proyecto AMCO (Automated Microscopic Characterisation of Ores) en el marco del programa H2020, con financiación del EIT Raw Materials. Este proyecto está planteado como un "Upscaling" del proyecto CAMEVA, con el objetivo primordial de incrementar el nivel de madurez de la tecnología (TRL: Technology Readyness Level) desde el nivel 5+ de CAMEVA hasta un nivel 7-8 que permita integrar un prototipo más avanzado del sistema, de fácil manejo, concebido para su aplicación industrial y comercialmente viable.

Otros objetivos adicionales del sistema $\mathrm{AMCO}$ son, respondiendo a prioridades recientemente establecidas por el EIT Raw Materials, los siguientes:

- Facilitar el aprendizaje y la formación continua en microscopía proporcionando al estudioso una herramienta innovadora que aporta información objetiva y de alto valor diagnóstico para la identificación de menas

- Contribuir a la reducción del impacto ambiental de la minería mediante el control mineralógico de los residuos del proceso y la identificación de componentes tóxicos

El sistema AMCO incorpora numerosas mejoras sobre el sistema CAMEVA, entre las que se pueden destacar:

- Incorporación de una nueva rueda de filtros de 22 posiciones de la firma TOFRA, Inc. Esta mejora vino impuesta por la desaparición de la empresa DTA, que fabricaba la rueda seleccionada para CAMEVA.

- Selección de un nuevo tipo de filtros de interferencia denominado "hardcoated", con características notablemente mejoradas respecto al anterior en cuanto a transmisividad, robustez frente a condiciones ambientales adversas (alta temperatura, humedad, etc.).

- Incorporación de un mayor número de filtros en la parte visible del espectro, con paso de banda y separación de $25 \mathrm{~nm}$, con el fin de conseguir una mayor resolución espectral. 
- Incorporación de un filtro UV con alta transmisividad, de forma que admita tiempos de integración razonables (en el sistema CAMEVA el intento de utilizar filtros UV fracasó por su muy baja transmisividad, que obligaba a utiliza tiempos de integración de varios segundos, a todas luces excesivos).

- Selección de un nuevo modelo de cámara basado en la más moderna tecnología CMOS, con características netamente superiores a las de la cámara CCD elegida en CAMEVA.

- Posibilidad de extender el rango espectral en el que se adquieren las imágenes, gracias al uso de una segunda cámara sensible al rango SWIR, entre 900 y $1700 \mathrm{~nm}$, acoplada a un adaptador de documentación motorizado, de forma que se puede dirigir la luz a la cámara VNIR o a la cámara SWIR, bajo control del programa. Incorporación de una segunda rueda de filtros de 12 posiciones de la firma TOFRA, Inc, intercalada entre el adaptador de documentación y la cámara SWIR, cargada con un juego de filtros del rango SWIR que va de 1050 a $1600 \mathrm{~nm}$, con un paso de banda y un espaciado de 50nm.

- Elaboración de aplicaciones informáticas mejoradas, tanto para la captura de imágenes multiespectrales (adquiridas manualmente o mediante barrido de una sección pulida) como para su posterior análisis automático, que hacen uso de la librería de proceso de imágenes OpenCV, que es gratuita, en lugar de tener que recurrir a la librería MIL 10 de Matrox, que tiene un coste no desdeñable.

- Desarrollo de funciones auxiliares para monitorizar la evolución de la calibración en el tiempo y con la temperatura ambiente, que son los dos parámetros que más influyen en ella.

- Elaboración de una nueva base de datos de reflectancia especular multiespectral de los distintos minerales considerados, con capacidad para determinar la imagen (muestra, campo y zona) de la que procede cada una de las zonas empleadas para obtenerla.

- Incorporación de un cubo reflector para fluorescencia, con excitación en 450-490 nm y filtro pasalto a $512 \mathrm{~nm}$, con el fin de poder adquirir imágenes de fluorescencia.

- Uso de aditivos coloreados o fluorescentes para la resina al hacer preparaciones con muestras de partículas, con el fin de reconocer con facilidad la distribución de la resina y conseguir una adecuada discriminación ganga-resina. Esta investigación fue objeto del proyecto de fin de grado de Úrsula Grunwald Romera.

- Uso de nuevos patrones de reflectancia especular, fabricados y calibrados en el Instituto de Óptica del CSIC.

- Uso de una fuente de alimentación con capacidad para suministrar una corriente constante, para estabilizar al máximo la potencia de la fuente luminosa.

- Integración con microscopía electrónica. Correlative light and electron microscopy (CLEM). Esta integración permite obtener resultados mucho mejores que cada una de 
las técnicas por separado, ya que aprovecha los puntos fuertes de cada una para compensar las deficiencias de la otra. Este novedoso enfoque del análisis presenta notables ventajas y no resulta mucho más caro que el uso exclusivo de la microscopía electrónica, por lo que parece tener un brillante futuro que podría facilitar la futura comercialización del sistema AMCO.

\subsection{PROBLEMAS PENDIENTES}

La identificación de minerales píxel a píxel sobre la imagen puede presentar dificultades en los bordes de los granos, debido tanto al efecto del relieve originado por las diferentes durezas de los minerales (más aún si el pulido es imperfecto) como a la contaminación espectral producida por la interacción de fases minerales próximas. Se sugiere abordar la segmentación de las fases minerales previamente a su identificación, para prevenir el efecto de la proximidad a bordes de grano, arranques u otros defectos de pulido sobre la calidad de la medida de la reflectancia.

Esto abre la puerta a la caracterización integral de menas desde el punto de vista geometalúrgico mediante técnicas de análisis de imagen para reconocimiento de texturas que han sido objeto de una tesis doctoral (Pérez Barnuevo 2014), pero que aún no han sido incorporadas al software.

Las fuentes luminosas de microscopio clásicas actualmente existentes en el mercado, a pesar de ser las elegidas para el sistema por sus prestaciones, presentan problemas de estabilidad cuya superación mejoraría notablemente el rendimiento del sistema. Una solución interesante sería incorporar una fuente luminosa multiespectral basada en la combinación de la luz emitida por una serie de diodos LED especialmente seleccionados para cubrir el rango espectral considerado. No obstante, a pesar de la intensa búsqueda realizada, no ha sido posible encontrar en el mercado una fuente adecuada para esta aplicación, por lo que la única posibilidad alternativa a la fuente luminosa halógena sería desarrollar una fuente LED adecuada específicamente para esta aplicación.

El rendimiento del sistema podría mejorarse aún más cuando estén disponibles fuentes luminosas multiespectrales de estado sólido, cuya estabilidad debería ser notablemente superior a la de las lámparas halógenas actualmente existentes, y que estarían prácticamente exentas de la necesidad de dedicar tiempo de uso a los procesos de calibración y control de la misma. 


\section{CAPÍTULO 8: REFERENCIAS BIBLIOGRÁFICAS}




\subsection{REFERENCIAS BIBLIOGRÁFICAS}

Agarwal, J.C., Schapiro, N. and Mallio, M.J., 1976. Process Petrography and Ore Deposits. Mining Cong. Jour. 62(3), 28-35.

Aiglsperger, T., Galí, S., Longo, F., Font, M., Llovet, X., Catalina, J.C., Castroviejo, R., Villanova, C., Vendrell, M., Roqué, J. y Lewis, J.F. 2018. PROENZAITE: A new mineral proposal (submitted to IMA/COM). IMA/COM. Disponible en Internet en: $<$ https://drive.google.com/drive/folders/1-boNQ05GprLf1FzfND4VWQQHlsuGRjtp>.

Amstutz, G.C., 1962. How Microscopy Can Increase Recovery in Your Milling Circuit. Mining World 24, 19-23.

Atkin, B.P., y Harvey, P., 1979. The use of quantitative color values for opaque mineral identification. Can. Mineral. 17, 639-647.

Beck, R., 1865. Description of a new form of live trap and parabolic reflector. Trans. Microsc. Soc. 13, 113-118.

Berek, M., 1931. Das Problem der quantitativen Mikroskopie der Erzmineralien und seine Lösung. Zeits. Kristallogr. 76, 396-480 \& 77, 1-22.

Berek, M., 1937. Optische Messmethoden im polarisierten Auflicht insonderkeit zur Bestimmung der Erzmineralien, mit einder, Theorie der Optik absorbierender Kristalle. Fortschr. Mineral. Kristallogr. Petrog. 22, 1-104.

Bernhardt, H.-J., 1979. Computer-gestützte Erzmineral-Diagnose mittels Reflexionsspektren in sichtbarem Licht. Neues Jahrb. Mineral. Mon., 403-407.

Bernhardt, H.-J., 1987. A simple, fully-automated system for ore mineral identification. Mineralogy and Petrology, 36, 241-245.

Bernhardt, H.-J., 1990. Microscopic identification, and identification schemes, of ore minerals. Pp. 189-212, in: Jambor, J.L. and Vaughan, D.J., eds. Advanced Microscopic Studies of Ore Minerals. Short Course Handbook 17, Mineralogical Association of Canada, Ottawa, 426 p.

Berrezueta, E. y Castroviejo, R., 2007. Reconocimiento automatizado de menas metálicas mediante análisis digital de imagen: un apoyo al proceso mineralúrgico. I: ensayo metodológico. Rev. Metalurgia, 43 (4), 294-309. 
Berzelius, J.J., 1814. Letter to the editor (Aus einem Briefe des Herrn. Prof. Berzelius über den Magnetkies und seinen Versuch einer wissenchaftlichen Mineralogie.) Gilbert's Annalen des Physik B48, 209-210.

Bowie, S.H.U and Simpson, P.R., 1978, 1980. The Bowie-Simpson System for the Microscopic Determination of Ore Minerals. First Students Issue. Applied Mineralogy Group of the Mineralogical Society, McCrone Research Associates, London, 10 p.

Bowie, S.H.U. and Taylor, K. 1958. A system of ore mineral identification. Mining Mag. (London) 99, 265-277, 337-345.

Brea, C., 2009. Aplicación del análisis multiespectral al reconocimiento automatizado de menas con microscopio de reflexión. Tesis de Maestría, Máster oficial Aprovechamiento Sostenible de los Recursos Minerales. UPM (ETSI de Minas).

Brea, C., Castroviejo, R., Samper, J., 2010. New data on the specular reflectance of ores (VNIR: $400-1000 \mathrm{~nm}$ ) and their significance for ore microscopy. IMA2010 (20th General Meet. Internat. Mineralogical Association). Acta Mineral. Petrogr. Abstr. Ser. (HU ISSN 0324-6523 / HU ISSN 1589-4835), Szeged, Budapest, p. 281. (Proc. CD_ROM, Session EG53_Geometallurgy and Process mineralogy, Code 4NF15).

Cabri, L.J. and Vaughan, D.J., eds. Modern Approaches to Ore and Environmental Mineralogy. COM/IMA Short Course Series, vol. 27, Ottawa, Ontario, 421 p.

Castroviejo, R. y Berrezueta, E., 2009. Reconocimiento automatizado de menas metálicas mediante análisis digital de imagen: un apoyo al proceso mineralúrgico. II: criterios metalogenéticos discriminantes. Rev. Metalurgia, 45 (6), 439-456.

Castroviejo, R., Catalina, J.C., Bernhardt, H.J., Espí, J.A., Pirard, E., Samper, J., Brea, C., Segundo, F., Locutura, J., Pérez-Barnuevo, L., Sánchez, L., Fidalgo, A., 2008. Caracterización y cuantificación automatizadas de menas metálicas mediante visión artificial: Proyecto CAMEVA. Proc. Symp. Mineralogía Apl. Geometalurgia, abs. R8, XIII Congr. Latinoamericano de Geología, Lima, 29 sept-3 oct 2008.

Castroviejo, R., Catalina JC, Bernhardt HJ, Pirard E, Segundo F, Brea C, Pérez Barnuevo L., 2010. A fully automated system for multispectral ore microscopy. IMA2010 (20th General Meet. Internat. Mineralogical Association). Acta Mineral. Petrogr. Abstr. Ser. (HU ISSN 03246523 / HU ISSN 1589-4835), Szeged, Budapest, p. 281. (Proc. CD_ROM, Session EG53_Geometallurgy and Process mineralogy, Code 4NF15). 
Castroviejo, R., Catalina, J.C., Bernhardt, H.J., Pirard, E., Brea, C., Pérez-Barnuevo, L., Segundo, F., Espí, J.A., 2010. Multispectral (visible and near infra-red, 400-1000 nm range) reflectance data file from common ore minerals.

(http://www.minasyenergia.upm.es/laboratorio/microscopia_aplicada).

Castroviejo, R., Catalina, J.C., Bernhardt, H.J., Pirard, E., Brea, C., Perez-Barnuevo, L. y Segundo, F. 2014. Multispectral (visible and near infrared, 400-1000 nm range) reflectance data file from common ore minerals. International Mineralogical Association / Commission on Ore Mineralogy. Disponible en Internet en: http://projects.gtk.fi/com/results/reflectance_data.html

Catalina, J.C., Alarcón, D. and Prado, J.G., 1995. Automatic maceral and reflectance analysis in single seam bituminous coals. Eighth International Conference on Coal Science. Oviedo. Coal Science and Technology 24, vol. I. J.A. Pajares \& J.M.D. Tascón, editors. Elsevier, Amsterdam.

Catalina, J.C., Llamas, B., Prado, J.G. and Borrego, A.G., 2003. An Automated Petrographic Analysis System for Coal Blends. Proceedings of the 12th International Conference on Coal Science. Cairns (Australia).

Catalina, J.C., Segundo, F., Fernández, G. y Alarcón, D., 2008. Aplicación de la visión artificial al desarrollo de sistemas de análisis microscópico automatizado. Proc. Symp. Mineralogía Apl. Geometalurgia, abs. R3, XIII Congr. Latinoamericano Geología, Lima, 29 sept- 3 oct 2008.

Cervelle, B. and Moello, Y., 1990. Reflected-light optics. Pp. 87-108, in: Jambor, J.L. and Vaughan, D.J., eds. Advanced Microscopic Studies of Ore Minerals. Short Course Handbook 17, Mineralogical Association of Canada, Ottawa, $426 \mathrm{p}$.

Cook, N.J., Ciobanu, C.L., Ehrig, K., Slattery, A., Verdugo-Ihl, M.R., Courtney-Davies, L. and Gao, W., 2017. Advances and Opportunities in Ore Mineralogy. Minerals 2017, 7, 233; doi:10.3390/min7120233 (www.mdpi.com/journal/minerals).

Craig, J.R. and Vaughan, D.J., 1994. Ore microscopy \& ore petrography, $2^{\text {nd }}$ Ed. J Wiley, New York, 434 p.

Criddle, A.J., 1998. Ore Microscopy and Photometry (1890-1998). In Cabri, L.J. and Vaughan, D.J., eds. Modern Approaches to Ore and Environmental Mineralogy. COM/IMA Short Course Series, vol. 27, Ottawa, Ontario, 421 p.

Criddle, A.J. and Stanley, C.J., eds. 1986. The Quantitative Data File for Ore Minerals of the Commission on Ore Microscopy of the International Mineralogical Association, 2nd issue. British Museum (Natural History), London, 420 p. 
Criddle, A.J. and Stanley, C.J., eds. 1993. Quantitative Data File for Ore Minerals, 3rd edition. Chapman \& Hall, London, 635 p.

Figueroa, G., Moeller, K., Buhot, M., Gloy, G. and Haberlah, D., 2011. Advanced Discrimination of Hematite and Magnetite by Automated Mineralogy. Broekmans, MATM (editor). Proceedings, 10th International Congress for Applied Mineralogy (ICAM). 1-5 August 2011, TRONDHEIM, Norway. ISBN-13: 978-82-7385-139-0

Folinsbee, R.E., 1949. Determination of reflectivity of ore minerals. Economic Geology 44, 425-436.

Font-Altaba, M., (editor) 1970. International Tables for the Microscopic Determination of Crystalline Substances Absorbing in Visible Light, Provisional Issue IMA/COM. Departamento de Cristalografía y Mineralogía de la Universidad de Barcelona, Spain.

Frick, H., 1930. Reflexionsmessungen en Erz- und Metallanschliffen mit Hilfe eines Reflexions-Photometerokulars. Neues Jahrb. Mineral. Beil. Bd. 61. A, 31-86.

Gerlitz, C.N., Leonard, B.F. and Criddle, A.J., 1989. QDF database system, version 1.0: reflectance of ore minerals -a search-and-match identification system for IBM and compatible microcomputers using the IMA/COM Quantitative Data File for Ore minerals, second issue. U.S. Geol. Surv. Open-File Report 89-0306A-E.

Gray, I.M. and Millman, A.P., 1962. Reflection characteristics of ore minerals. Econ. Geol. 57, 325-349.

Gribble, C.D. and Hall, A.J., 1992. Optical Mineralogy: Principles \& Practice. Routledge, London, 303 p.

Henry, N.F.M., (editor) 1977. IMA/COM Quantitative Data File, first issue. International Mineralogical Association - Commission on Ore Microscopy. Distributed by McCrone Research Associates Ltd., London.

Jambor, J.L. and Vaughan, D.J., eds. 1990. Advanced Microscopic Studies of Ore Minerals. MAC Short Course, Ottawa, Canada, 426 p.

Kühnel, R.A., Prins, J.J. and Roorda, H.J., 1980. The 'Delft' System for Mineral Identification. Delft Univ. Press, Delft, The Netherlands, 204 p. 
López-Benito, A., Gervilla, F., Catalina, J.C. and Castroviejo, R., 2017. Chromite typology and composition characterized through multispectral specular reflectance. Ore Geology Reviews 89, $132-142$.

McLeod, C. R., and Chamberlain, J.A., 1968. Reflectivity and Vickers microhardness. Paper 68-64, Geol. Surv. Can.

Melles Griot, 2007. Interference filters (Chapter 13 of Melles Griot Catalog). http://www.mellesgriot.com.

Murphy, D.B., 2001. Fundamentals of Light Microscopy and Electronic Imaging. John Wiley \& Sons, New York, 368 p.

Orcel, J., 1927. Sur l'emploi de la pile photoélectrique pour la mesure du pouvoir réflecteur des menéraux opaques. C. R. Acad. Sci. 185, 2055-2057.

Peckett, A., 1992. The colours of opaque minerals. John Wiley \& Sons, New York, 471 p.

Pérez-Barnuevo, L., 2014. Caracterización automatizada de texturas de menas mediante análisis digital de imagen para su aplicación geometalúrgica. Tesis Doctoral en la modalidad de Doctorado Internacional, Universidad Politécnica de Madrid y Université de Liège, Madrid, 234 p. + Anexos. (http://oa.upm.es/23458/1/LAURA_PEREZ_BARNUEVO_a.pdf)

Pérez-Barnuevo, L., Castroviejo, R. y Berrezueta, E., 2008. Ensayo metodológico para optimizar la caracterización mineralógica de menas metálicas. Estudio de un caso de aplicación mineralúrgica. Proc. Symp. Mineralogía Apl. Geometalurgia, abs. R5, XIII Congr. Latinoamericano de Geología, Lima, 29 sept - 3 oct 2008.

Picot, P. and Johan, Z., 1977. Atlas des Mineraux Metalliques. Mem. B.R.G.M., 90. 1982. Atlas of Ore Minerals. B.R.G.M./Elsevier.

Piller, H., 1966. Colour Measurements in Ore-Microscopy. Mineralium Deposita, 1, pp. 175192.

Pirard, E., 2004. Multispectral imaging of ore minerals in optical microscopy. Mineralogical Magazine, April 2004, Vol. 68(2), pp. 323-333

Pirard, E., 2016. Optical Microscopy, pp. 51-66, in Becker, M., Wightman, E.M. and Evans, C.L., eds. Process Mineralogy, SMI JKMRC, The University of Queensland, Australia, 470 p. 
Pirard, E., Bernhardt, H.J., Catalina, J.C., Brea, C., Segundo, F. and Castroviejo, R., 2008. From Spectrophotometry to Multispectral Imaging of Ore Minerals in Visible and Near Infrared (VNIR) Microscopy. 9th Internat. Cong. Appl. Mineralogy, Brisbane, QLD, 8-10 sept 2008, ext. abst, p 1-6.

Pirard, E., Lebrun, V. and Nivart, J.F., 1999. Optimal Acquisition of Video Images in Reflected Light Microscopy. European Microscopy and Analysis, 60, 9-11.

Ramdohr, P., 1955. Die Erzmineralien und ihre Verwachsungen. Akademie Verlag, Berlin, 875 p.

Ramdohr, P., 1960. The ore minerals and their intergrowths. Akademie Verlag, Berlin, 875 p.

Ramdohr, P., 1980. The ore minerals and their intergrowths, 2nd edition. Pergamon Press, Oxford. 2 volumes, $1205 \mathrm{p}$.

Schneiderhöhn, H. and Ramdohr, P., 1931. Lehrbuch der Erzmikroskopie, Zweiter Band. Gebrüder Borntraeger, Berlin, 714 p.

Schneiderhöhn, H., 1952. Erzmikroskopisches Praktikum. E. Schweizerbart'sche Verlagsbuchhandlung, Stuttgart, $274 \mathrm{p}$.

Schwartz, G.M., 1923. Solving Metallurgical Problems with the Reflecting Microscope. Eng. And Mining Jour. 116, 237-238.

Schouten, C., 1962. Determination tables for ore microscopy. Elsevier Publishing Company, Amsterdam, $242 \mathrm{p}$.

Sutherland, D.N. and Gottlieb, P., 1991. Application of automated quantitative mineralogy in mineral processing. Minerals Engineering, Vol. 4, Nos 7-11, pp. 753-762.

Uytenbogaardt, W. and Burke, E.A.J., 1971. Tables for microscopic identification of ore minerals, 2nd edition. Elsevier, Amsterdam.

Zeiss, 2010. Axioskop 2 plus, Axioskop 2 mot plus, Upright Microscopes for the Life Sciences. In “Axioskop 2 MOT plus.pdf”. Carl Zeiss Light Microscopy. P.O.B. 4041 - 37030 Göttingen GERMANY. http://www.zeiss.de/micro

Zeiss, 2018. Education in Microscopy and Digital Imaging.

http://zeiss-campus.magnet.fsu.edu/index.html 